\section{IRS[]}

\section{INSTITUT}

DE RADIOPROTECTION ET DE SÛRETÉ NUCLÉAIRE

Enhancing nuclear safety
Jean Couturier, Hassan Abou Yéhia \& Emmanuel Grolleau

\section{Elements of nuclear safety Research reactors}

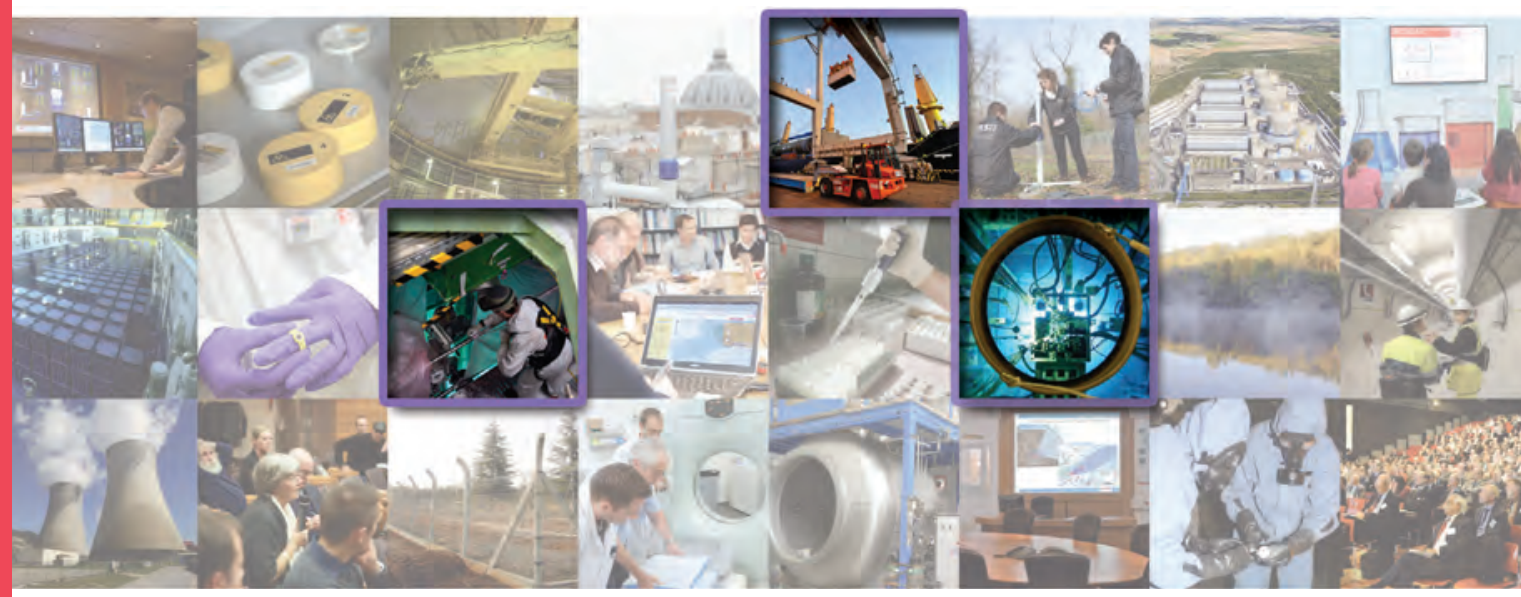

Elements of Nuclear Safety, Radiological Protection and Security series 



\title{
Elements of nuclear safety - Research reactors
}

\author{
Jean Couturier and Hassan Abou Yéhia \\ with the help of Emmanuel Grolleau \\ and contributors to the IRSN's Nuclear Safety Pole
}


Cover image: mosaics of photographs related to the subjects dealt with the different volumes of the Elements of nuclear safety, radiological protection and security series. Highlighted, outlined in purple, are those illustrating the themes developed in this second volume of the series.

Printed in France

ISBN (print) : 978-2-7598-2356-7 - ISBN (ebook): 978-2-7598-2357-4

DOI : 10.1051/978-2-7598-2356-7

All rights relative to translation, adaptation and reproduction by any means whatsoever are reserved, worldwide. In accordance with the terms of paragraphs 2 and 3 of Article 41 of the French Act dated March 11, 1957, "copies or reproductions reserved strictly for private use and not intended for collective use" and, on the other hand, analyses and short quotations for example or illustrative purposes, are allowed. Otherwise, "any representation or reproduction - whether in full or in part - without the consent of the author or of his successors or assigns, is unlawful" (Article 40, paragraph 1). Any representation or reproduction, by any means whatsoever, will therefore be deemed an infringement of copyright punishable under Articles 425 and following of the French Penal Code.

(c) IRSN 2019 


\section{Preface}

As part of IRSN's Science and Technology Series, the aim of the new "Elements of nuclear safety, radiological protection and security" series is, like the 1996 publication entitled Elements of nuclear safety by Jacques Libmann, to provide all those whose work involves ionizing radiation, primarily in the nuclear industry, with information regarding the technological culture relative to prevention and management of the related risks. This new series is the result of the desire not only to update the 1996 publication, but also to extend its scope to areas previously not covered or only touched upon.

In its collection of scientific works, IRSN promotes the most advanced knowledge acquired either within the Institute or in the context of national or international collaborations, focusing particularly on the educational value of its presentation. With this in mind, the specifications for this new series include clear explanations through recounting the history of developments in techniques, ideas, approaches, organizations and regulations, or through questions raised and lessons learned from accidents and operating feedback in general.

The series also aims to provide access for all those interested in these issues to technical knowledge and information that has been properly established and that can be checked in the subject areas referred to, thereby applying IRSN's three core values, Knowledge, Independence and Accessibility, as defined in its Code of Ethics and Professional Conduct.

We hope that this "Elements of nuclear safety, radiological protection and security" series, coordinated by Jean Couturier, will contribute to disseminating knowledge, especially as a new generation of nuclear scientists and technicians takes over from the old.

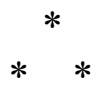

The first part of this publication gives a broad international overview of the diversity and complementarity of research reactors. It describes the many uses of these reactors, 
not least their significant contribution to research for power reactors' industrial development and safety - whether related to the development of more efficient fuels or the study of the types of accident affecting these reactors -, and it discusses some safety issues specific to research reactors. Although the objectives, principles and safety (and radiological protection) approaches adopted for the design and operation of research reactors are similar to those developed over time and used for power reactors, research reactors are very diverse in terms of design and use very varied quantities of radioactive material. Some of them are operationally flexible enough to be used for a wide variety of experiments, with experimental devices that pose varying levels of risk (from the irradiation of inert materials in a capsule to tests of nuclear fuel melt in a loop, in liquid sodium, in pressurized water, etc.).

In addition, many of the research reactors around the world are old and have been through periods of temporary shutdown. Appropriate measures are necessary to manage the ageing and obsolescence of some of their components and, on an organizational and human level, to keep them operating safely. There are also different types of operators involved either in the operation of these reactors or their use; this can have an impact on safety and radiological protection, and therefore also needs to be taken into consideration.

Two specific chapters are devoted to the safety standards established under the aegis of the IAEA for research reactors and to criticality and reactivity accidents at research reactors.

These safety and radiological protection issues are discussed in more detail and illustrated in the case of French research reactors, in the second part of the publication. There are also specific chapters on the French regulatory system and the official texts applicable to these reactors, on experience feedback from significant events and accidents - including the Fukushima Daiichi nuclear power plant accident in 2011 - , on the account taken of reactivity accidents in the design of French research reactors, and on the ten-yearly safety reviews carried out in France.

I would particularly like to thank Jean Couturier, the coordinator and main editor of this publication with Hassan Abou Yéhia, for this important - and unparalleled - synthesis of the subject, as well as Emmanuel Grolleau and everyone else who gave their valuable support. 


\section{Main contributors}

Jean COUTURIER has worked for the office of IRSN's Director General since 2012, supporting the roll-out of a knowledge management programme. He is also a senior expert in safety policy and risk analysis. He began his career working for Novatome on the design of fast neutron reactors, in the areas of fuel and safety analysis. He joined IPSN in 1986 to assess the safety aspects of the PHENIX and SUPERPHENIX fast neutron reactors. His activities then broadened to the nuclear safety of research reactors and pressurized water reactors. From 2003 to 2005 he was Strategic Programme Director for Generation IV systems. He is a member of the standing group of experts for nuclear reactors.

Hassan ABOU YEHIA retired from IRSN in 2017. Having completed a doctorate in physical sciences, from 1980 he held various technical and managerial posts at the CEA followed by IPSN and IRSN, including safety assessment for different types of nuclear facilities in France - and throughout the world as part of assignments for the IAEA. From 2006 to 2012 he was responsible for the IAEA's Research Reactor Safety Section (which also covers nuclear fuel cycle facilities). Until the end of 2016 he coordinated IRSN's nuclear safety training activities and participated in the training courses organized by the European Nuclear Safety Training \& Tutoring Institute (ENSTTI).

Emmanuel GROLLEAU, has been, since the middle of 2018, assistant head of the service responsible for confinement and aerodispersion of polluants. Previously, he spent several years within the criticality studies and computation service at SGN, part of the AREVA group. He joined IRSN in 2004 to work for the assessment service responsible for research reactor safety. In particular, he directed a number of assessments on which presentations were given to the Advisory Committee for Nuclear Reactors. From 2007 to 2011 he worked for IRSN's Strategy and Partnerships Department. From 2012 to the middle of 2018, he has been assistant head of the service responsible for conducting safety assessments of research-related facilities and reactors undergoing dismantling within IRSN's Nuclear Safety Expertise Directorate. 



\section{List of abbreviations}

\section{Glossary of institutions}

AFCEN: French association producing rules for the design, construction and in-service inspection of nuclear power plant components

AISI: American Iron and Steel Institute

ANCCLI: French national association of local information commissions

ANL: Argonne National Laboratory, USA

AREVA: French nuclear designer and operator (which subsequently became Orano and Framatome)

ARILL: Institut Laue-Langevin Retirees Association

ASME: American Society of Mechanical Engineers (ASME is often used to refer to the design and construction rules drawn up by this American society and used by nuclear reactor designers [Westinghouse, etc.])

ASN: Autorité de sûreté nucléaire (French nuclear safety authority)

AVN: Association Vinçotte-Nucléaire, Belgium

CEA: Commissariat à l'énergie atomique et aux énergies alternatives (Alternative Energies and Atomic Energy Commission), France

CERCA: Compagnie pour l'étude et la réalisation de combustibles atomiques (nuclear fuel design and manufacturing company), France

$\mathrm{Cl}$ : Information commission

CIS: Internal security committee

CLI: Local information commission

CNRS: Centre national de la recherche scientifique (National Centre for Scientific Research), France

CSIA: Commission de sûreté des installations atomiques (nuclear facility safety commission), France

DAE: Department of Atomic Energy, India

DEP: Nuclear Pressure Equipment Department, ASN 
DOE: Department of Energy, USA

DSN: Nuclear Safety Department, CEA

DSND: representative in charge of nuclear safety and radiological protection for French defence-related activities and facilities

EDF: Electricité de France (French power utility)

ENSREG: European Nuclear Safety Regulators Group (a European Commission consultative group of independent experts)

FzK: Forschungszentrum Karlsruhe (Karlsruhe Institute of Technology, Germany)

GAAA: Groupement Atomique Alsacienne Atlantique, a French company

GRS: Gesellschaft für Anlagen- und Reaktorsicherheit (safety organization for nuclear reactors and facilities, Germany)

HCTISN: Haut comité pour la transparence et l'information sur la sécurité nucléaire (High Committee for Transparency and Information on Nuclear Security), France

IAEA: International Atomic Energy Agency, Vienna, Austria

ICRP: International Commission on Radiation Protection

ILL: Institut Laue-Langevin, France

INL: Idaho National Laboratory, USA

IPSN: Institut de protection et de sûreté nucléaire (Institute for Protection and Nuclear Safety), France

IRSN: Institut de radioprotection et de sûreté nucléaire (Institute for Radiological Protection and Nuclear Safety), France

JRC: Joint Research Centre, European Commission

KIT (formerly FzK and KfK): Karlsruhe Institute of Technology, Germany

LLB: Laboratoire Léon Brillouin (joint CEA/CNRS research unit)

LSTC: Livermore Software Technology Corporation, USA

NEA: Nuclear Energy Agency, OECD

OECD: Organisation for Economic Co-operation and Development

PNC (formerly JAEA): Power reactor and Nuclear fuel development Corporation, Japan

SCK CEN: Studiecentrum voor Kernenergie - Centre d'étude de l'énergie nucléaire (nuclear energy research centre), Belgium

SCSIN: Service central de sûreté des installations nucléaires (central nuclear facility safety service), France

SODERA: Société pour le développement de la recherche appliquée (company for the development of applied research), France

WENRA: Western European Nuclear REgulators Association

\section{Technical glossary}

ADS: Accelerator Driven System (subcritical hybrid reactor)

ALARA: As Low As Reasonably Achievable (a radiological protection principle)

ALIZÉ: name of a CEA nuclear research reactor (now permanently shut down)

APOLLO: name of a 2D neutron simulation software used for establishing multiparameter libraries of effective neutron cross-sections

AQUILON: name of a CEA nuclear research reactor (now permanently shut down) 
ARS: seismic reactor shutdown (high flux reactor in Grenoble)

ASTEC: Accident Source Term Evaluation Code (system of simulation codes for evaluating the physical phenomena occurring during a core melt accident in a pressurized water reactor)

ASTER: Analyses des Structures et Thermomécanique pour des Etudes et des Recherches (thermomechanical and structural analysis simulation software system for studies and research)

ASTRID: Advanced Sodium Technological Reactor for Industrial Demonstration

ATPu: Atelier de technologie du plutonium (plutonium technology facility, now closed; its main activity was the production of MOX [mixed oxide fuel] fuel for nuclear reactors)

ATWS: Anticipated Transients Without Scram (automatic reactor shutdown without insertion of control absorbers or transients with failure of the automatic reactor shutdown system - also known as ATWR for anticipated transient without reactor trip) AZALEE: name of a shaking table at CEA Saclay

$B C S$ : control and safety rods (CABRI reactor)

BDBA: Beyond Design Basis Accident

BNCT: Boron Neutrons Capture Therapy (cancer treatment)

BORAX: BOiling water ReActor eXperiment (experimental reactor in the USA)

BR2: Belgium Reactor 2 (at the Mol research centre in Belgium)

CABRI: name of a CEA test reactor at Cadarache used to study accident situations in reactors (PWRs, SFRs)

CASHIMA: name of a research project looking at seismic "site effects"

Cast3M: name of a simulation software using the finite element method for structural and fluid mechanics

CATHARE: Code Avancé de THermohydraulique pour l'Etude des accidents de Réacteurs à Eau (advanced thermohydraulic simulation software used for water reactor accident analyses)

CDS: seismic depressurization system (RHF)

CEN: groundwater supply system (RHF)

CERES: name of a software for calculating the radiological impact of a release in an accident situation

CES: emergency cooling system (RHF)

CESAR: name of a CEA research reactor (now permanently shut down) or name of a thermohydraulics module in the ASTEC software system

CFD: Computational Fluid Dynamics

CIP: Cabri International Program (an international program to study the behaviour of nuclear fuel rods and cladding during a reactivity injection accident in pressurized water reactors)

CPA: name of a module in the ASTEC software system

CRISTAL: name of a calculation route developed jointly by IRSN, CEA and AREVA to evaluate the risk of criticality in all nuclear facilities and transport casks containing fissile materials

CRONOS: name of a simulation software for 3D core neutronics calculation 
CRP: Coordinated Research Project

CRU: emergency core cooling (reflood) system (RHF)

CSA: Complementary Safety Assessment (post Fukushima Daiichi accident)

CSS: Commission on Safety Standards (IAEA)

DBA: Design Basis Accident

DEC: Design Extension Conditions

DIRAS: information package related to the cleanup of structures

DISCO: DIspersion of Simulated COrium (KIT experimental facility to study airborne contamination/dispersion of corium, using inactive powders)

DULCINEE: name of a software used to simulate core thermohydraulics and the thermal behaviour of fuel in a reactor

ECS: évaluation complémentaire de sûreté (see CSA)

EFPD: Equivalent Full Power Days

EIP: element important for protection (of "interests", concept in French regulations)

EL2: Eau Lourde 2 (a CEA research reactor, now dismantled)

EL3: Eau Lourde 3 (a CEA research reactor currently being dismantled)

EL4: Eau Lourde 4 (Brennilis nuclear power plant, France)

EOLE: name of a CEA nuclear research reactor

EPIC: French industrial and commercial public undertaking

EPR: European Pressurized Water Reactor

ESPN: nuclear pressure vessel

ETRR-2: Egypt Test and Research Reactor Number two

EUROPLEXUS: name of a finite element simulation software

FINAS: Fuel Incident Notification and Analysis System (run by the IAEA)

FLICA: name of a software that calculates the thermohydraulics of a reactor core during transients

FP: fission products

FRM-II: Forschungsreaktor München II (research reactor in Garching, Germany)

GAZAXI: name of a software used for calculating the radiological impact of a release in an accident situation

GCR: gas-cooled, graphite-moderated reactor

GOR: General Operation Rules

GPD: standing group of experts for waste

GPDEM: standing group of experts for dismantling

GPE: standing group of experts

GPESPN: standing group of experts for nuclear pressure equipment

GPMED: standing group of experts for medical exposure

GPR: standing group of experts for nuclear reactors

GPRAD: standing group of experts for radiation protection (non-medical)

GPT: standing group of experts for transport

GPU: standing group of experts for laboratories and factories

GUS: ultimate diesel generator (JHR)

HARMONIE: name of a CEA nuclear research reactor (now dismantled) 
HEMERA: Highly Evolutionary Methods for Extensive Reactor Analyses (software chain for simulating the thermohydraulics and neutronics of transients in a nuclear reactor) HFR: High Flux Reactor (high flux reactor at the JRC in Petten, Netherlands)

HIFAR: High Flux Australian Reactor

HTR: High Temperature Reactor

IAEA: International Atomic Energy Agency, Vienna, Austria

IEA-R1: Instituto de Energia Atômica-Reactor 1 (Brazilian research reactor)

IGORR: International Group on Research Reactors

INB: basic nuclear installation

INES: International Nuclear Event Scale (developed by the IAEA)

INSAG: International Nuclear Safety Group

INSARR: Integrated Safety Assessment of Research Reactors

IODE: name of a module in the ASTEC software system

IRR1: Israel Research Reactor-1

IRS: International Reporting System for operating experience (system run by the IAEA for reporting incidents at power reactors)

IRSRR: Incident Reporting System for Research Reactors (system run by the IAEA for reporting incidents at research reactors)

ISIS: name of the critical assembly of the OSIRIS nuclear research reactor at Saclay

ISTP: International Source Term Program

ITER: International Thermonuclear Experimental Reactor (under construction at Cadarache)

JHR: Jules Horowitz Reactor (CEA nuclear research reactor currently under construction) LOOP: loss of off-site power

LS-DYNA: name of a finite element simulation software for dynamic structural analysis MARIUS: name of a CEA nuclear research reactor (now permanently shut down)

MASURCA: critical assembly of the CEA at Cadarache

MC3D: name of a 3D multi-phase thermohydraulic software used to simulate the interaction between molten materials and coolant

MCNP: Monte Carlo N-Particle transport code (3D simulation software for particle transport based on the Monte Carlo method)

MELUSINE: name of a CEA nuclear research reactor (now dismantled)

MHPE: Maximum Historically Probable Earthquake

MINERVE: name of a CEA nuclear research reactor at Cadarache

MNSR: Miniature Neutron Source Reactor

MORET: simulation software that solves the neutron transport equation using Monte Carlo methods, mainly used for criticality studies

MOX: Mixed Oxide Fuel $\left(\mathrm{UO}_{2}+\mathrm{PuO}_{2}\right)$

MTR: Material Testing Reactors (used for testing various materials and nuclear fuels)

NGO: non-governmental organization

NRU: National Research Universal (research reactor of Chalk River Laboratories, Canada)

NRX: National Research eXperimental (research reactor of Chalk River Laboratories, Canada) 
NSRR: Nuclear Safety Research Reactor (Japanese research reactor used for safety tests)

NUSSC: NUclear Safety Standards Committee (IAEA)

OLC: Operational Limits and Conditions

OPAL: Open Pool Australian Lightwater (an Australian research reactor)

ORPHÉE: name of a CEA nuclear research reactor at Saclay

OSIRIS: name of a CEA nuclear research reactor at Saclay (now permanently shut down)

OTHELLO: name of an experimental loop in the OSIRIS reactor

PAl: iodine filter

pcm: per cent mille

PSA: Probabilistic Safety Assessment

PCS: emergency control room (RHF)

PEGASE: name of a CEA research reactor (now permanently shut down)

PEGGY: name of the critical assembly of the PEGASE research reactor

PGA: Peak Ground Acceleration

PHEBUS: name of a CEA experimental reactor in Cadarache

Phebus-FP: international research programme to study the behaviour of fission products in core melt situations in a pressurized water reactor

PHENIX: name of a CEA prototype nuclear power (and experimental) reactor at Marcoule, a sodium-cooled fast neutron reactor (currently being dismantled)

PROSERPINE: name of a CEA research reactor (now permanently shut down)

PSA: Probabilistic Safety Assessment

PUI: on-site emergency plan

PWR: Pressurized Water Reactor

RA-2: name of an Argentinian research reactor

RADIOSS: name of a finite element simulation software

RAPSODIE: name of a CEA experimental sodium-cooled fast neutron reactor at Cadarache (now permanently shut down)

RASSC: Radiation Safety Standards Committee (IAEA)

RCC-CW: rules for design and construction of French PWR nuclear civil works

RCC-E: design and construction rules for electrical components of French PWR nuclear islands

RCC- M: design and construction rules for mechanical components of French PWR nuclear islands

RCC-MRx: design and construction rules for mechanical components of nuclear installations high-temperature, research and fusion reactors

RERTR: Reduced Enrichment for Research and Test Reactors (US program)

RFS: fundamental safety rule

RGEP: guillotine break of a "particular element" (concept used in the safety analysis of the Jules Horowitz reactor)

RGSE: general surveillance and maintenance rules 
RHF: high flux reactor at Grenoble, France (nuclear research reactor of the Institut LaueLangevin)

RIA: Reactivity Injection Accident

RLC: risk limitation conditions (concept used in the safety analysis of the Jules Horowitz reactor)

RRDB: Research Reactor DataBase (run by the IAEA)

RSE-M: equipment in-service surveillance rules of French PWR nuclear islands

RSG-GAS: Reaktor Serba Guna - Gerrit Augustinus Siwabessy (Indonesian research reactor)

RUS: Strasbourg university reactor or emergency secondary cooling system of the Jules Horowitz Reactor, in construction at Cadarache, France

SAFARI-1: South African Fundamental Atomic Research Installation 1 (nuclear research reactor)

SBO: station blackout

SCANAIR: software for simulating the thermomechanical behaviour of the fuel rods in pressurized water reactors during power transients

SCARABEE: name of a CEA research reactor at Cadarache (now dismantled)

SFRs: sodium-cooled fast neutron reactors

SIGMA: Seismic Ground Motion Assessment

SILOE: name of a CEA nuclear research reactor at Grenoble (currently being dismantled) SILOETTE: name of a CEA thermal nuclear research reactor in Grenoble (critical assembly of the SILOE nuclear reactor) (now dismantled)

SIMMER: name of a simulation software combining neutronics and fluid mechanics, used to simulate a fuel melt accident in a fast neutron reactor

SIREX: instrumentation and control electronic racks or cabinets in French research reactors

SL-1: Stationary Low Power Reactor Number One (Idaho National Laboratories, Idaho, USA)

SME: Safe Shutdown Earthquake

SND: hardened safety core design earthquake

SOFIA: Simulateur d'Observation du Fonctionnement Incidentel et Accidentel (simulator of the operation of PWRs used by IRSN)

SPERT: Special Power Excursion Reactor Tests, pressurized water type, operated by Phillips Petroleum Company as part of the U.S. Atomic Energy Commission program, USA

SSC: Structures, Systems and Components

TECDOC: TEChnical DOCument (IAEA)

TECV: French Act No 2015-992 on energy transition for green growth, adopted on 17 August 2015

HEPA: high efficiency particulate air (filter)

TRANSSC: TRANsport Safety Standards Committee (IAEA)

TREAT: Transient Reactor Test Facility (research reactor developed by Idaho National Laboratories, Idaho Falls, USA) 
TRIDENT: name of a simulation software

TRIGA: TRaining, Isotope, General Atomics (pool-type research reactor developed by General Atomics, USA)

TRIPOLI: TRIdimensionnel POLYcinétique (3D simulation software that uses the Monte Carlo method to solve the coupled neutron/photon transport equation)

TSN: French Act No 2006-686 of 13 June 2006 on nuclear security and transparency ULYSSE: name of a CEA nuclear research reactor (now dismantled). This was an Argonaut class reactor, a research reactor model developed by the Argonne National Laboratory in the USA (ARGONAUT stands for ARGOnne Nuclear Assembly for University Training)

VARMA: acceptable modelled value for residual activity

VENUS: Vulcan Experimental Nuclear System (JRC research reactor in Mol, Belgium)

WASSC: WAste Safety Standards Committee (IAEA)

ZEPHYR: Zero power Experimental PHYsics Reactor (a CEA reactor still in the planning phase)

ZOÉ: ZerO Energy, an alternative name for the EL1 reactor. France's first research reactor, located at the CEA centre in Fontenay-aux-Roses 


\section{Foreword}

This publication on nuclear research reactors and particularly on specific characteristics and issues of research reactors in terms of nuclear safety and radiological protection, was written by authors from IRSN, the French Institute for Radiological Protection and Nuclear Safety.

It assumes that the reader already has a basic knowledge of the physics of nuclear reactors and their operation; however, reminders are provided throughout the text on these subjects in the form of notes or focus texts.

Jean Couturier is the main author - and the project coordinator - with contributions from Hassan Abou Yéhia on international aspects, and assistance from Emmanuel Grolleau and the unit in charge of assessing safety and radiological protection at French research reactors. Specific contributions were made by Maud Corbel, Stanislas Massieux, Ludovic Maas, Vincenzo Tiberi, Patrice François, Sandrine Soares, Elodie Cahen, Florence Gupta, Stéphanie Kanamori, Mathieu Derotte, Céline Gelis, Eric Dumonteil, Bertrand Cochet, Tonino Sargeni and Jacques Ducau.

An effort has been made to ensure that external sources of information, including illustrations, have been credited. This was the case for the "monographs" by the Nuclear Energy Directorate of the French Alternative Energies and Atomic Energy Commission (of the greatest interest), and for publications produced for conferences, official texts, presentations available on websites, etc.

Daniel Quéniart carefully proofread the publication in its draft version. His contribution was important to the production of the final version.

Thierry Bourgois, Martial Jorel, Gianni Bruna and Michel Bourguignon also proofread draft versions of the whole text or sections of it. Their comments were taken into account when it was finalized.

Odile Lefèvre and Georges Goué prepared the work for publication. 
Finally, during the production of this text we were keen to do more than simply describe research reactors and their objectives and general principles in terms of nuclear safety and radiological protection, which would have duplicated the work of many other French and international publications; this would have produced a much less useful document, especially from an educational point of view. Technical substance was necessary to illustrate these objectives and principles. The authors would like to thank in this regard the Division operating the high flux reactor (RHF) in Grenoble (Institut Laue Langevin [ILL]) for providing information and illustrations and allowing us to publish them. This material gives a practical illustration, in the case of this particular reactor, of a number of (French) nuclear safety and radiological protection principles and practices (particularly the tenyearly safety reviews and the experience feedback from the Fukushima Daiichi accident). 


\section{Contents}

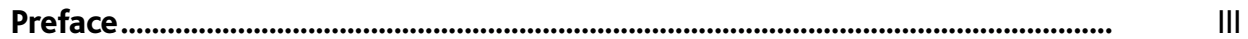

Main contributors...................................................................................................

List of abbreviations .................................................................................................. VII

Foreword.................................................................................................................... XV

\section{Chapter 1 \\ Introduction \\ Part 1 \\ General overview of research reactors at international level}

\section{Chapter 2}

The different types of research reactors, overall global situation, uses and associated risks

2.1. Types of research reactors

2.2. Global situation

2.2.1. Statistical data.

2.2.2. General nuclear safety and non-proliferation issues.

2.3. Uses of research reactors and main related risks.

2.3.1. Training

2.3.2. Fundamental research 
2.3.3. Experimental irradiation

2.3.4. Medical applications

2.3.5. Activation analysis.

2.3.6. Industrial applications.

\section{Chapter 3 \\ Aspects of the design and safety demonstration of research reactors at international level}

3.1. Convergence of practices on a few main safety objectives, principles and safety approaches.

3.2. The IAEA safety standards

3.2.1. Drafting process of the IAEA safety standards

3.2.2. Structure of the IAEA safety standards.

3.2.3. Brief presentation of the safety standards for research reactors..

3.2.4. Application of the IAEA safety standards

3.2.5. Supporting documents for application of the IAEA safety standards

3.3. IAEA exchange and assessment mechanisms

3.4. Some general principles and approaches related to safety

3.4.1. Organization of safety control, safety culture.

3.4.2. Confinement barriers, fundamental safety functions, defence in depth.

3.4.3. The deterministic approach, design and safety demonstration basis - Situation regarding probabilistic studies for research reactors

3.4.4. The graded approach.

3.5. Periodic safety reviews

3.6. Safety aspects of experimental devices

3.7. "Envelope" accidents taken into account in research reactor safety analyses.

3.7.1. Definition and characteristics of "envelope" accidents..

3.7.2. Source term evaluation for "envelope" accidents

3.8. Possible improvements to studies, research and development on research reactor safety 


\section{Chapter 4 \\ International experience feedback for research reactors}

4.1. The IAEA incident reporting system (IRSRR) ............................................................... 60

4.2. Serious incidents and accidents at research reactors................................................. 61

4.3. Complementary safety assessments carried out internationally following the accident at the Fukushima Daiichi nuclear power plant

Part 2

Research reactors in France

\section{Chapter 5}

\section{Evolution of the French research reactor "fleet"}

5.1. The diversity and complementarity of French research reactors ....................... 71

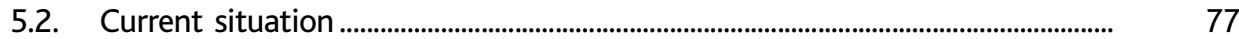

\section{Chapter 6}

Stakeholders and organization of research reactor safety in France

6.1. Operators ..................................................................................................................... 96

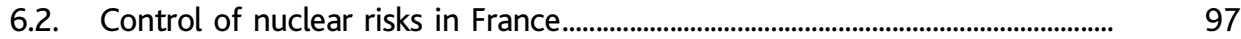

6.3. Key stages in the life of a research reactor................................................................. 105

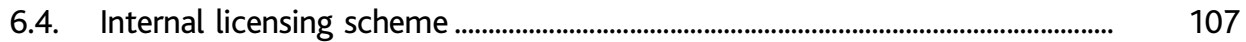

\section{Chapter 7 \\ Safety principles for French research reactors}

7.1. General safety principles, concepts, approaches and objectives

7.1.1. The defence in depth principle applied to research reactors

7.1.2. Events selected for the design and safety demonstration of research reactors

7.1.3. Reference accidents

7.1.4. Application of general safety objectives

7.1.5. The graded approach in France

7.2. Specific safety features of research reactors.

7.2.1. Power densities, fuel and core neutron characteristics.

7.2.2. Usage rates

7.2.3. Organisational and human factors 
7.3. Features of research reactors by main safety function ......................................... 130

7.3.1. Controlling core reactivity ................................................................................ 130

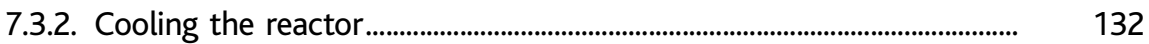

7.3.3. Confinement of radioactive substances......................................................... 137

7.3.4. Criticality risks......................................................................................................... 139

7.4. Hazards ..................................................................................................................... 141

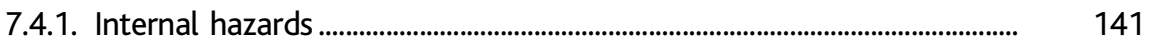

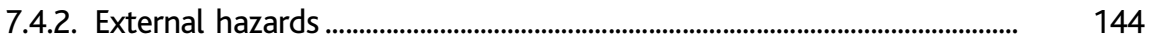

7.5. Experimental devices and research reactor-specific equipment ........................ 151

7.6. Radiological protection and waste substances......................................................... 153

7.6.1. Radiological protection................................................................................... 153

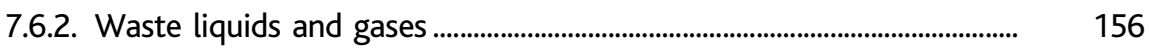

7.7. Emergency preparedness and management (crisis management)................................................................................................. 156

7.8. Safety aspects for decommissioning research reactors.......................................... 159

\section{Chapter 8 \\ The reference accidents selected for French research reactors}

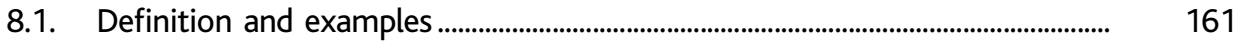

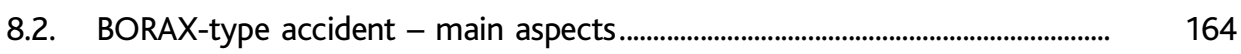

8.2.1. Accident at the SL-1 reactor .......................................................................... 164

8.2.2. Key lessons learned from the SL-1 reactor accident ................................ 166

8.2.3. Consideration of the BORAX-type accident in France............................ 167

8.3. Demonstrative testing conducted in France ............................................................ 172

\section{Chapter 9 \\ Maintaining compliance with the applicable requirements - Safety Reviews}

9.1. Maintaining compliance with the applicable requirements, managing obsolescence and ageing

9.2. Safety reviews 
9.2.1. History and approach ..................................................................................... 178

9.2.2. Examples of significant safety reviews........................................................... 180

\section{Chapter 10 \\ Operating experience feedback from French research reactors}

10.1. Trends, some notable events and their management......

10.1.1. Trends

10.1.2. Some notable events and their management

10.2. Measures to improve the safety of French research reactors following the Fukushima Daiichi accident

Chapter 11

Overview of simulation software used in design studies and safety analyses for French research reactors 



\section{Chapter 1 Introduction}

Since nuclear fission ${ }^{1}$ was first discovered in 1938, scientists have taken a great interest in this property of matter which, when properly managed, can produce large amounts of energy that can be converted into electricity. To develop the use of this form of energy, it has been necessary over time to conduct numerous studies and experiments, mostly using research reactors, which are essential for acquiring knowledge and developing the techniques necessary to design and operate nuclear power plants under sufficiently safe conditions. But, in parallel, many other uses of research reactors have also developed.

For the purposes of this publication, the widely used English term "research reactor" is used, even though in France many of these facilities are known as "réacteurs d'experimentation" (experimental reactors). Research reactors are not to be confused with experimental or prototype nuclear power reactors, such as the $\mathrm{EL}^{2} 4$ heavy water reactor in France (Brennilis nuclear power plant) or the Lucens nuclear power reactor in Switzerland. However, some nuclear power reactors will be discussed if experiments were or are being conducted there (e.g. PHENIX, a sodium-cooled fast neutron reactor used for electricity production) even though they are not strictly categorized as research reactors.

Research reactors are nuclear facilities used to supply intense neutron fluxes ${ }^{3}$. These reactors, which operate at low temperatures and pressures, are simpler than nuclear

1. Phenomenon whereby the nucleus of a heavy atom splits into two smaller nuclei due to the impact of a neutron.

2. Eau lourde in French.

3. Refers to the number of neutrons passing through a closed unit of area during a unit of time. 
power reactors. They require little fuel and their fission product inventory ${ }^{4}$ remains much lower. However, they require the use of a fuel that is much more highly enriched with uranium-235 than the fuel used in power reactors. The enrichment level of research reactor fuel can be as high as $20 \%$ uranium-235, or even $93 \%$ in some cases.

Since the divergence ${ }^{5}$ of the first nuclear reactor (Chicago Pile-1) on 2 December 1942 by a team led by Enrico Fermi at the University of Chicago (the first divergence of a research reactor in France, the ZOÉ atomic pile ${ }^{6}$, took place in December 1948), more than 800 research reactors have been or are being built throughout the world. Around 220 research reactors are in operation in nearly 55 countries. Their thermal power varies from 0 to $250 \mathrm{MW}$ (compared to the thermal power of around 3,000 MW of a PWR producing $900 \mathrm{MWe}$ of electricity), but, in the case of around $90 \%$ of them, it is below $10 \mathrm{MW}$. Their designs, modes of operation and uses are very diverse.

The many uses of research reactors include fundamental research and applied research (i.e. research with defined practical objectives), education and training of engineers and nuclear power industry personnel, and the production of radioisotopes for medical use. In the applied research field, research reactors have played a key role in the development of nuclear power reactor technologies, including the technologies of devices and systems that perform a safety role. Research reactors have made it possible to conduct studies of the neutron physics of power reactor cores and to test the behaviour of the fuels and materials in these reactors under the effect of irradiation. They have also enabled studies of accident situations to be conducted, up to and including fuel melt and the resulting transfer of fission products into the environment.

As regards safety, like all nuclear reactors, research reactors host a chain reaction that needs to be controlled, and they are therefore subject to all the risks associated with any other type of nuclear reactor (damage to the fuel, dispersion of radioactive substances, irradiation of personnel, etc.). But the nature and scale of those risks varies according to the research reactor and its uses. Consequently, safety analyses need to be conducted on a case-by-case basis, and the conditions in which different experiments are run must be checked to ensure that they are compatible with safety requirements.

However, there are some generic safety issues for research reactors. For many existing reactors (in operation), the service life for which they were designed has already been exceeded; $60 \%$ of them are more than 40 years old. Consequently, there are some particularly pressing issues to be attended to as regards the ageing ${ }^{7}$ and obsolescence of certain components and the need for upgrading work, particularly to take account of more advanced knowledge of certain risks and changes in safety criteria.

Depending on type and use, research reactors can pose some specific problems regarding human and organizational factors. For example, conducting experiments in research reactors can involve many reactor core handling operations, including while the reactor is in operation.

4. Expression commonly used to refer to the quantities and types (isotopes) of fission products.

5. Nuclear divergence is the start of the nuclear chain reaction process in a nuclear reactor.

6. ZOÉ (ZerO Energy) an alternative name for the EL1 reactor.

7. Known as "ageing management". This concept will be discussed in more detail in paragraph 2.2.2. 
This publication is in two parts:

- the first part gives a general overview of research reactors internationally and looks at some generic aspects of the safety of these reactors. The actions and work of the IAEA are presented, along with serious incidents and accidents and the reassessments carried out internationally following the accident at the Fukushima Daiichi nuclear power plant in 2011;

- the second part, which goes into more detail, looks specifically at French research reactors and at different aspects of their safety: the agencies involved in and the structural organization of safety monitoring in France, general safety objectives, principles and procedures, accidents taken into account for their design, experience feedback (including from the accidents at the Chernobyl and Fukushima Daiichi nuclear power plants), key improvements made during safety reviews, etc. 

Part 1

General overview of research reactors at international level 



\section{Chapter 2 \\ The different types of research reactors, overall global situation, uses and associated risks}

\subsection{Types of research reactors}

\section{Different types for different applications}

Because research reactors are designed differently according to their purpose or application, they can be classified accordingly. In practice, we make a distinction between:

- Material Testing Reactors (MTRs), designed mainly for studying and testing different materials and nuclear fuels, especially those used in power reactors, or for producing radioisotopes for medical use;

- reactors with "neutron channels 8 ", often referred to as "neutron beams outside" reactors, which are mainly used for fundamental research, e.g. neutron scattering experiments;

8. In this document, the following expressions will be used: "neutron channel" will refer to the assembly consisting of - in the reactor pool - a "thimble" or "beam tube", (the end of which nearest the core, in the heavy water tank, is known as the "beam tube end") and - outside the reactor pool (in the experiment hall) - a "neutron guide". 
- critical assemblies (or critical mockups), with very low thermal power, used particularly to determine nuclear data for validating software used to simulate core neutronics (of power or research reactors);

- reactors for safety studies, which are used specifically for studying accident situations representative of those likely to occur in power reactors, such as loss of fuel cooling and reactivity injection ${ }^{9}$, which could lead to melting of fuel and the release of fission products into the environment;

- training reactors, which are generally of low thermal power and are used to train nuclear industry personnel and for teaching at universities.

\section{Different designs}

Unlike power reactors, which have gradually become limited to a small number of designs, in the case of research reactors there is a wide range of different designs. Among the wide variety of research reactors, there are two main groups:

- heavy-water reactors ${ }^{10}$ (in which heavy water is used as coolant, moderator or neutron reflector),

- reactors cooled and moderated by light water.

The other types of research reactors include those in which the neutrons are moderated by graphite, aqueous homogeneous reactors, which use a uranium nitrate or sulphate solution, and fast neutron reactors, which do not need a moderator but can use a mixed uranium oxide and plutonium oxide fuel.

- Heavy water reactors:

Heavy water reactors are "tank in pool" reactors. They can produce intense fluxes of thermal neutrons, which are extracted from the core by means of neutron channels, generally for fundamental physics research. The moderating properties of the heavy water enable neutron beams to be produced that contain no fast

9. In order to characterise the risk of core runaway, the concept of reactivity is used: it is a magnitude (represented by $\rho$ ) for measuring how far a core is from its just-critical state $(\rho=0)$. Typically, the inadvertent removal or ejection of a control or safety rod from the reactor core, because it reduces the proportion of neutron-absorbing materials in the core, will lead to excessive core "reactivity" and therefore an increase in heat, at least locally. If this is not controlled by the reactor's surveillance and protection systems, it can cause significant damage or even cause fuel elements in the core to melt. The terms "insertion" and "injection" are interchangeable in this context. The term "power excursion" refers to the power transient caused by a reactivity injection.

10. For reactors using uranium-235 fuel, it is the slow, low-energy neutrons $(E=0.025 \mathrm{eV})$ that have the highest probability of causing fission. With an effective moderator, the neutrons resulting from the fission of uranium-235 are slowed down until their kinetic energy is around the thermal agitation energy of the scattering medium $(0.025 \mathrm{eV}$ at a temperature of $300 \mathrm{~K})$, without being absorbed. Most fissions occur at this energy, and the reactor is referred to as a thermal-neutron reactor. Moderators are therefore used; heavy water $\left(D_{2} O\right)$ is the best moderator, ahead of graphite, beryllium and light water $\left(\mathrm{H}_{2} \mathrm{O}\right)$, in descending order. 
neutrons (considered to be parasites), which are ideal for experiments on the physics of matter. However, these reactors are not really suitable for material testing because the presence of a closed tank to hold the heavy water makes it difficult to access equipment near the reactor core.

- Light water reactors:

Light water reactors, also known as pool-type reactors, can have an open core or a core in an enclosed tank, in both cases in a pool ("tank in pool" reactor type). These reactors are multi-purpose facilities generally used for the irradiation of different materials. Of the different types of research reactor currently in operation throughout the world, these are the most common. Figure 2.1 below shows the HFR reactor ${ }^{11}$, a closed-tank reactor, at Petten in the Netherlands.
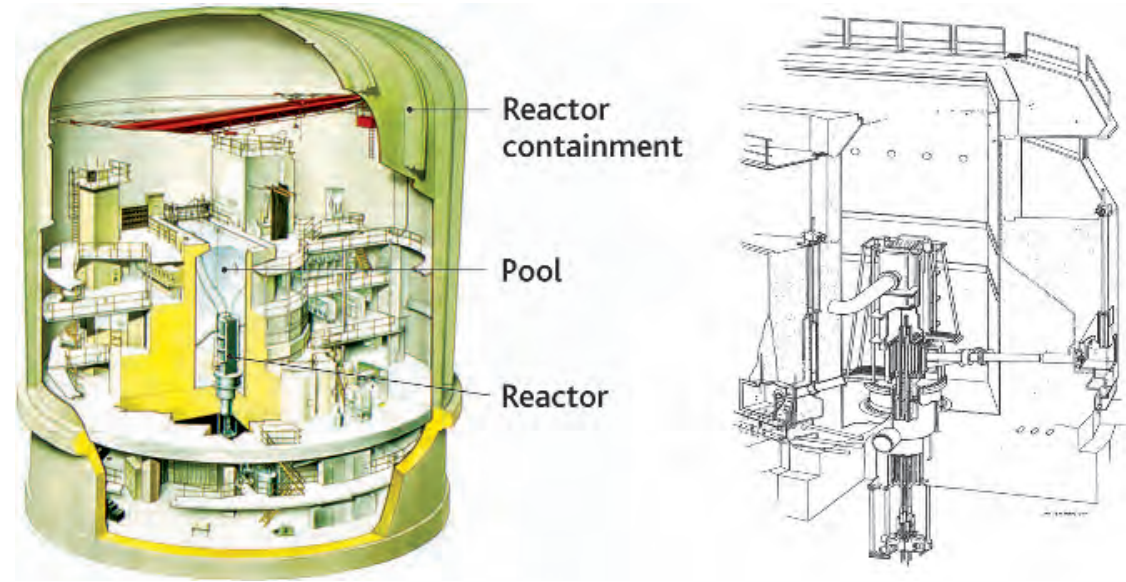

Figure 2.1. The HFR reactor at Petten, a closed-tank pool-type reactor. (C) NRG.

Open core pool-type reactors generally give easy access to the irradiation locations, but their low pressure of use (similar to hydrostatic pressure) means that there is less removable heat and therefore that the neutron fluxes are more limited.

In pool-type reactors with a closed tank, higher thermal power levels can be achieved (with greater pressures than in open core reactors), but they are more difficult to use for experimental irradiation because of the need for devices that penetrate the tank for closer access to the core; the neutron fluxes outside the tank are lower because of neutron absorption by the tank material.

Open core pool-type light water reactors operate at low pressures (a few bars), determined by the hydrostatic pressure of the height of water above the core (around ten metres) plus the discharge pressure of the pumps circulating the water in the core. With light water reactors where the core is in a closed tank and heavy water reactors, the operating pressures can be significantly higher (around 10 to 20 bars).

11. High Flux Reactor. 
Of the closed-vessel reactors, it is worth mentioning the design used for the BR2 ${ }^{12}$ reactor, developed by SCK CEN at the $\mathrm{Mol}$ research centre in Belgium ${ }^{13}$, to make it easier to conduct experiments. This reactor, rated at $100 \mathrm{MW}$, is moderated and cooled by light water at a pressure of 22 bars; the core consists of a beryllium matrix. To facilitate access to the irradiation locations, the core tank is in the shape of a hyperboloid of revolution (diabolo - figure 2.2) with the core in the narrow part. Its top cover, with a diameter around twice that of the narrow part, allows more room for the penetration sleeves of the irradiation devices, which are inclined slightly off the vertical ${ }^{14}$.

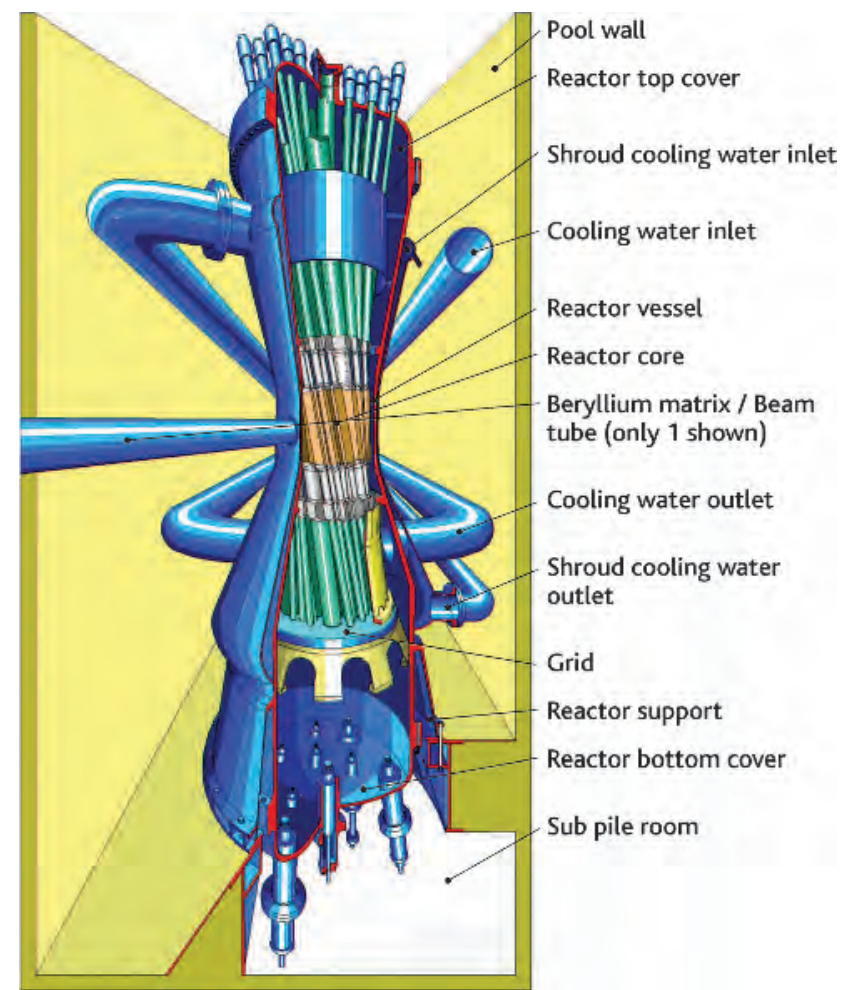

Figure 2.2. Diagram of the BR2 reactor. (C) SCK CEN.

\section{Fuel and core of research reactors}

In general, the cores of research reactors consist of fuel elements, control and safety elements containing materials that absorb neutrons, reflector elements to reduce

12. Belgian Reactor 2.

13. One of the biggest producers of radioisotopes for medical use.

14. "Les réacteurs de recherche", Francis Merchie, Encyclopédie de l'énergie, 2015. 
leakage of the neutrons produced in the reactor core, and spaces in which materials for irradiation can be placed.

The description below tends to refer to pool-type reactors.

With these reactors, the constituents of the core are placed on a grid supported by a metal structure at the bottom of the pool filled with demineralized water.

Fuel elements ${ }^{15}$ can come in the form of an assembly of uranium oxide-based rods, but more often they are in the form of plates of a uranium alloy-based fuel ( $\mathrm{UAl}_{\mathrm{x}}{ }^{16}$ or $\mathrm{U}_{3} \mathrm{Si}_{2}$ ) clad in an aluminium alloy (by "co-rolling") (figure 2.3), placed (the plates are crimped) in a vertical shell (figure 2.4) channelling the cooling water, which also acts as the moderator. The core reflector is generally made from beryllium or graphite. It can also be a tank of heavy water surrounding the reactor core. In the case of "neutron beams outside" reactors, there are openings in the side walls of the pool for the neutron channels to go through.

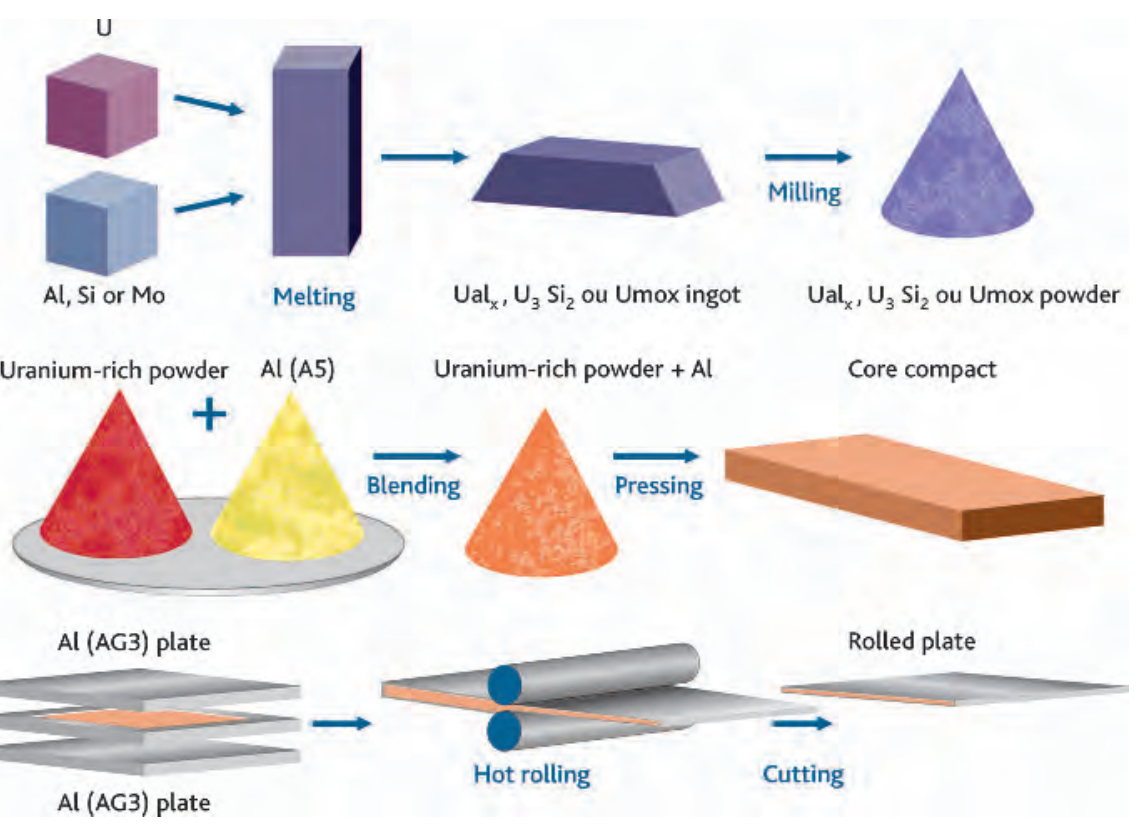

Figure 2.3. Stages in the "co-rolling" fuel plate fabrication process. The fuel core is a blend of fuel powder $\left(\mathrm{UAl}_{\mathrm{x}}, \mathrm{U}_{3} \mathrm{Si}_{2}, \mathrm{UMo}_{\mathrm{x}}\right)$ and aluminium from melting $\mathrm{U}$ and $\mathrm{Al}, \mathrm{Si}$ or Mo. (c) Georges Goué/IRSN.

Although some of the first research reactors could operate with natural uranium (containing $0.7 \%$ of its fissile isotope uranium-235), benefiting from the excellent

15. For more details, see the CEA's publication entitled "Nuclear fuels", a Nuclear Energy Division Monograph, 2008, especially the "Research reactor fuels" chapter.

16. This is usually referred to as UAl. The same applies for $\mathrm{UMo}_{\mathrm{x}}$, which will be discussed later on and is commonly referred to as UMo. 


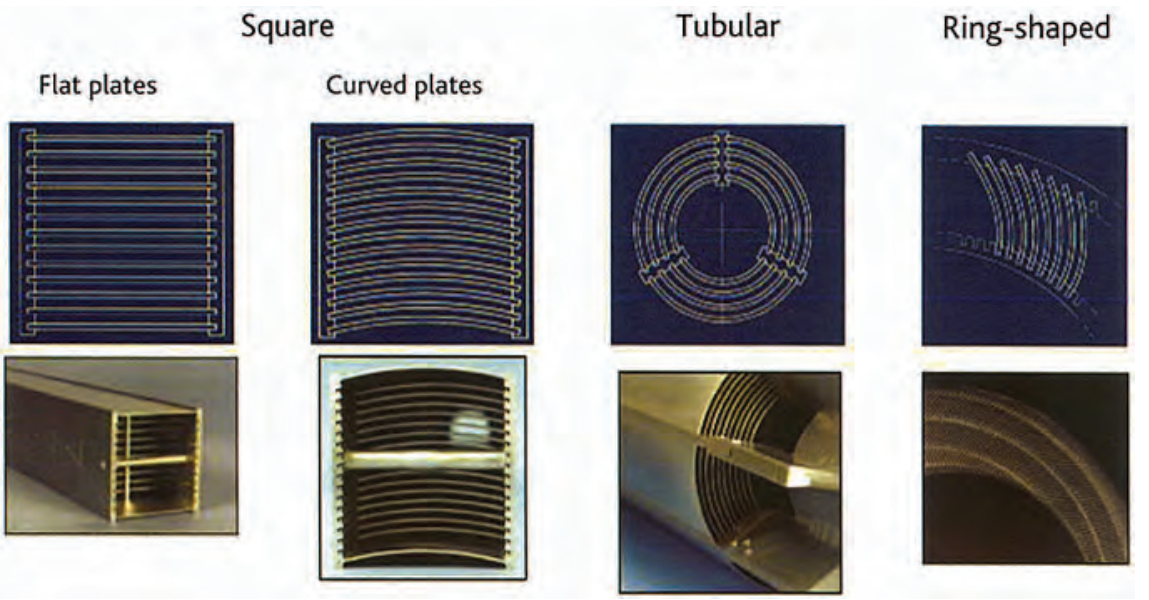

Figure 2.4. Different types of research reactor fuel elements and fuel assemblies. () AREVA-CERCA.

neutronic properties of heavy water or graphite as moderator and reflector ${ }^{17}$, most use uranium enriched to between $20 \%$ and $93 \%$ uranium-235.

Among the pool-type reactors widely used throughout the world, it is worth mentioning the TRIGA (Training, Isotope, General Atomics) reactors designed and built by the American company General Atomics ${ }^{18}$ (see figure 2.5 showing two of these reactors): some of their characteristics, particularly related to the fuel and the core, are of particular interest.

Nearly forty TRIGA reactors are currently in service. The most powerful of these reactors is the TRIGA reactor at the Pitesti nuclear centre in Romania, which has a thermal power rating of $14 \mathrm{MW}$. The thermal power of the other TRIGA reactors ranges from a hundred $\mathrm{kW}$ to $3 \mathrm{MW}$.

The core of a TRIGA reactor is positioned at the bottom of a pool containing demineralized water. It has a graphite or beryllium reflector and generally consists of around a hundred fuel rods containing pellets made from a blend of uranium and zirconium hydride $(\mathrm{UZrH})$ clad with stainless steel or 800 alloy ${ }^{19}$. The uniform blend of uranium (enriched to $19.75 \%$ of uranium-235) and zirconium hydride (used as moderator) produces significant and immediate neutron feedback if the temperature of the blend increases

17. The NRX (National Research eXperimental) and NRU (National Research Universal) reactors in Canada, for example.

18. In 1996, General Atomics joined forces with the French company CERCA (Compagnie pour l'étude et la réalisation de combustibles atomiques, a subsidiary of AREVA (Orano)) to create TRIGA International. Since then CERCA has been responsible for the fabrication of the fuel assemblies for TRIGA reactors.

19. Iron, nickel and chrome alloys, which combine good ultimate tensile strength with excellent resistance to oxidation and carburization at high temperatures in many aqueous environments. 

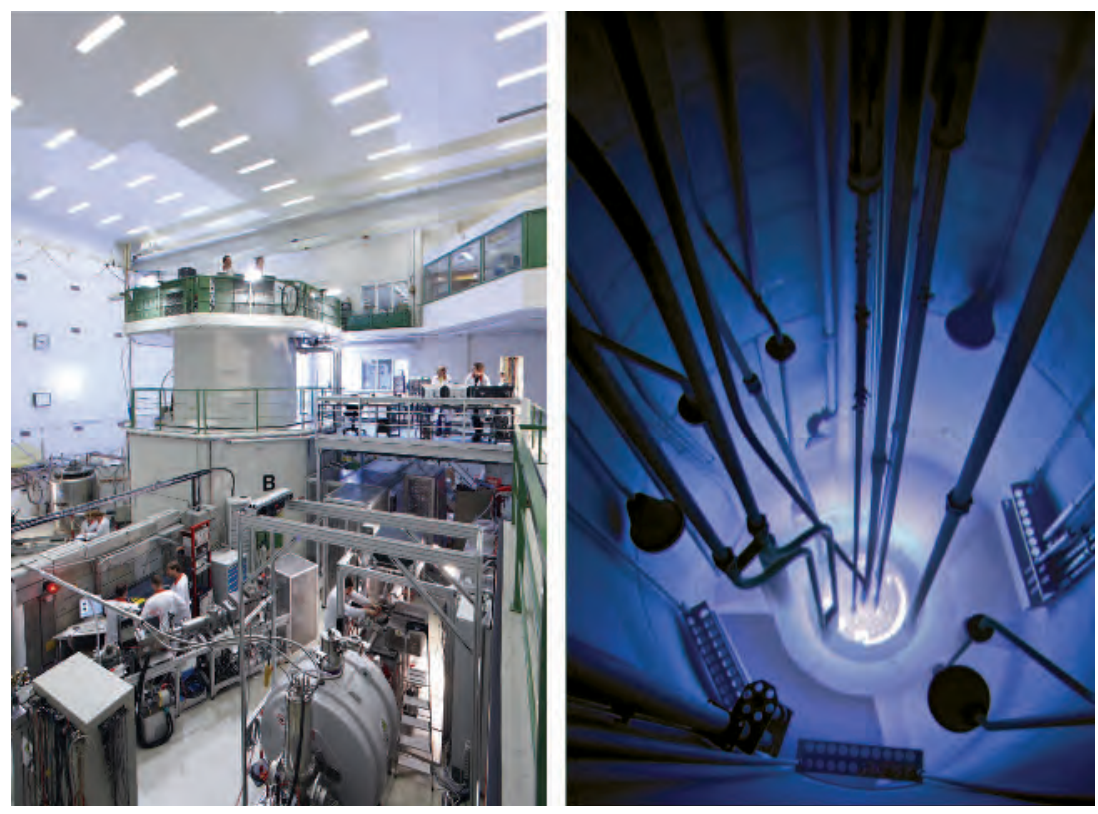

Figure 2.5. Left, the TRIGA reactor in Mainz, Germany. (C) Thomas Hartmann, Johannes Gutenberg University Mainz; right, the TRIGA reactor at the University of Oregon, USA. (c) Oregon State Radiation Center and School of Nuclear Science and Engineering.

(reactivity coefficient of around $\left.-10 \mathrm{pcm}^{20} /{ }^{\circ} \mathrm{C}\right)^{21}$. Because of the good metallurgical stability of this fuel and its ability to function at high temperatures (normally $750^{\circ} \mathrm{C}$, though the fuel blend is stable at up to $1,150^{\circ} \mathrm{C}$ ), and the high negative reactivity coefficient, the TRIGA reactor can be "pulsed" by injecting reactivity at very high power levels (of up to $22,000 \mathrm{MW}$ in the case of the TRIGA reactors currently in operation) for fractions of a second. The rapid increase in power is quickly brought to a halt by the negative reactivity effect of the moderator. It is also worth noting that $\mathrm{UZrH}$ fuel has good fission product retention potential compared to fuel plates made using aluminium.

\subsection{Global situation}

\subsubsection{Statistical data}

According to the RRDB database 22 - data from May 2018 - held by the International Atomic Energy Agency (IAEA), 807 research reactors have been built throughout the

20. pcm: per cent mille.

21. The coefficient $\Delta \mathrm{k} / \mathrm{k} /{ }^{\circ} \mathrm{C}$, representing the relative variation in the neutron multiplication factor by increasing the temperature by one degree Celsius.

22. Research Reactors Data Base. The figures in this database include research reactors cover not just civil nuclear facilities. 
world and 23 are planned or are under construction. Among the reactors already built, 430 have been decommissioned (more than half of these are in the USA), 223 are operational, and the other 154 are in extended shutdown without utilization (or not yet decommissioned). Around:

- $27 \%$ of research reactors have a thermal power of less than $1 \mathrm{~kW}$;

- $35 \%$ have a thermal power of between $1 \mathrm{~kW}$ and $1 \mathrm{MW}$;

- $38 \%$ have a thermal power of more than $1 \mathrm{MW}$.

Among the reactors in operation worldwide:

- more than $50 \%$ are MTRs and multi-purpose reactors (also produce, radioisotopes, have "neutron beams outside", etc.);

- around $20 \%$ of them are very low power critical assemblies;

- just over $10 \%$ of them are small reactors mainly used for education and training.

The Russian Federation has the largest number of research reactors (in operation or temporarily shut down) (54), followed by the USA (50), China (16), Japan (9), Germany (7) and France (5) ${ }^{23}$. Many developing countries also have research reactors or are planning to acquire them. Nine research reactors are under construction throughout the world and fourteen are planned.

Despite the growing interest in research reactors in developing countries, the total number of these reactors globally is steadily diminishing (the reduction in numbers since 2005 means that, on average, one research reactor is being closed per year). This may be due to the ageing of some facilities, which can only be brought up to a safety level considered acceptable today by carrying out major upgrading or modification work. It could also be due to a lack of funds to operate and maintain them, or even to there being no utilization programme for them. In this regard, it should be noted that nearly $40 \%$ of research reactors are underused (154 are in extended or permanent shutdown).

\subsubsection{General nuclear safety and non-proliferation issues}

Despite the variety of designs and uses, some important general safety issues have been raised in relation to many of the research reactors in operation throughout the world; these issues mainly concern:

- maintaining safety levels as facilities age (in the broadest sense, including as equipment becomes obsolescent),

- safety management by their operators,

- the effectiveness of regulatory monitoring of their safety.

23. The ISIS, RHF, CABRI, ORPHÉE and MASURCA reactors are counted here in the RRDB database. 
These issues have been highlighted particularly by the various safety reports produced by the IAEA within the framework of different meetings and technical workshops, based on experience feedback from its activities concerning research reactor safety, including the results of numerous "safety assessment ${ }^{24 "}$ missions.

Another key generic issue is the "conversion" of research reactors originally designed to use fuel highly enriched with uranium-235 to use less highly enriched fuel (containing no more than $20 \%$ uranium-235), for non-proliferation reasons.

Management of ageing and the "conversion" of research reactors that use highly enriched fuel are discussed in more detail below.

Moreover, it was stated above that nearly $20 \%$ of research reactors are in extended shutdown, which means that they are not used but there are no clear plans for their future. This is a cause for concern for the IAEA, which is engaged in various actions aimed in particular at improving the utilization of research reactors.

\subsubsection{Management of research reactor ageing}

There are two aspects to this issue:

- actual ageing, which is the result of various damage mechanisms - or pathologies - that can affect components (metal structures, civil engineering works, cables and other electrical equipment, etc.) over time, which can lead to latent deterioration (cracking, brittleness, etc.) despite the design, construction and operational precautions ${ }^{25}$ taken;

- equipment obsolescence in respect of the most recent technologies, standards and safety requirements.

The IAEA's experience feedback reports show that ageing and obsolescence are among the leading causes of incidents at research reactors throughout the world.

Ageing and obsolescence especially affect material testing reactors, some of which are also used to produce radioisotopes for medical use.

A country's decision to renovate a research reactor or to shut it down, replacing it (or not) with a new reactor, will depend on a number of factors, in particular:

- how much the facility is used;

- the radioisotope needs of the country (or region) for medical applications;

- the experimental studies required to support an existing or planned national nuclear power generation programme;

- changes in the reactor's environment (urban, industrial, etc.);

24. The Integrated Safety Assessments of Research Reactors (INSARR).

25. Particularly in the form of margins, corresponding to "provisions" in the case of damage mechanisms that can be anticipated and quantified. 
- the scale and the feasibility of the renovation work required, as well as the cost, including to reach a satisfactory safety level.

It should be noted that it is generally possible to replace all the components of research reactors, except their civil engineering works. This has been confirmed by the major renovations carried out on a number of different research reactors.

As with other types of nuclear facilities, ageing and obsolescence in the case of research reactors can lead to a reduction in safety margins (as regards dreaded phenomena) if those changes are not detected or corrected in time.

Obsolescence can in particular lead to difficulties procuring spare parts to replace safety-related components.

Ageing can affect safety-related equipment, e.g. corrosion of fuel element cladding, the reactor pool liner or coolant system pipes. It can also increase the risk of "common failure mode" ${ }^{26}$ of redundant components.

Although for many research reactors, most structures, systems and components $\left(\mathrm{SSC}^{27}\right)$ are replaceable, in order to manage ageing a systematic approach is necessary, combined with an effective programme for this management. This means, for example, the use of materials with good corrosion resistance or materials that are compatible with one another (for welding, for radiation protection in pools ${ }^{28}$, etc.) or setting up equipment inspection and maintenance programmes, including the surveillance of representative samples specifically to monitor and anticipate the ageing of safety-related equipment. Generally, all parameters that could affect the ageing of facilities and lead to the degradation of safety-related structures, systems and components should be monitored appropriately during the life of a reactor.

Ageing management should be set up and carried out in a proactive and anticipative way, during the different phases in the life of a research reactor. For example, modifications made to a research reactor or its experimental devices should not obstruct inspections or tests designed to detect signs that safety-related structures, systems and components are ageing - and if possible should facilitate them. This can be achieved by making the equipment accessible (at the initial design stage of the facility) and keeping it so (during operation), though without exposing those carrying out the inspections, or anyone else, to ionizing radiation.

Finally, existing experience feedback on ageing, including from industrial facilities, whether specific to the reactor in question or generic, must be taken into account as part of ageing management. The IAEA keeps a database on this subject, the aim of which is to share this knowledge worldwide.

26. Failures of several components due to the same cause.

27. "Structures, systems and components" is a standard expression used particularly in IAEA standards.

28. For example, lead can cause aluminium structures to corrode, depending on the physical and chemical state of the water. 


\subsubsection{2. "Conversion" of research reactors using fuel highly enriched with uranium-235}

Where research reactors using fuels highly enriched with uranium-235 are used, there is a risk that this fissile material could be diverted to a non-peaceful use. This risk is particularly high given that the low radioactivity level of the fuel makes it easy to handle.

Highly enriched uranium differs from the natural uranium or low enriched uranium used in power reactors because of its high uranium-235 content (which can be as much as $93 \%$ ). The maximum "non-proliferation" content is considered to be $20 \%$, given the risks associated with the diversion or theft of non-irradiated fuels and the risks related to the production of plutonium during the irradiation of low enriched fuels in a reactor.

In the 1950s and 1960s, the USA and the Soviet Union started to export highly enriched uranium as part of their civil nuclear cooperation programmes (especially the US Atoms for Peace programme launched in 1954).

In 1978, the US Department of Energy (DOE) launched the Reduced Enrichment for Research and Test Reactors (RERTR) programme, the aim of which was to "convert" research reactors using fuel highly enriched with uranium-235, of US origin, to the use of low enriched fuel (less than 20\%). In the mid-1980s, the programme was extended to include facilities that produce radioisotopes, in particular with the development of technologies to produce molybdenum-99 for nuclear medicine using low enriched with uranium-235 targets.

In the early 1990s, the programme was extended again, in collaboration with Russian institutes, this time to reactors using highly enriched fuel of Russian origin. This concerned highly enriched fresh and spent fuel at research reactors in Poland, Serbia, Ukraine and Uzbekistan, as part of their "conversion" to low enriched fuel.

After the terrorist attacks of 11 September 2001 on the World Trade Center in New York, efforts and resources to reduce the enrichment with uranium-235 of fuels used in research reactors were stepped up, especially with the launch by the US administration of the Global Threat Reduction Initiative programme in 2004, which brought the RERTR programme and other US initiatives together under a single umbrella. In particular it aimed to tighten the licensing conditions for exports of highly enriched uranium for research reactors and to take back any exported highly enriched nuclear fuels after use, to keep them secure.

From the launch of the RERTR programme to the end of 2011, some 75 research reactors had been converted to low enriched fuel or had been permanently shut down (out of the 129 research reactors selected for conversion under this programme, including American university reactors). The programme objective is to complete the "conversion" of the remaining reactors by 2020, bearing in mind that, for 28 of them, "conversion" requires the "qualification" of a new high density UMo ${ }^{29}$ fuel (containing around 7 grammes of uranium per $\mathrm{cm}^{3}$ ). 
It is worth noting that the majority of "conversions" in developing countries have been carried out in cooperation with the IAEA and that "conversion" has offered some of them an opportunity to renovate safety-related equipment.

\subsection{Uses of research reactors and main related risks}

A number of research reactors on university or research organization sites are used to train students, engineers and nuclear industry personnel, including personnel who operate research reactors and power reactors, and also nuclear safety authorities.

Research reactors are also used for fundamental and applied research, especially in the fields of nuclear physics and matter sciences, and for activation analysis, radiochemistry and nuclear medicine. They can be used to produce a wide variety of radioisotopes for medical or industrial applications, and for agriculture and research, and to create materials modified by transmutation ${ }^{30}$ for the electronics industry. They can also be used to test different types of nuclear fuel and to study the behaviour of different materials under irradiation or in simulated accident conditions.

These different research reactor uses are discussed in more depth in the next sections. It is also worth reading the report produced by the IAEA in 2007 giving a detailed overview of the different uses of research reactors throughout the world ${ }^{31}$.

\subsubsection{Training}

In principle, all research reactors can be used for education and vocational training in the nuclear field. But for safety and accessibility reasons, low power research reactors (up to a few hundred kilowatts) are best suited to training activities, which can include making neutron measurements and radiological protection measurements, and characterizing reactor cores by establishing the neutron-absorbing rod worth curve and measuring the temperature coefficient and power distribution. This type of reactor also enables trainees to acquire knowledge and practical experience of operating a nuclear reactor (approach to criticality, divergence, etc.). It is obviously important to use specific core configurations with low potential reactivity to prevent reactivity accidents if trainees do something wrong. It should also be noted that setting safety limits, a common operation in reactors used for teaching, requires special care from the point of view of human and organizational factors, especially on the part of trainers and operating personnel.

\subsubsection{Fundamental research}

The neutron beams of research reactors can be used for research into nuclear physics or the physics of condensed matter and to study crystalline structures by thermal

30. Doping of silicon for the manufacture of electronic components.

31. Technical Reports Series No. 455: "Utilization related design features of research reactors: a compendium", 2007. See also the CEA publication "Research Nuclear Reactors", a Nuclear Energy Division Monograph, 2012. 
neutron diffraction. Neutrons, which have a similar unit mass to that of a hydrogen atom and have a neutral electrical charge, can easily penetrate most materials and are therefore ideal for exploring matter. Thermal neutrons travel at around 2,200 m/s, and their wavelength is $0.18 \mathrm{~nm}$ (nanometres), which is perfect for studying crystalline structures through diffraction because it is the same order of magnitude as the lattice size of crystals ${ }^{32}$.

The reactors best suited to neutron scattering and diffraction experiments and studies of the physics of solids are generally the reactors with a thermal power greater than ten megawatts and a neutron flux of more than $10^{14}$ neutrons. $\mathrm{cm}^{-2} \cdot \mathrm{s}^{-1}$.

Using a "cold source" containing liquid hydrogen or liquid deuterium (at a temperature of around 20K) or a "hot source" containing graphite (at a temperature of around $1,500 \mathrm{~K}$ ) makes it possible to move the neutron energy spectrum and obtain higher or lower wavelengths for certain types of research. Using neutron channels, which can be up to a hundred metres long, is a way of increasing the number of experiments installed around the reactor.

The main risks associated with experiments conducted using neutron channels are normal industrial risks and irradiation risks for the experimenters. Severe irradiation of experimenters has happened at various facilities, due either to malfunctioning safety devices (such as neutron beam shutters, radiation monitors or radiation measurement and signalling devices), or to failure to respect safety instructions. Many of the experimenters affected have been from external organizations and have not necessarily been familiar with the different risks associated with the experimentation zones where they were working. As a result of these irradiation incidents, operators have taken measures to make experimenters more aware of the risks associated with the areas they are working in (e.g. putting up notices at the entrance to each experimentation zone showing the conventional and radiological risks in that zone). Material changes have also been made, e.g. an audible and visual alarm being triggered whenever there is unauthorised access to an experimentation zone where the dose rate is above a pre-set value.

Lastly, the risks associated with "cold sources" and "hot sources", especially the risks of hydrogen or deuterium explosion and of steam explosion (through the interaction of graphite and water), which are likely to affect the core of a reactor or its confinement "barriers", should be addressed in the context of the safety demonstration ${ }^{33}$ for that reactor.

\subsubsection{Experimental irradiation}

Research reactors with a thermal power above ten megawatts are the facility of choice for studying and qualifying nuclear fuels and the structural materials and components used in power reactors (vessels, internal equipment, neutron absorbers, etc.).

32. "Les réacteurs de recherche", Francis Merchie, Encyclopédie de l'énergie, 2015.

33. The measures taken by the operator to obtain an appropriate level of safety at the facility should be described in the documents justifying the rationale behind those measures and their adequacy, usually known as the "safety demonstration". 


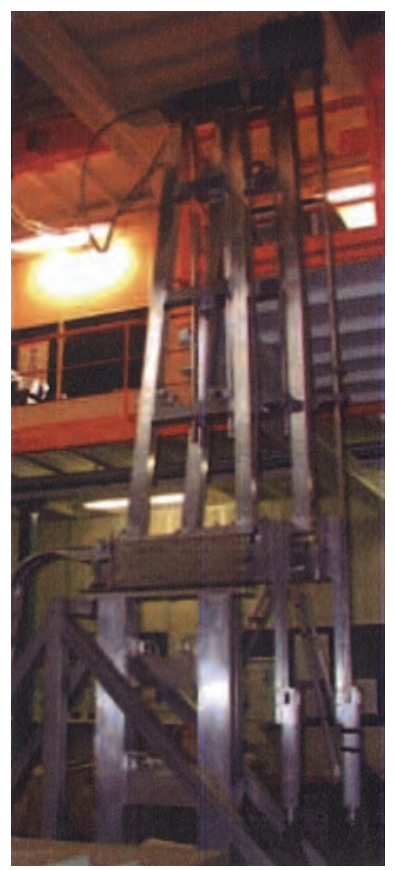

Figure 2.6. Telescopic device at the OSIRIS reactor used to carry out slow power ramps, according to IAEA Report 455. C DR.

Irradiation can be carried out under conditions representative of the neutronics and thermohydraulics of a power reactor in normal operation or, in the case of some reactors, under conditions representative of accident situations at power reactors, such as reactivity insertions or reductions in coolant flow rate to the reactor core, though not severe conditions (e.g. core melt), which are studied specifically using safety testing reactors.

The use of research reactors for this type of irradiation has major advantages over the use of power reactors:

- the higher neutron flux means that the intended irradiation doses can be obtained more quickly (e.g. for studying the ageing of materials subject to irradiation);

- having the ability to instrument the samples better means that more precise measurements can be made of temperature, pressure and neutron flux;

- being able to move the studied fuel samples closer to the reactor core using a (telescopic) "displacement device" makes it possible to simulate slow power ramps $^{34}$ (figure 2.6);

34. Slow changes in power in respect of rapid transients ("pulses"). 
- the risks are lower if an accident occurs while an irradiation experiment is taking place.

The irradiation is generally carried out in experimental devices containing the fuel samples or materials to be irradiated under clearly defined conditions in terms of temperature, pressure, neutron flux and surrounding fluid (inert gas, water as liquid or steam, liquid sodium, etc.).

Every irradiation device must be specially examined from a safety point of view, looking particularly at the risks from possible interactions between the device and the reactor, i.e. the potential impact of the device on the safety of the reactor and other "experiments", and the impact, on the safety of the device, of events (connected with the reactor itself or events such as internal or external hazards) taken into account in the design of the reactor and the associated safety demonstration.

The experimental devices used include irradiation capsules - which are not instrumented - and irradiation loops, containing water, gas or molten metal (e.g. sodium for sodium-cooled fast neutron reactors).

Irradiation capsules generally have two external physical "barriers" (metal envelopes) between the radioactive material and the outside, the integrity of which is surveyed by monitoring the pressure of the thin gas layer (nitrogen or helium) between the two barriers. The safety of the capsules relies on design choices justified by calculations of the heating and increase in pressure of their different components during irradiation, and on the chemical compatibility ${ }^{35}$ of the materials used. Incidents have occurred involving irradiation capsules, where the barriers have burst or their integrity has been lost, leading to contamination of the pool or other reactor structures, or even to the irradiation of experimenters.

Irradiation loops can be used to study the behaviour of nuclear fuels used in the different types of nuclear reactors, under conditions representative of normal, incident or accident operating conditions in power reactors. These loops which, like the irradiation capsules, have envelopes to act as barriers, differ in that they have a circuit to cool the samples being studied. As explained above, the coolant can be water (pressurized), a gas or even a molten metal.

The different parameters of an experimental irradiation device (pressures, temperatures, coolant flow rates in the case of loops, etc.) are continuously monitored while the irradiation is carried out. Security systems trigger automatic reactor scram or the device itself to be brought back to a safe state (e.g. if a pressurized loop loses pressure), as soon as predefined limits are exceeded.

The main risks associated with irradiation loops include:

- the risk of contamination and irradiation of personnel if the integrity of the loop barriers is lost;

- the risk of structural damage to the loop and the emission of projectiles, which can affect reactor safety if the fuel sample being tested melts, potentially

35. Risks of eutectic formation, galvanic corrosion (steel in contact with aluminium), etc. 
followed by a steam explosion (melting of the sample can be one of the objectives in some experiments).

Provisions are made to prevent these risks and limit their consequences.

\#FOCUs

\section{Some reactors used specifically for safety tests}

- CABRI (Cadarache Research Centre, France)

Testing of the behaviour of nuclear fuels in cases of rapid reactivity insertions (pressurized water reactors [PWRs], sodium-cooled fast neutron reactors [SFRs]).

- SCARABEE (Cadarache Research Centre, France) - this reactor has been shut down and dismantled

Tests to support the study of melting fuel accidents caused by fuel assembly blockage in SFRs.

- PHEBUS (Cadarache Research Centre, France)

Tests related to cooling accidents in PWRs and the associated fission product transfers.

- NSRR (Nuclear Safety Research Reactor, Tokai Mura, Japan)

Tests to support the study of rapid reactivity insertions in the case of fuels for SFRs and light water reactors.

- TREAT (Transient Reactor Test Facility - Idaho National Laboratories, Idaho Falls, USA)

Tests to support the study of rapid reactivity insertions in the case of various fuels (SFRs and light water reactors, etc.).

\subsubsection{Medical applications}

\subsubsection{Production of radioisotopes}

Research reactors enable radioisotopes to be produced for use in many fields, including nuclear medicine, industry, agriculture and research.

The use of radioisotopes for medical purposes is rapidly increasing globally. Every year more than 30 million examinations and cancer treatments are carried out worldwide. Molybdenum-99 ( $\left.{ }^{99} \mathrm{Mo}\right)$ is one example of a very commonly used radioisotope. It is used to prepare technetium-99m generators; technetium-99m is produced by the $\beta$ decay of molybdenum-99 (half-life 2.75 days). Molybdenum-99 is a fission product obtained by irradiating small UAl fuel plates (the uranium can be enriched to varying degrees). In some research reactors, molybdenum-99 is produced by neutron capture in targets enriched with molybdenum-98. 
The reactors that produce most of the world's molybdenum-99 are old reactors (BR2 in Belgium, HFR (Petten) in the Netherlands, NRU in Canada, SAFARI ${ }^{36}$ in South Africa - OSIRIS in France was shut down at the end of 2015), which frequently have to be shut down for maintenance, risking a global shortage of molybdenum-99.

The risks associated with the production of radioisotopes in research reactors obviously include the risks of contamination and irradiation of operational personnel and the risk of radioactive releases into the environment.

\subsubsection{Cancer treatment by neutron capture}

A number of research reactors are used to treat cancer (melanomas, brain tumours). The method they use, which is referred to by the acronym BNCT (Boron Neutron Capture Therapy), is based on the absorption of neutrons by boron-10. It consists of injecting a boron-10 solution into the tumour to be treated and irradiating it with a neutron beam from the reactor. The absorption of neutrons by the boron-10 leads to the emission of $\alpha$ (alpha) particles, which are highly ionizing. The cancer cells are destroyed locally by these particles, the distance of travel of which is of the same order of magnitude as the diameter of the cells.

Further research is necessary to reduce the irradiation time of the patients and the doses received by healthy cells.

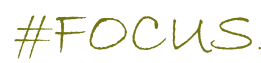

\section{Artificial radionuclides produced at research reactors and used in the medical sector}

- Diagnostic techniques:

Technetium-99m (from molybdenum-99), xenon-133, tritium $\left({ }^{3} \mathrm{H}\right)$, carbon-14, ruthenium-97, iodine-125;

- Therapeutic treatments:

- $\quad \boldsymbol{\beta}$ emitters (for synovitis, stenosis (diseases of the arteries), palliative treatments (bone cancer): yttrium-90, strontium-90, rhenium-186, erbium-169, copper-64, samarium-153,

- $\gamma$ emitters (for cancers): cobalt-60, iridium-192,

- $\quad \boldsymbol{\beta}$ and $\gamma$ emitter (for thyroid cancer and hyperthyroidism): iodine-131.

\subsubsection{Activation analysis}

Activation analysis is a method for precisely determining traces of impurities in samples of materials required to have a high chemical purity. It is based on the conver-

36. South African Fundamental Atomic Research Installation 1. 
sion of stable atomic nuclei into radioactive nuclei through neutron irradiation of the sample being tested and on measurement of the radiation emitted by the radionuclides formed in the irradiated material.

Activation analysis is the most common area of use of research reactors. Practically any reactor with a power of more than around 20 kilowatts can provide a sufficient neutron flux to perform these analyses. By using hydraulic or pneumatic tubes linking the reactor to the analysis laboratories, elements with a short radioactive half-life can be measured.

From a safety point of view, the risks associated with this type of research reactor use are generally low. They are the risk of contamination of premises or persons in the analysis laboratories, the risk of irradiation if a container carrying an irradiation capsule in a hydraulic or pneumatic tube system becomes trapped, and the risk of contamination of internal structures within the reactor if the irradiated samples overheat, causing the loss of integrity of these structures and the destruction of the irradiation capsule. The measures to be taken to avoid the above situations and to limit their consequences, and the list of materials which must not be irradiated in a reactor (e.g. mercury because of its corrosive properties), must be stated in the facility's operating rules.

\subsubsection{Industrial applications}

There are numerous industrial applications for research reactors. Only three of them, which are very common, will be mentioned below.

Neutron beams can be used for neutron radiography of various objects. Nondestructive testing using neutron radiography, which is based on the property of neutrons that they are stopped by light nuclei, is a complementary technique to radiography, because it enables both thin slivers of light elements and thick pieces of heavy elements to be examined. Neutron radiography is used for non-destructive testing in the aeronautical and space industries (e.g. for testing the pyrotechnic devices in rocket launchers), and in the nuclear sector. An example is the facility used for the neutron radiography of irradiated fuels associated with the PHENIX reactor at Marcoule, France, which consists mainly of a small reactor with a vessel containing a fissile solution (uranyl nitrate), equipped with a cooling system, a fixed reflector and a mobile reflector, which can be moved closer to the vessel to start the chain reaction.

The neutron irradiation of silicon ingots changes the silicon through the uniform generation of phosphorus-31, which turns it into a semi-conductor. This method can be used to achieve an excellent distribution of resistivity in silicon ingots used in the manufacture of components for the electronics industry, such as diodes and thyristors.

Irradiation with fast neutrons causes colouration of topaz, which is used in jewellery-making. This activity is prohibited in many countries, but is still carried out in some research reactors throughout the world. 


\section{Chapter 3 Aspects of the design and safety demonstration of research reactors at international level}

\subsection{Convergence of practices on a few main safety objectives, principles and safety approaches}

The construction of nuclear reactors (whether for research or power generation) began in the mid-20th century in a few countries (USA, former Soviet Union, France, UK, etc.) that were engaged in the research and development of technologies that could use the energy produced by nuclear fission to generate electricity.

In view of the safety and radiological protection issues raised by these facilities, which mobilized nuclear materials and radioactive fission products, and to avoid the exposure of workers and the public and the release of radioactive substances into the environment, the industry, in liaison with the safety organizations and authorities that were gradually set up, adopted various fundamental safety objectives, principles, procedures and criteria. These included, for example:

- compliance with "main safety functions", namely ${ }^{37}$, for all reactors, control of core reactivity, removal of the heat released by the radioactive material, and confinement;

37. The wording used by the IAEA (e.g. in document SSR-3, which will be discussed in section 3.2.3) is as follows: "The design for a research reactor facility shall ensure the fulfilment of the following main safety functions (...) for all states of the facility: (i) control of reactivity; (ii) removal of heat from the reactor and from the fuel storage; and (iii) confinement of the radioactive material, shielding against radiation and control of planned radioactive releases, as well as limitation of accidental radioactive releases." 
- the insertion of several physical confinement "barriers" between the radioactive materials or substances and the environment;

- the classification of equipment according to its importance for safety ("safety classification");

- or even the adoption of a redundancy principle ${ }^{38}$ for the most important safetyrelated systems.

They also adopted methods and approaches for safety analysis and demonstration, e.g. the determination and analysis of normal, incident and accident events related to the facilities themselves, and of events (hazards) that could cause damage to the facilities, whether of internal or external origin (fire, floods, earthquakes, etc.).

In parallel the industry developed rules for the design (including the dimensioning ${ }^{39}$ ) and the construction of equipment, based on proven best practice and offering different requirement levels - to be chosen for each item of equipment on the basis particularly of its safety classification.

The practice of sharing experience feedback was gradually established, nationally then internationally, and in some countries, particularly France, the practice of carrying out periodic safety reviews (described below in sections 3.5 and 9.2) developed, including for French research reactors from the 1990s onwards.

The representative bodies - industrial, technical safety organizations, safety authorities, etc. - in these countries contributed their experience and expertise to the drafting of the IAEA safety standards for international use. These IAEA safety standards, which incorporated this "knowledge", were the subject of a consultation with all the Member States $^{40}$ to achieve a broad consensus.

The IAEA safety standards are documents which are not binding but are used as reference documents on the basis of which the IAEA conducts safety assessments when asked to do so by a Member State. Particularly in the case of research reactors, many Member States have written these safety standards into their own national regulations.

This chapter, which looks at some issues of the design and safety analysis of research reactors at international level, refers to the document reference base of the IAEA.

\subsection{The IAEA safety standards}

The IAEA's statute enables it to establish safety standards, to promote their application by its Member States and to provide assistance in this area to any Member States that request it.

38. Redundancy, or possibly more, for certain systems, equipment or components, in order to improve the reliability of their functions.

39. Determining the technical characteristics (geometry of equipment, flowrate of pumps...) of a facility during the design process to satisfy pre-established criteria and regulatory requirements.

40. On 23 October 1956, 81 States approved the Statute of the IAEA, which came into being on 29 July 1957. On April 30, 2018, the IAEA had 170 Member States. 
A Code of (good) Conduct on the Safety of Research Reactors was adopted by the IAEA Board of Governors in March 2004. This Code, the text of which is similar to that of the Convention on Nuclear Safety, which applies solely to power reactors, is a high level document that is also not legally binding. It lays down guidelines for developing and harmonizing national practices as regards regulation and defines the ideal conditions for managing the safety of research reactors.

This Code of Conduct is a key element of the IAEA's programme of activities related to research reactors. This programme, approved by the Board of Governors, in particular involves the development of safety standards which inform or contribute to the application of the Code of Conduct, the organization and performance of safety assessments (INSARR), the organization of regional or international meetings on specific issues, and training carried out nationally or regionally to promote the guidance in the Code of Conduct. The IAEA intends that this programme will facilitate the sharing of operating experience feedback and lessons learned from events occurring at research reactors, especially through the Incident Reporting System for Research Reactors (IRSRR) and associated periodic meetings (see chapter 4 for more details). The IRSRR is managed by the IAEA, just like the IRS ${ }^{41}$ for power reactors and the FINAS ${ }^{42}$ system for fuel cycle facilities. However, it should be noted that only a few major or valuable incidents in terms of the lessons learned are entered into these databases.

\subsubsection{Drafting process of the IAEA safety standards}

The IAEA Secretariat organizes the drafting of the IAEA safety standards with the support of four specialist committees (competent respectively in the fields ${ }^{43}$ of nuclear safety, radiation safety, transport safety, and waste safety), overseen by the Commission on Safety Standards (CSS). The work of the CSS has to be approved by the Member States within the Board of Governors. The process of drafting new standards or revising existing standards is shown in the diagram in figure 3.1. IRSN and the the French nuclear safety authority (ASN) are extensively involved in the development of these IAEA safety standards.

It is worth mentioning that other specialist international organizations sometimes take part in the development of these standards, either through direct involvement in their drafting or by commenting on the draft texts.

Through the process described above, a broad consensus is reached on the IAEA safety standards among the Member States. Consequently, implementation of the high level standards (safety fundamentals and requirements - see section 3.2.2) can be viewed as necessary to achieve an adequate level of safety for nuclear facilities, bearing in mind that responsibility for monitoring their safety remains a national responsibility. All safety standards (including guides) are generally reviewed five years after publication to decide whether revision is necessary.

41. International Reporting System for operating experience.

42. Fuel Incident Notification and Analysis System.

43. To be more specific, the Nuclear Safety Standards Committee (NUSSC), the Radiation Safety Standards Committee (RASSC), the Waste Safety Standards Committee (WASSC) and the Transport Safety Standards Committee (TRANSSC). 


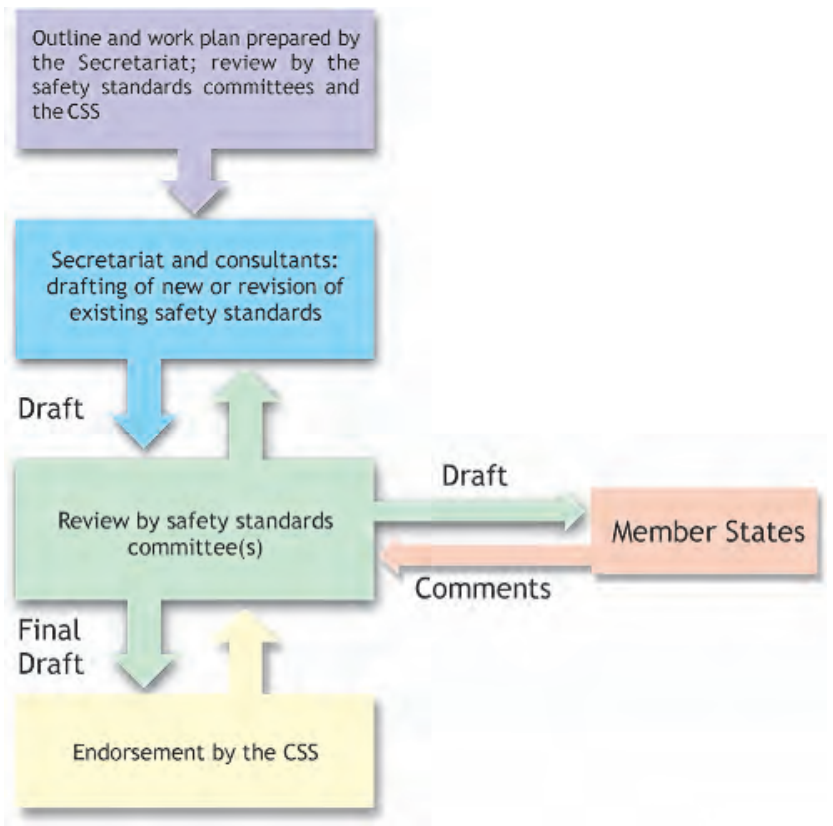

Figure 3.1. Process for the development or revision of the IAEA safety standards (note that for safety requirements and safety fundamentals, final endorsement is given by the Board of Governors). @ Georges Goué/IRSN.

\subsubsection{Structure of the IAEA safety standards}

The IAEA safety standards consist of three types of document: from the most general to the most specific, there are the safety fundamentals, the safety requirements and the safety guides.

The safety fundamentals present the objectives and general principles on which the IAEA's different standards for nuclear safety are based.

The safety requirements specify the requirements to be met to protect people and the environment.

The safety guides provide information and clarifications to help with applying the fundamentals and requirements; where appropriate, they are accompanied by examples of best practice.

The IAEA safety standards can be split into two main families: thematic standards and standards specific to a particular type of nuclear facility or activity. Separate safety requirements can therefore be drawn up for cross-cutting (thematic) fields and for specific facilities or activities (nuclear power plants, research reactors, fuel cycle facilities, radioactive material handling and transport, etc.). There are not very many thematic safety guides, but there are numerous guides for the different types of facility. 
In 2006 the IAEA adopted a new structure for the safety standards (figure 3.2), which aims to ensure that there are clear, logical links between the safety fundamentals, the safety requirements and the safety guides.

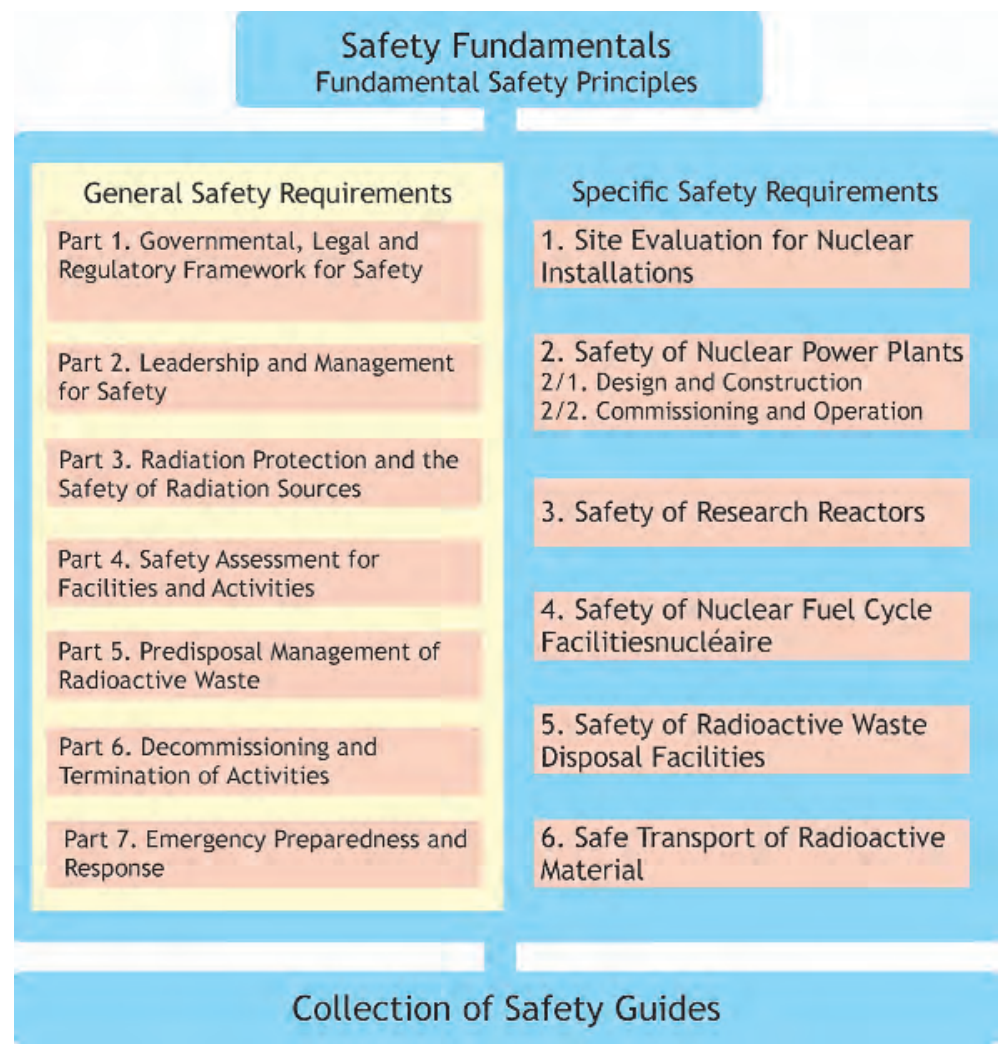

Figure 3.2. Structure of the IAEA safety standards Series. @ Georges Goué/IRSN.

Within this structure, the general safety requirements have been grouped together in a single document, whereas the facility- and activity-specific safety requirements are separate documents. The new structure also takes the same approach to integration of the different fields (nuclear safety, radiation safety, waste safety and transport safety) as the approach used for the safety fundamentals.

\subsubsection{Brief presentation of the safety standards for research reactors ${ }^{44}$}

A set of safety standards has been established by the IAEA as part of its research reactor safety activities. Whereas the majority of these standards fall into the category

44. Published up to June 2018. 
of standards specific to a type of facility, other important safety issues for research reactors, such as emergency preparedness and response ${ }^{45}$, fall into the thematic category.

All organizations involved in research reactor safety, whether designers, operators or users, or indeed inspection bodies, can find these safety standards useful. They are written especially so that they can be used when drafting national regulations.

The standard SSR-3 (Safety of Research Reactors - Specific Safety Requirements) published in 2016 to replace the standard NS-R-4, contains safety requirements applicable to different types of research reactors cooled by (light or heavy) water with a thermal power of no more than a few tens of megawatts. For other types of research reactors and for research reactors with a higher thermal power rating, the safety requirements in the safety standards for power reactors can be used.

Compared to the standard NS-R-4, the standard SSR-3 introduces additional requirements on topics including:

- the "design extension conditions" ${ }^{46}$; this topic, which means that the account taken of postulated events in the design and for the safety demonstration of a nuclear reactor is extended, is discussed further later on;

- the use of a "graded approach"; this also is explained in more detail later on;

- the feedback of operating experience;

- the interface between nuclear safety and nuclear security ${ }^{47}$ - safety measures and security measures should not compromise one another;

- the management of waste from research reactor operation.

The requirements in the standard SSR-3 deal with essential safety issues, including safety governance, regulatory control, safety demonstration and quality assurance, but also all the key stages in the life of these facilities, from choice of site, design (confinement barriers, main safety functions, defence in depth, etc.), construction, commissioning, operation, utilization and modification of research reactors, to final decommissioning.

The standard SSR-3 also requires that operators of research reactors have an independent safety committee (or advisory group ${ }^{48}$ ) to advise them on the safety aspects of

45. See the IAEA documents: General Safety Requirements No. GSR Part 7: "Preparedness and Response for a Nuclear or Radiological Emergency", and General Safety Guide No. GS-G.2.1: "Arrangements for Preparedness for a Nuclear or Radiological Emergency".

46. Accidents that are more severe than Design Basis Accidents, caused by internal or external hazards (based on the IAEA's definition of postulated initiating events).

47. This topic is not discussed in this report; for more information please refer to the document " $A$ comparative approach to nuclear safety and nuclear security", Reference documents series, IRSN 2009/117, available on the IRSN website.

48. Independent of the operating organization or the reactor manager (the member of the reactor management team to whom the operator gives direct responsibility for, and authority over, operation of the research reactor and whose functions consist primarily of fulfilling this responsibility). 
their reactor (design, commissioning, operation) and its utilization (experiments, training, etc.).

The committee members should be specialists in different fields on which the safety of the research reactor concerned depends; they may be external experts independent of the operating organization. The safety questions or issues to be considered by the committee include:

- the design, including the chemical composition, of nuclear fuel elements and reactivity control elements,

- modifications to operational limits and conditions,

- proposed new tests or experiments, and also systems, equipment or procedures that have significance for safety,

- proposed modifications to elements of the facility that have significance for safety,

- incidents that must be or have been reported to the regulatory body,

- periodic safety reviews of the facility,

- reports on radioactive discharges into the environment (in normal, incident or accident conditions) and on radiation doses to personnel at the facility and to the public.

There are a number of safety guides to help with the application of the requirements presented in standard NS-R-4 (and consequently those listed in standard SSR-3) for research reactors. A list of them, with comments, is provided in table 3.1 at the end of this chapter (guides in existence as at July 2018).

\subsubsection{Application of the IAEA safety standards}

As stated above, the IAEA safety standards are the expression of an international consensus aimed at protecting people and the environment. Despite this, the Member States are not legally bound to apply the safety standards. However, the IAEA does apply them to its own activities carried out under agreements to provide assistance or equipment signed with Member States. These agreements also stipulate that the country receiving assistance with acquiring or operating a research reactor must adhere to the IAEA safety standards.

More generally, the IAEA encourages its Member States to include in their national regulations and apply to their facilities the safety standards on research reactors as well as the standards on the regulatory and governmental infrastructure required for nuclear safety, radiation safety, the safety of radioactive waste and the safety of radioactive materials transport.

Finally, as stated above in section 3.1, all the standards are used as a reference by the IAEA when conducting safety assessments. 


\subsubsection{Supporting documents for application of the IAEA safety standards}

Other documents known as safety reports and technical documents (TECDOC) are published by the IAEA in addition to the safety standards. They do not make any new recommendations and their only purpose is to facilitate the application of the safety guides by providing technical information, practical examples and detailed methods. There are many documents of this type related specifically to research reactors. They cover areas such as the technical and regulatory infrastructure to be set up by countries wishing to launch a nuclear power generation programme by building their first research reactor, the "conversion" of research reactors (to use low enriched with uranium-235 fuels), site evaluation, source term ${ }^{49}$ evaluation and evaluation of the radiological consequences of accidents, implementation of an integrated management system, ageing, extended shutdown and decommissioning of facilities, and the corresponding safety analyses.

The process of preparing these documents is simpler than for the safety standards, because they do not have to undergo the full review and approval process used for the IAEA safety standards.

We saw earlier that a significant proportion of research reactors are in extended shutdown. In 2004 the IAEA wrote a technical document on this subject, TECDOC1387 entitled Safety Considerations for Research Reactors in Extended Shutdown. This document makes some recommendations and suggests practices considered satisfactory in relation to the various safety issues raised by this situation, for example:

- maintenance of skills and a memory of the facility's technical history,

- qualification of the personnel used,

- human resources, retention of enough personnel to respond in an emergency,

- equipment (including instrumentation) that can be decommissioned,

- conditions for the preservation of equipment (which can mean removing it for storage in a less harsh environment [mothballing], e.g. unloading of the core for storage),

- surveillance, periodic testing and maintenance of structures, systems and components,

- preventing criticality risks, dealing with neutron moderators used to operate the reactor (e.g. in the case of heavy water reactors, removal of the water for safe storage),

- radiological protection,

- adaptation of the operating rules, the associated documentation, updating of documentation,

49. The expression "source term" refers to releases from a facility in an accident, expressed as Becquerels (Bq) of each radionuclide. 
- procedures for restarting a reactor after an extended shutdown (especially pre-operational testing of equipment), etc.

\subsection{IAEA exchange and assessment mechanisms}

The IAEA uses the following resources in the context of its activities to improve safety at research reactors worldwide:

- international or regional meetings on the application of the Code of Conduct on the Safety of Research Reactors. Indeed, these meetings amount to discussions forums where the participants can share their experience and identify safety best practices. Self-assessments carried out during these meetings also enable the IAEA to identify more clearly the Member States' needs and any areas where safety management at research reactors could be improved. This information is then taken into account in the definition and performance of the IAEA's programmes of activities;

- national or regional training workshops on specific topics identified by the IAEA as important for the requesting country or the region;

- INSARR missions, which can be carried out at Member States' request to assess the safety of research reactors or to help resolve safety or radiological protection issues of a technical or organizational nature, including on inspection and regulation. These assessments cover around twenty topics. They are carried out by the IAEA with the participation of experts from operator organizations or safety bodies in different countries;

- more specific expert missions can also be organized to give the requesting bodies advice and assistance with resolving specific safety issues;

- periodic meetings, organized on average every 18 months as part of the IRSRR system, to exchange information about significant events that have occurred at research reactors and that could offer lessons for all research reactors.

Finally, the IAEA's technical cooperation programmes provide financial support to promote the participation of specialists from Member States that are (nuclear) developing countries in the meetings and workshops listed above. The IAEA's resources are also used to conduct INSARR missions and expert missions required as part of technical cooperation projects set up with the countries concerned.

\subsection{Some general principles and approaches related to safety}

\subsubsection{Organization of safety control, safety culture}

The fundamental safety principles and objectives are the subject of document SF-1 entitled "Fundamental Safety Principles", published by the IAEA in 2006. This document 
sets out the basis for the safety requirements. The ten safety principles discussed in this document concern nuclear safety and radiological safety. The document states that the fundamental safety objective is to protect people and the environment from harmful effects of ionizing radiation. The key principles presented concerning the organization of safety are:

- the prime responsibility for safety rests with the person or organization responsible for facilities and activities that give rise to radiation risks. The licensee retains the responsibility throughout the lifetime ${ }^{50}$ of the facility or activity and cannot delegate it;

- an effective legal and governmental framework for safety must be established and sustained. The government is responsible for the establishment and adoption of the necessary legislation and regulations. It is also responsible for establishing a regulatory body independent of the operator organizations, with legal authority, technical and managerial competence, and the resources to fulfil its responsibilities;

- an effective integrated management system (for quality, safety, etc.) must be established, that ensures the promotion of a "safety culture" (a concept explained in more detail later on). Regarding accidents, the primary means of preventing them and mitigating the consequences of any that do occur is defence in depth (see section 3.4.2);

- the safety of facilities and activities that give rise to radiation risks must be assessed using a "graded approach" taking account proportionately of the potential risks associated with them (see section 3.4.4).

In practice, there are major disparities in the application of these safety principles and objectives at research reactors throughout the world. These disparities concern:

- the effectiveness and independence of the regulatory and inspection bodies, taking account of the skills and resources at their disposal;

- the updating of safety documentation to reflect the true state of facilities;

- the validity and the "envelope" nature of the safety analyses of these facilities.

However, it should be noted that, in countries where the construction of a new research reactor is considered to be an important step in preparations for a nuclear power generation programme, safety and regulatory texts generally refer these days to the IAEA safety standards and to international best practice.

The concept of safety culture emerged from the reflection process following the accident at the Chernobyl nuclear power plant on 26 April 1986. While the measures taken following the Three Mile Island accident in 1979 focused particularly on the ergonomic and cognitive aspects of workstations in reactors and other nuclear facilities, the Chernobyl accident raised questions of a different kind, concerning organizational factors. The development of a safety culture within organizations active in the nuclear

50. Including, at the end of its life, issues related to dismantling and waste management. 
sector has generally been considered to be the appropriate response. As a result of the post-Chernobyl reflection process, it was felt that a more international vision of nuclear safety was necessary. This led to the issue of various reports by INSAG ${ }^{51}$, an international group of experts in nuclear safety created within the IAEA. They included the Summary Report on the Post-accident Review Meeting on the Chernobyl Accident (Safety Series No.75-INSAG-1 ${ }^{52}$ ) published in September 1986, which introduced the safety culture concept. The concept was discussed in more detail in 1991 in the report entitled Safety Culture (Safety Series No.75-INSAG-4). Safety culture is defined as "that assembly of characteristics and attitudes in organizations and individuals which establishes that...) safety issues receive the attention warranted by their significance". In particular, safety culture assumes that, within an organization, a questioning, careful and thorough approach and good communication between individuals are encouraged.

Two other INSAG reports are worth mentioning:

- the report entitled Management of Operational Safety in Nuclear Power Plants (Safety Series No.75-INSAG-13), published in 1999. This report discusses safety management issues of significance in promoting a safety culture, accompanied by recommendations and best practices. In particular, it contains recommendations on the maintenance of safety management during periods of organizational change, on monitoring safety performance and on early identification of declining safety performance before it has a significant impact on safety;

- the report entitled Key Practical Issues in Strengthening Safety Culture (Safety Series No.75-INSAG-15), published in 2002. This report, which includes some questions that can be asked as part of a safety culture self-assessment within an organization, discusses key issues such as: the importance of the manner of communication and of ensuring messages on safety are being received and understood, and especially of users understanding why procedures are used, the reporting culture and the attention that should be given to "near miss" incidents and to possible deviations ('to tolerate is to validate ${ }^{53}$ ), an organization's ability to challenge itself at all levels (the "learning organization ${ }^{54 ")}$.

The explanations and recommendations in these different INSAG reports are relevant to all types of facility, including research reactors - and also to operators, designers or other organizations that make a significant contribution to their operation. It is worth

51. International Nuclear Safety Group.

52. Updated in 1992 by report Safety Series No.75-INSAG-7.

53. Regarding the latter topic, it is worth mentioning here work done by an American sociologist, Diane Vaughan, on the Space Shuttle Challenger accident, published in 1996 in the book "The Challenger Launch Decision, Risky Technology, Culture and Deviance at NASA". It shows that what in hindsight appears to be a series of clearly identifiable errors is actually a series of decisions and interpretations that are perfectly understandable in the context in which they were made, but which are in fact slight deviations from normal limits and lead imperceptibly to the normalization of deviation.

54. INSAG-15 also points out that, although safety culture cannot be directly regulated, it is important that safety bodies understand how their actions affect the development of a safety culture and the improvement of the less formal human aspects of safety in organizations operating in the nuclear sector. 
mentioning that, while there are production challenges for research reactors just as there are for power reactors (performing experiments, production of radioisotopes, etc. in the case of research reactors; production of electricity in the case of power reactors), the safety culture concerns two populations: the operating personnel, but also to a certain extent the experimenters. Regarding experience feedback from incidents, section 10.1.1 discusses the importance of the operators involved in experiments having sufficient awareness of nuclear safety and radiological protection.

\subsubsection{Confinement barriers, fundamental safety functions, defence in depth}

Historically, in terms of safety, reactor design has naturally followed the principle of placing multiple physical confinement barriers between radioactive materials and the environment and "fundamental safety functions" have been adopted. These were explained in section 3.1.

The deployment of multiple confinement barriers was already in itself a type of defence in depth. But over time this concept has taken on a much broader meaning and can now be described as follows.

The defence in depth principle can be summarised as the deployment of a succession of different "levels of defence" such that, if one level fails, the consequences of the failure are mitigated by higher levels. The independence of the different levels of defence is therefore a key element ${ }^{55}$ in meeting this objective, and should therefore be sought as far as reasonably achievable ${ }^{56}$.

The general objectives of defence in depth are:

- to compensate for human and component failures;

- to maintain the effectiveness of the barriers by averting damage to the facility and to the barriers themselves;

- to protect the public and the environment from harm in the event that these barriers are not fully effective.

A concept associated with the defence in depth principle has been developed over time and was formalised in the INSAG-10 report ("Defence in Depth in Nuclear Safety") published in 1996, as five levels. The five levels are shown in figure 3.3.

In defence in depth, the concept of level corresponds to a set of measures such as the intrinsic characteristics of the facility in question (reactor, fuel pool, etc.), physical measures (structures, systems and components) and procedures.

Even though the implementation of the levels may differ from country to country and may depend on facility design, the main principles are universal.

55. Expression used in INSAG-10.

56. Improving the independence of the levels of defence in depth "as far as reasonably achievable" is one of the safety objectives of WENRA for reactors of the future. 


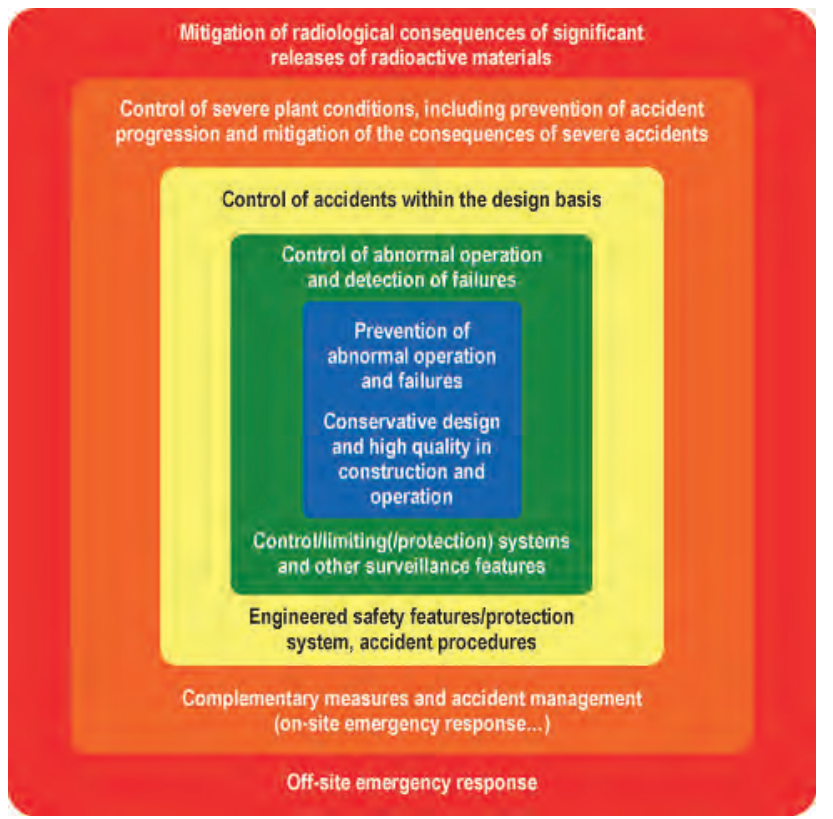

Figure 3.3. The defence in depth concept as developed in the INSAG-10 report: objectives and means. (c) Georges Goué/IRSN.

Because level 1 is the first level, it performs the main prevention function. Because levels 4 and 5 are the last levels, their main function is to limit the consequences of severe accidents.

There must also be a balance between the different levels of defence in depth. The INSAG-10 report stresses that accident management (level 4) may not be used to excuse design deficiencies at prior levels.

Conservative assumptions and safety margins (in relation to postulated phenomena) should be general features of the first three levels of defence in depth (choice of site, design and safety demonstration [e.g. when setting the limits for triggering protection and safeguard systems], construction, operation and modification, etc.). Measures should be taken to anticipate ageing (in the case of known mechanisms). At defence in depth levels 4 and 5, "best estimate", or reasonably conservative, considerations are used.

The INSAG-10 report also highlights the fact that, when implementing the defence in depth principle, internal and external hazards (fire, flooding, earthquakes, etc.) require particular attention because they could simultaneously impair several levels of defence in depth.

The INSAG-10 report also states that if it is not feasible to implement defence in depth against some events (such as sudden failure of a component under pressure), several levels of precautions should be introduced into the design and operation. These 
precautions could, for instance, be taken by choosing certain materials, by incorporating additional margins of safety during design, by reducing the length of welds, by using appropriate procedures for in-service monitoring, etc.

The various levels of defence-in-depth are explained below.

\section{Level 1: prevention of abnormal operation and failures}

A nuclear facility such as a reactor (power or research reactor) should be intrinsically robust so as to reduce the risks of failure. This means that, once the initial definition of the facility (and the selection of the design options) is complete, the normal and abnormal conditions of operation should be clearly identified (i.e. as exhaustively as possible) in order to ensure the systems and components are sufficiently robust and resistant, including in accident conditions. According to the defence in depth concept, level 1 must offer an "initial basis of protection" against internal and external hazards (earthquake, plane crash, fire, explosion, etc.), though additional measures may be required at higher levels. The study of these hazards would lead, for example, to the selection of a seismic reference level, maximum weather conditions (expressed in terms of temperatures, wind speed, weight of snow), a maximum overpressure wave due to external industrial explosions, and the duration of exposure to these phenomena. The choice of site plays a key role in limiting these constraints.

The facility's various SSCs can then be designed, built, inspected, installed, tested and operated and be subject to appropriate preventive maintenance, following well established and qualified rules, with a sufficient margin beyond the limits defined for correct operation of the facility, and more specifically to ensure the SSCs perform the functions required for them in the various envisaged situations. These margins should prevent regular use of systems designed to cope with abnormal situations, particularly recourse to the measures taken for defence in depth levels 2 and 3.

Binding rules laid down in design and construction $\operatorname{codes}^{57}$ define precisely the conditions for the design, procurement, manufacture, assembly, inspection, testing and preventive maintenance of safety-related equipment, to guarantee its quality in the broadest sense.

They are used to define the facility's authorised normal operating domain and its general operating rules.

A reactor technology ${ }^{58}$ that changes state slowly and has automated controls can reduce the risk of stress for operating personnel. The design of the human-machine interface and the time available before manual intervention is required can make an important positive contribution.

57. Which reflect proven industrial best practice. Worth mentioning are the American ASME (American Society of Mechanical Engineers) code, the RCC-M (design and construction rules for mechanical components) for French PWRs, and the RCC-MRx (design and construction rules for mechanical components of nuclear installations: high-temperature, research and fusion reactors), applicable to research reactors in particular.

58. Designers often use the term "process" to refer to the technology of a reactor. 
The choice of personnel involved at each phase in the life of a facility (design, manufacture, inspection and testing, operation, decommissioning), their training, the general organization of the different bodies involved - particularly in quality assurance and safety culture -, the sharing of responsibilities, and operating procedures, all help to prevent failures throughout the life of the facility.

Methodically taking account of experience feedback is also a key element that helps to improve prevention of failures.

\section{- Level 2: control of abnormal situations and detection of failures}

The facility should be prevented from leaving the authorised operating domain defined above and systems should be designed that are sufficiently reliable and that can stop abnormal changes before equipment is beyond design conditions chosen so that there is no failure risk.

A reactor design with a stable core and good thermal inertia makes it easy to keep the reactor within its authorised operating domain.

Surveillance of the facility's compliance with the design assumptions by means of in-service inspection and appropriate periodic testing of equipment is necessary to detect any degradation before it can affect the safety of the facility ${ }^{59}$ and to carry out essential repairs (curative maintenance, replacement, etc.).

Systems that measure the radioactivity of different fluids and the atmosphere in different rooms can be used to verify the effectiveness of confinement barriers and purification systems.

Clear information in the control room about faults but also about the state or configuration of the facility's structures, systems and components makes it easier for operating personnel to deal with faults within an appropriate time scale.

Systems that limit adverse trends and can rapidly stop an undesirable phenomenon, not properly controlled by regulation, from occurring are deployed, including reactor shut down.

\section{Level 3: control of accidents within design basis}

The first two levels of defence in depth - prevention and control of abnormal situations - are designed to prevent the occurrence of accidents.

However, in spite of the attention paid to these two levels, obviously for safety reasons a number of accidents are postulated, leading to failures such as a break in a reactor coolant pipe, regardless of the precautions taken to make them unlikely, or indeed

59. For French PWRs, in-service inspection of equipment is the subject of a document entitled RSE-M (equipment in-service surveillance rules), published by AFCEN (the French association that produces rules for the design, construction and in-service inspection of components for nuclear plants). There is no generic equivalent for research reactors because of the variety of their different designs. 
very unlikely. This approach is usually described as "deterministic", and it is an important part of the design of a facility and essential for the safety demonstration. These accidents have to be chosen at the start of the project design phase, so that systems can be designed that prevent severe damage to the core (e.g. core melt) and to ensure these systems are properly integrated into the other part of the facility. They have to be chosen with the utmost care because it is very difficult to integrate major systems at a later date into a facility that has already been built.

The systems defined are known as safeguard systems; they do not play any role in the normal operation of the facility. Where necessary, these systems start up automatically and they only require human intervention once sufficient time has elapsed for diagnostics to be carried out under calm conditions. The correct functioning of these systems ensures that, in the postulated situations, the integrity of the core structure is maintained and it can therefore continue to be cooled. Releases into the environment would be therefore very limited.

To ensure these safeguard systems are sufficiently reliable, particular attention should be given to the risk of common mode failures, hence the adoption of principles such as redundancy, geographical separation, diversification, etc. In-service monitoring and appropriate maintenance must also be carried out on the safeguard systems. Particular attention must be given to the procedures used to qualify these systems for accident conditions, which obviously cannot involve triggering an accident at the facility itself.

\section{Level 4: prevention of accident progression and mitigation of the consequences of severe accidents}

The accident at the Three Mile Island power plant in 1979 prompted efforts to develop the means to cope with situations not covered by the first three levels of defence in depth, involving severe core damage. The challenge was to try to limit releases caused by situations where the core is badly damaged, for example in the event of core melt, and to buy time in which measures can be taken, if necessary, to protect the offsite population. Maintaining the containment function under the best possible conditions is essential in this case.

Special measures are taken by the operator of the damaged facility as part of the on-site emergency response plan: alerting the public authorities, monitoring the state of the damage facility, following appropriate operating procedures, implementing means of communication, response, etc. Periodic exercises are run with the different stakeholders that would be mobilised in an emergency, to ensure these measures will be effective should such situations occur.

\section{Level 5: mitigation of the radiological consequences of significant external releases of radioactive substances}

The use of measures (off-site emergency response) to protect the population if significant releases occur ([enhanced] monitoring of activity levels and radiological exposure, sheltering, evacuation and control of foodstuffs, etc.), assumes that the previous 
measures have not been effective or have failed. The public authorities decide the conditions for evacuation or sheltering. They also take measures to control the consumption or marketing in the short, medium or long term of foods that could be contaminated. The decision to apply these measures is based on analyses of the situation by the operator and the safety bodies and on environmental radioactivity measurements.

Periodic exercises are also required, obviously involving the relevant public services, to ensure the intended logistical resources are effective.

Some specific aspects of the adaptation of defence in depth to French research reactors will be mentioned in chapter 7 , giving examples.

\subsubsection{The deterministic approach, design and safety demonstration basis - Situation regarding probabilistic studies for research reactors}

In particular, to take account of safety objectives and requirements when designing research reactors and establishing their safety demonstrations, a deterministic approach (see above) must be taken, using conservative data that considers the most unfavourable configurations, for the reactor, of the core and the experimental devices or experiments. In accordance with this approach, to comply with the recommendations in the IAEA safety standards for research reactors, the safety analysis must consider a selection of postulated initiating events that can result from equipment failure, system malfunction, human error, or an internal or external hazard. A list of the initiating events generally postulated for research reactors is given in IAEA safety standard SSR-3; table 3.3 at the end of this chapter lists a selection of these events, grouping them into various families.

The deterministic approach involves studying a number of "facility states ${ }^{60 ", ~ d e t e r-~}$ mined on the basis of the initiating events, some of which can be categorized according to the estimated frequency of the associated initiating events, has been refined over time. Most research reactors in operation were designed on a more cursory basis though they are often still quite robust - than the more recent research reactors. The safety reviews discussed in sections 3.5, 4.3, 9.2.2 and 10.2 or other important administrative stages (e.g. see below for the HFR at Petten) enable the safety analyses to be extended by reference to more recent practices.

Probabilistic studies can be used in addition to the deterministic approach. However, it should be pointed out that the majority of research reactors are less complex than power reactors (e.g. pressurized water reactors), and that the value of probabilistic

60. According to IAEA terminology, especially in the standard SSR-3, the facility states are "Normal operation", "Anticipated operational occurrences", "Design basis accidents" and "Design extension conditions" (which includes "Severe accidents"). "Normal operation" and "Anticipated operational occurrences" are "Operational states". There is a limited number of facility states, with each one chosen to cover the corresponding family of events (events affecting core reactivity, core cooling, etc.). 
safety analyses is therefore less obvious. But even with research reactors, probabilistic studies can be useful to identify relative weaknesses in their design or to assess quantitatively the contribution of implemented or planned improvements or modifications $^{61}$. In addition, the use of probabilistic methods can give a better assessment of the relative importance of systems for the safety of a research reactor and identify more accurately their potential interactions.

It is worth mentioning in this regard that some safety authorities have asked operators of research reactors to conduct probabilistic safety analyses as part of the licensing process. For example, in 2003, probabilistic safety analyses (PSAs) at level 1 (assessment of the sequences leading to core damage and the overall probability of that damage) and level 2 (assessment of the different categories of radioactive releases into the environment and their probabilities) were carried out for the HFR reactor at Petten as part of the license renewal for operation of the reactor with low enriched uranium fuel. In particular, these probabilistic analyses were used to determine the dominant sequences of damage to the core (loss of off-site power, large-break loss of coolant outside the pool) or fuel elements (blockage of water circulation in the core, etc.) ${ }^{62}$.

\subsubsection{The graded approach ${ }^{63}$}

IAEA Safety guide No. SSG-22, entitled Use of a Graded Approach in the Application of the Safety Requirements for Research Reactors, published in 2012, presents recommendations for the "graded" application of the standard NS-R-4, and of the new standard SSR-3 that replaces it, which are applicable to research reactors and were mentioned above (in section 3.2.3).

The diversity of research reactors in terms of design, technical characteristics (power, quantity and nature of radioactive materials and substances, etc.), mode of operation and utilization, technological maturity and experience feedback is reflected in the diversity of associated risks. This diversity of risks has naturally led to the development of the graded approach concept.

The graded approach concerns many issues and applies at all stages in the life of a research reactor. For every research reactor, the design measures, application of the defence in depth principle, level of detail of the safety analyses, verifications of all kinds, documentation, activities and procedures used to implement the safety requirements, and more generally the resources dedicated to safety and safety monitoring, should be in proportion to the potential hazards posed by that reactor. The concept of potential hazards is very important for understanding and making correct use of the graded approach: grading should be based on the potential hazard of the facility in its environment due in particular to the inventory of radioactive material and substances, the

61. These uses are less affected by the lack of valid data on equipment reliability for the different research reactors, due mainly to the wide range of different research reactor designs, uses and modes of operation.

62. The probabilities of this damage are overall of the same order of magnitude as those for core melt in power reactors (a few $10^{-5}$ per year).

63. The expression "proportionality" is also used. 
energy capable of disseminating that material, the site characteristics, the proximity of local populations, etc. For example, the resources dedicated to off-site emergency response plans should be proportionate to the robustness and containment capacity of the reactor building and to the radioactive releases envisaged in accident situations, their radiological impact on the populations likely to be affected, etc.

The purpose of the graded approach is to ensure the efforts made by operators and safety organizations are in proportion to the significance of the safety issues they address. According the IAEA safety guide, the graded approach can be applied to the following:

- the level of detail of procedures and operating instructions,

- the approval of documents or the authorization of modifications to the facility and experiments,

- training programmes,

- regulatory and other inspection programmes (e.g. frequency and duration of inspections),

- the integrated management system (safety, quality),

- emergency preparedness and response,

- the frequency of maintenance, equipment calibration, etc.

In some countries, like France, the application of the graded approach is written into national regulations.

\subsection{Periodic safety reviews ${ }^{64}$}

Internationally, periodic safety reviews are not a widespread practice at research reactors. Safety reviews are often carried out only for the purpose of renewing operating licences issued by safety authorities for a limited period of time. But for many research reactors worldwide, the licence does not set a maximum period of operation, and consequently periodic safety reviews cannot be carried out systematically, even though they are useful for:

- assessing whether continued operation is acceptable from a safety perspective, in view of any modifications made to facilities or to their operating procedures and any changes in their environment;

- identifying safety improvements to be made to these facilities on the basis of operating experience feedback (for the facility in question and similar facilities elsewhere in the world), better knowledge of certain risks and changing safety requirements or criteria.

IAEA safety guide No. SSG-25 entitled Periodic Safety Review for Nuclear Power Plants, published in 2013, makes recommendations for carrying out periodic safety

64. This is the expression used in the IAEA safety standards. 
reviews on power reactors. The maximum recommended time between reviews is 10 years. With certain adaptations to reflect the specific nature of research reactors and the application of the graded approach, these recommendations can be used for research reactors.

In general, periodic safety reviews consist of the systematic review of safety at a nuclear facility at regular intervals, taking account in particular of the effects of ageing, modifications made to the facility, operating experience feedback, changes at the site, new knowledge acquired (e.g. concerning seismic risk), and best practices; changes to safety requirements are also considered. The aim of a review is to determine whether measures to ensure safety at a facility, which may have been modified in the light of other safety reviews, will still be adequate by the next safety review (or until the facility is permanently shut down). French practice - based on a ten-yearly frequency - is discussed in section 9.2 and illustrated by some of the most notable safety reviews conducted in France.

Periodic safety reviews carried out at research reactors generally cover:

- the safety management system, including quality assurance measures;

- the physical state, due to ageing, of structures, systems and components, which may have become brittle from the effect of radiation or could have eroded or corroded (e.g. components exposed to humidity if there is no air conditioning or if ventilation systems are not working);

- changes to safety requirements and the applicable criteria;

- changes to the site of the facility, such as an increase in population density, the advent of industries involving hazardous materials, the construction of highways to transport those materials, or changes in traffic (road and air traffic, etc.);

- experimental devices and experiments;

- maintenance programmes, test programmes and periodic inspection programmes;

- experience feedback, including international,

- organizational aspects concerning the operating personnel (recruitment, mobility, qualification, training, maintenance of skills and knowledge);

- the doses received by operating personnel;

- management of effluent and radioactive waste, the associated reports;

- the safety and operating documentation for the facility (safety report, general operating rules, on-site emergency plan, operating procedures).

Weaknesses and non-compliances identified during periodic safety reviews have in most cases led to safety improvement programmes at the facilities concerned, with precise timescales, subject to the safety authority's approval.

Although, during these improvement programmes, components of significance for the safety of research reactors may be replaced (in case of obsolescence or significant ageing), the configuration of civil engineering structures can, in some cases, make it 
difficult or even impossible to achieve adequate physical separation of the different "trains" of redundant safety systems during renovation work, and the safety analysis should take account of this.

The periodic safety reviews are an important step for maintaining a satisfactory level of safety. On the basis of these reviews, the safety authority may say whether the facility can continue operating or not.

The IAEA continues its efforts to promote and extend the practice of periodic safety reviews for research reactors with the forthcoming publication of a specific safety report and the organization of training activities on the subject.

\subsection{Safety aspects of experimental devices}

An experimental device ${ }^{65}$ contains one or more samples to be irradiated in a neutron flux produced by a research reactor. The device contains the sample supports and the equipment for producing and controlling the desired irradiation conditions.

Experimental devices are generally installed in the core of a research reactor, in its reflector or around its periphery. A wide variety of experiments or irradiations are carried out with these devices. In particular, they can involve the irradiation of:

- fuel samples, subjected to pressure and temperature conditions and to coolant fluids that may be very different from those in the research reactor where they are irradiated; in this case the irradiation device is an experimental loop. The thermohydraulic conditions in the experimental loop may reflect incident or accident situations that the samples could be subject to in a power reactor. In these experiments, the fuel samples studied can be tested to the point of cladding failure and/or fuel melt;

- various materials for industrial applications;

- targets for the production of radioisotopes for medical or other uses.

An experimental device mainly consists of an "in-pile" part and an "out-of-pile" part.

The in-pile part contains the sample(s) to be irradiated and can be used to achieve and control the desired characteristics for the environment of these samples. In terms of safety, it has one or more barriers separating the sample from the reactor core coolant. The requirements for these barriers depend on the irradiation conditions and the risks posed by the experimental device as a whole.

The out-of-pile part consists in particular of the power supplies, the instrumentation and control units for the device, the fluid circuits and, with some irradiation loops, cells for analysing the fission products released by the fuel being tested. The out-of-pile part of an experimental loop helps to obtain the desired experimental conditions, particularly in terms of pressure and temperature, to which a sample should be subjected.

65. They are not experimental in themselves but are used for experiments. The name "experimentation device" would therefore be more appropriate; however, the usual term has been retained in this document. 
It is important to emphasise that possible interactions between the experimental device(s) and the reactor where the irradiation is being performed, should be carefully examined from the point of view of safety.

Because there are common aspects to planning experiments in research reactors and planning modifications to those facilities, such as organization, safety analysis, management of authorizations and commissioning tests, in 2012 the IAEA published guide No. SSG-24 entitled Safety in the Utilization and Modification of Research Reactors. This guide recommends that the operator of a research reactor has responsibility for all aspects of reactor safety connected with preparing and carrying out experiments - even if other organizations (research organizations, universities, hospitals, industrial companies, etc.) are in charge of the design and programming of these experiments and even though the performance of certain tasks may be subcontracted to other organizations. The safety committees mentioned in section 3.2.3 (standard SSR-3) may be called upon to examine the suitability and safety of experiments and to make recommendations to the reactor manager. The guide recommends that the safety authority of the country where a research reactor is located should define and implement a licensing process (including the possibility for the operators of "internal" licensing under certain conditions) for experiments in research reactors and should check that operators are taking appropriate measures to manage and control the safety of these experiments.

The guide also recommends that:

- planned experiments be categorized on the basis of their significance for safety (as part of a graded approach);

- procedures be established for the safety analysis and approval of experiments;

- experiments with a major or significant effect on reactor safety be designed following the same principles as the reactor itself (defence in depth, single failure criterion, etc.) and be subject to formal licensing by the safety authority in the country concerned; experiments with only a minor effect on the safety of the reactor may be internally licensed by the operator.

The guide lists various safety aspects specific to experiments that should be examined for each:

- the reactivity worth ${ }^{66}$ of the experimental device, which should remain within operational limits and conditions (negative reactivity of the core when the reactor is shut down, etc.);

- the protection system associated with the experiments, which can also be designed to protect the reactor;

- the heat produced in the experimental device and the ability of the device's cooling circuit to remove that heat, which should not affect the ability to cool the reactor;

66. The reactivity worth of any constituent of a reactor core is expressed in pcm (per cent mille). A fuel element has a positive worth because it contributes reactivity to the core, whereas a neutron absorbing rod has a negative worth. An experimental device can have positive reactivity (e.g. if it contains fissile material) or negative reactivity (e.g. if it is an irradiation capsule for steel samples). 
- any risks associated with pressure in the experimental device, especially with regard to equipment important to reactor safety;

- the compatibility of the materials in the experimental device with one another and with the materials of the reactor (risk of corrosion, of eutectic formation, etc.);

- the possible interactions between the experimental device and the reactor (neutron flux disturbance, mechanical interactions, etc.);

- updating of the safety documentation for the facility (safety report, general operating rules, emergency procedures, etc.).

The guide also recommends application of the ALARA principle ${ }^{67}$ to operator exposure when carrying out experiments and that the main risks associated with each experiment zone be displayed at the entrance to that zone.

Finally, the guide recommends that appropriate measures are taken to ensure that any equipment can be stored or disposed of safely on decommissioning or when the reactor is dismantled.

\section{7. "Envelope" accidents taken into account in research reactor safety analyses}

\subsubsection{Definition and characteristics of "envelope" accidents}

Certain aspects of research reactors and their uses, and experience feedback from their operation, very early on prompted designers and safety organizations to consider the possibility of accidents involving damage to the fuel in the reactor core or to the core as a whole, to the point of core melt. These aspects include:

- the fact that many handling operations take place in the reactor core or in proximity to it;

- some research reactors being sited close to populated areas;

- the occurrence of a number of reactivity accidents internationally, as explained in section 4.2 below.

Directly postulated "envelope" accidents determined from initiating events (single or multiple failures) of internal origin, are defined in order to verify the acceptability of the design ${ }^{68}$ and the operating procedures. They are also used to define organizational and physical measures for emergency response. Studies of these accidents are

67. As Low As Reasonably Achievable. This principle, developed from the study of risk (cyndinics), was formulated for the first time in 1977 by the ICRP in its publication No. 26.

68. Architecture of systems, functional requirements of equipment, technical characteristics of this equipment (thickness of a concrete wall, rebar ratio, flow rate of a pump, thickness of a tank or vessel, materials used, type of welds, etc.). 
conducted to assess radioactive releases and their radiological consequences for humans and the environment, based on the behaviour of the confinement barriers under the stresses they are subject to.

Various terms are used throughout the world to refer to the accidents in question at research reactors, which does not make understanding them any easier: envelope accident, reference accident (a term used particularly for French research reactors), maximum credible accident or maximum hypothetical accident, controlled severe accident, etc. The English terms Design Basis Accident (DBA) and Beyond Design Basis Accident (BDBA) are also used - for the newest research reactors or in the context of recent safety reassessments - to refer to concepts involved in the deterministic approach that has developed over time.

From a terminology point of view, it may be worth recalling the definitions given in the IAEA glossary (2007 version) for the different facility states:

- the design basis accident (DBA) is defined as "accident conditions against which a facility is designed according to established design criteria";

- beyond design basis accident (BDBA) refers to "accident conditions more severe than a design basis accident";

- severe accident refers to "accident conditions more severe than a design basis accident and involving significant core degradation" (making it a subset of the BDBA domain).

It therefore seems to be the case that the "envelope" accidents used for research reactors are mostly, by nature, beyond design basis accidents, or even severe accidents.

The term Design Extension Conditions (DEC) ${ }^{69}$ has also been introduced by the international community - particularly the IAEA in document SSR-3 - for accidents that were previously described as beyond design basis (multiple failures, complex events, fuel melt accidents), and consequently the study of these accidents should aim to determine whether the design of the facility (including the ultimate confinement barrier) can adequately limit their consequences, or whether reinforcement (e.g. of the ultimate barrier) or the installation of extra equipment (additional power supplies, ultimate water makeup, etc.) should be envisaged.

A wide variety of "envelope" accidents are studied for the various research reactors throughout the world, a fact illustrated particularly by table 3.3 - though this presents only a selection. These accidents cover a wide range of states of core degradation, ranging from minimal damage to a fuel element to partial or total core melt. Although there are factors that partially explain this diversity (different designs and intrinsic characteristics [neutron feedback, etc.], varying robustness of safety systems [architecture, redundancy, diversification, etc.]), there is no denying that there are also disparities in the "envelope" accidents considered for research reactors that are technically similar.

69. The term in French is "domaine complémentaire", which has become "domaine de conception étendu" in more recent texts (see for example ASN Guide No. 22 "Exigences de sûreté et recommandations pour la conception des réacteurs à eau sous pression"). 
The Nuclear Energy Agency (NEA) and IRSN have highlighted ${ }^{70}$ the value of identifying and establishing best practices for defining "envelope" accidents for research reactors.

Specifically in the case of pool-type research reactors that use uranium-aluminium fuel, which are widespread throughout the world, "envelope" accidents initiated by a rapid and large-scale reactivity injection leading to core melt - so-called BORAX accidents ${ }^{71}$ - are considered. However, the mechanical effects of the interaction between molten fuel and cooling water, in the form of a steam explosion, have not been uniformly taken into account for all these reactors, especially as regards the mechanical robustness of the reactor pool and containment; in addition, the potential consequences of projectiles hitting the containment wall due to a steam explosion have not always been examined.

Other differences concern the data used to calculate the radioactive releases from "envelope" accidents; this issue is discussed in the next section.

Chapter 8 of this report, on BORAX accidents, discusses the issues mentioned above, and how these accidents are taken into account in the case of French pool-type research reactors.

\subsubsection{Source term evaluation for "envelope" accidents}

Source term evaluation when studying the radiological consequences of an accident causing damage to the fuel in the reactor core (cladding failure, fuel melt) assumes that the nature and extent of the damage is known, as well as the pathways and quantities of fission products released by the fuel in the reactor building, and from that, the releases of fission products into the environment, and finally the doses and (long-term) contamination that could occur at various distances from the facility. For some reactors, the cancer risk from the radiation has been worked out ${ }^{72}$.

These elements need to be evaluated on a case-by-case basis taking account of the specific characteristics of the reactor building (integrity, possible bypasses, etc.) and the ventilation (extraction rate, effectiveness of filtration systems), and specific characteristics of the site, considering that the accident could happen during a loss of off-site power, etc.

When fuel melt happens under water, the fission products are released in the pool water, from which a fraction is assumed to be released instantly into the atmosphere in the reactor building (particularly all the noble gases). The release of fission products then continues over time (partly through evaporation of the water in the pool - depending on the temperature difference between the water and the air in the reactor building and the evaporation surface area). When fuel melt happens in the air, the fission products are assumed to be released straight into the atmosphere in the reactor building.

70. In particular see the paper: "Safety of research reactors: views of the NEA committee on the safety of nuclear installation" - IAEA International conference on research reactors, Rabat, Morocco, 14-18 November, 2011.

71. BOiling water ReActor eXperiment.

72. For example, in 2003 in the case of the HFR reactor at Petten, when the operating license was being renewed to use the reactor with low enriched with uranium-235 fuel (see section 3.4.3). 
There are differences in the assumptions used throughout the world to calculate the transfer of fission products from the fuel to the water, from the water to the air in the reactor building hall, and finally from the hall to the environment. As far as the release of radionuclides from fuel is concerned, the noble gases (xenon, krypton) are generally assumed to be released in their entirety. The differences between safety analyses concern the other species (iodine, caesium, ruthenium, strontium, actinides). They are often due to a lack of transposable experimental data (the transfer rates depend in particular on the burnup of the fuel, the maximum temperature reached by the fuel, and the medium it is in [water, air, steam-air, etc.]). Big differences have been observed, for example for iodine-131 and caesium-137, release rates from molten fuel into water vary from 0.1 in some reactors to 0.8 in others (OSIRIS reactor, etc.). The value 0.8 came from an analysis by the operator of the OSIRIS reactor after six fuel plates melted in the SILOE reactor in 1967 - attributed to a loss of cooling at the inlet of the affected fuel element (this event is described in section 10.1.2).

For transfer from the hall of the reactor building to the environment, the differences mainly relate to whether or not the deposition of fission products on surfaces and the effectiveness of filtration systems are taken into account.

\subsection{Possible improvements to studies, research and development on research reactor safety}

While research reactors can be used to acquire knowledge that is useful for assessing the safety of power reactors, their own safety does of course need to be justified by sufficient supporting data. Using very conservative values to study postulated initiating events can prove excessive and cause difficulties with design, construction or operation. Assumptions that are more informed (realistic) could be a way, provided that sufficient validated knowledge is available.

Acquiring further knowledge of the release rates of fission products from fuel elements in incident or accident conditions would be particularly useful, as previously turned out to be the case with evaluation of the source term linked to fuel melt accidents. Although the designers and operators of research reactors, and more specifically of the fuels to be used in these reactors, undertake experimental programmes to qualify these fuels, the programmes mainly explore temperature and pressure conditions, etc. in normal operation or during research reactor transients. The NEA (and IRSN) has drawn the attention of research reactor designers and operators to the value of using tests to improve knowledge of fuel behaviour in research reactors in incident and accident conditions ${ }^{73}$.

In addition, various thermohydraulic simulation codes originally developed for power reactors have been adapted for studies related to research reactors in normal operating conditions, during transients, and in incident or accident conditions. However, disparities have emerged in the mathematical models and the correlations used in these codes, and in their degree of validation specifically for research reactors. This is because

73. See footnote 72 . 
data or knowledge were either not shared or not shared sufficiently, and because the connections between neutronics and thermohydraulics need to be improved. A Coordinated Research Project ${ }^{74}$ (CRP) of the IAEA was run from 2003 to 2006 to compare simulations performed by different codes of operating transients in a reactor chosen as a reference (the Brazilian IEA-R1 reactor). The CRP mainly identified a need to benchmark the simulation codes using experimental data (qualification process), which led to a second CRP $^{75}$ run from 2008 to 2013 , in which IRSN participated (see chapter 11). The aim of the second CRP was to assess the ability of simulation codes to reproduce a number of neutronics and thermohydraulics measurements taken straight from the cores of different research reactors ${ }^{76}$. In most cases, the neutronic data included core parameters such as the effective multiplication factor, the neutron flux distribution in the core, the fission rate in the fuel, some kinetic parameters, and the "worth" of the neutron-absorbing elements. The thermohydraulic data included, most notably, the temperature of the water measured at the inlet and outlet of the fuel elements. These data were for stable operating states and for reactivity and flow rate transients - including reductions in flow until natural convention was established, possibly with reversal of the direction of flow of the water in the core, for the ETRR-2, IEA-1 and RSG-GAS reactors. The final report of the second CRP is in preparation.

Other areas for improvement have been identified by the NEA and IRSN ${ }^{77}$; they are:

- acquisition and sharing of data on the mechanical characteristics of specific materials used in research reactors (e.g. the aluminium or zirconium alloys used for reactor tanks), and the changes in these characteristics over time and/or under irradiation;

- knowledge management, a particularly important subject given the long service life of many research reactors, extended shutdown periods, and related refresher training of operating personnel.

Among other IAEA initiatives, it is worth mentioning CRP T12029 Benchmarks of Computational Tools against Experimental Data on Fuel Burnup and Material Activation for Utilization, Operation and Safety Analysis of Research Reactors. This CRP was begun in 2015 and should end in 2019. It aims to contribute to the validation of the methods and codes used for computing fuel burnup and material activation by comparing experimental data collected from various operators. The results of this CRP will consist of a database of experimental results, measurements and associated facility specifications, and a publication comparing the experimental results with those from the different simulation codes and methods used.

74. IAEA CRP J7.10.10: "Safety Significance of Postulated Initiating Events for Different Research Reactor Types and Assessment of Analytical Tools".

75. IAEA CRP 1496: "Innovative Methods in Research Reactor Analysis: Benchmark against Experimental Data on Neutronics and Thermal-hydraulic Computational Methods and Tools for Operation and Safety Analysis of Research Reactors".

76. Measurements taken at the ETRR-2 reactor in Egypt, IEA-R1 in Brazil, McMaster Nuclear Reactor in Canada, MINERVE in France, MNSR in Syria, OPAL in Australia, RSG-GAS in Indonesia, and SPERT III and IV in the USA.

77. See footnote 72 . 
Table 3.1. IAEA guides for research reactors.

\begin{tabular}{|c|c|c|}
\hline Reference & Description & Comments \\
\hline SSG-10 & $\begin{array}{l}\text { Ageing Management for Research } \\
\text { Reactors }\end{array}$ & $\begin{array}{l}\text { This guide presents recommendations on establishing } \\
\text { an ageing management programme depending on the } \\
\text { actual state of facilities. This is a particularly impor- } \\
\text { tant issue for research reactors, around two thirds of } \\
\text { which are more than } 40 \text { years old. }\end{array}$ \\
\hline SSG-20 & $\begin{array}{l}\text { Safety Assessment for Research } \\
\text { Reactors and Preparation of the } \\
\text { Safety Analysis Report }\end{array}$ & $\begin{array}{l}\text { This guide presents recommendations for preparing, } \\
\text { examining and assessing the safety documents for a } \\
\text { research reactor (safety report, general operating } \\
\text { rules, on-site emergency plan, etc.). This safety guide } \\
\text { focuses particularly on the design and construction } \\
\text { stages of research reactors. It can be used not only as } \\
\text { part of new reactor licensing procedures but also } \\
\text { during periodic safety reviews of existing reactors. }\end{array}$ \\
\hline SSG-22 & $\begin{array}{l}\text { Use of a Graded Approach in the } \\
\text { Application of the Safety Require- } \\
\text { ments for Research Reactors }\end{array}$ & $\begin{array}{l}\text { Safety requirements should generally be applied in a } \\
\text { way that is proportionate to the risks presented by a } \\
\text { facility. This guide aims to clarify the graded approach } \\
\text { and makes practical recommendations for the differ- } \\
\text { ent phases in the life of a research reactor. }\end{array}$ \\
\hline SSG-24 & $\begin{array}{l}\text { Safety in the Utilization and Modi- } \\
\text { fication of Research Reactors }\end{array}$ & $\begin{array}{l}\text { This safety guide presents recommendations for the } \\
\text { utilization and modification of research reactors. It is } \\
\text { intended primarily for existing reactors but can also be } \\
\text { useful to organizations considering carrying out new } \\
\text { experiments at a research reactor. }\end{array}$ \\
\hline SSG-37 & $\begin{array}{l}\text { Instrumentation and Control Sys- } \\
\text { tems and Software Important to } \\
\text { Safety for Research Reactors }\end{array}$ & $\begin{array}{l}\text { This guide presents recommendations for the design, } \\
\text { production and qualification of instrumentation and } \\
\text { control systems and the associated components and } \\
\text { software, including the architecture of those systems, } \\
\text { their safety classification, their human-machine inter- } \\
\text { face, and security with regard to malicious acts. These } \\
\text { recommendations are applicable both to instrumen- } \\
\text { tation and control systems for new reactors and } \\
\text { to the modernization of instrumentation and control } \\
\text { systems at research reactors already in operation. }\end{array}$ \\
\hline SSG-40 & $\begin{array}{l}\text { Predisposal Management of radio- } \\
\text { active waste from nuclear power } \\
\text { plants and research reactors }\end{array}$ & $\begin{array}{l}\text { This guide provides recommendations on how to meet } \\
\text { the requirements for the management of radioactive } \\
\text { waste generated at nuclear power plants and research } \\
\text { reactors (including subcritical or critical models). It } \\
\text { covers all the stages of the management of such } \\
\text { waste, from its generation until its elimination (but } \\
\text { not its elimination), including its treatment (pretreat- } \\
\text { ment, treatment and conditioning). Radioactive waste } \\
\text { generated during normal operation and in the event of } \\
\text { an accident is taken into account. This guide covers all } \\
\text { phases of the life of waste management facilities, } \\
\text { including the choice of site location, design, construc- } \\
\text { tion, implementation, commissioning, operation, clo- } \\
\text { sure, and decommissioning. }\end{array}$ \\
\hline
\end{tabular}


Table 3.1. (Continued)

\begin{tabular}{|c|c|c|}
\hline Reference & Description & Comments \\
\hline NS-G-4.1 & Commissioning of Research Reactors & $\begin{array}{l}\text { Commissioning is one of the most important } \\
\text { stages in the life of a reactor. Although this safety } \\
\text { guide is more directly applicable to the commi- } \\
\text { ssioning of newly designed and built research } \\
\text { reactors, it can also be used when re-commi- } \\
\text { ssioning a reactor after an extended shutdown or } \\
\text { major modifications, and when commissioning } \\
\text { new experimental devices in a research reactor. }\end{array}$ \\
\hline NS-G-4.2 & $\begin{array}{l}\text { Maintenance, Periodic Testing and } \\
\text { Inspection of Research Reactors }\end{array}$ & $\begin{array}{l}\text { This safety guide presents various international } \\
\text { practices considered satisfactory, particularly as } \\
\text { regards the preventive and corrective main- } \\
\text { tenance of structures, systems and components } \\
\text { of significance for safety, and periodic tests to } \\
\text { ensure compliance with the operational limits and } \\
\text { conditions defined for the facility. }\end{array}$ \\
\hline NS-G-4.3 & $\begin{array}{l}\text { Core Management and Fuel Handling } \\
\text { for Research Reactors }\end{array}$ & $\begin{array}{l}\text { This guide presents recommendations on core } \\
\text { management and fuel handling for research reac- } \\
\text { tors in accordance with the applicable safety re- } \\
\text { quirements and the service limits associated with } \\
\text { the fuel. The guide covers core design and opera- } \\
\text { tion, core control parameters, the steps and pro- } \\
\text { cesses involved in the receipt, handling and trans- } \\
\text { port of fuel, core loading, and the handing and } \\
\text { transport of new or irradiated fuel. }\end{array}$ \\
\hline NS-G-4.4 & $\begin{array}{l}\text { Operational Limits and Conditions } \\
\text { and Operating Procedures for Rese- } \\
\text { arch Reactors }\end{array}$ & $\begin{array}{l}\text { This safety guide presents recommendations for } \\
\text { the establishment not only of operational limits } \\
\text { and conditions (OLC), but also of operating pro- } \\
\text { cedures. Detailed recommendations are made for } \\
\text { their development, formulation and implemen- } \\
\text { tation, both for the operation of the reactors and } \\
\text { for the experiments conducted in the reactors. }\end{array}$ \\
\hline NS-G-4.5 & $\begin{array}{l}\text { The Operating Organization and the } \\
\text { Recruitment, Training and Qualifi- } \\
\text { cation of Personnel for Research Re- } \\
\text { actors }\end{array}$ & $\begin{array}{l}\text { This guide is based on the premise that, for a } \\
\text { reactor to be operated under satisfactory safety } \\
\text { conditions, an appropriate and clearly defined } \\
\text { organizational structure must be put in place with } \\
\text { qualified personnel, and a safety culture must be } \\
\text { developed. This safety guide makes recommenda- } \\
\text { tions concerning the operation of a research } \\
\text { reactor, and the recruitment, training and qualifi- } \\
\text { cation of the operating personnel (including those } \\
\text { involved in maintenance operations), based on } \\
\text { international best practice. }\end{array}$ \\
\hline NS-G-4.6 & $\begin{array}{l}\text { Radiation Protection and Radioactive } \\
\text { Waste Management in the Design } \\
\text { and Operation of Research Reactors }\end{array}$ & $\begin{array}{l}\text { This guide provides recommendations on radia- } \\
\text { tion protection and the management of radio- } \\
\text { active waste from research reactors. It identifies } \\
\text { important elements that should be considered at } \\
\text { the design stage with regard to facilitating } \\
\text { radiological protection and radioactive waste } \\
\text { management, and good practices in developing } \\
\text { and implementing radiological protection } \\
\text { programmes during facility operation. }\end{array}$ \\
\hline
\end{tabular}


Table 3.1. (Continued)

\begin{tabular}{|c|c|c|}
\hline Reference & Description & Comments \\
\hline WS-G-2.1 & $\begin{array}{l}\text { Decommissioning of nuclear power } \\
\text { plants and research reactors }\end{array}$ & $\begin{array}{l}\text { This guide provides recommendations to ensure } \\
\text { that the decommissioning process for nuclear } \\
\text { power plants and research reactors is conducted } \\
\text { in a safe and environmentally acceptable manner. } \\
\text { It applies to these facilities and their sites. It } \\
\text { mainly addresses the radiological risks resulting } \\
\text { from the activities associated with the decom- } \\
\text { missioning of the reactors, and in particular the } \\
\text { decommissioning after the planned final shut- } \\
\text { down. A large number of provisions also apply to } \\
\text { decommissioning as a result of an abnormal event } \\
\text { that has resulted in contamination or severe } \\
\text { damage to the reactor. In this case, the guide can } \\
\text { serve as a basis for the development of special } \\
\text { decommissioning provisions. The guide does not } \\
\text { explicitly address non-radiological hazards, such } \\
\text { as those due to potential sources of fire or those } \\
\text { resulting from a release of abestos, which may be } \\
\text { generated by decommissioning operations but } \\
\text { which must also be managed. }\end{array}$ \\
\hline
\end{tabular}


Table 3.2. Illustration of the diversity of fuel melt accidents studied for research reactors ${ }^{78}$.

\begin{tabular}{|c|c|c|c|c|}
\hline $\begin{array}{l}\text { Reactor } \\
\text { year commissioned } \\
\text { - year } \\
\text { decommissioned }\end{array}$ & Country & $\begin{array}{l}\text { Power } \\
(\mathrm{MW})\end{array}$ & Fuel & $\begin{array}{l}\text { Fuel melt accidents considered } \\
\text { (fuel melt under water, } \\
\text { unless otherwise stated) }\end{array}$ \\
\hline $\begin{array}{c}\text { HIFAR } \\
1958-2007\end{array}$ & $\begin{array}{l}\text { Australia } \\
\text { (Lucas } \\
\text { Heights) }\end{array}$ & 10 & $\begin{array}{l}\text { UAl enriched to } \\
\text { around } 60 \%{ }^{235} \mathrm{U}\end{array}$ & Total core meltdown (loss of cooling) \\
\hline $\begin{array}{l}\text { HFR } \\
1961\end{array}$ & $\begin{array}{l}\text { Netherlands } \\
\text { (Petten) }\end{array}$ & 50 & $\begin{array}{l}\text { Originally UAl en- } \\
\text { riched to } 91 \%{ }^{235} \mathrm{U} \text {, } \\
\text { then } \mathrm{U}_{3} \mathrm{Si}_{2} \text { enriched } \\
\text { to around } 20 \%{ }^{235} \mathrm{U}\end{array}$ & $\begin{array}{l}\text { (Reactivity accident excluded because } \\
\text { water circulation direction would pre- } \\
\text { vent ejection of neutron-absorbing } \\
\text { rods } \\
\text { Blockage of a cooling channel in a } \\
\text { fuel element: does not lead to fuel } \\
\text { melt) }\end{array}$ \\
\hline $\begin{array}{c}\text { BR2 } \\
1963\end{array}$ & $\begin{array}{l}\text { Belgium } \\
\text { (Mol) }\end{array}$ & 100 & $\begin{array}{l}\text { UAl enriched to } \\
\text { around } 93 \%{ }^{235} \mathrm{U}\end{array}$ & $\begin{array}{l}\text { Core melt (power excursion - with } \\
\text { aluminium-water interaction) }\end{array}$ \\
\hline $\begin{array}{l}\text { SAFARI-1 } \\
1965\end{array}$ & $\begin{array}{l}\text { South Africa } \\
\text { (Pelindaba) }\end{array}$ & 20 & $\begin{array}{l}\text { Originally UAl enriched } \\
\text { to } 87 \%-93 \%{ }^{235} \mathrm{U} \text {, } \\
\text { then } \mathrm{U}_{3} \mathrm{Si}_{2} \text { enriched to } \\
\text { around } 20 \%{ }^{235} \mathrm{U}\end{array}$ & Core melt \\
\hline $\begin{array}{c}\text { OSIRIS } \\
1966-2015\end{array}$ & $\begin{array}{l}\text { France } \\
\text { (Saclay) }\end{array}$ & 70 & $\begin{array}{l}\mathrm{U}_{3} \mathrm{Si}_{2} \text { enriched to } \\
\text { around } 20 \%{ }^{235} \mathrm{U}\end{array}$ & $\begin{array}{l}\text { Core melt (power excursion - with } \\
\text { aluminium-water interaction) }\end{array}$ \\
\hline $\begin{array}{l}\text { RHF } \\
1971\end{array}$ & $\begin{array}{l}\text { France } \\
\text { (Grenoble) }\end{array}$ & 57 & $\begin{array}{l}\text { UAl enriched } \\
\text { to } 93 \%{ }^{235} \mathrm{U}\end{array}$ & $\begin{array}{l}\text { Melting of the fuel element in the } \\
\text { core under water (power excursion - } \\
\text { with aluminium-water interaction) } \\
\text { Various accidents leading to the } \\
\text { melting of one or more fuel ele- } \\
\text { ments, in the core, during handling } \\
\text { or in a storage channel, under water } \\
\text { or in air, in the short term ( }<24 \mathrm{~h}) \text { or } \\
\text { longer term }\end{array}$ \\
\hline $\begin{array}{l}\text { ORPHEE } \\
1980\end{array}$ & $\begin{array}{l}\text { France } \\
\text { (Saclay) }\end{array}$ & 60 & $\begin{array}{l}\text { UAl enriched } \\
\text { to } 93 \%{ }^{235} \mathrm{U}\end{array}$ & $\begin{array}{l}\text { Core melt (power excursion - with } \\
\text { aluminium-water interaction) }\end{array}$ \\
\hline $\begin{array}{l}\text { RSG-GAS } \\
1987\end{array}$ & $\begin{array}{l}\text { Indonesia } \\
\text { (Serpong) }\end{array}$ & 30 & $\begin{array}{l}\mathrm{U}_{3} \mathrm{Si}_{2} \text { enriched to } \\
\text { around } 20 \%{ }^{235} \mathrm{U}\end{array}$ & $\begin{array}{l}\text { Melting of a fuel element (blockage) } \\
\text { Melting of five fuel elements (trans- } \\
\text { ient with postulated failure of the } \\
\text { protection system [ATWS]) }\end{array}$ \\
\hline $\begin{array}{l}\text { FRM-II } \\
2004\end{array}$ & $\begin{array}{l}\text { Germany } \\
\text { (Garching) }\end{array}$ & 20 & $\begin{array}{l}\mathrm{U}_{3} \mathrm{Si}_{2} \text { enriched to } \\
\text { around } 90 \%{ }^{235} \mathrm{U}\end{array}$ & $\begin{array}{l}\text { Total core meltdown (loss of cooling } \\
\text { or power excursion, no aluminium- } \\
\text { water interaction) }\end{array}$ \\
\hline $\begin{array}{l}\text { OPAL } \\
2007\end{array}$ & $\begin{array}{l}\text { Australia } \\
\text { (Lucas } \\
\text { Heights) }\end{array}$ & 20 & $\begin{array}{l}\mathrm{U}_{3} \mathrm{Si}_{2} \text { enriched to } \\
\text { around } 20 \%{ }^{235} \mathrm{U}\end{array}$ & $\begin{array}{l}\text { Melting of three fuel plates (partial } \\
\text { blockage of channels in a fuel ele- } \\
\text { ment) } \\
\text { Melting of } 36 \text { UMo targets (loss of } \\
\text { cooling) }\end{array}$ \\
\hline
\end{tabular}

78. This table is based on information that IRSN was able to gather. 
Table 3.3. Selection of postulated initiating events for research reactors according to the IAEA SSR-3 standard.

Loss of electrical power supplies:

- Loss of normal electrical power.

Insertion of excess reactivity:

- criticality during fuel handling (due to an error in fuel insertion),

- startup accident,

- control rod failure or control rod follower failure,

- control drive failure or control drive system failure,

- failure of other reactivity control devices (such as a moderator or reflector),

- unbalanced rod positions,

- failure or collapse of structural components,

- insertion of cold water,

- changes in the moderator (e.g. voids, leakage of $\mathrm{D}_{2} \mathrm{O}$ into $\mathrm{H}_{2} \mathrm{O}$ systems, etc.),

- effects of experiments and experimental devices (e.g. flooding or voiding, temperature effects, insertion of fissile material or removal of absorber material),

- etc.

Loss of flow:

- primary pump failure,

- reduction in flow of primarycoolant (e.g. due to valve failure or a blockage in piping or a heat exchanger),

- rupture of the primary coolant boundary leading to a loss of flow,

- fuel channel blockage or flow reduction (e.g. due to foreign material),

- improper power distribution due to, for example, unbalanced rod positions in core experiments or in fuel loading (power-flow mismatch),

- reduction in coolant flow due to bypassing of the core,

- deviation of system pressure from the specified limits,

- loss of heat sink (e.g. due to failure of a valve or pump or a system rupture).

Loss of coolant:

- rupture of the primary coolant boundary,

- damaged pool,

- pump-down of the pool,

- failure of beam tubes or other penetrations.

Erroneus handling or failure of equipement or components:

- failure of the cladding of a fuel element,

- mechanical damage to core or fuel (e.g. mishandling of fuel or dropping of a transfer flask onto fuel),

- failure of the emergency core cooling system,

- malfunction of the reactor power control,

- criticality in fuel in storage,

- failure of the means of confinement, including the ventilation system,

- loss of coolant to fuel in transfer or storage,

- loss or reduction of proper shielding, 
Table 3.3 (Continued)

- failure of experimental apparatus or material (e.g. loop rupture),

- etc.

Special internal events:

- internal fires or explosions, including internally generated missiles,

- internal flooding,

- loss of support systems,

- security related incidents,

- malfunctions in reactor experiments,

- improper access by persons to restricted areas,

- fluid jets or pipe whip,

- exothermic chemical reactions,

- drop of heavy loads.

\section{External events (hazards):}

- earthquakes (including seismically induced faulting and landslides),

- flooding (including failure of an upstream or downstream dam and blockage of a river and damage due to a tsunami or high waves),

- tornadoes and tornado missiles,

- sandstorms,

- hurricanes, storms and lightning,

- tropical cyclones,

- explosions,

- aircraft crashes,

- fires,

- toxic spills,

- accidents on transport routes (including collisions into the research reactor building),

- effects from adjacent facilities (e.g. nuclear facilities, chemical facilities and waste management facilities),

- biological hazards such as microbial corrosion, structural damage or damage to equipment by rodents or insects,

- extreme meteorological phenomena,

- electromagnetic interference (e.g. from solar events),

- lightning strikes,

- power or voltage surges on the external supply line. 



\section{Chapter 4 International experience feedback for research reactors}

The gathering of relevant information about events occurring at research reactors during operation and the analysis of this information, which constitute what is known as experience feedback, are essential to improve the safety of these reactors. Despite the wide variety of different designs and operational conditions of these reactors, the lessons learned from an incident at a research reactor can prevent a similar incident happening again at that reactor or at another reactor. For example, incidents of excessive exposure of operators or experimenters to ionizing radiation, loss of integrity of water tanks or radioactive effluent storage tanks, incidents caused by organizational or human failures, and incidents due to the obsolescence or ageing of equipment, or to insufficient quality of operating procedures can offer lessons that apply to many different types of facility. Following the example of initiatives regarding experience feedback implemented by a number of countries - including France, a topic that will be discussed in more detail in chapter 10 in the second part of this document - the IAEA developed and implemented the Incident Reporting System for Research Reactors (IRSRR), the principles and operation of which are very similar to the system for power reactors (Incident Reporting System, or IRS).

However, although experience with research reactors can be shared very widely at international level using the IRSRR system, not all incidents are fed into it.

Bilateral and multilateral relations have developed between research reactor operators which generally enable more targeted exchanges to take place. For example, every 18 months the International Group on Research Reactors (IGORR) organizes conferences where safety issues related to research reactors are explained and discussed. 
Finally, the concept of experience feedback should be broadened to include the analysis of events affecting other types of facility such as power reactors, from which generic lessons can be learned that are also relevant to research reactors; the example of the Fukushima Daiichi nuclear power plant accident is a good illustration, which will be discussed in more detail later on.

\subsection{The IAEA incident reporting system (IRSRR)}

The IRSRR system was set up by the IAEA in January 2000 and is the only global platform for sharing experience of research reactor operation. The system is used to collect and disseminate technical information about safety-related events (including radiological events) at research reactors, including those that happened before the system was set up. The information contained in the IRSRR database is technical information, unlike the information in the INES ${ }^{79}$ database. The purpose of the INES database is to provide quick general information to the media and the public about events that occur at nuclear facilities, with an assessment of their real or assumed severity (INES classification).

The IRSRR guidelines for use define incident categories, the format and content of the reports to be sent, and a list of identification and incident type codes. This information makes it easier to search for a particular event in the database, which can only be accessed by the countries that contribute to it.

In particular, an incident report must state what happened during the event, and give an analysis of the causes and the lessons learned, and the corrective measures taken to prevent it happening again.

Each of the 54 countries that contribute to the IRSRR system officially appoints a national coordinator, who becomes the contact person for the manager of the system within the IAEA. These coordinators are responsible in particular for submitting reports of incidents that have occurred in their country to the IAEA, and for disseminating information received from the IRSRR system within their country. IRSN has been designated national coordinator for France. The incident reports that it sends to the IAEA are prepared jointly with the operators concerned.

For the IRSRR system to be effective, each contributing country must as quickly as possible send the IAEA reports of incidents at its research reactors that meet the incident reporting criteria defined in the IRSRR guidelines. According to these criteria, relevant incidents are incidents considered to be significant as regards safety, incidents from which lessons can be learned that could be useful for other facilities, and incidents leading to significant radioactive releases or significant exposure of people to ionizing radiation.

Digests are regularly prepared by the IAEA (with contributors from the Member States), and the IAEA also organizes periodic meetings (approximately every two years) of the national coordinators, where the incident reports sent in by the participating

79. International Nuclear Event Scale. 
countries are presented and discussed. An IAEA document ${ }^{80}$ published in 2015 summarises the incidents entered into the IRSRR database up to 2015; it shows that the majority of incidents at research reactors include causes related to organizational or human factors or causes related to the ageing of facilities. A breakdown of the identified causes is given in figure 4.1 below.

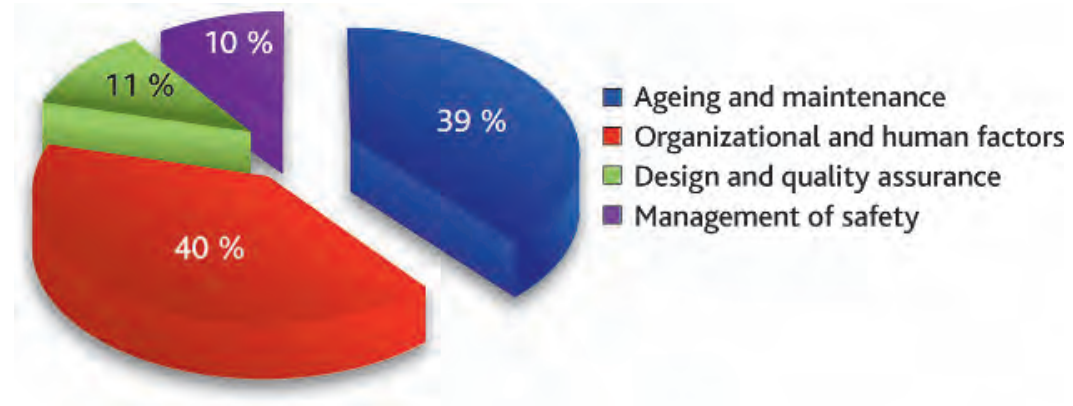

Figure 4.1. Distribution of the identified causes of events entered into the IRSRR database, according to IAEA-TECDOC-1762. (c) Georges Goué/IRSN.

\subsection{Serious incidents and accidents at research reactors}

Modifications (which are quite common) to the configuration of a research reactor core for experimental purposes, the associated handling operations, and the high reactivity "worth" of components of the core, all lead to higher risks of a reactivity accident or an object being dropped on the core or on fuel elements stored nearby than at other types of nuclear facility. In the past, a number of reactivity - or criticality - accidents happened at nuclear facilities (research reactors and other facilities) throughout the world that led to serious irradiation of personnel (operators or experimenters), or even their death; however, the frequency of these accidents has diminished considerably since the early $1970 \mathrm{~s}^{81}$.

A selection of a few serious incidents and accidents at different research reactors ${ }^{82}$ is presented in brief below.

80. IAEA-TECDOC-1762, "Operating Experience from Events Reported to the IAEA Incident Reporting System for Research Reactors", 2015.

81. See the very comprehensive document published by the Los Alamos National Laboratory (run by the University of California on behalf of the US DOE) - entitled "A Review of Criticality Accidents") (reference LA 13638, 2000 revision). From 1945 to the early 1960s, several accidents happened each year at research facilities in the broad sense (reactors and other facilities); there were four in 1968, then two in 1971, one in 1983 and one in 1997.

82. The estimated doses are not always stated in the available sources; for some of these accidents, the values given in different sources are not consistent with one another. 


\section{December 1952 - NRX reactor (42 MW) - Chalk River Laboratories (Ontario, Canada)}

A power excursion at the NRX reactor, a light water-cooled and heavy water-moderated reactor, occurred as a result of failures and human errors, especially the deliberate reduction of the flow of light water for cooling the fuel elements. Because light water acts as a neutron poison, this reduction in flow increased the reactivity and the power of the reactor to around twice the maximum authorised power. The power excursion was stopped by draining the heavy water. The core was destroyed and $3.7 \times 10^{14} \mathrm{~Bq}$ was released into the building basements in around $4,000 \mathrm{~m}^{3}$ of reactor cooling water. 31 people were irradiated at effective doses ranging from $0.04 \mathrm{~Sv}$ to $0.17 \mathrm{~Sv}$. The accident led to a significant transfer of radioactivity into the environment (via the facility's stack).

\section{- 24 May 1958 - NRU reactor (135 MW) - Chalk River Laboratories (Ontario, Canada)}

A fuel element in the NRU heavy water reactor caught fire while it was being unloaded. This element had been damaged the previous day along with other fuel elements during a reactor power increase. This accident caused large-scale contamination of the reactor building and the irradiation of workers.

\section{- 15 October 1958 - (Zero-power) research reactor at the Boris Kidric Institute in Vinca (former Yugoslavia)}

A power excursion occurred in the reactor when the heavy water exceeded the critical level due to incorrect regulation (the chambers used for reactor power measurement were saturated). This accident, which was halted by an operator who ordered the cadmium safety rods to be dropped, did not cause any damage to the reactor core, but six people received significant amounts of radiation: one of them received around 4.3 Sv and died; the other five were treated in France by bone marrow transplant.

\section{- 3 January 1961 - SL-1 reactor $^{83}$ (3 MW) - National Reactor Testing Area, Idaho, USA}

A power excursion occurred during a maintenance operation to prepare the SL-1 reactor to be restarted. The maintenance procedure required the control rods to be withdrawn by a few centimetres to reconnect them to their drive motors. The accident occurred when one of the control rods was withdrawn too quickly and too far from the planned position. The reactor power reached nearly $20 \mathrm{GW}$ in $4 \mathrm{~ms}$ and the resulting energy release caused a pressure wave that pushed the control rods upwards. This accident caused the death of three people (two operators were killed instantly by the explosion following the power excursion and a third died two hours later).

The accident and the lessons learned are described in more detail in chapter 8.

83. Stationary Low Power Reactor Number One. 


\section{December 1965 - VENUS reactor ${ }^{84}(0.5 \mathrm{~kW})$ - Mol (Belgium)}

A limited power excursion occurred as a result of a handling error. The experimental programme on the day of the accident consisted of determining the "efficiency" of the control rods based on the correlation between the displacement of the rods and the displacement of the level of the moderator (a mixture of heavy water and light water), with the reactor in a critical state. The operator made a handling error, withdrawing a control rod before inserting another, despite the fact that the written instructions stated that the other rod should be inserted first. There was no damage to the facility but the operator received a severe dose of radiation (doses received: $5 \mathrm{~Sv}$ in the chest and $40 \mathrm{~Sv}$ on one foot). He was saved but had to have the irradiated foot amputated.

\section{November 1967 - SILOE reactor (15 MW) - Grenoble (France)}

The partial melting of six fuel plates in a "control element ${ }^{85}$ " occurred during a reactor power increase. The incident, attributed to a plate cooling failure, led to the release of around $2 \times 10^{15} \mathrm{~Bq}$ into the pool water and $7.4 \times 10^{13} \mathrm{~Bq}$ through the stack (mainly noble gases). This event is described more fully in chapter 10.

\section{September 1983 - RA-2 critical assembly - Constituyentes (Argentina)}

A power excursion (representing 10 to $15 \mathrm{MJ}$ of thermal energy brought to the fuel in a few milliseconds) was caused by failure to follow the safety instructions when modifying the core configuration of the RA-2 reactor ${ }^{86}$ (the reactor vessel had not been emptied first). The doses received by the operator were around $23 \mathrm{~Gy}$ due to gamma radiation and $1.7 \mathrm{~Gy}$ due to neutrons. The operator died 48 hours after the accident. Two people in the reactor control room were irradiated (receiving doses of around 0.2 Gy due to gamma radiation and 0.15 Gy due to neutrons), along with five others who received total doses of between 40 and $200 \mathrm{mGy}$ and another two who received total doses of around 10 mGy.

\subsection{Complementary safety assessments carried out internationally following the accident at the Fukushima Daiichi nuclear power plant}

Following the accident that occurred on 11 March 2011 at the Fukushima Daiichi nuclear power plant, operated by TEPCO, a number of initiatives were rapidly introduced to enable complementary assessments to be conducted in the light of the events affecting the Fukushima Daiichi plant, based on experience feedback from the accident.

84. Vulcan Experimental Nuclear System.

85. Fuel element containing an absorbing element.

86. Critical assembly similar to EOLE (see section 5.2). 
The European Council meeting on 24 and 25 March 2011 demanded that the various EU Member States conduct these complementary safety assessments, known as "stress tests", on their nuclear power plants. A specification was drawn up for this purpose, based on proposals by WENRA ${ }^{87}$.

Complementary safety assessments were therefore simultaneously carried out in the different EU countries based on similar specifications, and in some cases extended - as was the case in France and Belgium - to other types of nuclear facility or even to other issues ${ }^{88}$. These complementary safety assessments could therefore be conducted not only on nuclear power reactors, but also on research reactors, fuel cycle facilities, etc.

Some of the first lessons learned from the accident at the Fukushima Daiichi nuclear power plant were indeed generic in nature. In particular they concerned the robustness of facilities with respect to the extreme hazards that can affect nuclear facility sites, emergency response, organization and also the role of the safety authorities. Because these issues are also relevant to research reactors and fuel cycle facilities, many countries have included these in their list of facilities to undergo complementary safety assessments, with priorities relevant to the risks they present (inventory of radioactive materials, age, proximity to residential areas, etc.).

The complementary safety assessments carried out in the EU Member States have generally looked at:

- the possibility of extreme hazards occurring that exceed those considered when the facility was designed, leading to station blackout or total loss of cooling, so that additional measures can be identified where necessary to limit the consequences of these accident situations;

- the actual physical conditions of structures, systems and components significant to the safety of each facility and the potential effects of the failure of non-safety class elements on elements significant to safety, should an extreme event occur (hence the need to conduct detailed inspections of the facility);

- the ability of I\&C and facility monitoring equipment to provide appropriate information in the accident situations considered by the complementary safety assessments (extreme hazards, loss of power or cooling).

The key features of the complementary safety assessments carried out on research reactors in France are presented in section 10.2.

Complementary safety assessments have also been carried out or are planned in countries other than the EU Member States, prioritised on the basis of the risks presented by each facility.

In June 2011, the IAEA organized a conference at ministerial level. An action plan was put in place by the IAEA to improve nuclear safety worldwide.

87. Western European Nuclear Regulators Association.

88. Issues concerning the contractors used by operators were therefore addressed in France. 
In this context, in 2011 the IAEA began preparing a procedure for conducting safety reassessments of research reactors, based on the lessons learned from the accident at the Fukushima Daiichi nuclear power plant. The purpose of this procedure, which was the subject of a final report ${ }^{89}$ published in March 2014, was to obtain consistency between the different approaches of different countries, and to form the basis for any reassessments yet to be carried out. Some of the principles expressed in this IAEA report are explained below.

In this report, the IAEA expressly states firstly that, although the inventory of radioactive material, and consequently the potential hazard associated with research reactors worldwide, is much lower than that for nuclear power plants, generally speaking there are aspects that justify safety reassessment in the light of feedback from the accident at the Fukushima Daiichi nuclear power plant: "the majority of research reactors worldwide were designed decades ago, and their design requirements are not fully in conformance with IAEA Safety Standard No. NS-R-4. In addition, many research reactors are located near populated areas, and for some of these the leaktightness of their confinement buildings is inadequate. These issues complicate the management of accidents that result in radioactive releases. In some other cases, the characteristics of the research reactor site and the site area and site vicinity may have changed since the facility was constructed. Not all the above mentioned issues are reflected in the safety analysis for many facilities". Whether a reassessment is required should be decided on the basis of the potential hazard associated with each research reactor.

In terms of feedback from the accident at the Fukushima Daiichi nuclear power plant, the IAEA draws particular attention in this report to the role and responsibilities of the safety authorities, which need to be clearly defined for both normal operating conditions and accident situations. Moreover, the safety authorities must have the necessary expertise to supervise and review the post-Fukushima reassessments to be carried out by operators.

The main objective of the reassessment is "to evaluate the robustness of the existing reactor protection, in terms of design features and procedures, against the impact of extreme events, with an emphasis on fulfilment of the basic safety functions". A reassessment should consist of:

- a review of the design basis of the reactor facility (taking account of the experimental devices and associated equipment), as described in the safety analysis report;

- a study of events that are beyond the design basis of the facility ${ }^{90}$, which can be initiated by extreme initiating events, in order to assess their potential impact on the basic safety functions and the adequacy of existing measures to mitigate the consequences of accidents, in order to identify the safety improvements needed from both a technical and an organizational point of view.

89. IAEA report entitled "Safety Reassessment for Research Reactors in the Light of the Accident at the Fukushima Daiichi Nuclear Power Plant" - Safety Reports Series No. 80 - 2014.

90. Beyond design basis accidents. 
These reassessments must refer to the current status of the facility as built and as operated (maintenance carried out, modifications made, etc.), the most unfavourable permitted operating conditions, including core configurations, and current and planned experimental devices.

Safety reassessments should consider the possibility of the simultaneous occurrence of more than one external hazard, as well as events that could occur as a result of this.

On the basis of these reassessments, additional measures to prevent or mitigate the consequences of accidents should be defined and implemented if necessary.

Reassessment of the site should look at changes in the site characteristics since the facility was built. This includes changes in the distribution of workers on the site and in the surrounding population, changes made to other facilities within the site area, including changes of use, changes in local transportation routes, changes in local land use and changes in hydrology and topography. Accidents that could occur simultaneously at different facilities should be considered.

The potential impact of extreme hazards on access to the reactor site for operating or on-site response personnel, and the availability of off-site response organizations and response personnel, should also be reassessed. In other words, the emergency response measures must be assessed to make sure they are adequate and can be implemented, including if an extreme hazard occurs that affects several facilities simultaneously.

Reassessments also provide an opportunity to verify:

- the existence of an adequate chain of command for response to an emergency and of procedures and means for effective communication during an emergency;

- preparedness of the on-site response teams and off-site response organizations to manage effectively an emergency affecting several facilities on a single site simultaneously;

- the availability of emergency equipment and the performance of periodic checks on that equipment;

- site accessibility for off-site response teams and the availability of the necessary logistical support.

At a conference held by the IAEA in November 2015, various research reactor operators (e.g. the operators of the IRR1 reactor ${ }^{91}$ in Israel and the SAFARI- 1 reactor in South Africa) presented the actions plans that they had proposed to their respective safety regulators following the safety reassessments conducted on the basis of the IAEA's report mentioned above or the recommendations of ENSREG (European Nuclear Safety Regulators Group ${ }^{92}$ ) in the case of the stress tests.

Generally speaking, and by way of illustration, through the installation of new equipment that can withstand earthquakes associated with the sites, including safety margins, or through the modification of existing equipment to improve this earthquake

91. Israel Research Reactor-1.

92. A European Commission consultative group of independent experts. 
resistance, the reassessments have resulted in proposals to improve the safety of reactors such as:

- seismic detection linked to the reactor protection system, causing an automatic reactor scram in the event of an earthquake;

- an extra system to shut down the chain reaction (injection of a soluble neutron poison, etc.);

- an emergency power supply in addition to the existing power supplies (mobile generator or backup battery), addition of easily accessible external connections;

- additional means of emergency cooling, fire service connections, core spray systems;

- strengthening of the containment vessel to improve its resistance to external natural hazards;

- improvements to emergency ventilation systems and their filtration systems;

- reinforcement of the means provided for effective emergency response, creation of off-site emergency control rooms with feedback of the information necessary to monitor the facility, etc.

Most of these measures had already been implemented at research reactors in France, at the time of safety reviews, or had been reinforced or supplemented during the stress tests carried out following the accident at the Fukushima Daiichi nuclear power plant (this is discussed in section 10.2).

Other proposed improvements resulting from the reassessments concern the safety culture, organizational aspects, and training and qualification programmes of operating personnel.

Schedules have been drawn up for the implementation of these proposed improvements.

In conclusion, the complementary safety assessments performed on research reactors on the basis of feedback from the accident at the Fukushima Daiichi nuclear power plant will help to improve defence in depth, including as regards emergency response. Peer review of the results of this work has been conducted under the auspices of the IAEA, at various technical meetings. 

Part 2

Research reactors in France 



\section{Chapter 5 Evolution of the French research reactor "fleet"}

\subsection{The diversity and complementarity of French research reactors}

In the IAEA's Research Reactor Database (RRDB), 42 reactors in France are identified as being research reactors ${ }^{93}$ (including those no longer in operation, the Jules Horowitz reactor (JHR) which is under construction, and the research reactors at defence-related facilities $\left.{ }^{94}\right)$.

General de Gaulle created the French Atomic Energy Commission (CEA ${ }^{95}$ ) by decree in 1945, giving it responsibility for directing and coordinating the development of applications for the fission of the uranium atom nucleus. In this context, a team led by Lew Kowarski started up the first French research reactor in 1948, the ZOÉ atomic pile built at the CEA centre at Fontenay-aux-Roses (figure 5.1). The core of this reactor, consisting of uranium oxide-based fuel elements $(1,950 \mathrm{~kg})$ sitting in heavy water ( 5 tonnes) in an aluminium tank surrounded by a $90 \mathrm{~cm}$-thick graphite wall, stood within a 1.5 metrethick concrete containment wall designed to absorb the different types of ionizing radiation emitted by the nuclear reactions in the core. The ZOÉ reactor was used up to a power of $150 \mathrm{~kW}$ to study the behaviour of materials under irradiation, and at

93. This database gives the full list of French research reactors. See also the CEA publication entitled "Research Nuclear Reactors", a Nuclear Energy Division monograph - 2012, or the publication (in French) "Les réacteurs de recherche" by Francis Merchie, Encyclopédie de l'énergie, 2015.

94. This publication does not cover research reactors used for defence-related purposes.

95. Which would later become the Alternative Energies and Atomic Energy Commission. 


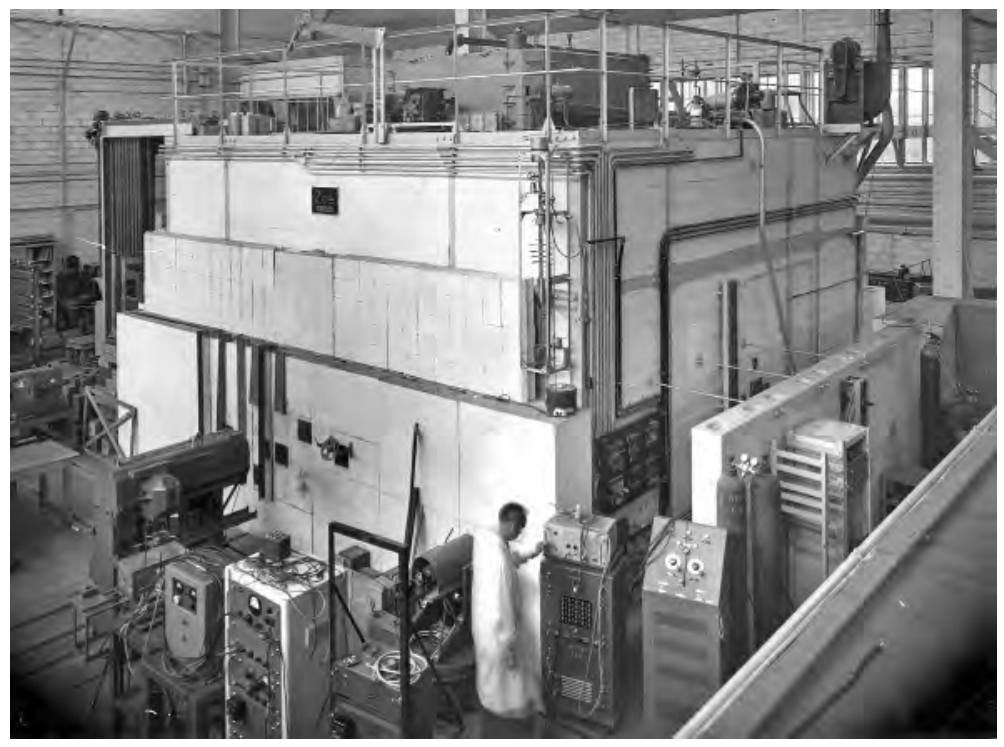

Figure 5.1. View of ZOÉ, France's first "atomic pile". CEA historic archives. @ CEA/Documentation service.

low power to characterize the neutronic properties of the materials used in atomic piles at the time (worldwide).

In the 1950s, some ten research reactors were commissioned in France. Having no industrial enrichment capability of its own at the time, France set about improving knowledge of the nuclear data for reactors using natural uranium. The AQUILON reactor at Saclay was designed for this purpose. This reactor and the ALIZÉ reactor (also at Saclay) were then used to support the design of the on-board reactors in the first French nuclear-powered submarines. The PROSERPINE reactor, also at Saclay, was used specifically for studying "homogeneous ${ }^{96}$ " reactors, using plutonium in solution as fissile material. PROSERPINE was light water-moderated. It was used to compare the neutron characteristics of two fundamental fissile elements: plutonium-239 and uranium-235.

In parallel during the 1950s, reactors were built for material testing and technological research. Thus the EL2 then the EL3 reactors were commissioned at Saclay for the purpose of producing artificial radioisotopes for studying the behaviour under irradiation of materials of structures used in reactors.

Towards the end of the 1950s, it became apparent that there was a need for better knowledge of the fundamental neutronics parameters involved in nuclear reactor core physics. In response to this need in particular, the MINERVE reactor was designed and commissioned in 1959 at the CEA centre at Fontenay-aux-Roses.

96. The fuel in a homogeneous reactor is in liquid form (nitrate or sulphate). 
A further twenty or so research reactors were commissioned in the 1960s. The development of the nuclear energy industry was already in full swing at the time but there were limited computing resources available. The use of critical assemblies or mockups $^{97}$ and material testing reactors appeared necessary to complete the acquisition of knowledge and data to support the industrial development of nuclear energy. France was attempting to develop the $\mathrm{GCR}^{98}$ (gas-cooled, graphite-moderated) reactor type using natural uranium as fuel. The MARIUS research reactor (commissioned in 1960 on the Marcoule site, then transferred in the mid-1960s to the CEA site at Cadarache) and the CESAR research reactor (commissioned in 1964 at Cadarache) were used in the early 1960s to conduct studies for the nuclear energy industry.

The use of fast neutron reactors was also explored at this time, especially for the purpose of using the plutonium resulting from the operation of the GCR reactors. The development of SFRs led in particular to the construction:

- of the HARMONIE reactor at Cadarache, which first went critical in 1965 and was used mainly to determine the neutron characteristics of radiological protection materials (the lateral neutron shielding around the core in fast neutron reactors);

- the MASURCA ${ }^{99}$ critical assembly, also situated at Cadarache and commissioned in 1966, which was used to study neutronics and, much later, to conduct research into the transmutation of the actinides present in highly radioactive nuclear waste.

The RAPSODIE reactor at Cadarache was the first fast neutron research reactor and ran on plutonium ${ }^{100}$ fuel and liquid sodium coolant. Numerous irradiation experiments were conducted in RAPSODIE between 1967 (the year of its first criticality) and 1982 (permanent shutdown in 1983), as part of the development of steel cladding for sodium-cooled fast neutron reactors (SFRs). Experiments known as "end-of-life testing", extending as far as the melting of fuel at the core of certain fuel rods, were conducted in 1982 (DISCO and FONDU tests).

The CABRI reactor, the first French reactor designed specifically for studying accident situations in SFRs (in a sodium loop), was built at Cadarache at the start of the 1960s; the first criticality of this reactor took place in December 1963. Tests were also carried out in the sodium loop to study accident situations in pressurized water reactors (tests known as REP-Na). The SCARABEE reactor, used in the 1980s for tests related to sodium-cooled fast neutron reactors (since shut down and dismantled), shared the main equipment of the CABRI reactor. It had a sodium loop of larger diameter than the one used in the CABRI reactor.

The willingness of the USA to supply highly enriched fuel with uranium-235 meant that it was possible in the 1960s to design higher power reactor cores with more intense

97. Reactors using fuel element arrangements representative of the cores being studied ("assembly") and operating at almost zero power ("just critical").

98. UNGG (Uranium Naturel Graphite-Gaz) in French.

99. Breeding assembly at the Cadarache Research Centre.

100. The RAPSODIE reactor, like subsequent French SFRs, ran on mixed $\cup_{2}-\mathrm{PuO}_{2}$ fuel; axial and radial "blankets" of uranium-238 (depleted uranium), a fertile material under a fast neutron flux, were also placed around the fissile zone. 
neutron fluxes, so the reactors could be used for material testing. In France, three material testing reactors were designed at this time: the $30 \mathrm{MW}$ PEGASE reactor at Cadarache, the $35 \mathrm{MW}$ SILOE reactor at Grenoble (forced downstream water circulation; this reactor was in operation from 1963 to 1997), and the 70 MW OSIRIS reactor (figure 5.2) at Saclay (upstream water circulation; in operation from 1966 to 2015). These reactors were each accompanied by a critical assembly: PEGGY for PEGASE, SILOETTE (figure 5.2) for SILOE and ISIS for OSIRIS.
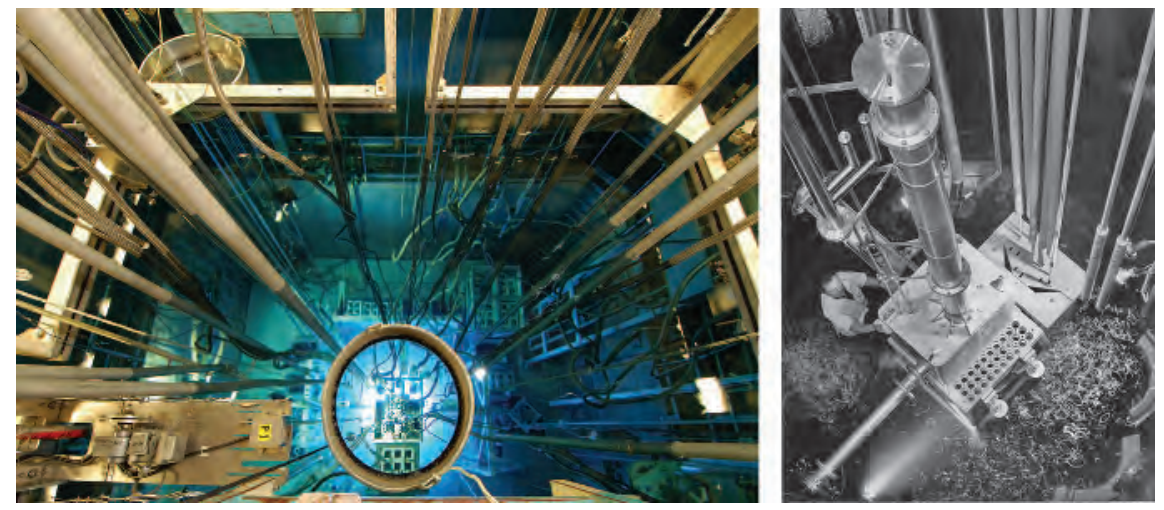

Figure 5.2. Left, Osiris reactor core. View of the submerged neutron radiography installation (2004). (c) L. Godart/CEA; right, view of the SILOETTE critical assembly. @ CEA.

Unlike the high flux reactor $\left(\mathrm{RHF}^{101}\right)$ in Grenoble and the ORPHEE reactor, SILOE was a light water pool-type reactor built for irradiating materials and equipment. The core (figure 5.3) consisted of elements containing fuel enriched to $90 \%$ uranium- 235 .

However, the SILOE reactor also had neutron channels not aimed directly at the core, as well as a beryllium ${ }^{102}$ wall along one of the four sides of the core ${ }^{103}$. To start with, there were only two radial channels. After the MELUSINE reactor was shut down in 1988, a tangential channel was added to SILOE, which aimed at the beryllium wall through the slice. This brought the number of instruments to six, with two devices per channel (spectrometers, diffraction meters). Despite difficult working conditions for the scientists (high temperatures, confined spaces, etc.), this equipment gave excellent service from a scientific point of view and was used to train scientists, especially in powder diffraction and single crystal diffraction, as well as polarised neutron scattering.

In 1969, France took the decision to stop building GCR reactors in favour of USdesigned pressurized water reactors. In the decade that followed, with experimental

101. Réacteur à Haut Flux in French.

102. This material is a neutron source when struck by high energy gamma rays in particular.

103. Source: ARILL ("Association des retraités de l'Institut Laue-Langevin"): "Le réacteur de recherche Siloé". 


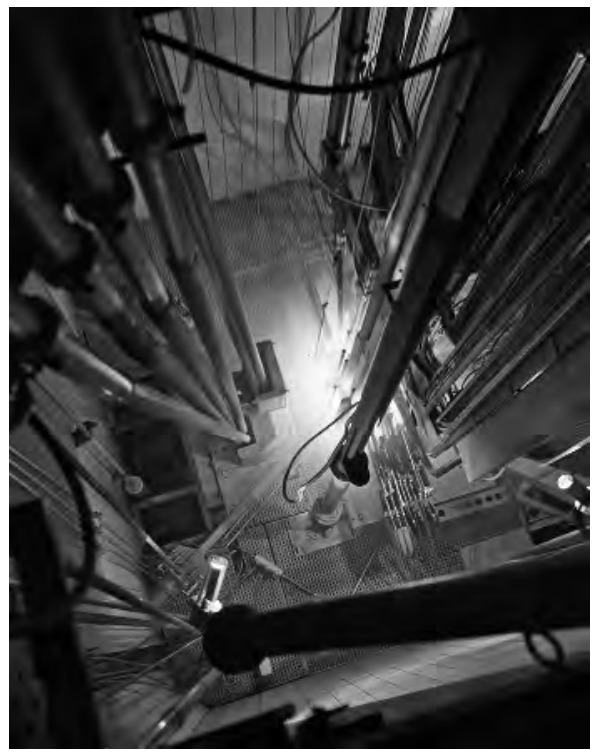

Figure 5.3. View of the SILOE reactor core. @ CEA.

needs largely being met, few new research reactors were built compared to the 19501970 period.

However, two high flux reactors, with neutron beams for fundamental physics experiments, were then commissioned: the high flux reactor (the $58 \mathrm{MW} \mathrm{RHF)} \mathrm{at}$ Grenoble, run by the Institut Laue-Langevin (ILL), which went critical in 1971, and the ORPHEE reactor (14 MW) at Saclay, which went critical at the end of 1980.

In 1972, in association with EDF, the CEA set up the Pile Construction Department within the Atomic Piles Division at the CEA. The Department was subsequently hived off and attached to the company Technicatome ${ }^{104}$, which would become the TA branch of the company AREVA. These entities and companies made a major contribution to the design and construction of research reactors, up to and including the Jules Horowitz reactor.

As regards the development of fast neutron reactors, a large number of experimental irradiations were carried out in the PHENIX power reactor, at Marcoule, which was commissioned in 1974, until its final shutdown in February 2010. As was the case with the RAPSODIE reactor, later tests also known as "end-of-life ${ }^{105 "}$ tests related to safety issues were carried out (e.g. the possibility of initiating natural convection of the sodium in different reactor circuits, the risk of cladding failure in the event of partial melting in the core of a pin containing fuel pellets, etc.).

104. The company GAAA (Groupement Atomique Alsacienne Atlantique), which later became Novatome, worked with the CEA and EDF on the design of the fast neutron reactors.

105. See the publication by Joël Guidez "PHENIX - The experience feedback", Chapter XV, Collection: Hors Collection, EDP sciences, 2013. 
Similarly, the PHEBUS test reactor was commissioned in 1978 at Cadarache to study cooling accidents in pressurized water reactors.

Finally, the CEA launched a project to build a new material testing reactor, the Jules Horowitz reactor. The reactor, which is under construction at Cadarache, will take over from the OSIRIS reactor, the final shutdown of which took place at the end of 2015 . We will look at this new reactor in more detail later on.

Table 5.1 below presents the French reactors used either wholly or partially for experiments, with their commissioning date (excluding facilities used for defence purposes).

Table 5.1. List of French reactors used wholly or partially for experiments, with their commissioning date.

\begin{tabular}{|c|c|c|c|c|}
\hline $\begin{array}{l}\text { Reactor } \\
\text { type } \rightarrow \\
\text { uses } \\
\downarrow\end{array}$ & $\begin{array}{l}\text { Reactors using } \\
\text { (light or heavy) } \\
\text { water or air for } \\
\text { core cooling }\end{array}$ & $\begin{array}{l}\text { Reactors } \\
\text { using liquid } \\
\text { sodium for } \\
\text { core cooling }\end{array}$ & $\begin{array}{l}\text { Critical } \\
\text { assemblies }\end{array}$ & $\begin{array}{l}\text { Neutron beam } \\
\text { reactors (heavy } \\
\text { water/light } \\
\text { water) }\end{array}$ \\
\hline $\begin{array}{l}\text { Studies of } \\
\text { reactor } \\
\text { physics } \\
\text { (including the } \\
\text { determination } \\
\text { of nuclear } \\
\text { data), } \\
\text { radiological } \\
\text { protection, } \\
\text { irradiation }\end{array}$ & $\begin{array}{l}\text { ZOE (1948) } \\
\text { EL2 (1952) } \\
\text { EL3 (1957) } \\
\text { MELUSINE (1959) } \\
\text { TRITON (1959) } \\
\text { NEREIDE (1960) } \\
\text { PEGASE (1963) } \\
\text { SILOE (1963) } \\
\text { OSIRIS (1966) } \\
\text { JHR (under } \\
\text { construction) }\end{array}$ & $\begin{array}{l}\text { RAPSODIE (1966) } \\
\text { PHENIX (1974) }\end{array}$ & $\begin{array}{l}\text { AQUILON (1956) } \\
\text { PROSERPINE (1958) } \\
\text { ALIZE (1959) } \\
\text { RUBEOLE (1959) } \\
\text { MINERVE (1959) } \\
\text { MARIUS (1960) } \\
\text { PEGGY (1961) } \\
\text { RACHEL (1961) } \\
\text { SILOETTE (1964) } \\
\text { CESAR (1964) } \\
\text { EOLE (1965) } \\
\text { ISIS (1966) } \\
\text { HARMONIE (1965) } \\
\text { MASURCA (1966) }\end{array}$ & \\
\hline Safety tests & $\begin{array}{l}\text { CABRI (sodium loop, } \\
\text { 1972) } \\
\text { PHEBUS (1978) } \\
\text { CABRI (water loop) }\end{array}$ & $\begin{array}{l}\text { RAPSODIE (1966) } \\
\text { PHENIX (1973) } \\
\text { (for "end-of-life" } \\
\text { tests) }\end{array}$ & & \\
\hline $\begin{array}{l}\text { Studies of the } \\
\text { physics of } \\
\text { matter }\end{array}$ & & & & $\begin{array}{l}\text { RHF (1971) } \\
\text { ORPHEE (1980) }\end{array}$ \\
\hline Teaching & $\begin{array}{l}\text { MINERVE (1959) } \\
\text { ULYSSE (1961) } \\
\text { Argonaut class } \\
\text { SILOETTE (1964) } \\
\text { RUS « Cronenbourg » } \\
\text { (1966) } \\
\text { Argonaut class } \\
\text { ISIS (1966) }\end{array}$ & & & \\
\hline
\end{tabular}




\subsection{Current situation}

Since the ZOÉ pile, around forty research reactors have therefore been built and operated in France. In mid-2018, with the shutdown of the OSIRIS reactor, there were seven research reactors left "in operation"106. The others are scheduled for permanent shutdown without utilization (PHEBUS), are decommissioned or dismantled, or have already been dismantled.

Of the reactors still in operation, three are critical assemblies: EOLE, MINERVE and MASURCA, now all at Cadarache. The MINERVE reactor (figure 5.4) was commissioned in 1959 at the Fontenay-aux-Roses centre but was transferred to Cadarache in 1977. It is dedicated to the neutron characterization of materials (fissile, fertile, neutron-absorbing or structural materials) and to studying the physics of cores of different types of reactor. It is a pool-type reactor with a maximum operational power of $100 \mathrm{~W}$. The reactor core, which consists of fuel elements in the form of UAl alloy plates, enriched to around $93 \%$ uranium-235, is surrounded by graphite reflector elements and submerged in a large volume of demineralized water $\left(140 \mathrm{~m}^{3}\right)$, which protects the operators from ionizing radiation and removes the (small amount of) heat from the core.

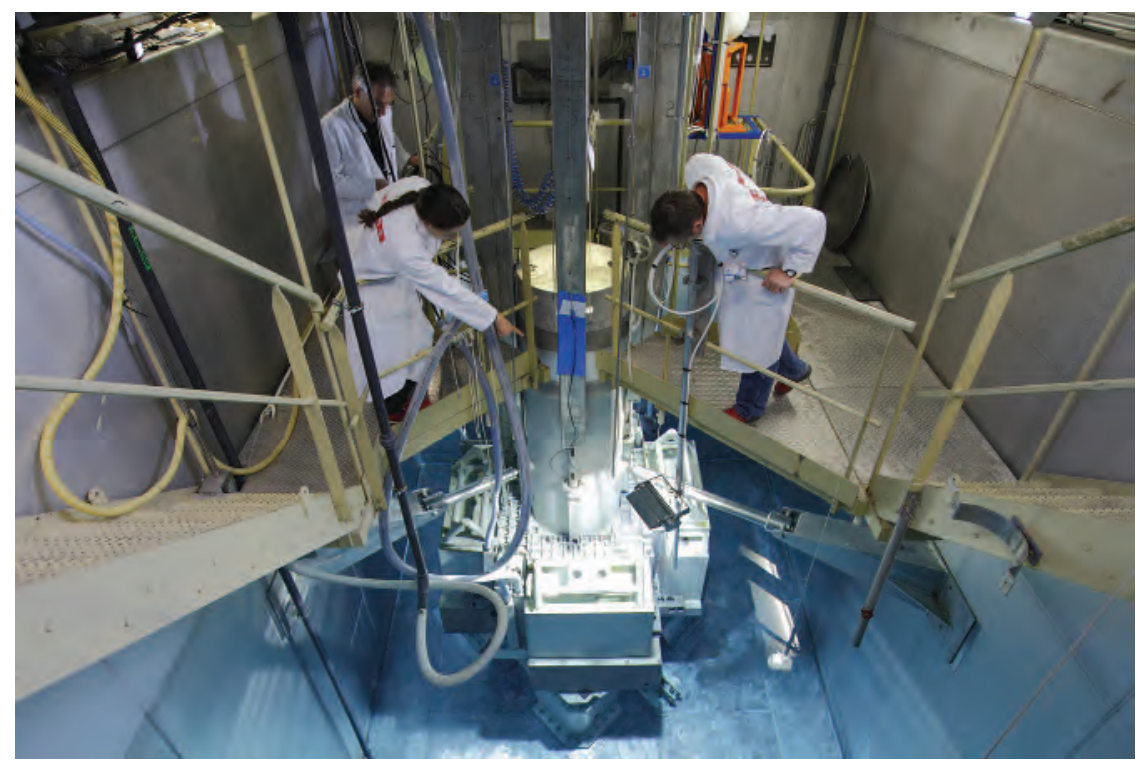

Figure 5.4. The MINERVE pool. Loading a sample into the central cavity to measure the reactivity effect using the "oscillation method". @ G. Lesénéchal/CEA.

The EOLE reactor (figure 5.5), commissioned in 1965, is in the same building as the MINERVE reactor. It also operates at very low power (100 W maximum), but its design is very different to that of the MINERVE reactor. The EOLE reactor, which has a variety

106. ORPHEE, ISIS, MASURCA, CABRI, EOLE, MINERVE and the RHF. 


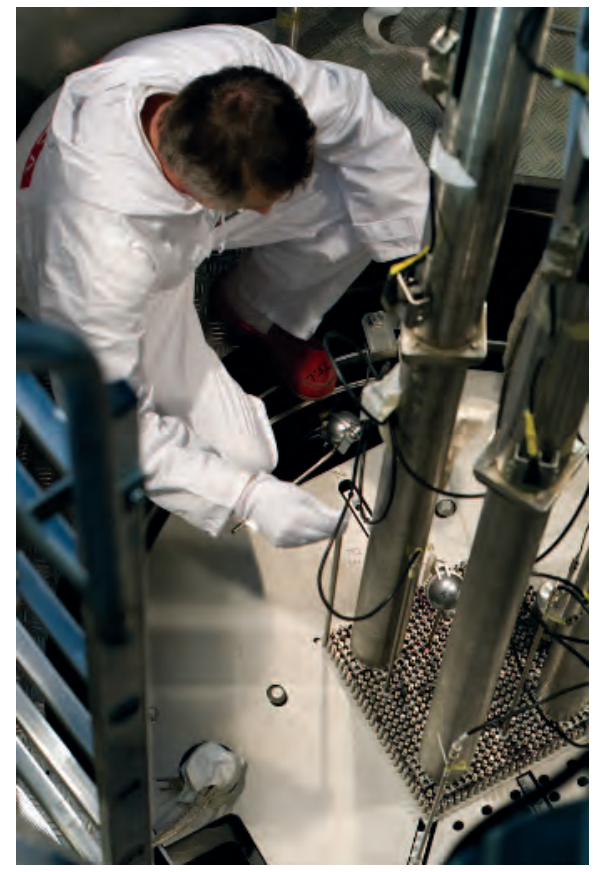

Figure 5.5. View of the EOLE reactor vessel configured for the PERLE experiment (2008). C P. Dumas/CEA.

of measuring equipment ( $\gamma$ spectrometry, fission chambers, thermoluminescent detectors), can entirely characterize core configurations from a physics and neutronics point of view. During every experimental programme conducted in the EOLE reactor, a new core is loaded using the facility's available fuel elements. The core is placed in a small metal vessel (around 1 metre high by 1 metre in diameter) into which water, maintained at a consistent temperature and possibly borated, is gradually injected until criticality is reached. Measurements are then carried out on the fuel elements not only while it is at power but also once the reactor has been shut down. By repeating these measurements for different experimental core configurations (change of material, replacement of a fuel element by water, insertion of an experimental device, etc.), it is possible not only to characterize the effects of the tested materials and devices on core reactivity, but also to assess characteristic neutronics parameters such as the Doppler effect or the effect of the moderator (neutron feedback). The EOLE reactor, for example, played a part in the qualification of neutronics modelling tools used to design the Jules Horowitz research reactor (JHR).

The MASURCA critical assembly (figure 5.6), also at Cadarache, has the particular characteristic of being cooled not by water but by air. The experimental cores loaded into it are much bigger (up to $6 \mathrm{~m}^{3}$ in volume) than those that can be loaded into the EOLE and MINERVE reactors. The MASURCA assembly, which has a maximum power of $5 \mathrm{~kW}$, was specifically designed to study the characteristics of fast neutron reactor cores. Each experimental core consists of tubes of square section filled by hand with 


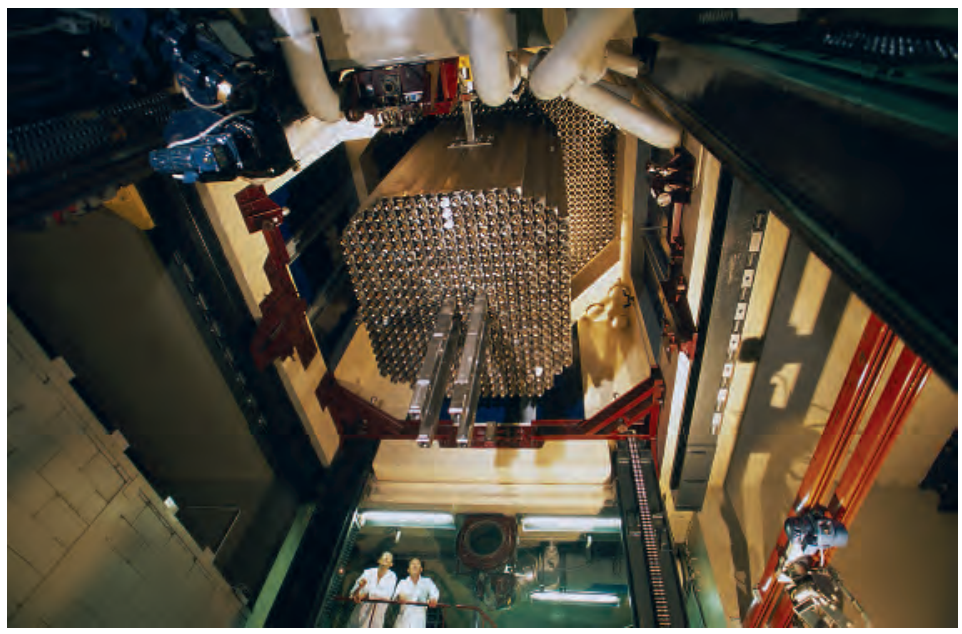

Figure 5.6. MASURCA reactor: core viewed from below, fuel elements being dropped. ( ) P. Stroppa/ CEA.

small fuel elements (in the form of rodlets or platelets), neutron-absorbing elements or coolant elements (sodium in solid form) representing the lattice to be studied from a neutronics point of view. The ability to create "à la carte" cores means that core concepts for very varied and innovative reactors, such as accelerator driven systems (ADS) and high temperature reactors (HTR), can be studied. The MASURCA assembly has been shut down since 2007 and the CEA is going to carry out major renovation work on it to answer neutronics questions related to the Generation IV fast neutron reactors, particularly for the ASTRID (Advanced Sodium Technological Reactor for Industrial Demonstration) project.

Whereas the MASURCA reactor has been kept in operation mainly to support studies related to the ASTRID project, experiments in the EOLE and MINERVE reactors were stopped at the end of 2017; there are plans to build a facility named ZEPHYR to replace them.

The low power research reactors also include reactors used for teaching. They are valuable for delivering the teaching programmes of educational establishments specializing in nuclear, as well as the training programmes of nuclear operators and safety bodies. Within these programmes, the reactors used are either reactors dedicated almost exclusively to training (the ISIS reactor at Saclay), or reactors that have training periods included in their operation (MINERVE reactor at Cadarache).

The ISIS reactor (figure 5.7) was designed as a neutron mockup of the OSIRIS reactor at a scale of 1:10. It has a maximum power of $700 \mathrm{~kW}$ and can be used to carry out tests related to new configurations of the OSIRIS core and new fuels or new irradiation experiments in the reactor. The ISIS reactor underwent major renovation work between 2004 and 2006 in order to adapt it fully for training activities. In particular, the control room was redesigned to accommodate participants in training sessions. A supervision 

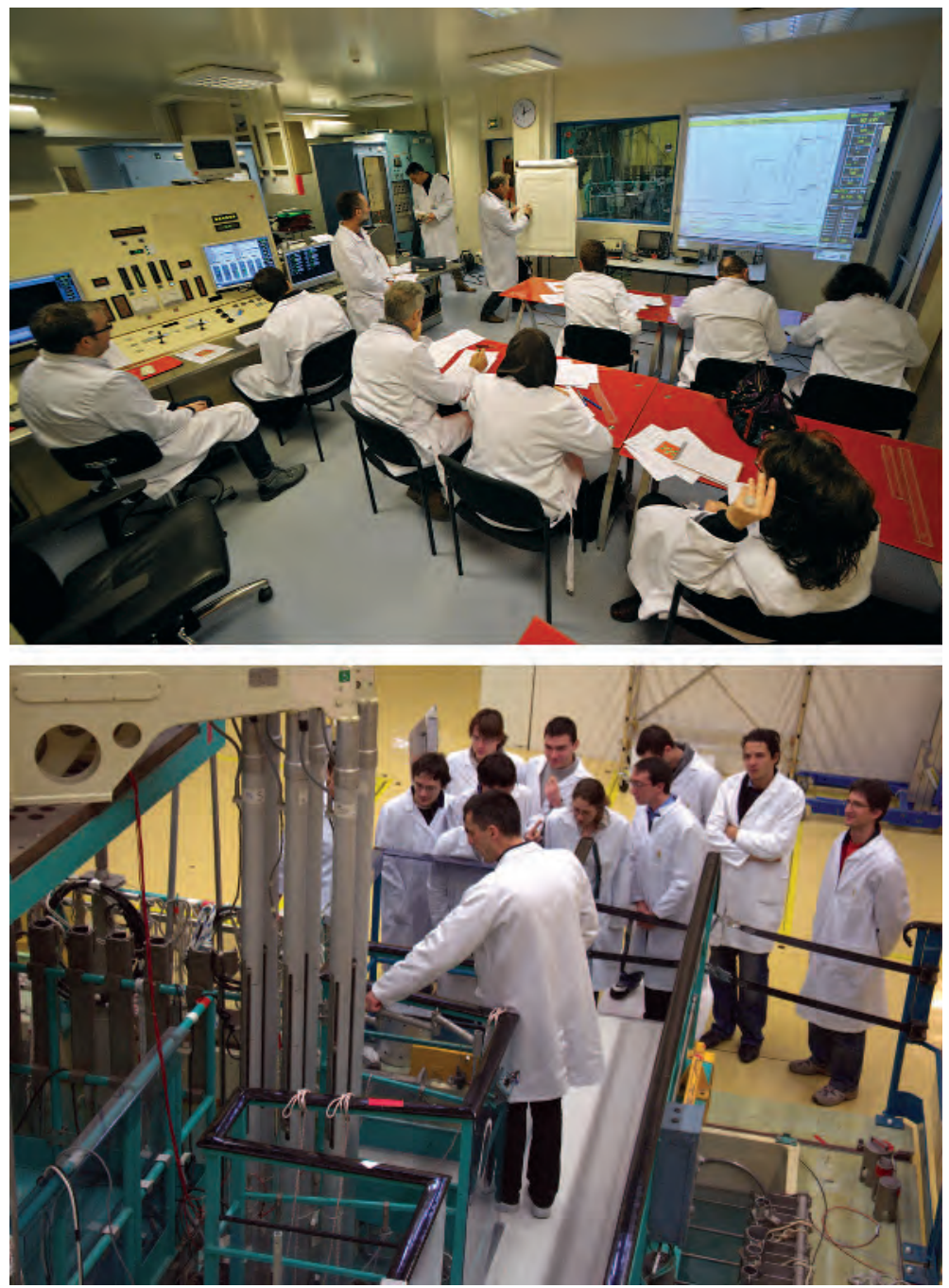

Figure 5.7. Top, French Master's course, practical work in the ISIS reactor control room (2013). () PF. Grosjean/CEA. Bottom, practical work in the ISIS reactor; students from the École des Ponts et Chaussées on the "Principles and operations on nuclear reactors" course (2010). ๑ S. Renard/CEA.

software was developed for monitoring changes to significant parameters during handling operations in the reactor. Around a hundred half-day practical training sessions are carried out each year at this facility, which is now assigned solely to training; its shutdown is scheduled for 2018.

For material testing, France particularly made use (until 2015) of the OSIRIS reactor at Saclay. The corresponding activities will be taken over by the Jules Horowitz 
reactor, which is under construction at Cadarache but is not expected to be commissioned until $2020^{107}$.

As a reminder, material testing reactors are designed to produce relatively high neutron fluxes and to accommodate devices inside the reactor core or around the edge of it, in which to place the items to be irradiated.

The OSIRIS reactor (figure 5.8), commissioned in 1966, was an open core pool-type reactor. The water acted simultaneously as moderator ${ }^{108}$, as coolant ${ }^{109}$, and as radiological shielding. Its core, which was fairly small $(57 \mathrm{~cm} \times 57 \mathrm{~cm} \times 60 \mathrm{~cm})$, contained 44 fuel elements and could release a maximum power of $70 \mathrm{MW}$. The water circulated from bottom to top in the core. The high neutron fluxes, both inside the core and around it, were greater than those in a PWR power reactor, making it possible to study

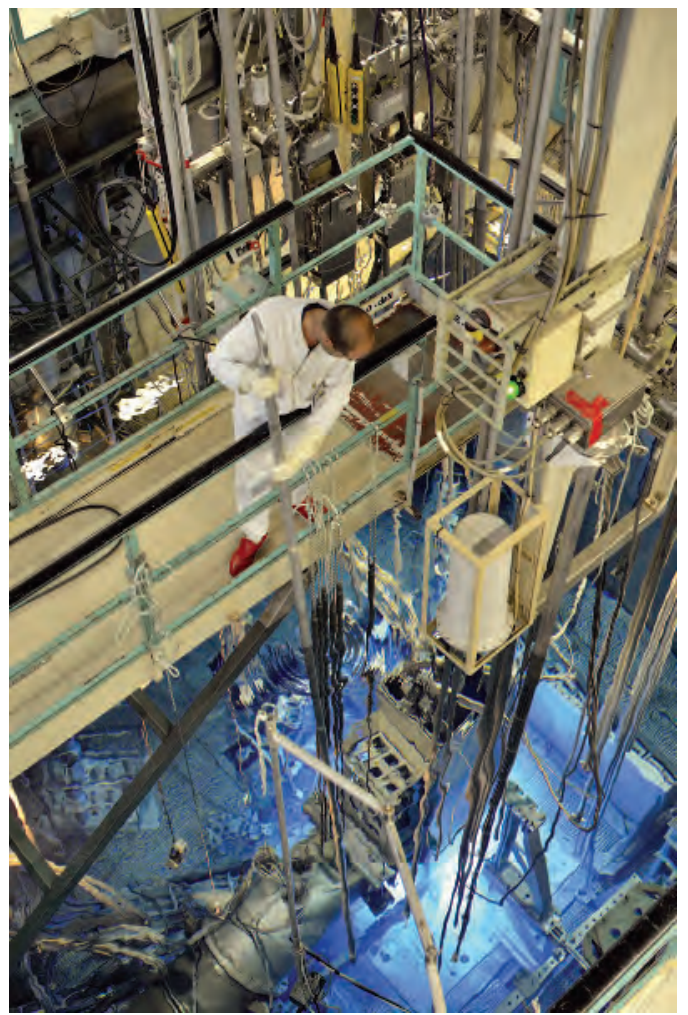

Figure 5.8. OSIRIS reactor pool. (c) Laurent Zylberman/Graphix-Images/IRSN.

107. "Le chantier du réacteur Jules Horowitz", Libération $\left\{\right.$ Sciences $\left.^{2}\right\}, 25$ January 2016.

108. A moderator is a material that slows down neutrons through a succession of collisions with atoms (generally hydrogen) present in the material.

109. A coolant absorbs and removes the heat produced in the fuel by the fission reactions. 
the accelerated ageing of materials under irradiation in these reactors. They could also be used to produce artificial radioisotopes used in medicine for diagnosis by scintigraphy or for treating certain cancers (brachytherapy) and other diseases. Also, the irradiation of monocrystalline silicon ingots made it possible to alter the atomic structure of the silicon, giving it the properties of a semiconductor (silicon "doped" in this way is used by the electronics industry).

\section{A new generation material testing reactor: the Jules Horowitz reactor}

The Jules Horowitz reactor ${ }^{110}$, or JHR, for which the design process was begun by the CEA in 1998, should meet the need expressed by the European Commission for a modern, flexible research facility (the other European reactors that can perform the same functions date from the 1960s, see table 5.2 below) to carry out experiments around twenty at once - contributing to:

- improving the competitiveness and service life of nuclear power reactors in operation,

- developing the performance of nuclear fuels in "third-generation" reactors such as the EPR (European Pressurized Reactor ${ }^{111}$ ),

- developing new materials and fuels for "fourth generation" (Gen IV) reactors such as the one for the ASTRID project,

- improving the reliability of European radioisotope supplies for the medical sector.

Table 5.2. Material testing reactors in Europe (source CEA).

\begin{tabular}{|l|c|c|c|}
\hline Country & Research reactor & Age (in 2017) & Power (MWth) \\
\hline Belgium & BR2, Mol & 54 & 60 \\
\hline Netherlands & HFR, Petten & 56 & 45 \\
\hline Norway & HRP, Halden & 57 & 19 \\
\hline France & OSIRIS & Shut down in 2015 after 49 years in operation & 70 \\
\hline Sweden & R2, Studsvik & Shut down in 2005 after 45 years in operation & 50 \\
\hline
\end{tabular}

Within the JHR project, the CEA is working with Belgian, Czech, Spanish, Finnish and Japanese research institutes and the companies EDF and AREVA (Framatome) in France and Vattenfall in Sweden. In 2008, India's Department of Atomic Energy (DAE) joined

110. Sources used: Nuclear Research Reactors, a Nuclear Energy Division monograph - 2012, pages 95 to 106, The JHR, CEA Cadarache website (http://www.cea.fr/english/Pages/researchareas/nuclear-energy/jules-horowitz-research-reactor-JHR.aspx ), which in particular links to the report published on the ASN's website "Réacteur Jules Horowitz - Évaluation complémentaire de la sûreté au regard de l'accident survenu à la centrale nucléaire de Fukushima I" (CEA/DEN/CAD/ DIR/CSN DO 575 13/09/11), the Wikipedia article and its references, etc.

111. European version of a pressurized water reactor. 
the seven original partners in the project. The agreements signed between these partners will give them access to the facility to conduct their own experiments.

The objective of the promoters of the JHR project is to create a major European infrastructure open to international collaboration that will help to cover research and development needs over several decades.

The JHR is a closed core pool-type reactor. The core will be composed of fuel elements of circular cross-section, with curved fuel plates, cooled by water streaming in an upward direction (primary coolant system). This assembly will be surrounded by reflector elements (water and beryllium) and will be placed in a pool. In terms of performance, its maximum power will be $100 \mathrm{MW}$ and the aim is to achieve a neutron flux of around $10^{15}$ neutrons. $\mathrm{cm}^{-2} \cdot \mathrm{s}^{-1}$ (energy greater than $0.1 \mathrm{MeV}$ ), with a fast neutron flux of energy greater than $1 \mathrm{MeV}$ of around $5 \times 10^{14}$ neutrons. $\mathrm{cm}^{-2} \cdot \mathrm{s}^{-1}$. A particular feature of the neutron spectrum is that it will have two energy peaks, enabling material testing to be carried out in the thermal neutron range (applications for common existing reactors) and partially in the fast neutron range (applications for Gen IV fast neutron reactors ${ }^{112}$ ).

Irradiation devices can be inserted in the centre of fuel elements (see diagram at the bottom of figure 5.10), can be positioned in place of fuel elements, or can be placed in the reflector (figure 5.9). Displacement systems in the core periphery can also be used to simulate conditions representative of transients, incidents or accidents likely to occur particularly in power reactors (slow power ramps).

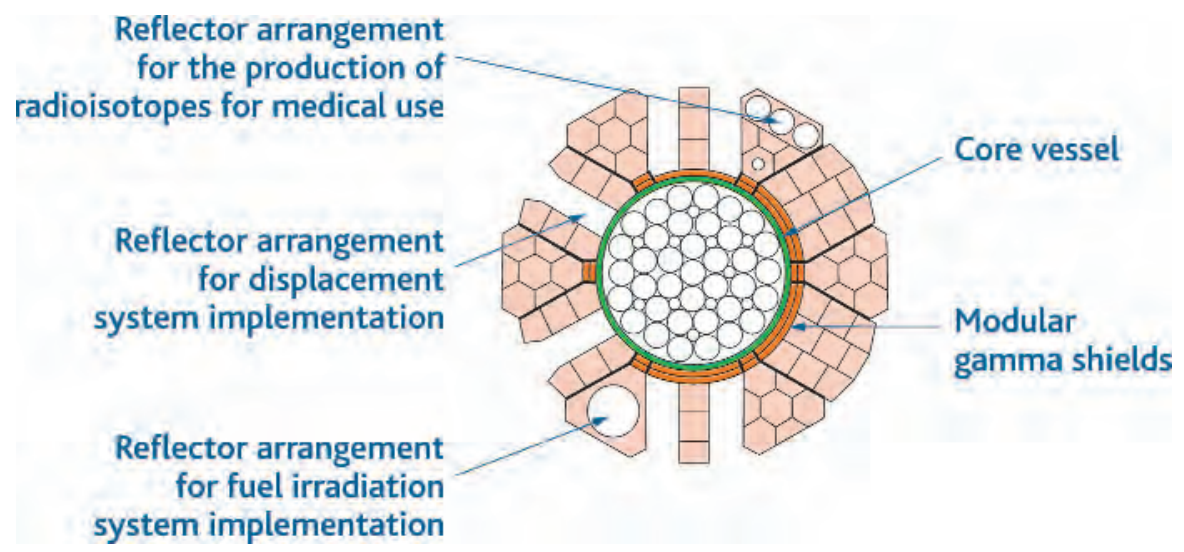

Figure 5.9. Planned layouts in the reflector area of the Jules Horowitz reactor. ๑ Georges Goué/IRSN.

Most of the samples that will be placed in the JHR core will be prepared and analysed in the fuel laboratories at the CEA centre at Cadarache, located close to the JHR to reduce the transport of radioactive materials (and the associated risks).

112. See the publication "Overview of Generation IV (Gen IV) Reactor Designs/Safety and Radiological Protection Considerations", Reference Documents Series, IRSN 2012/158, available at www.irsn.fr/EN. 


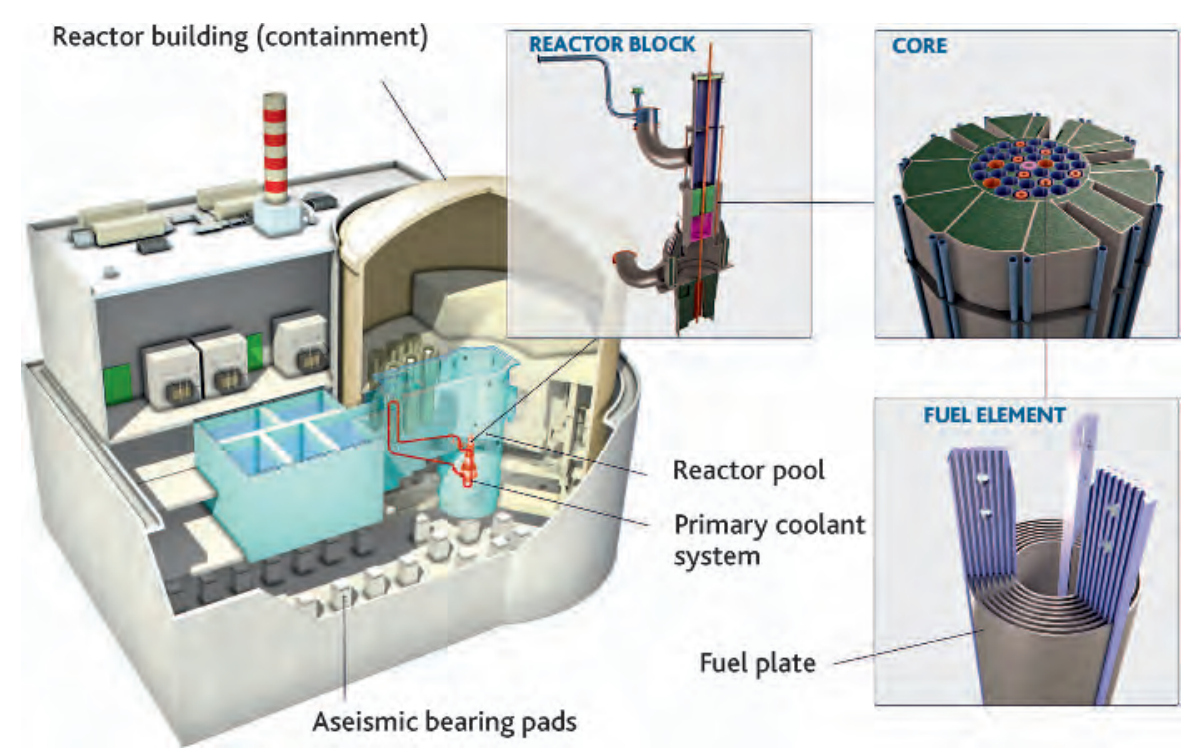

Figure 5.10. Jules Horowitz Reactor: diagrams of the nuclear unit, reactor block, core and a fuel element. (c) ASN.

It is expected that the JHR will contribute $25 \%$ of European radioisotope production for medical use, or even up to $50 \%$ if necessary. Since the OSIRIS reactor was shut down, technetium $-99^{\mathrm{m}}$ has been produced particularly at the HFR research reactor in Petten (Netherlands) and at the BR2 research reactor in Mol (Belgium) - the Canadian NRU reactor dating from 1957, which is responsible for more than $40 \%$ of global production, is back in operation after various shutdowns, particularly following the discovery in $\mathbf{2 0 0 9}$ of a heavy water leak at the base of the reactor vessel.

In terms of general architecture, the JHR consists of two buildings (see figure 5.10):

- the reactor building, which houses the reactor itself, the equipment needed to operate it, and the equipment used to monitor experiments (workstations for experimenters, electrical equipment, instrumentation and control equipment, etc.);

- the nuclear auxiliary building, which contains hot cells for preparing, conditioning and examining experimental samples, and three storage pools.

Both buildings will be on the same foundation raft; they constitute the "nuclear unit". Seismic isolation is achieved by means of aseismic bearing pads. This will be explained in more detail in section 7.4.2.

The reactor has three systems:

- the primary coolant system, which cools the reactor core through the circulation of pressurized water (at about 10 bars at the core inlet). This closed circuit is inside the reactor building. The reactor core and part of the primary system are submerged in the reactor pool (figure 5.11); 

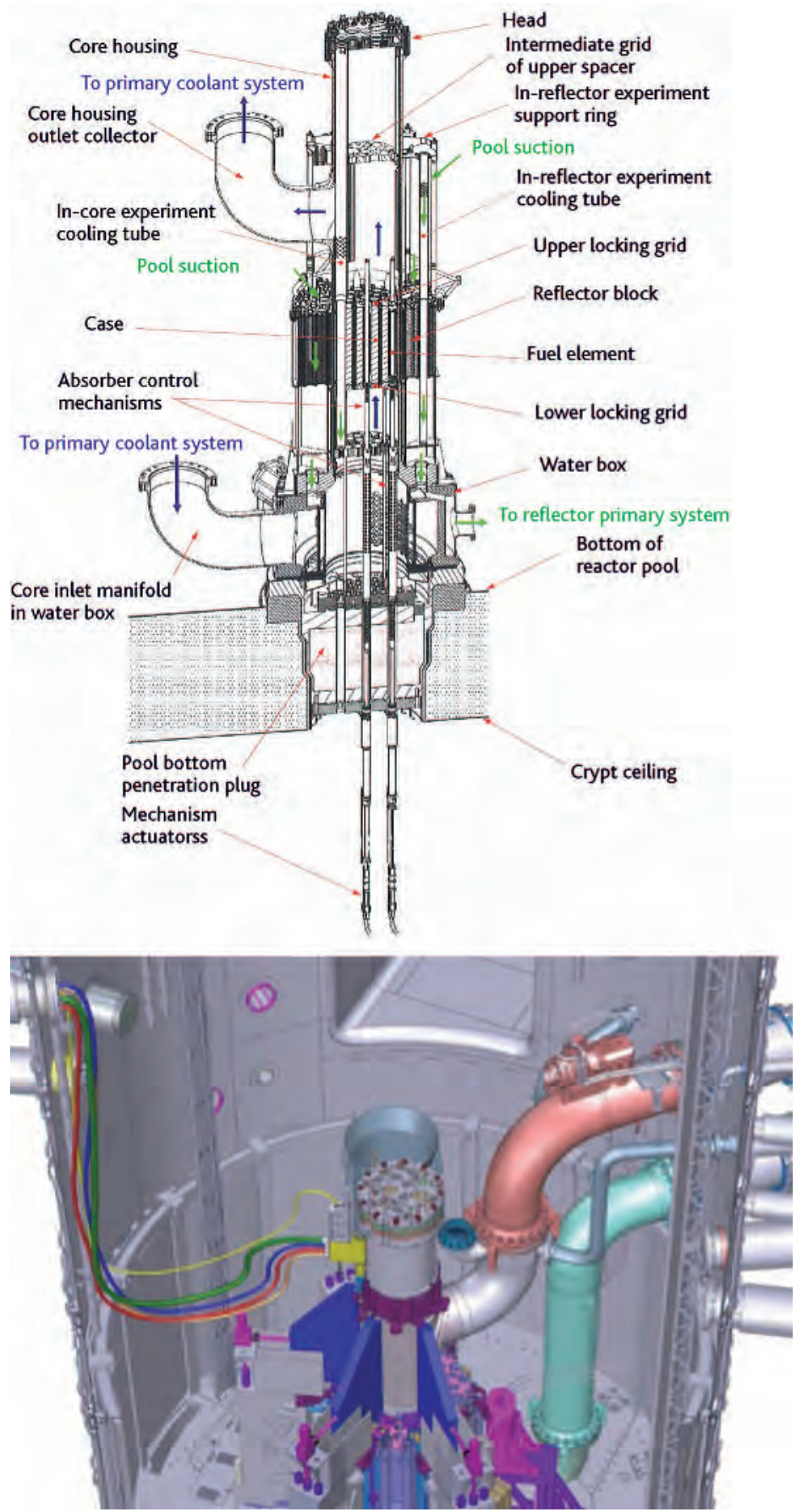

Figure 5.11. Reactor block of the JHR. @ DR. 
- the secondary coolant system, which is isolated from the primary system and cools the primary system by means of heat exchangers placed between the two systems in the reactor building. The pressure in the secondary system is higher than the pressure in the primary system so that, if there is a leak between the primary and secondary systems, the secondary system is not contaminated;

- an external coolant system, which cools the water in the secondary system by means of other heat exchangers placed in another building at the facility (the coolant building). This system will be connected by a channel to the Canal de Provence. The water will be returned to the EDF canal, ensuring that the water in the canal remains below a temperature of $25^{\circ} \mathrm{C}$, in accordance with regulations.

These three systems in series will reduce the risk of contamination being transferred from the core to the environment (the water in the EDF canal).

The JHR facility has three storage pools:

- the spent fuel storage pool, which will be used to store spent fuel from the reactor before it is processed at the Cogema plant at La Hague;

- the irradiated devices storage pool, which will be used to store (around thirty) experimental devices and to perform examinations under water;

- the irradiated components storage and dismantling pool, which will be used to store components from the reactor's internal structures, core structures (reflector) and tools used for handling and dismantling.

The fuel elements and experimental devices will be transferred between the reactor and the pools or hot cells under water.

The general safety objectives used for the design of the JHR, in terms of radiological consequences of incidents and accidents, are similar to those used for new generation power reactors such as the EPR; this will be discussed in more detail in chapter 7.

The gaseous discharges associated with the JHR will be generated mainly when experimental devices are opened in the hot cells and when degassing the primary circuit. The ventilation systems will be fitted with HEPA filters and iodine filters to limit the quantity of gaseous discharges. The activity of these discharges - consisting mainly of noble gases (xenon, krypton, etc.), halogens (iodine, etc.) and tritium - is expected to be similar to the activity measured at existing research reactors, considering the experiments conducted there.

Liquid waste should be generated mainly during experiments, decontamination of the hot cells, and regeneration of the resins used to purify the water in the reactor pool and the storage pools. These radioactive effluents will be managed by the treatment plant at the Cadarache Centre.

According to CEA estimations, when the JHR is in operation, gaseous discharges and liquid waste from the Cadarache Centre should remain at a few percent of the values stipulated by the annual authorizations for the Centre. 
The construction licence for the JHR was granted by decree ${ }^{113}$ in 2009 (it is not expected to be commissioned until 2020).

Among its reactors in operation, France also has two reactors delivering neutron beams used for scientific research. They are the ORPHEE reactor, operated by the CEA at Saclay ${ }^{114}$, and the high flux reactor (RHF), operated by the Institut Laue-Langevin at Grenoble.

These reactors operate in cycles of several weeks, separated by shutdowns for refuelling and maintenance. In these reactors, heavy water is used to slow the neutrons produced by fission (neutron moderation) and make them usable for testing matter:

- in the RHF reactor, heavy water is used as the core coolant (the core consists of a single fuel element), placed in a heavy water vessel, with the whole assembly sitting in a light water pool;

- in the ORPHEE reactor, light water is used as the core coolant and heavy water is used as the reflector, with the whole assembly sitting in a light water pool (see figure 5.12).
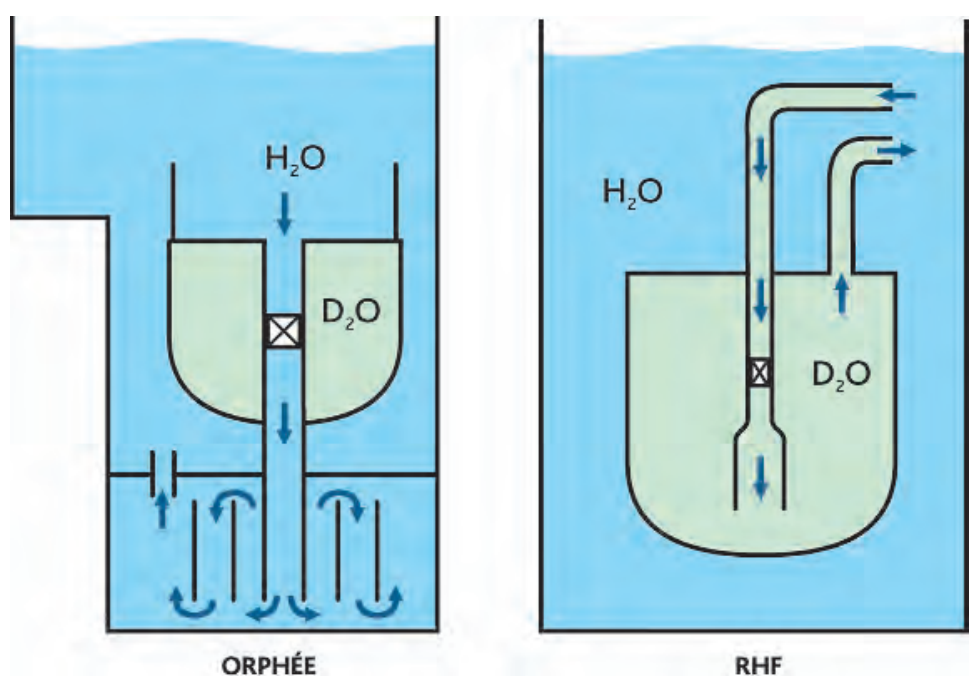

Figure 5.12. Respective uses of light water and heavy water in the ORPHEE and RHF reactors. In both cases, the water circulates downwards in the core. (C) Georges Goué/IRSN.

Because the energy of the neutrons must be controlled to suit the experiments being conducted, special devices are used to modify this energy locally. A container

113. Decree No 2009-1219 of 12 October 2009.

114. The corresponding basic nuclear installation (INB $\left.N^{\circ} 101\right)$ consists of the ORPHEE reactor and the Laboratoire Léon Brillouin (LBB) where researchers from the CNRS and the CEA work in the field of neutron spectrometry. 
filled with hydrogen or liquid deuterium (at a temperature of around $-250^{\circ} \mathrm{C}$ ) is used to obtain slow neutrons ("cold source ${ }^{115 ")}$ ) and a block of graphite heated to more than $1,000^{\circ} \mathrm{C}$ is used to obtain high energy neutrons ("hot source").

The neutrons (thermal, slow or fast) are "collected" for experimental use via "beam tube ends" directed at the reactor core. The collected neutrons are then guided out of the pool where they are filtered to extract the neutrons with the correct wavelength for irradiation of the material sample being tested (in the experimental area or neutron guide hall around the reactor - figure 5.13). The other neutrons in the beam are stopped by a concrete wall which acts as a shield.
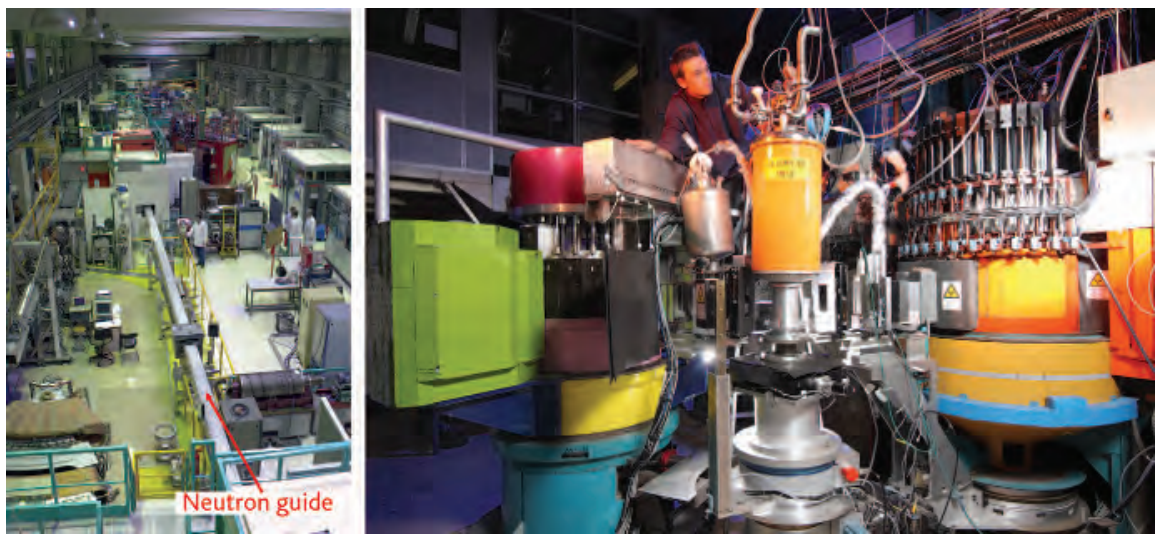

Figure 5.13. Left, a neutron guide hall (RHF). (C) Artechnique/ILL; right, "D10" device. @ ILL.

These reactors also have vertical channels near the heavy water vessel, used mainly for irradiation.

The ORPHEE reactor has nine horizontal (multiple beam) beam tubes at a tangent to the core, which enable 20 neutron beams to be used (figure 5.14). The beam tube ends are in the moderator (heavy water) near the core, where the heated neutron flux is at its greatest; three beam tube ends are directed at two "cold sources", and two others at one "hot source". The physicists doing research at ORPHEE belong to a laboratory run jointly by the CEA and the CNRS, known as the Laboratoire Léon Brillouin (LLB), and work in fields as varied as chemistry, biology, metallurgy and physics. The ORPHEE reactor is also used for activation analyses in partnership with the Laboratoire Pierre Süe (CEA), for irradiating samples and for producing radioisotopes for industrial and medical use (Cis-bio international), and finally for doping monocrystalline silicon by nuclear transmutation.

With a maximum power of $14 \mathrm{MW}$, the ORPHEE reactor (figure 5.15) delivers a neutron flux of up to $3 \times 10^{14}$ neutrons. $\mathrm{cm}^{-2} . \mathrm{s}^{-1}$ in the heavy water vessel. Its core, which consists of eight fuel elements of square cross-section, with flat fuel plates, containing

115. Not to be confused with the external source of cooling of a reactor (water from a river, the sea, air, etc.). 


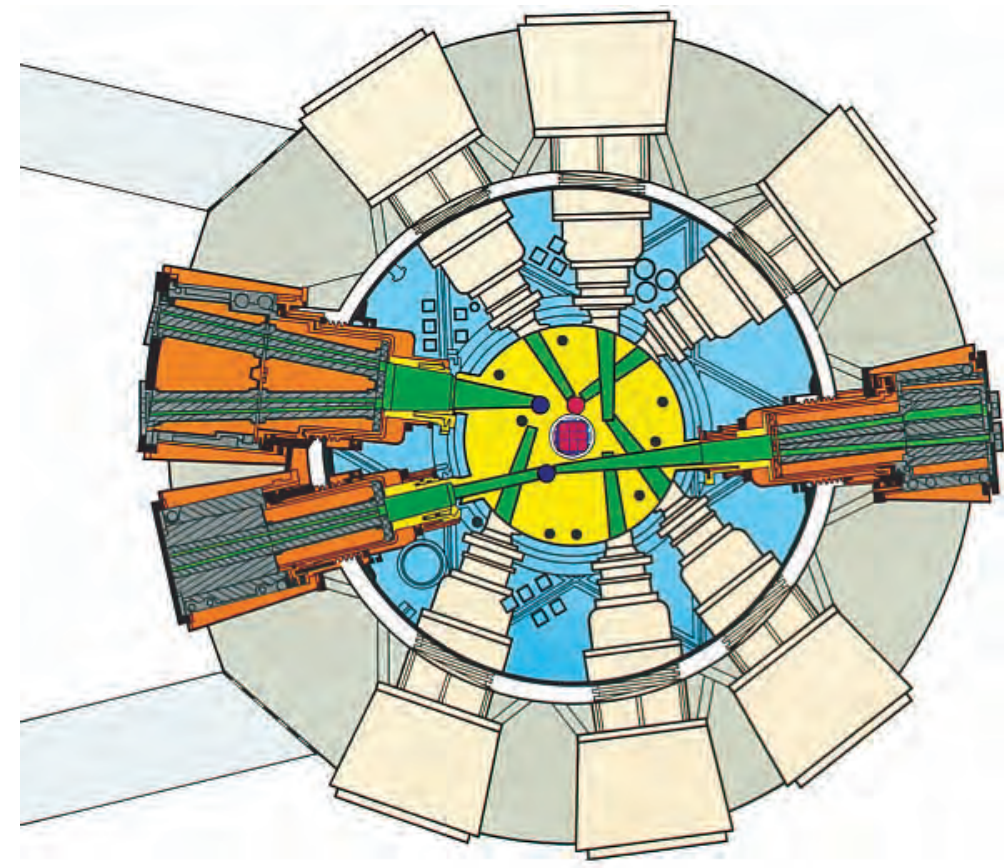

Figure 5.14. Horizontal cross-section of the ORPHEE reactor showing the nine beam tubes of the neutron channels. At the centre of the core, the red spots indicate the "cold sources" and the "hot source"; the heavy water is represented in yellow and the light water in blue. () CEA.

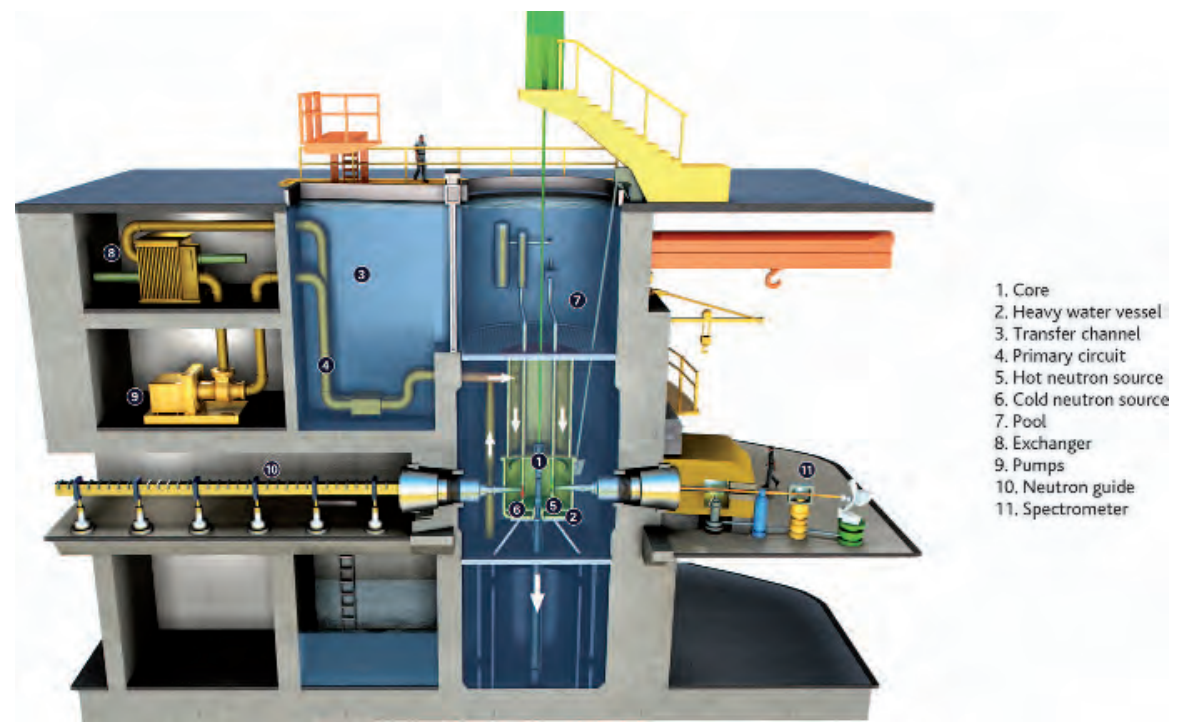

Figure 5.15. ORPHEE reactor: diagram of the reactor block, vertical section. ๑ CEA. 
highly enriched uranium (93\%), is cooled by light water circulating at a rate of $7.5 \mathrm{~m} / \mathrm{s}$. The assembly consisting of the reactor core and the heavy water vessel (made from stainless steel) is submerged in a light water pool.

The high flux reactor at Grenoble (RHF, figure 5.16), an international research facility, has 13 horizontal beam tubes, four inclined tubes and two vertical tubes (one of which is used for the startup neutron source). It can simultaneously deliver neutrons to around forty different experimental devices. Nine beam tubes are directed at two "cold sources" and four beam tubes are directed at the "hot source". The core of the RHF consists of a single annular fuel element containing curved fuel plates of highly enriched uranium (93\% of uranium-235). It is cooled with heavy water circulating at a rate of $5.5 \mathrm{~m} / \mathrm{s}$. It produces most intense neutron flux to date, of $1.5 \times 10^{15}$ neutrons. $\mathrm{cm}^{-2} . \mathrm{s}^{-1}$ (thermal neutron flux in the heavy water vessel). As with ORPHEE, the assembly consisting of the reactor core and the heavy water vessel (made from an aluminium alloy known as AG3NET in the case of the RHF) sit in a light water pool.

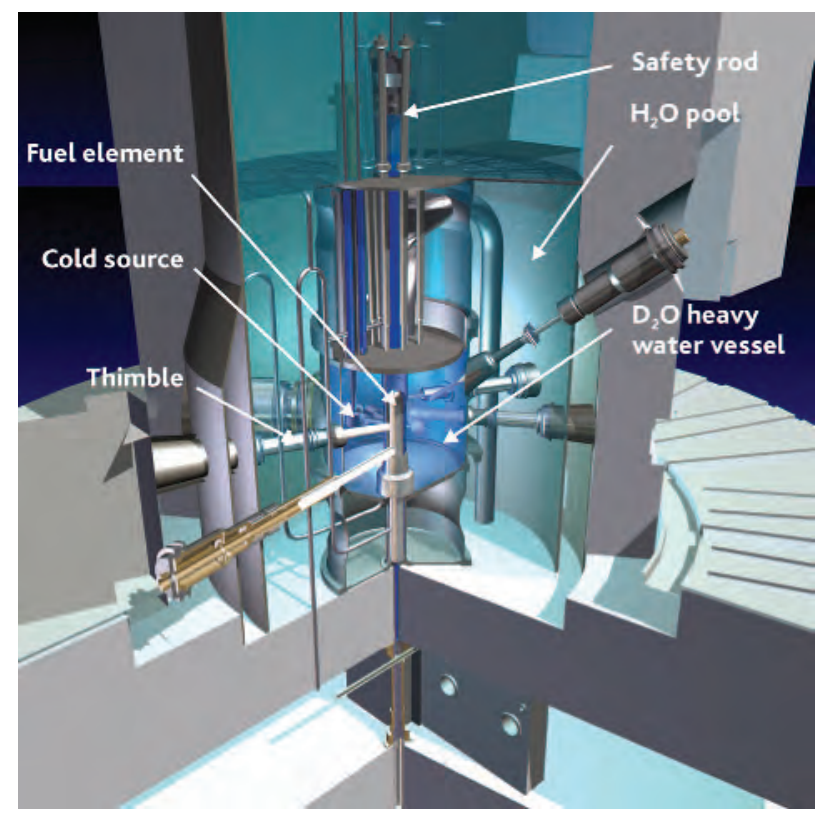

Figure 5.16. Diagram of the RHF. (C) ILL.

The heavy water detritiation facility, which used to be near the ILL, has been permanently shut down, so the operator has decided to contract out the detritiation of the heavy water to a Canadian company.

In 2016 France was still operating a research reactor dedicated entirely to safety testing, or more precisely to studying the behaviour of the fuel elements of light water nuclear power plants in certain accident situations. This was the CABRI reactor (figure 5.17), located at the CEA's Cadarache centre, which can be used to test a fresh or irradiated nuclear fuel sample under the conditions which would result from a 


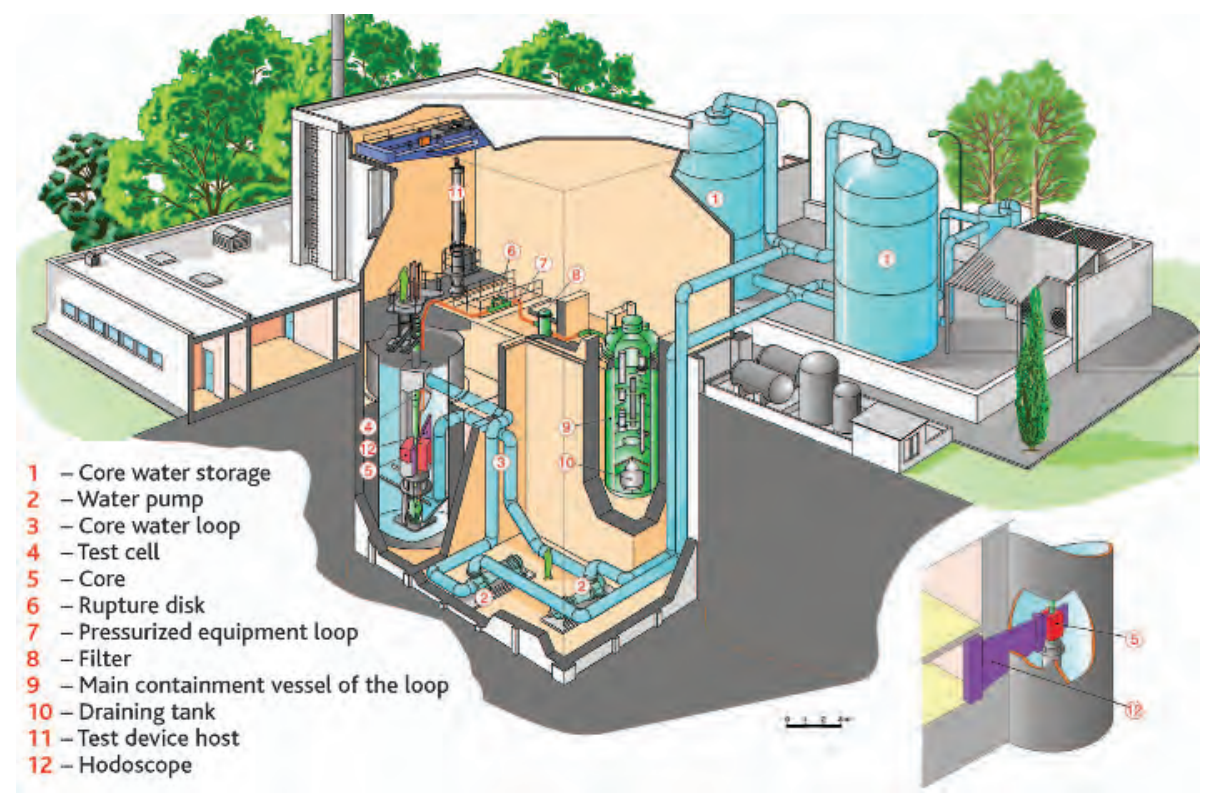

Figure 5.17. Diagram of the CABRI and its pressurized water test loop. @ DPAM/IRSN.

reactivity-initiated accident in a power reactor. The reactor consists of a driver core and an experimental loop. The part of the loop in the centre of the driver core holds the test device containing the fuel to be tested. The driver core supplies the neutron flux necessary to obtain the desired power in the fuel being tested, and the experimental loop makes it possible to apply thermohydraulic conditions representative of the conditions in a power reactor. A particular feature of this reactor is its controlled reactivity injection system. Instead of the last ring of fuel rods, four assemblies in the driver core are equipped with peripheral cylindrical tubes ${ }^{116}$, which are filled with pressurized helium-3 before the reactor is started (this gas is a good neutron-absorber). Once the reactor has reached nominal power and the required thermohydraulic conditions are obtained in the experimental loop, these tubes are depressurized by opening some valves in a specific sequence, which alters the reactivity ${ }^{117}$ and therefore the power delivered by the driver core. To study very rapid reactivity injections, it is possible to increase the power of the CABRI reactor from $100 \mathrm{~kW}$ to $20 \mathrm{GW}$ in a few milliseconds; the power then drops again as rapidly as it increased due to neutron feedback (in particular the Doppler effect).

In the past, the CABRI reactor had had a sodium loop, which was used for a number of different programmes until the $2000 \mathrm{~s}$ - not just for sodium-cooled fast neutron reactors but also for pressurized water reactors (REP-Na tests). This sodium loop was replaced by a pressurized water loop.

116. Also known as "transient rods".

117. As the gas disappears from the core, the number of neutrons in the core increases, causing more fissions. 
\#FOCUS.

\section{Some safety issues of nuclear power reactors explored with experimental programmes conducted at French research reactors}

Research reactors are essential tools for scientific and technological research and for supporting the development of nuclear power reactors. The experiments conducted in these reactors have helped to improve the safety of power reactors as regards accidents, through better knowledge of the phenomena involved.

The OSIRIS reactor has been used to study the behaviour of fuel cladding in pressurized water reactors subject to a slow pressure increase (slow power ramps of several tens of seconds to several minutes). These tests were carried out on sections of irradiated fuel rods and were used to establish limits for the use of different cladding materials.

Test programmes run at the CABRI reactor have studied the behaviour of fuel elements in power reactors in the event of the removal or ejection of neutronabsorbing elements from the cores of these reactors ${ }^{118}$.

From 1978 to 2001, the CABRI a reactor was used to study accidents involving inadvertent control rod withdrawal in sodium-cooled fast neutron reactors (SFRs), through (slow power ramp) tests conducted on single fuel pins ${ }^{119}$ in a sodium-filled loop. In particular, the risk of ejection of molten fuel from a pin with a pre-existing cladding defect was explored.

The SCARABEE reactor was also used from 1983 to 1989 to study, in a sodium loop of larger diameter than the CABRI loop, hypothetical accidents involving the blockage or melting of fuel assemblies in an SFR. The tests were conducted on small assemblies of up to 37 pins.

The sodium loop in the CABRI reactor was also used to study the behaviour of fuel rods in pressurized water reactors (PWRs) under neutron-absorbing rod cluster control assembly ejection conditions. This type of accident assumes that the cluster mechanism has ruptured. Ejection is caused by the pressure difference between the reactor coolant system and the containment vessel. This violent ejection causes a local runaway effect in the nuclear reaction for several tens of milliseconds (power pulse), leading to a rapid increase in fuel temperature. Neutron feedback limits the power transient before reactor scram, which occurs in a second phase. The sudden heating of the fuel pellets during the power pulse causes them to expand rapidly and, in some cases, to release the fission gases in the fuel. Subject to these stresses, the rod cladding can break up, releasing extremely hot fuel

118. See the publication "Current State of Research on Pressurized Water Reactor Safety", Science and Technology Series, IRSN/EDP Sciences, 2017.

119. Term used for SFRs. For PWRs, the term "rod" is used. 
fragments. For pressurized water reactors, criteria were set in the 1970 s based on the results of the SPERT tests ${ }^{120}$ conducted in the USA on fresh or lightly irradiated fuel. The tests conducted in the CABRI reactor in the 1990s (and at the NSRR reactor in Japan) on sections of industrial fuel rod pre-irradiated in pressurized water reactors studied the mechanical phenomena that occur during the first tens of milliseconds of the power excursion, when the cladding temperature is not really affected. These were known as the REP-Na tests, and in particular they included a test on MOX fuel ${ }^{121}$ that had reached a burnup of $55 \mathrm{GWd} / \mathrm{tU}$, and a test with a rod clad with a new alloy known as M5 ${ }^{\circledR}$.

To study phenomena that occur after the first few milliseconds (drying and swelling of the cladding), and the consequences in terms of a pressure wave of any dispersion of fuel in the coolant, IRSN has planned further tests in the CABRI reactor's pressurized water loop - this is the OECD ${ }^{122} /$ NEA project known as the Cabri International Programme (CIP), conducted in partnership with EDF and many foreign safety organizations and companies.

The PHEBUS reactor has made a major contribution to the acquisition of knowledge about the physics of accidents that can lead to partial or total core melt in a PWR ${ }^{123}$. The international Phebus-FP programme (FP for fission products), run by IRSN, has made it possible to simulate core melt on a small scale. The main aim of this programme was to contribute to improving knowledge of the radioactive releases that can occur in the environment during this type of accident. Five tests were conducted for this purpose from 1993 to 2004 in an experimental device installed in the PHEBUS reactor. These tests aimed to reproduce the main physical phenomena that could govern core melt in a pressurized water reactor and the transfer of radioactive substances from the nuclear fuel into the containment vessel. The experimental device (figure 5.18), which was used to simulate the core, the reactor primary coolant syste and the containment vessel, consisted of an in-pile part, passing into the core of the PHEBUS reactor, and an out-of-pile part known as the "FP container". The fuel used in the experiment, which was first irradiated in a research reactor or power reactor, was inserted into the in-pile part of the device. More than 200 measurement sensors and around 100 sampling devices constituted the test instrumentation. Following operation of the PHEBUS reactor at power to recreate short-lived fission products such as iodine-131 in the test assembly, the power was reduced and cooling of the test assembly was stopped. The test fuel then heated up rapidly until it melted. The fission products released by the fuel cladding were then guided into the FP container. The experiments carried out provided important data for understanding the mechanisms of core degradation in a PWR and the behaviour of the fission products released in the circuits. These tests also

120. SPERT (Special Power Excursion Reactor Test) is the name given to power excursion research reactors at the Idaho Falls research centre in the USA.

121. Mixed Oxide Fuel (mixed $\mathrm{UO}_{2}+\mathrm{PuO}_{2}$ fuel).

122. Organisation for Economic Co-operation and Development.

123. See the publication "Current State of Research on Pressurized Water Reactor Safety", Science and Technology Series, IRSN/EDP Sciences, 2017, and the publication "Nuclear Power Reactor Core Melt Accidents - Current State of Knowledge", Science and Technology Series, IRSN/EDP Sciences, 2013. 


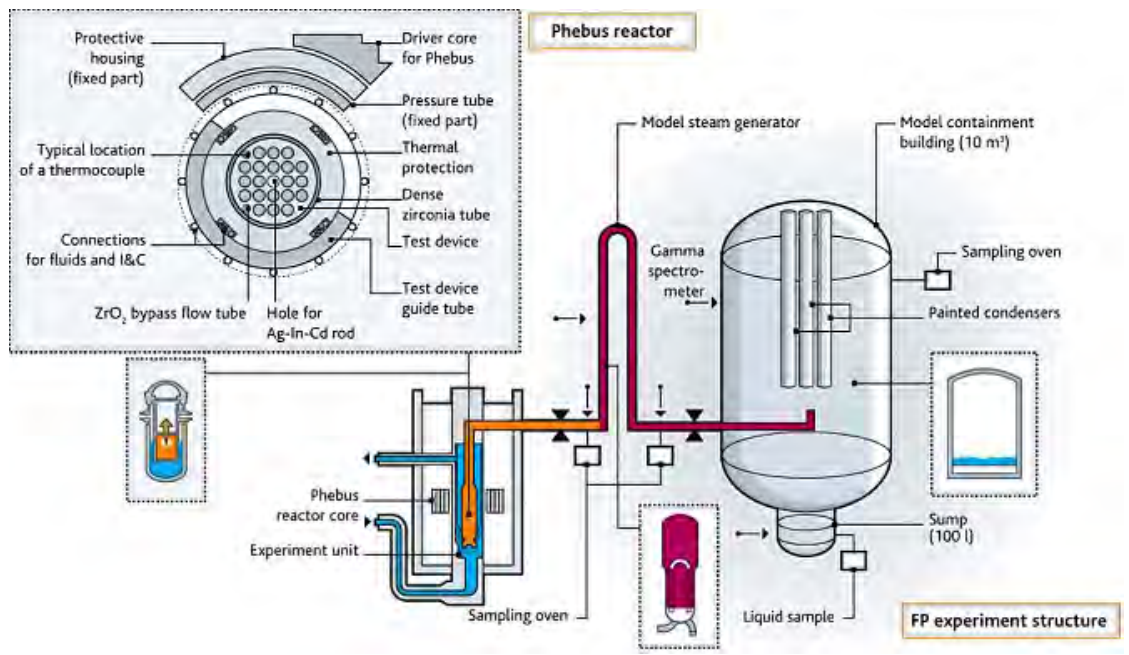

Figure 5.18. Diagram of the Phebus-FP facility. (C) Stéphane Jungers/IRSN -Source IRSN.

confirmed knowledge already acquired in laboratory experiments and helped to improve and validate several codes for simulating core melt accidents developed and used throughout the world, including some used by IRSN for its safety assessments or level 2 probabilistic safety analyses (ASTEC ${ }^{124}$ software).

124. Accident Source Term Evaluation Code (system of simulation codes for evaluating the physical phenomena occurring during a core melt accident in a pressurized water reactor). 


\section{Chapter 6 Stakeholders and organization of research reactor safety in France}

The organization of safety in France has changed over time. While the intention is not to provide a complete history of the organization of safety ${ }^{125}$ in this chapter, some of the aspects most relevant to a publication specifically about research reactor safety are nevertheless worth mentioning.

The organization of safety originally relied on the French Atomic Energy Commission (CEA), which was given responsibility when it was created in 1945 for developing all necessary aspects of the use of this type of energy - in particular by building and operating research reactors. However, a decree was passed in 1973 setting up a special safety body, the SCSIN (Service central de sûreté des installations nucléaires), within the Ministry of Industry. This body underwent a number of changes and had various different names at different times, but it eventually finished up with the creation in 2006 of an independent authority, the French Nuclear Safety Authority (Autorité de sûreté nucléaire, or ASN).

In addition, the part of the CEA concerned particularly with safety and radiological protection research and assessment was turned into a separate institute, the Institute for Protection and Nuclear Safety (IPSN), in 1976. The IPSN is the forerunner of the IRSN, created in 2002, which is now independent of the CEA and includes the Office for Protection against lonizing Radiation (OPRI), previously under the authority of the Ministry of Health.

125. For this, see the work by Philippe Saint Raymond entitled "Une longue marche vers l'indépendance et la transparence - Histoire de l'Autorité de sûreté nucléaire française", La documentation française, 2012. 


\subsection{Operators}

The organization of safety in France - obviously in line with the principles and recommendations issued by international organizations like the IAEA - takes account of specific national factors. France's largest nuclear facilities are operated by large organizations: Électricité de France (EDF) for power reactors, Cogéma, once part of AREVA (now Orano), for most fuel cycle facilities, and the CEA for most research reactors (and other facilities), the exception being the Institut Laue-Langevin (ILL), an international body, which operates the RHF at Grenoble.

French operators are therefore much less fragmented than in most other countries and generally participate in the design of their facilities. They consequently have a particularly high level of expertise. The CEA also has specific scientific and technical expertise in fields related to nuclear safety, particularly through its heavy involvement in research and development programmes in this area.

A fundamental principle, promoted in IAEA documents, is that operators are responsible for the safety of their facilities, because only they can take the practical action that directly influences safety. In French regulations, this principle is set out in the Environment Code (Article L. 593-6): "The operator of a nuclear facility is responsible for controlling the risks and drawbacks presented by its facilities".

However, operators must provide evidence of this to the public authorities responsible for protecting people and property throughout France. This evidence must be provided in the form of binding written documents sent to the ASN, containing the operators' own analyses. Operators may also have to provide any further details or information considered necessary, in an appropriate form, in the context of inspections carried out by the ASN, assessments by IRSN or meetings with the standing groups of experts commissioned by the ASN, or at meetings of local information commissions $\left(\mathrm{CLI}^{126}\right)$ or the national association of local information commissions (ANCCLI $\left.{ }^{127}\right)$.

Moreover, in accordance with the Act on nuclear security and transparency adopted in 2006 (known as the TSN Act - see section 6.2), all operators of basic nuclear installations must produce a report each year stating:

- "the nuclear safety and radiological protection measures taken;

- nuclear safety and radiological protection incidents and accidents subject to the reporting obligation (...) that have occurred at the installation, as well as the measures taken to limit their development and mitigate the consequences for human health and the environment;

- the nature and results of measurements of radioactive and non-radioactive releases from the installation into the environment;

- the nature and quantity of radioactive waste stored at the installation site, and the measures taken to limit the volume and effects of the waste on health and on the environment, especially soil and water".

126. Commission locale d'information in French.

127. Association nationale des comités et commissions locales d'information in French. 
This report is made public and a copy is sent to the local information commission and to the High Committee for Transparency and Information on Nuclear Security (HCTISN ${ }^{128}$ ).

The roles of the ASN, the IRSN and the standing groups of experts are briefly explained in the next section.

\subsection{Control of nuclear risks in France}

As explained in previous chapters, research reactors can vary greatly in terms of utilization, technical characteristics and operating procedures. However, all research reactors are categorized as basic nuclear installations $\left(\mathrm{INB}^{129}\right)$ and are therefore subject to the regulatory requirements applicable to all INBs.

The adoption of Act No 2006-686 of 13 June 2006 on nuclear security and transparency (known as the TSN ${ }^{130} \mathrm{Act}$ ) has been the most significant change in recent years to the institutional and legal framework applicable to basic nuclear installations. Specifically, the TSN Act set up, for civil-related facilities and activities, an independent administrative authority, the French Nuclear Safety Authority (ASN). The Act sets out the general principles governing nuclear activities (in addition to the principle of the operator having prime responsibility, there are other such as the precautionary principle, the preventive action principle, the "polluter pays" principle, etc., which are briefly explained in the focus section below). More recently, the Act on energy transition for green growth (TECV ${ }^{131}$ Act No 2015-992 of 17 August 2015) strengthened some aspects of the TSN Act, particularly as regards transparency and public information, management of subcontracting at INBs, and permanent shutdown and dismantling of INBs.

\section{\#FOCUS \\ The principles of nuclear safety, radiological protection and environmental protection in France ${ }^{132}$}

Nuclear activities must be carried out in compliance with the fundamental principles set out in law and in international standards. In particular:

- in France, the principles set out in the Environmental Charter attached to the Constitution, and in different codes (Environment Code, Public Health Code, etc.);

128. Haut Comité pour la transparence et l'information sur la sécurité nucléaire in French.

129. Installations nucléaires de base in French.

130. Now codified in the French Environment Code.

131. Transition énergétique pour la croissance verte in French.

132. According to the ASN's publication "The principles and stakeholders in nuclear safety regulation, radiation protection and protection of the environment". 
- at European level, the rules defined by directives establishing a Community framework for the safety of nuclear facilities and for the responsible and safe management of spent fuel and radioactive waste;

- at international level, the fundamental safety principles established by the IAEA and implemented under the Convention on Nuclear Safety, which establishes the international framework for nuclear safety regulation and radiological protection.

There is significant overlap between these different measures. They can be summarised in the form of eight principles, as follows:

\section{- Principle of prime responsibility of the operator}

This principle was presented in section 6.1.

- "Polluter pays" principle

The "polluter pays" principle is the adaptation of the principle of prime responsibility of the operator to the terms of the Environment Code, namely that the polluter responsible for environmental damage must bear the cost of measures to prevent and reduce pollution.

- Prevention principle (or principle of preventive action or rectification at source)

The prevention principle requires the implementation of rules and actions to anticipate environmental damage, which must take account of the best available techniques at an economically acceptable cost.

\section{- Participation principle}

The participation principle requires public participation in decision-making by the public authorities; it stems directly from the Aarhus Convention. In the nuclear field, the practical expression of this principle is the organization of national public debates, which are mandatory prior to the construction of a nuclear power plant, for example, and public inquiries, especially during the examination of licence applications to construct or dismantle nuclear facilities.

\section{- Precautionary principle}

Under the precautionary principle, a lack of certainty in view of current scientific and technical knowledge should not delay the adoption of environmental protection measures. It is defined in the Environmental Charter as follows: "Where there is the possibility of severe and irreversible damage to the environment, even though this is not a certainty given the current state of scientific knowledge, the public authorities shall ensure, by applying the precautionary principle in the areas within their remit, that procedures are followed to assess the risks and that provisional, proportionate measures are taken to prevent the damage". As regards the biological effects of small doses of ionizing radiation and low dose rates, the precautionary principle assumes that the relationship between dose and effect is linear, with no threshold. 


\section{- Justification principle}

The Public Health Code states that "a nuclear activity or operation may be performed only if it is justified by the advantages it provides, especially for health, society, the economy, or science, compared to the risks it may pose of exposure of persons to ionizing radiation".

- Optimization principle

The Public Health Code states that "exposure of persons to ionizing radiation resulting from a nuclear activity or operation must be kept to the lowest level that can reasonably be achieved, taking account of technical, economic and social factors, and, where relevant, the medical objective sought". This principle, also known as the ALARA principle, can for example, in the case of discharge permits, lead to the permitted quantities of radionuclides in radioactive effluent discharged by nuclear facilities being reduced, can mean that exposure monitoring at workstations is required to keep exposure to the level strictly necessary, and can mean monitoring is necessary to ensure medical exposure due to diagnostic procedures remains within pre-established reference levels.

- Dose limitation principle

The Public Health Code states that "the exposure of a person to ionizing radiation resulting from a nuclear activity may not cause the sum of received doses to exceed regulatory limits, except when the exposure is for medical or biomedical research purposes". There are strict limits on exposure of the general population or workers due to nuclear activities. These limits include wide safety margins to prevent effects on health. They are also well below the doses for which probabilistic effects (cancer) begin to be observed. Exceeding these limits is considered to be unacceptable. In France it can lead to administrative or criminal sanctions. In the case of medical exposure, no strict dose limit is set since this deliberate exposure is justified by the expected health benefit for the exposed person.

According to Article 1 of the TSN Act, nuclear security encompasses nuclear safety, radiological protection, prevention of and protection from malicious acts, as well as civil protection in the event of an accident. The requirements for basic nuclear installations, from construction to permanent shutdown and dismantling, are laid down by the 2007 "INB procedures" decree ${ }^{133}$ (and the 2016 amending decree ${ }^{134}$ ) and the order of 7 February 2012 setting general rules for basic nuclear installations, known as the "INB" order. This order - which entered into force on 1 July 2013 - has gradually been supplemented by the ASN's regulatory decisions on particular generic issues. These constitute the regulatory basis applicable to all INBs.

133. Decree $N^{\circ} 2007-1557$ of 2 November 2007 on basic nuclear installations and on the control, as regards nuclear security, of the transport of radioactive substances.

134. Decree $\mathrm{N}^{\circ} \mathbf{2 0 1 6 - 8 4 6}$ of 28 June 2016 on the modification, permanent shutdown and dismantling of basic nuclear installations and on subcontracting. 
Between 1980 and 1992, 40 "fundamental safety rules" (RFS ${ }^{135}$ ) were established in France on different topics and different types of INB. The purpose of these rules was to set out the conditions be met by a particular type of facility for it to be considered compliant with French technical regulatory practice, while giving the operator (and the designer) the option of non-compliance if it could justify that the safety objectives were met by other means. Further texts of a similar nature are being produced, known as "ASN Guides "136".

Two fundamental safety rules ${ }^{137}$ specific to research reactors were established in the 1980s and 1990s. They were:

- the fundamental safety rule SIN N C-12308/86 (RR1) of 4 August 1986, on purification equipment in research reactor ventilation systems. Because research reactors are facilities with one or more vessels kept under negative pressure by ventilation circuits providing "dynamic" confinement, the rule sets out a number of recommendations for the implementation of devices to filter and purify the air: high efficiency particulate air (HEPA) filters to trap the aerosols, and iodine filters $\left(\mathrm{PAI}^{138}\right)$ consisting of solid adsorbent materials ${ }^{139}$. These recommendations concern the design, implementation, installation and assembly, efficiency and use of this equipment, especially as regards in-service inspection. In particular the rule states that PAls must be preceded, where relevant, by systems that rapidly reduce the relative humidity of the gases to be purified so that the efficiency of these filters is acceptable at first use.

- the fundamental safety rule SIN No C-12670/91 (RR2) of 1 July 1991 on protection against fire risks at research reactors. ASN Decision No 2014-DC-0417 of 28 January 2014, supplementing the "INB" order, sets out the requirements for controlling fire risks at basic nuclear installations; the safety approach followed by this Decision is explained in section 7.4.1.

\section{\#FOCUS}

\section{Pyramid of official texts applicable in France to basic nuclear installations}

The pyramid of official texts applicable in France to INBs is shown in figure 6.1 below.

- Laws

A law (Act) is a written rule, generally passed by parliament (National Assembly and Senate) following legislative procedure. A law can be

135. Règles fondamentales de sûreté in French.

136. More than thirty ASN Guides were in existence as at mid-2018.

137. "Législation et règlementation, Sûreté nucléaire en France", Les Journaux officiels, May 1999.

138. Pièges à iode in French.

139. Such as activated carbon. 


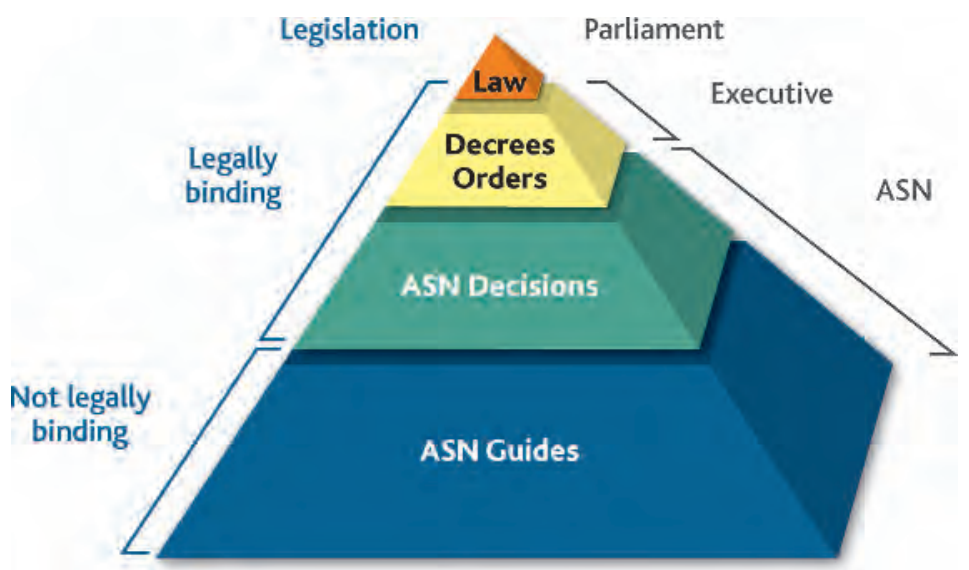

Figure 6.1. Diagram showing the pyramid of official texts applicable to INBs. C) Georges Goué/ IRSN.

adopted on the initiative of parliament (proposition de loi) or of the government (projet de loi). Once it has been promulgated by presidential decree, everyone must abide by it. Before it is promulgated, it may be put through a test of its constitutionality by the Constitutional Council.

- Decrees

A decree is a regulatory act signed either by the French President or by the Prime Minister. Some decrees (décrets en Conseil d'État) can only be enacted after consulting the Conseil d'État. Decrees are often adopted in application of a law. They may be supplemented by ministerial orders.

- Orders

An order (arrêté) is an administrative decision which is either general or specific (to a sector or geographical area) in scope. Orders can be issued by ministers (ministerial or interministerial orders), prefects (prefectoral orders) or mayors (municipal orders).

- ASN Decisions

Act No 2006-686 of 13 June 2006 (TSN Act) lists the different categories of regulatory and individual decisions that the ASN takes, for example:

- regulatory decisions of a technical nature for the application of decrees or orders on nuclear safety and radiological protection,

- commissioning licences for INBs,

- permits and approvals for the transportation of radioactive materials or for medical facilities and equipment using ionizing radiation.

\section{- ASN Guides}

In replacement of the fundamental safety rules, the ASN Guides are documents for use by professionals affected by nuclear safety and 
radiological protection regulations (designers, operators, users or transporters of radioactive materials, health professionals). They aim to:

- explain a regulation and the rights and obligations of persons concerned by the regulation;

- explain the objectives of the regulation and where necessary describe the practices which the ASN considers satisfactory;

- provide practical and useful information on nuclear safety and radiological protection.

The equipment in research reactors may be subject to French regulations on pressure equipment, especially the order of 30 December 2015 on nuclear pressure equipment (known as the "ESPN ${ }^{140 "}$ order). This order lays down a number of requirements, classifying equipment:

- according to levels (three levels, N1, N2 and N3, in descending order of the radioactive emissions that could result from their failure);

- and categories (five categories, 0, I, II, III and IV, in ascending order of other risks, particularly those associated with the volume and pressure of the fluids they contain).

Fixed equipment in research reactors and experimental devices (e.g. pressurized loops) may be subject to the provisions of this order. This will not be discussed further in this report ${ }^{141}$.

As stated earlier, the operator of an INB has prime responsibility for the safety of the facility and must provide evidence that the measures taken to ensure the facility's safety are appropriate (the safety demonstration). This evidence is presented in a set of documents, which are used by the public authorities to decide whether or not to grant licences for the operation of facilities. These documents are:

- the safety report, which describes the facility and specifies the design of its systems, structures and components and existing or planned measures to prevent incidents and accidents and to limit the consequences of any incidents or accidents that do occur;

- the general operating rules ( $R G E^{142}$ ), an operational document setting out the operating procedures, which must be consistent with the evidence presented in the safety report;

140. Équipements sous pression nucléaires in French.

141. However, please see the comprehensive paper in the journal Contrôle No. 186 from 2010, entitled "Les équipements sous pression nucléaires dans les réacteurs de recherche" by F. Koskas, P. Trémodeux, D. Bourguignon, J. Reuchet and D. Acker, CEA. Most equipment items in research reactors subject to the "ESPN" order are classified as N2 or N3.

142. Règles générales d'exploitation in French. 
- the impact study justifying existing or planned measures to limit the impact of normal operation of the facility on the public and the environment;

- the on-site emergency plan (PUI ${ }^{143}$ ), which describes the specific organization, resources and actions to be implemented by the operator in the event of an accident affecting the facility that could cause radioactive substances (or chemicals) to be released into the environment;

- the decommissioning plan, which explains the general measures put in place by the operator with a view to the permanent shutdown and dismantling of the facility.

In addition, the ASN can, under conditions clearly defined by regulatory decision, place specific requirements on the operator related to the safety of the facility, or if there are risks considered to be serious and possibly imminent, it can even suspend ${ }^{144}$ the operation of a facility temporarily on a precautionary basis (for example, a decision $^{145}$ was taken in October 2009 to partially suspend the operation of the plutonium technology facility (ATPu ${ }^{146}$ ) at Cadarache).

The safety documents for INBs produced by the operators are examined by the ASN, which regularly seeks technical advice in this context from IRSN or, for the most important issues, from the standing groups of experts.

\section{IRSN}

Within the French system, IRSN has the status of an industrial and commercial public undertaking (EPIC ${ }^{147}$ ) and its missions are laid down in Decree No 2002-254 of 22 February 2002, then in Decree No 2016-283 of 10 March 2016. The TECV Act mentioned above, which was promulgated on 17 August 2015, laid the foundations of the "dual system" of two independent bodies, the ASN and IRSN, and wrote IRSN's missions into the Environment Code.

IRSN is supervised by the five ministries responsible for the environment, industry, research, defence and health. It is the main expert in nuclear and radiological risks for both civil and defence facilities and activities. It assesses exposure of humans and the environment to ionizing radiation and proposes measures to protect the population in the event of an accident. It contributes to public policy on nuclear safety and on health and environmental protection against ionizing radiation, as it did when the TECV Act was being prepared.

Its nuclear safety expertise is based on scientific and technical knowledge; for this purpose, IRSN devotes significant resources to:

- monitoring and analysing experience feedback from events in France and elsewhere in the world;

143. Plan d'urgence interne in French.

144. In "procedures" decree no. 2007-1557 of 2 November 2007.

145. Decision No. 2009-DC-160 of 14 October 2009.

146. Atelier de technologie du plutonium in French.

147. Établissement public à caractère industriel et commercial in French. 
- studies and research and development ${ }^{148}$, including the development of simulation software.

Research requiring major resources is carried out in collaboration with other partners, in various contexts (national, European, international), sometimes with the involvement of universities or the CNRS.

IRSN employs around 1,700 people of whom 1,200 are general and specialist researchers and experts (in mechanics, criticality and neutronics, thermohydraulics, statistics and probability, fire, earth sciences, medicine, biology, agronomy, metrology, etc.) spread across nine sites.

IRSN also takes part in public debates and seminars organized by local information commissions and by ANCCLI - and by the Information Commission ( $\mathrm{CI}$ ) in the case of defence-related nuclear facilities.

At the request of the relevant authority (ASN, or DSND for defence-related facilities), IRSN examines the files submitted by the operators and gives the authority its opinions and recommendations. IRSN's expertise provides valuable support for decision-making; it finds information corresponding to the best state of technical or scientific knowledge in situations where the decision-maker is confronted with issues for which it cannot immediately provide a response.

In the context of the ASN/IRSN "dual system", the TECV Act placed an obligation on IRSN to publish all its expert opinions immediately, before ASN had stated its position.

IRSN's role has a regulatory context but does not simply amount to verifying compliance with regulations. It consists of providing technical clarity as a result of a technical dialogue with the operators. This clarity is based on its wide-ranging and in-depth technical and scientific knowledge - which comes from experience feedback, studies and research -, detailed analysis of data, and the ability to synthesise different specialist contributions. To give an opinion, different components of an overarching problem need to be taken into account, and sometimes these may at first seem irreconcilable. Through the diversity of its expertise, IRSN is able to integrate these different components in its opinions.

Technical dialogue with operators is essential, partly to confirm IRSN's experts' understanding of the safety and radiological protection issues presented in documents submitted by the operators, and partly to avoid a drift towards the submission of applications with no technical or operational substance. Technical dialogue is also a way of sharing safety concerns with operators.

\section{- Standing groups of experts}

Where required by some safety or radiological protection issues, the ASN relies on the support of advisory committees, set up in 1972 and renewed a number of times,

148. The publication "Current State of Research on Pressurized Water Reactor Safety", Science and Technology Series, IRSN/EDP Sciences, 2017, presents some of the research and development in which IRSN is involved - and has been for more than 40 years in some cases. 
named standing groups of experts. There are eight standing groups ${ }^{149}$ of experts (GPEs), each with its own area of expertise (nuclear reactors [GPR], transport [GPT], laboratories and plants [GPU], radiological protection of workers and the public [GPRAD], radiological protection of health professionals, patients and the public for medical applications of ionizing radiation (including industrial applications and research) [GPMED], waste [GPD], nuclear pressure equipment [GPESPN] and - a new one in 2018 - dismantling [GPDEM]).

The standing group members are appointed on the basis of their individual expertise. They come from universities and expert bodies, particularly IRSN, designers (AREVA-NP then Framatome, etc.), operators (EDF, CEA, AREVA-NC then Orano, etc.) and research bodies (CEA, etc.) in the relevant areas. Since June 2014, the broad representation in these standing groups has been enhanced by the presence of representatives from civil society (members of CLIs, representatives of NGOs, etc.). Each standing group of experts can also seek assistance from anyone (in France or elsewhere) with recognised expertise in specific areas.

For each of the issues dealt with, the standing group of experts' discussions are usually based on assessments conducted in advance by IRSN or by the Nuclear Pressure Equipment Department (DEP ${ }^{150}$ ) in the case of the GPESPN, and presented by them. They formally record the conclusions of their examinations in opinions and recommendations sent to the ASN office that referred the matter to them. The standing groups' opinions to the ASN are made public.

The standing groups of experts to which issues related to research reactors are referred are:

- most often, the standing groups of experts for nuclear reactors (GPR),

- the standing groups of experts for nuclear pressure equipment (GPESPN),

- the standing groups of experts for laboratories and plants (GPU) concerning the overall management of safety and radiological protection within CEA or the permanent shutdown and dismantling of reactors (in association with the GPR).

\subsection{Key stages in the life of a research reactor}

From an administrative point of view, the key stages in the life of a research reactor are similar to those for the power plants in the French fleet. Schematically, these key stages correspond to the following types of licence or prescription ("procedures" decree):

- the initial construction licence issued by decree on the basis of a set of documents including, among other things, an impact study, a preliminary version

149. Groupe permanent d'experts in French of réacteurs (GPR), transport (GPT), usines (GPU), radioprotection des travailleurs et du public (GPRAD), radioprotection dans les applications médicales (GPMED), déchets (GPD, équipements sous pression nucléaire (GPESPN) and démantèlement (GPDEM).

150. Direction des équipements sous pression in French. 
of the safety report, and a risk control report presented in an appropriate form for local consultations and the public inquiry;

- the commissioning licence issued by the ASN on the basis, in particular, of an updated version of the safety report, a summary report of the facility startup tests, etc.;

- the decommissioning "prescription" issued by decree, following a public inquiry, on the basis of a special set of documents including the updated decommissioning plan, the impact study and the updated safety report and general surveillance and maintenance rules $\left(\operatorname{RGSE}^{151}\right)$.

Because substantial modifications may be made to the design or utilization of a research reactor during its operating life (e.g. new experimental programmes), specific licences may be necessary, possibly including amendments by decree to the original construction licence decree.

These substantial modifications may cause the research reactor to spend periods on "standby". Under French regulations, a new licence issued by decree is required if the operation of an INB is interrupted for more than two years ${ }^{152}$. Special requirements may be imposed for periods on standby, such as the requirement for a minimum number of personnel to be present to carry out appropriate surveillance, and periodic tests and inspections at suitable frequencies.

For new INBs, the submission of a "safety options report" has become common practice. In the case of research reactors, it can apply not only to new reactor projects (e.g. the Jules Horowitz reactor) but also to large-scale modifications to reactors in service (such as the renewal of the CABRI reactor with installation of the pressurized water loop).

Finally, the obligation to carry out periodic safety reviews of their facilities (in practice every 10 years), stipulated in the TSN Act, applies to research reactor operators. From the point of view of documentation, there are two major milestones in a periodic safety review, involving not only the operator, but also the ASN and experts (IRSN, advisory committees):

- the submission by the operator of a safety review preparation file specifying the perimeter and scale of the compliance review and safety reassessment that it plans to carry out (see section 9.2);

- once the examinations and the safety reassessment studies are complete, the submission by the operator of a report presenting its conclusions including, where necessary, the changes it plans to make in order to improve safety at the facility.

151. Règles générales de surveillance et d'entretien in French.

152. However, as a result of the adoption of the TECV Act No 2015-992 of 17 August 2015, Article L 593-24 of the Environment Code states that "if a basic nuclear installation ceases to operate for a continuous period of more than two years, it is deemed to have been permanently shut down, but the minister responsible for nuclear safety may, at the operator's request, extend this twoyear period by a maximum of three years, by means of an order explaining the grounds for this extension, having first sought the ASN's opinion. At the end of the period stipulated in the first paragraph of this Article, the facility operator is no longer permitted to operate the facility...". 


\subsection{Internal licensing scheme}

Decree No 2007-1557 of 2 November 2007 (the "procedures" decree) introduced the possibility for INB operators to set up an internal licensing scheme enabling them to dispense with reporting to the ASN some minor modifications to their facilities or their general operating rules. The operator must make an application to do this, showing that it has an internal control system and presenting sufficient guarantees of quality, independence and transparency, and must obtain the ASN's approval for the scheme, specifying:

- the type of modifications or operations to be handled in this way;

- the process used to approve the operations, in particular with automatic notification, prior to any operation, of a body that is independent of the persons in charge of the operation;

- the identities of the persons authorised to issue internal licences;

- the procedures for periodically reporting to the ASN on the operations planned or performed.

The requirements applicable to a scheme of this kind were subsequently clarified by the ASN in 2008 in its Decision No. 2008-DC-0106 of 11 July 2008.

For example, the internal licensing scheme proposed by the CEA was approved in 2010. The corresponding decision ${ }^{153}$ listed the INBs concerned, the type of modifications that could not be licensed internally, and the criteria to be met for a modification to be eligible for internal licensing. Most of the CEA's research reactors are on the list of facilities for which the internal licensing scheme approved in 2010 can be used.

As part of this, the CEA sends the ASN, every six months, a provisional programme of operations likely to be internally licensed in the coming year, giving its justification for the approval of these operations by the internal licensing scheme. These programmes are examined by IRSN, which can express reservations to the ASN regarding the rationale for using the internal licensing scheme or regarding the measures planned by the operator in question.

More recently, Decree $n^{\circ} 2016-846$ of 28 June 2016, which amends several aspects of the "procedures" decree (modification, permanent shutdown and dismantling of INBs, use of subcontracting), introduced two regimes for all INB operators:

- a "reporting regime" for minor modifications (obviously ones that do not have an impact on the safety report or the impact study for the facility), a list of which is given in an ASN decision, taking account of the type of facility and the scale of the risks and drawbacks it presents, the operator's technical capabilities and the internal control measures it has implemented in preparation for these modifications;

- a "licensing regime" for other modifications.

153. ASN Decision No. 2010-DC-0178 of 16 March 2010. 



\section{Chapter 7 Safety principles for French research reactors}

\subsection{General safety principles, concepts, approaches and objectives}

This chapter presents the general safety principles, concepts, approaches and objectives that have guided the design and operation of French research reactors. It also highlights changes that have been made over time, which have generally brought practices into line with those adopted for nuclear power reactors, including those of the European Pressurised Water Reactor (EPR). Several features specific to research reactors will be covered, including the most important, which involves taking into account core melt accidents in the design of some French research reactors in the 1960s.

The nuclear safety and radiological protection measures adopted for the design and operation of nuclear power or research reactors must limit the number of incidents, the potential occurrence of accidents and meet the fundamental safety objective as stated in IAEA document SF-1, which is to "protect people and the environment from harmful effects of ionizing radiation". This objective is of course entrenched in French law, and specifically in the Public Health Code (Article L. 1333-1) and in the Environmental Code (Article L. 110-1).

Design principles focus on various aspects, including the intrinsic characteristics of the reactor (e.g. core neutronics), the general architecture of systems, material redundancy and diversification, protection against internal and external hazards, radiological protection systems, the choice of coolants used and the effluent management and 
treatment measures, the choice of materials, etc. Beneficial feedback can be capitalised on by adopting proven practices for the design and manufacture of equipment. It is also important to adopt the best available techniques ${ }^{154}$ such as can be applied to the facility in question.

Document SF-1 and, in France, the abovementioned texts, the French Act on nuclear security and transparency (TSN) and the Order setting general rules regarding basic nuclear installations, also state a number of major principles, such as the primary responsibility of the operator to prevent accidents and limit their consequences should they occur, introducing the "defence in depth" principle.

The abovementioned fundamental objective is generally broken down into general safety objectives that are expressed in a qualitative manner for the various events studied for a facility, based on their estimated frequency of occurrence. For the Jules Horowitz Reactor project, these objectives were set basically in keeping with those adopted for the EPR. Therefore, for the most frequently foreseeable incidents, their consequences must not require any counter measures for the public and the environment, and also remain within the authorised limits for gaseous and liquid discharges. For the most serious accidents studied involving core meltdown, their consequences in terms of the extent and duration must only require very limited counter measures to protect the public and the environment (no permanent relocation, no emergency evacuation beyond the facility's immediate vicinity, limited sheltering, etc.). In other words ${ }^{155}$, the following must be avoided:

- early radioactive releases that would require off-site emergency measures but with insufficient time to implement them;

- large radioactive releases that would require protective measures that could not be (sufficiently) limited in area or time.

Some aspects of theses general safety objectives are developed in greater detail in section 7.1.4.

Like power reactors, research reactors present risks associated with the radioactive materials that they use. lonising radiation is released from fission reactions and by the radioactive products created by these fission reactions, or by activation. The primary channel of exposure is direct radiation from the nuclear reactor or the associated systems as radioactive sources. Several measures are implemented to provide protection against exposure (staying away from the source, use of absorbent materials such as lead, concrete or water). Another potential channel of exposure is contamination from the release of radioactive substances into the atmosphere. Measures taken to ensure that these substances are contained in normal or accident operating conditions are therefore fundamental.

154. This concept is explained in Appendix I of the Order dated 26 April 2011 pertaining to the implementation of the best available techniques, as stipulated in Article R. 512-8 of the French Environmental Code.

155. These objectives are formalised in Council Directive 2014/87/EURATOM of 8 July 2014 amending Directive 2009/71/Euratom establishing a Community framework for the nuclear safety of nuclear installations. 
Research reactor safety relies on various principles, concepts and procedures that are not necessarily specific to these types of reactors:

- installation of several physical confinement barriers between radioactive substances and workers, the public and the environment in order to contain these substances. For reactor core radioactive substances, three "barriers" are generally put in place (specific measures for research reactors will be identified later):

- fuel cladding,

- the boundary of the core cooling system or reactor pool,

- the building housing the reactor core,

- implementation of measures to ensure the three fundamental safety functions ${ }^{156}$ :

- control over nuclear chain reactions,

- removal of heat produced from radioactive substances and nuclear reactions,

- confinement of radioactive substances.

- the adoption of a redundancy or technological diversification principle for the most important safety systems (which perform the two primary fundamental safety functions), in order to achieve sufficient reliability for these systems. This is mainly the case for reactor protection and engineered safeguard systems, which are involved in defence in depth;

- the adoption of an analysis-based deterministic safety approach ${ }^{157}$ incorporating suitable conservative measures, and a number of postulated events ${ }^{158}$ (related to failures specific to the facility [including human errors], or internal or external hazards - see section 7.1.2), even though probabilistic studies can provide useful insight (see below). However, applying the deterministic approach to research reactors requires case-by-case analysis (particularly to establish the list of postulated events) due to the diverse range of designs and risks which these reactors present.

The cladding of fuel elements (plates, rods), often made of aluminium alloy, must at the very least maintain its leaktightness in situations corresponding to postulated events with the highest estimated frequency. This means that heat transfer between the fuel and coolant must be controlled (or more specifically, the ratio between the heat released by the fuel and the coolant flow), failing which, the temperature of cladding would rise irremediably, causing distortion, failure, or even melting (aluminium melts at $\left.660^{\circ} \mathrm{C}\right)$.

156. The first two of these three safety functions contribute to maintaining the confinement barriers.

157. Approach which, over the course of time, has indirectly taken into account probabilistic considerations, particularly by classifying operating conditions into categories based on the estimated frequency (or probability) of initiating events. The design rules depend on these (addition or not of a single failure, way of taking uncertainties into account, criteria to be complied with for equipment, etc.).

158. Postulated initiating events in IAEA documents, événements déclencheurs (initiating events) in French regulations. 
Furthermore, potentially major heat increases or surges could occur in the reactor core. If the chain reaction is not controlled, the energy released could cause fuel meltdown.

In a nuclear reactor, the reactivity is controlled using two types of elements:

- the intrinsic neutronic characteristics at the core, related to the type of fuel and coolant, and the core geometry (which determines neutron leakage): delayed neutron fraction ( $\beta$ and expressed in $p c m$ ), neutron feedback linked to the Doppler Effect in the fuel and the effect of dilation or contraction of structures and the coolant, etc. Several values for these characteristics are given as an example in section 7.2 for different types of research and power reactors;

- added components, mainly in the form of rods or plates made of neutron absorbing materials that can be inserted into or removed from the core manually or automatically if thresholds associated with specific reactor operating parameters are exceeded.

The design studies and choices must be such that these components ensure optimum behaviour of the reactor in the event of disturbances such as reactivity insertion accidents. The aim is to avoid a prompt criticality as much as possible ${ }^{159}$, and maintain, in shutdown situations, a significant margin (negative or deficit reactivity) with respect to a critical state, with absorbers inserted in the core (apart from safety absorbers maintained in withdrawn position ${ }^{160}$ ). Furthermore, the number of absorbers and each of their reactivity contributions must ensure that in the event of a reactor shutdown, the shutdown must be able to occur even if the most effective absorber does not drop.

\subsubsection{The defence in depth principle applied to research reactors}

A general outline of the defence in depth principle was presented in chapter 3.

However, specific features of the defence in depth principle require further explanation for research reactors:

- the first level of defence in depth seeks to prevent operating anomalies and structure, system and component (SSC) failures. This requires high quality in the design and manufacture of these SSC's and in the operation of the reactor (including preventive maintenance). Maintaining quality can require particular attention for research reactors ${ }^{161}$, for several reasons:

159. Prompt criticality occurs if the core reactivity, with counter reactions taken into account, becomes higher than the delayed neutron fraction.

160. For example, to provide negative reactivity in the event of a core loading error.

161. The information below can also apply to other nuclear facilities, such as power reactors, if plans are made to extend their service life. The level of attention to be focused on these issues must of course be adjusted according to a graded approach, depending on the risks presented by the facility in question. 
- they may have a long service life which may be requested to be extended beyond what was originally planned at the time of design,

- because of this, the risks associated with aged equipment and obsolescence can become a problem,

- the necessary recruitment of new operating personnel entails risks of knowledge not being properly passed on. This can lead to operating errors and even significant events ${ }^{162}$,

- research reactors can experience phases of non-use with reduced monitoring and maintenance operations,

- for the second and third levels of defence in depth, the low pressure of reactor coolant in most research reactors means that safety injection systems do not need to be installed ${ }^{163}$. The Jules Horowitz Reactor is the only research reactor with this type of system due to the power density in the core and the coolant pressure (a dozen bars at the core inlet). For many research reactors, their intrinsic characteristics allow them to be cooled via natural convection;

- for the fourth level of defence in depth, for many research reactors, a design-basis accident with fuel melt was adopted for the design or verification of a suitable design $^{164}$ of the reactor pool, the reactor building superstructures and the ventilation and filtration systems. This subject is covered in further depth later in this chapter.

Some research reactors have also been built in areas that have gradually become more urbanised. This increases the attention that needs to be focused on reducing the consequences of accident situations and ensuring that emergency plans are suitable. This can be a prerequisite for their continued operation.

In France, various design and construction codes can be used or serve as a reference (for those formally addressing pressurised water reactors) for a project to build a research reactor and its associated systems, or for modifications to be made to an existing research reactor (new experimental system, modifications made under a safety review, etc.). In this regard, the RCC-MRx design code, developed by the CEA and manufacturers, has been applied to the mechanical equipment of the Jules Horowitz Reactor (see focus below). The RCC-E (design and construction rules for electrical and I\&C components of PWR nuclear islands), and RCC-CW (design and construction rules for civil works in PWR nuclear islands) can serve as references for research reactors.

162. This concern in particular involved the PHENIX reactor when it returned to operation in the early 2000 s after a long period of being shutdown for renovation and safety improvement work. Due to the unique nature of some research reactors, maintaining knowledge and skills on site is equally essential for aspects related to design, construction and commissioning tests.

163. Even though research reactors have reactor makeup water systems or water capacity communication systems.

164. Due to the potential radiological impacts of such an accident. 
\#FOCUS

\section{Codified design and construction rules for mechanical compo- nents, particularly in research reactors: the $\mathrm{RCC}-\mathrm{MRx}^{165}$}

The RCC-MRx “code" results from the merger of two documents in 2009:

- the RCC-MR, developed in 1985 for sodium-cooled fast neutron reactors (reactors operating at high temperatures of up to $500^{\circ} \mathrm{C}$ under normal operation);

- the RCC-MX, developed in 1998 by the CEA, AREVA-TA and AREVA-NP for the specific needs of the Jules Horowitz Reactor project (reactor and its associated experimental auxiliary systems). It can also apply to the design and construction of components or systems for research reactors in operation.

The RCC-MRx extends the potential scope of application to nuclear fusion reactors (e.g. ITER project). It provides rules for mechanical components involved in areas subject to significant creep (fast neutron reactors) or significant irradiation (fast neutron reactors, research reactors and their experimental devices). It provides the mechanical characteristics for an extensive range of materials (steel, 800 alloys, aluminium and zirconium alloys that meet the neutron transparency needs for research reactors), design rules for thin shells and box structures, and new welding processes (electron beam, laser, diffusion, etc.).

The 2015 version of the RCC-MRx reflects feedback from the use of previous editions, particularly in current projects, such as the Jules Horowitz Reactor. This includes feedback on inspection and welding procedures for aluminium processes.

The edition was developed and updated with special attention paid to consistency between the RCC-MRx and other reference documents that interact with the code, including RCC-M, official French legislation and European and international standards.

Some of the subjects covered by the RCC-MRx are given below.

\begin{tabular}{|l|}
\hline 1. \\
INTRODUCTION \\
- Scope of the code \\
- French ESP/ESPN regulations \\
-. \\
\hline 2. MATERIALS - GRADES, PRODUCTS, PROCUREMENT \\
- Material selection \\
- Product procurement conditions
\end{tabular}

165. According to the AFCEN website. This section makes reference to the 2015 version of the RCCMRx, which was the most recent edition at the time writing. 


\section{DESIGN - ANALYSIS}

- General design rules

- Design by analysis

- Design rules for shells-vessels, supports, pumps, valves, piping, bellows, box structures, heat exchangers

4. PROPERTIES OF MATERIALS (APPENDIX A3) AND WELDED JOINTS (APPENDIX A9)

5. EXAMINATION METHODS

- Mechanical, physical and chemical tests

- Ultrasonic examination

- Radiographic examination

- Liquid penetrant examination

- Leak detection methods

6. WELDING

- Acceptance of filler materials

- Qualification of filler materials

- Welding procedure qualification

- Qualification of welders and operators

- Technical qualification of production workshops

- Production welds

- Weld deposited hardfacing on steel

- Mechanical tests

- Special provisions of aluminium and zirconium alloy welding

7. FABRICATION

- Marking procedure

- Cutting - repair without welding

- Forming and dimensional tolerances

- Surface treatment

- Cleanliness

- Brazed and bolted mechanical joints

- Heat treatments

- ... 


\subsubsection{Events selected for the design and safety demonstration of research reactors}

The design of a research reactor and its related safety demonstration is based on the identification of all events (internal failures, internal and external hazards) which could affect the facility. However, depending on the event in question, the estimated frequency of the event is more or less high. For example, complete failure of a pipe is considered less likely than a moderate leak from the pipe.

For the oldest research reactors, a small number of events related to internal failures specific to equipment or operator errors were selected. These have an envelope nature and are broadly broken down into three major categories - normal events, incidents and accidents.

For the most recent research reactors or for safety reviews of the oldest research reactors, in line with practices applied for power reactors, a number of envelope "operating conditions" (up to several dozen) are adopted and classified into four categories based on the estimated frequency of the "family ${ }^{166 " ~ o f ~ i n i t i a t i n g ~ e v e n t s ~ t h e y ~ c o v e r . ~}$

Table 7.1 , at the end of this section shows the different categories of operating conditions with some of the operating conditions of a neutron beam reactor given as examples.

Different "operating conditions" are studied to determine various thermomechanical loads on the components of the facility, called design basis situations, which are also divided into categories. Component design involves checking or ensuring that the design choices made comply with design and construction code criteria (e.g. RCC-MRx) selected based on the design basis situation studied. The criteria selected also depend on other considerations such as the component's importance for safety (its safety classification) and its role (whether active or passive) in the situation in question.

"Service limits" for the core fuel of a research reactor are generally associated with the various operating condition categories. Particular attention must be paid to ensuring that $1^{\text {st }}$ and $2^{\text {nd }}$ category operating conditions (normal operating conditions and frequent transient conditions) do not cause cladding leakage or fuel melt.

The approach involving operating condition categories was not really put into practice for research reactors until the 2000s. The first case where it was actually applied was with the CABRI reactor, involving the installation of a pressurised water loop and a complete safety review of the reactor. The same approach was then used in preparing the construction licence application for the Jules Horowitz Reactor.

One of the specific features of research reactors concerns the establishment of first category, or normal operating conditions. Besides the stable operation of the reactor and normal startup and shutdown transients for the reactor, all the normal transients associated with the planned irradiation experiments should be taken into account. This is because during the basic design phase for a research reactor, the designer or operator

166. Events linked to the neutron reactivity of the core, events linked to reactor cooling, etc. Table 3.3 in the first section shows events grouped into families. 
does not always have sufficiently detailed information on the experiment programme that will be carried out. The chosen approach therefore involves defining a sufficiently broad envelope of normal transients for the potential experiments, in terms of changes over time, for the reactor, fluid temperatures in the reactor's various systems, pressure in these systems, fluid flows, neutron flux in the core, etc.

Furthermore, to establish the list of incidents and accidents that can occur in a research reactor, or second, third or fourth category operating conditions, the potential failures or errors that could occur during experiments and impact the reactor itself must be taken into account. This can raise some problems if the various types of experimental systems for the reactor have not yet been fully defined.

Various technical exchanges took place in the 2000s between the CEA, ASN and IRSN concerning interactions between a research reactor and its associated experimental systems when the CEA was developing its own design guidelines for experimental systems. For ASN, creating these guidelines was a condition for establishing an internal authorisation system $^{167}$ at the CEA. The aim of the guidelines was to formalise several major principles and an analysis approach to be used specifically for designing experimental systems based on various information. This included potential risks posed by the system, the number and robustness of "barriers" separating the test area within the system and the reactor core ${ }^{168}$, and gripping and hold-down mechanisms ${ }^{169}$ for the system.

In the guidelines, as established in January 2007, the recommended analysis approach was based on a "lines of defence" concept ${ }^{170}$. The guidelines also define the rules allowing the CEA to internally authorise the installation of a new experimental system in one of its research reactors.

The guidelines generally improved and facilitated analysis and safety inspections for experimental systems. Although the ASN did not issue a formal opinion on the guidelines, even though it was involved in work meetings and discussions on it, it recognised them by authorising the CEA to implement and organise its internal authorisation system.

The foregoing only concerns the operating safety of the reactor (with its experimental systems). It is important to remember that the reactor environment can be a source of hazards that can affect facilities. Two types of hazards must be considered - internal hazards, which originate within the facilities, such as a fire, and external hazards, such as an earthquake or airplane crash. All the potential sources of hazards must be identified and covered for the design of the reactor and associated safety demonstration. External

167. Concept already covered in section 3.6 in the first part of this document.

168. With one of the constraints being to obtain a sufficiently transparent neutron separation between the reactor core and the test area.

169. For example, this concerns experimental systems that are likely to increase core reactivity in the event of unplanned vertical movement or ejection. This type of event could be the natural consequence of energetic phenomena which could occur - or even intentionally be initiated within a system, depending on the objectives of an experiment being conducted with the system.

170. See footnote 168 below. 
hazards also determine design basis situations for components, often called load cases, where the general objective for hazards is to ensure that they do not prevent fundamental safety functions from being performed, despite their direct and indirect effects.

Therefore, like the pressurised water reactors in the nuclear power reactor fleet, the "load case" approach has been supplemented (for safety reviews and new research reactor projects) by the implementation of an "event-level earthquake" approach, which takes into account the fact that an earthquake can be the cause of other internal hazards due to the failure of components not designed for earthquakes. It should be noted that in principle, this type of approach can be applied to other hazards besides earthquakes. The approach is used to:

- identity components not specifically designed for earthquakes;

- study the impacts should they fail in the event of an earthquake in order to determine whether they can jeopardise the functional requirements of components designed for earthquakes and that perform fundamental safety functions;

- if this is the case, decide on any measures to be taken: reinforce components not designed for earthquakes, protect major components that could be affected.

It is assumed that an earthquake will cause the loss of off-site power supplies ${ }^{171}$ (loss of off-site power).

Just as for power reactors from the nuclear power reactor fleet, an additional category of operating conditions corresponding to multiple failures or accumulated events (which can be highly unlikely) is now taken into account for the design and safety demonstration of research reactors. An example of this is a station blackout ${ }^{172}$, or a seismic margin earthquake ${ }^{173}$ while a heavy load is being lifted in the reactor building, with the requirement that the load not be dropped. For this, the designer of the Jules Horowitz Reactor uses the expression risk limitation conditions (RLC), which include controlled severe accidents (CSA) under the $4^{\text {th }}$ level of defence in depth.

Finally, just as for reactors in the nuclear power reactor fleet, particular attention must be paid to events excluded from the list of operating conditions. These events are not covered by specific measures to limit their consequences (as they may be unachievable). Their exclusion must therefore be justified by proving that their occurrence is physically impossible or highly unlikely with a high level of certainty. In the latter case, a case-by-case analysis should be performed, as a generic probability threshold does not appear to be relevant ${ }^{174}$. Preventing "excluded" events requires stronger design, construction and in-service inspection measures compared to those adopted to prevent events whose occurrence has not been excluded.

171. LOOP: Loss Of Off-site Power.

172. Combination of loss of off-site power and main emergency diesel generators (SBO: station blackout).

173. See section 7.4.2.

174. See the "technical directives for the design and construction of next-generation pressurised water reactors", established by the GPR with German experts in October 2000 and used for the EPR reactor project. 
The abovementioned approach is gradually being applied to old research reactors during their safety reviews. Besides the case of the CABRI reactor mentioned above, this includes the ORPHEE reactor at Saclay, and the RHF.

Some of the events studied for research reactors are therefore similar to those adopted for reactors from the nuclear power reactor fleet, such as a breach or even complete failure of a reactor coolant main pipe, the inadvertent removal of an absorber component from the core area, or partial or complete loss of electrical power. Some other events are specific to research reactors given the experiments that are conducted in them or planned.

Safety analyses and assessments carried out by IRSN as part of work to upgrade the $C A B R I$ reactor, which included the installation of a pressurised water loop to replace the sodium loop, led to the adoption of rules and practices used for pressurised water reactors - the loop, related systems, its containment tank constituting the coolant circuit, related systems and the containment building of a PWR. The following are examples of some of these aspects:

- while the operating conditions associated with the reactor itself were defined by drawing heavily on events adopted for pool-type research reactors, the operating conditions associated with the loop were naturally drawn from the operating conditions adopted for pressurised water reactors;

- the water loop containment tank was designed to withstand a "design pressure" equivalent to the pressure attained in the event of break of the loop (equivalent to the primary coolant main pipe in a PWR), corresponding to the loss of coolant accident (LOCA) studied for this type of reactor ${ }^{175}$. The recommendations for metal containment vessels in the ASME design and construction code, which is widely used across the world for light water reactors, were used as a point of reference in this area;

- the risk of complete failure of the part of the loop in the reactor ("in-reactor cell") which could have severe consequences on the driver core (sudden depressurisation of the loop water which could compact assemblies in the driver core and prevent absorber rods from dropping) should be made sufficiently unlikely. The safety valves on the loop's coolant system obviously help prevent such an event. However, they needed to comply with regulations for safety components (valves) for pressure devices;

- the pressurised water loop complies with requirements contained in the regulations for pressurised devices ("ESPN" Order).

These cases of combined use of the rules and practices used for research reactors and pressurised water reactors did not create any problems, which suggests good consistency and compatibility between the approaches.

175. This involves a complete double-ended guillotine break of the loop inside the tank containment of the loop (figure 5.17) (i.e. 2A, where A refers to the cross-sectional flow area of the coolant in the system), combined with a compressed air pipe break, which could be caused by the first break. 
As stated above, in some cases, probabilistic safety assessments can provide useful insight along with the deterministic approach for new projects, major modifications or safety reviews of research reactors ${ }^{176}$. For example, targeted probabilistic assessments can help guide design decisions. A probabilistic assessment of potential residual heat removal failures can be used to choose design options for the general architecture of cooling systems, redundancy and equipment diversification. Probabilistic safety assessments can also be used to confirm or modify the safety classification of components. Furthermore, if probabilistic safety assessment models are not available, a simplified "lines of defence" approach ${ }^{177}$ can also provide useful insight, as was the case in the early 2000s with the safety review of the high-flux reactor in Grenoble.

\subsubsection{Reference accidents}

As stated earlier, when the first research reactors were being designed around fifty years ago, potential incidents and accidents were taken into account. Incidents and accidents began being studied, especially what are referred to in France as "reference accidents". These accidents were considered as worst-case scenarios and used to assess the acceptable nature of technical and organisational provisions adopted to ensure the safety of the facility in question.

These reference accidents were defined taking into account the specific features of reactors and generally considering the failure of several systems or human errors, which would or could potentially damage fuel elements or the reactor core.

For water-cooled research reactors that use uranium- and aluminium-based fuel (with aluminium cladding), the BORAX-type accident, named after the American facility where tests for this type of accident were conducted, was adopted in France. This type of accident is representative of the risks involved with a sudden insertion of high reactivity into the core, i.e. partial or complete core meltdown potentially followed by a steam explosion in the pool.

Reactivity insertion causes a runaway chain reaction that can be limited by the effects it produces as increased fuel and water temperatures have a negative effect on reactivity (neutron feedback). However, if the reactivity insertion is too quick or substantial, the neutron feedback is not enough to prevent damage to the fuel. In the case of the BORAX-type accident, which concerns reactors that use uranium- and aluminium-based fuel, fuel and cladding quickly reach their melting temperature $\left(660^{\circ} \mathrm{C}^{178}\right)$. The fuel can then disperse in the water, which remains relatively cool given

176. See section 3.4.3. In 2010, IRSN conducted a feasibility study for a Level 1 PSA for the Jules Horowitz Reactor. See the presentation made at the PSAM 2010 conference: "10th International Probabilistic Safety Assessment, Feasibility study to develop a PSA for the Jules Horowitz research reactor", Laborde A., Georgescu G., Cochemé F., Lanore J.-M.

177. This approach was presented by M. Lavérie (head of the SCSIN from 1986 to 1993) at a conference held in 1982 in Lyon on liquid metal cooled fast neutron reactors (see Proceedings of the LMFBR Safety Topical Meeting, Lyon (1982), p.l-335.

178. This value corresponds to the melting temperature of aluminium. 
the kinetics of the accident, and cause a steam explosion due to the sudden transfer of energy from the melted substances to the water.

Due to the destructive impacts of such an accident, the initial focus is to prevent the failures that could cause it. However, the accident could still potentially occur. As its kinetics are too rapid for an emergency shutdown to be sufficiently effective, measures are taken to limit its consequences. These measures are mainly based on the ability of the pool to resist a potential steam explosion and maintain the melted core under water (as the water provides cooling and a biological shield), and the ability of the reactor building to withstand the accident and contain the radioactive substances released in the building. Outside France, this type of accident has not been fully taken into account (fuel-water interaction) for the design of pool-type research reactors with a uranium and aluminium alloy-based fuel, except for the BR2 reactor at the Mol centre in Belgium.

For the OSIRIS, ORPHEE and RHF, an "in-air" melt accident involving a fuel element being handled in the reactor (caused by failures during handling) was also adopted. Unlike an underwater core melt accident such as the BORAX-type accident, an "in-air" melt accident causes more radionuclides to be released in the reactor building as there is no water to trap the fission products. The possibility of "in-air" core meltdown began being taken into account when the RHF was being designed.

Chapter 8 will cover reference accidents adopted for French research reactors and the BORAX-type accident in particular.

\subsubsection{Application of general safety objectives}

The general safety objectives were expressed qualitatively in section 7.1. However, just as with nuclear power reactors, the designers and operators of research reactors can adopt general safety objectives expressed quantitatively in terms of "acceptable" radiological consequences for humans and the environment, in the form of "reference values" for doses, different categories of operating conditions and the conditions of the complementary domain (BDBA or DEC). Although this is useful for structuring basic designs and assessing the choices made at this stage, in line with the Farmer diagram (figure 7.1), these "reference values" can under no circumstances be considered as acceptability criteria, as the radiological consequences must always be limited as far as reasonably possible while taking into account economic and social factors (optimisation principle).

Safety is above all assessed by applying the defence in depth principle and not just comparing the radiological consequences of pre-established values. In particular, calculating the individual radiological consequences would not reflect their severity, which depends on the number of people affected (which can be high for research reactors located in highly urbanised areas) and the degree and duration of contamination resulting from an accident.

In addition, designers and operators can apply the general safety objectives as "relay" criteria or "decoupling" criteria used to study operating conditions and determine whether measures to limit their consequences are sufficient (percentage of fuel element cladding failures, percentage of molten fuel, etc.). 


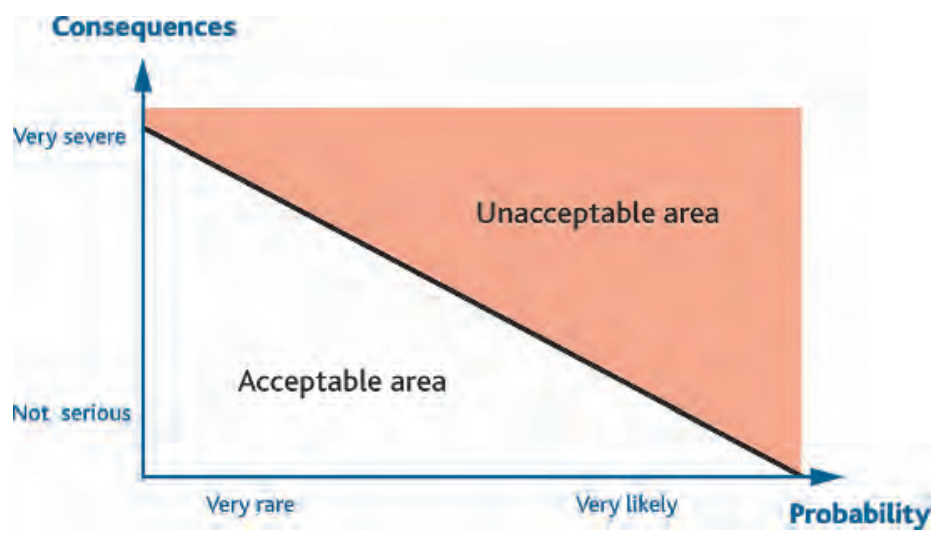

Figure 7.1. Farmer diagram showing the relationship between probability and consequences.

\subsubsection{The graded approach in France}

The Order of 7 February 2012 establishes the general rules for the design, construction, operation, permanent shutdown, dismantling, maintenance and monitoring of basic nuclear facilities. It states that "Their application is based on an approach that is proportional to the extent of the risks or drawbacks inherent to the installation". The Order particularly underscores the "proportional approach" for the number and effectiveness of confinement barriers (especially for the design of research reactors, as the number of barriers can vary from one reactor to the next), the qualification of the facility's major components, the frequency of emergency exercises or the monitoring of external service providers.

The use of a deterministic approach that defines and studies operating conditions from internal initiating events, internal hazards (linked to the reactor itself) and external hazards (linked to the reactor site) for the design, safety demonstration or safety reviews of research reactors automatically leads to safety measures that are adapted to the research reactor in question and its site, and proportional to their risks.

It should also be noted that the safety classification of equipment within the same nuclear facility means that a number of their requirements are proportioned to their importance to safety (safety coefficients for their design, types of welding authorised by design and construction codes, scope and nature of completion inspections, inservice inspections, etc.).

\subsection{Specific safety features of research reactors}

\subsubsection{Power densities, fuel and core neutron characteristics}

Despite having much lower overall power, the power densities generated by research reactors are often higher than for power reactors, given the size of their core, 
Table 7.1. Operating conditions: categories and examples for a pool-type reactor.

\begin{tabular}{|c|c|c|}
\hline $\begin{array}{l}\text { Categories of } \\
\text { operating } \\
\text { conditions }\end{array}$ & $\begin{array}{l}\text { Order of magnitude for } \\
\text { the annual frequency } \\
\text { per reactor (and upper threshold } \\
\text { expressed as a probability) }\end{array}$ & $\begin{array}{l}\text { Examples of operating conditions for a } \\
\text { pool-type reactor, with neutron channels } \\
\text { (indicated by }{ }^{*} \text { ), using heavy water } \\
\text { (indicated by }{ }^{* *} \text { ) - Excluding events to be } \\
\text { taken into account for fuel transfer casks } \\
\text { (loss of cooling, etc.) }\end{array}$ \\
\hline $\begin{array}{l}\text { CATEGORY } 1 \\
\text { Normal operating } \\
\text { conditions }\end{array}$ & $\begin{array}{l}\text { Number of occurrences defined } \\
\text { according to the operating } \\
\text { programme } \\
(P=1)\end{array}$ & $\begin{array}{l}\text { - Stable states and normal transient } \\
\text { conditions (including irradiation } \\
\text { experiments) }\end{array}$ \\
\hline $\begin{array}{l}\text { CATEGORY } 2 \\
\text { Minor yet frequent } \\
\text { incidents }\end{array}$ & $\begin{array}{l}\text { Up to several occurrences } \\
\text { per year } \\
(P<1)\end{array}$ & $\begin{array}{l}\text { - Loss of fuel cladding leaktightness } \\
\text { - Coolant leak or break of small } \\
\text { equivalent diameter (e.g. } \Phi<10 \mathrm{~mm}) \\
\text { - Partial loss of coolant flow } \\
\text { - Total loss of secondary coolant } \\
\text { system flow } \\
\text { - Leak affecting a heat exchanger } \\
\text { between light water and heavy } \\
\text { water }(* *) \\
\text { - Coolant pump shutdown during } \\
\text { shutdown } \\
\text { - Loss of integrity of a thimble casing } \\
\text { resulting in heavy water entering the } \\
\text { thimble }(*)(* *) \\
\text { - Leak or break affecting effluent } \\
\text { discharge systems } \\
\text { - Short-term loss of offsite } \\
\text { electrical supply (e.g. < } 1 \text { hour) } \\
\text { - .. }\end{array}$ \\
\hline $\begin{array}{l}\text { CATEGORY } 3 \\
\text { Unlikely accidents }\end{array}$ & $\begin{array}{c}<10^{-2} \\
\left(P<10^{-2}\right)\end{array}$ & $\begin{array}{l}\text { - Inadvertent removal or withdrawal of an } \\
\text { absorber element (possible in Cat. } 2 \text { ) } \\
\text { - Coolant break of "intermediate" } \\
\text { equivalent diameter } \\
\text { (e.g. } 10 \mathrm{~mm} \leq \Phi<100 \mathrm{~mm}) \\
\text { - Break of a standard aluminium thimble } \\
(*) \\
\text { - Failure of a heavy water sleeve }\left(^{* *}\right) \\
\text { - Clogging of a core fuel element } \\
\text { cooling channel } \\
\text { - Clogging of several channels of a fuel } \\
\text { element in a storage area } \\
\text { - Dropped transport cask containing fuel } \\
\text { elements in the facility } \\
\text { - ... }\end{array}$ \\
\hline
\end{tabular}


Table 7.1. (Continued)

\begin{tabular}{|c|c|c|}
\hline $\begin{array}{l}\text { CATEGORY } 4 \\
\text { Major yet } \\
\text { hypothetical } \\
\text { accidents }\end{array}$ & $\begin{array}{c}<10^{-4} \\
\left(P<10^{-4}\right)\end{array}$ & $\begin{array}{l}\text { - Absorber ejection (potentially causing core meltdown) } \\
\text { - possibly studied as an additional operating condition } \\
\text { if multiple failures are involved } \\
\text { - In-pool reactor block failure (causing reciprocal } \\
\text { transfers between light water and heavy water) }\left(^{(*}\right) \\
\text { - Coolant break of large equivalent diameter } \\
\text { (e.g. } \Phi \geq 100 \mathrm{~mm} \text { ) } \\
\text { - Break of a zirconium alloy thimble } \\
\text { - Core coolant bypass' }{ }^{179} \text { (potentially causing core meltdown) } \\
\text { - In-pool double-ended guillotine break of a water } \\
\text { inlet collector }{ }^{180} \text { in the core }{ }^{181} \\
\text { - In the hot cell, accidental cutout of a fuel element } \\
\text { - ... }\end{array}$ \\
\hline $\begin{array}{l}\text { Beyond design- } \\
\text { basis area }\end{array}$ & $\begin{array}{l}<10^{-6}, 10^{-7} \\
\text { per family }\end{array}$ & $\begin{array}{l}\text { Additional operating conditions (some may cause melting in } \\
\text { the core or core meltdown under water or in the air in the } \\
\text { event of fuel element uncovery) } \\
\text { - Inadvertent removal of an absorber with failure of } \\
\text { the reactor protection system } \\
\text { - Failure of the main heavy water system with failure of } \\
\text { the vacuum relief valve }\left(^{*}\right) \\
\text { - Loss of secondary coolant system flow with failure of } \\
\text { the protection system } \\
\text { - Total failure of a thimble with isolation failure } \\
\text { ("window" and safety valve or upstream and downstream } \\
\text { safety valves'182) }(* *) \\
\text { - Complete loss of offsite and back-up electrical power supply } \\
\text { - Loss of offsite electrical power supply and failure } \\
\text { of the reactor protection system } \\
\text { - BORAX-type accident (reactivity accident) } \\
\text { - Loss of entire reactor water inventory (heavy and } \\
\text { light water) }(* *) \\
\text { - ... }\end{array}$ \\
\hline & & $\begin{array}{l}\text { Other accidents studied or excluded by prevention } \\
\text { measures } \\
\text { - Uncovery of stored fuel elements } \\
\text { - Failure of the two "heat source" or "heat sink" vessels }\left(^{*}\right) \\
\text { - Explosion of a "cold source" thimble, causing } \\
\text { internal damage to the reactor block }\left(^{*}\right) \\
\text { - Core meltdown with total containment failure } \\
\text { - ... }\end{array}$ \\
\hline
\end{tabular}

179. For example, in the case of the RHF, a break in the "stack", located above the core tank.

180. Case of the RHF: see figure 5.12.

181. In the case of the RHF, this would result in light water entering the fuel assembly in the core (instead of heavy water).

182. See the description of these components in section 7.3.2. 
Table 7.2. Core power densities and coolant temperatures for different types of reactors.

\begin{tabular}{|l|c|c|l|l|c|}
\hline & $\begin{array}{c}\text { Pressurised } \\
\text { water reactor }\end{array}$ & $\begin{array}{c}\text { Sodium-cooled } \\
\text { fast neutron } \\
\text { reactor }\end{array}$ & OSIRIS & RHF & JHR \\
\hline $\begin{array}{l}\text { Power } \\
\text { density } \\
\text { in } k W / l\end{array}$ & $\sim 100$ & $\sim 300$ & $\sim 300$ & $\sim 1,200$ & $\sim 600$ \\
\hline $\begin{array}{l}\text { Coolant temperature } \\
\text { at core inlet and } \\
\text { outlet in }{ }^{\circ} \mathrm{C}\end{array}$ & $286-323^{(*)}$ & $350-550$ & $38-48$ & $30-48$ & $25-36$ \\
\hline
\end{tabular}

${ }^{(*)}$ These values are for Bugey 900 MWe PWRs.

in order to obtain the neutron fluxes required for experiments or irradiation ${ }^{183}$. Table 7.2 shows several power densities in the cores of different types of reactors, including power reactors.

The power density generated depends on the type of fuel used. It can be high with fuel that is highly enriched in fissile uranium-235. Several types of fuel are used in research reactors, depending on their use. For critical assemblies where flexible use is essential, operators generally have a broad inventory of fuel elements in the form of rodlets or platelets, allowing them to create cores "à la carte". For this type of reactor, core assemblies are created manually in the installation itself.

For irradiation reactors and "neutron beam outside" reactors, whose main purpose is to produce strong neutron fluxes, it is essential for fuel assemblies to be properly cooled when the reactor is in operation. Fuel elements are designed to meet this purpose. For example, the use of curved plates (figure 7.2) provides greater stiffness and ensures that the desired spacing is maintained between the plates in various degraded or hazard conditions (earthquake, etc.).

As stated in chapter 2, as part of international efforts to prevent nuclear weapons proliferation, procurement of highly enriched with uranium-235 fuels can be a problem. A number of research reactors have therefore converted to the use of silicide fuel, using a $\mathrm{U}_{3} \mathrm{Si}_{2}$ formula alloy that reduces uranium-235 enrichment to less than $20 \%$ while maintaining the potential and capacities of these reactors. However, this "conversion" can raise problems for some research reactors due to dimensional and other constraints, making it difficult to make changes, especially in their cores. To

183. Research reactor designs must achieve the best compromise between several contradicting requirements. This includes designing a small core to achieve high fission densities, creating a sufficient experimental volume to install all experimental devices, extract high power densities without negatively affecting the neutron performance of the core or hinder its experimental use ("Les réacteurs de recherche", Francis Merchie, L'Encyclopédie de l'énergie, 2015). 


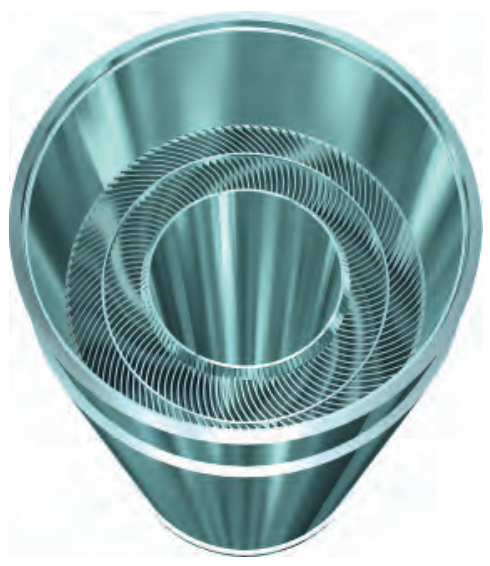

Figure 7.2. Curved plate fuel element used in the FRM-II reactor in Garching, Germany. () FRMII Technical University of Munich.

compensate for the loss of uranium-235 enrichment, new higher density uranium alloys ${ }^{184}$ are being studied, but these would come with other drawbacks (more frequent replacement of core fuel, less efficient neutron absorbers, etc.). This issue is still being explored and is at the heart of the question around choosing the type of fuel for the Jules Horowitz Reactor ${ }^{185}$. Research is being carried out to develop and qualify other types of fuel. The CEA and other organisations ${ }^{186}$ are studying fuel made of $20 \%$ enriched uranium-235 and molybdenum grains with aluminium alloy cladding (currently called UMo).

Aluminium (or aluminium alloys such as AG3NET or zirconium) is widely used in research reactors for fuel, fuel cladding, internal structures and components (such as neutron channels). To achieve a good thermodynamic yield, nuclear power plants operate at the highest possible temperatures, whereas apart from a few exceptions, research reactors are "cold" reactors. This allows for the use of these types of materials, which have much better neutron characteristics than steel (neutron transparency), although they may have poorer mechanical properties depending on their composition and treatment (in terms of yield strength, rupture elongation, etc.).

In terms of neutronics ${ }^{187}$, the thermal neutron fluxes that can be used for experimental programmes must achieve values of $1.10^{13}$ to over $1.10^{15}$ neutrons. $\mathrm{cm}^{-2} \cdot \mathrm{s}^{-1}$. The neutron flux in a reactor is made up of fast neutrons resulting directly from fission, thermal neutrons after slow-down in the moderator, and intermediate neutrons in the

184. NUREG-1313 silicide has a density of $4.8 \mathrm{gU} / \mathrm{cm}^{3}$. With new fuel, the aim is to achieve a density that is approximately twice higher.

185. "Les combustibles nucléaires", Monograph by the CEA Nuclear Energy Division, 2008.

186. The United States (ANL), Canada, Russia, South Korea and Argentina are contributing to the qualification of this new fuel. Experiments have been conducted in the OSIRIS reactor, and the HFR and BR2 reactors are also being used.

187. "Les réacteurs de recherche", Francis Merchie, L'Encyclopédie de l'énergie, 2015. 
Table 7.3. Neutron parameters for the cores of different types of reactors.

\begin{tabular}{|l|c|c|c|c|c|}
\hline & $\begin{array}{c}\text { Pressurised } \\
\text { water reactor }\end{array}$ & $\begin{array}{c}\text { Sodium-cooled } \\
\text { fast neutron } \\
\text { reactor } \\
\text { PHENIX }(*)\end{array}$ & OSIRIS & RHF & JHR \\
\hline $\begin{array}{l}\text { Maximum flux in } \\
\text { neutrons.cm }{ }^{-2} . \mathrm{s}^{-1}\end{array}$ & 1 to $3.10^{13}$ & $4.510^{15}$ & $5.410^{14}$ & $1.910^{15}(* *)$ & $1.110^{15}$ \\
\hline Doppler effect & $-3 \mathrm{pcm} /{ }^{\circ} \mathrm{C}$ & $-0.6 \mathrm{pcm} /{ }^{\circ} \mathrm{C}$ & $-3 \mathrm{pcm} /{ }^{\circ} \mathrm{C}$ & & $-2.5 \mathrm{pcm} /{ }^{\circ} \mathrm{C}$ \\
\cline { 1 - 4 } $\begin{array}{l}\text { Moderator } \\
\text { effect }\end{array}$ & $\begin{array}{c}\text { from }-10 \text { to } \\
-60 \mathrm{pcm} /{ }^{\circ} \mathrm{C}\end{array}$ & $\begin{array}{c}\text { generally } \\
-0.06 \mathrm{pcm} /{ }^{\circ} \mathrm{C} \\
\text { but positive in } \\
\text { some areas of } \\
\text { the core }\end{array}$ & $-14 \mathrm{pcm} /{ }^{\circ} \mathrm{C}$ & $\begin{array}{c}-17 \mathrm{pcm} /{ }^{\circ} \mathrm{C} \\
\text { (including }\end{array}$ & $-20 \mathrm{pcm} /{ }^{\circ} \mathrm{C}$ \\
\cline { 1 - 4 } $\begin{array}{l}\text { Effective beta } \\
\text { (delayed } \\
\text { neutron } \\
\text { fraction) }\end{array}$ & $\begin{array}{r}300 \mathrm{pcm} \\
\text { Dopler effect) }\end{array}$ & $731 \mathrm{pcm}$ & $713 \mathrm{pcm}$ & $730 \mathrm{pcm}$ \\
\hline
\end{tabular}

${ }^{(*)}$ The values given are for the PHENIX reactor operating at a maximum power of $350 \mathrm{MWth}$ (power adopted for its operation from 2003 to 2010).

${ }^{(* *)}$ This corresponds to the sum of $1.510^{15}$ neutrons. $\mathrm{cm}^{-2} \cdot \mathrm{s}^{-1}$ of thermal neutrons available in the end of thimbles, and $3.510^{14}$ neutrons. $\mathrm{cm}^{-2} \cdot \mathrm{s}^{-1}$ of fast neutrons in the core fuel element.

process of slowing down (slowing occurs via successive collision of neutrons against the nuclei of moderator atoms). Depending on whether the reactor is well-moderated or under-moderated, the neutron spectrum will have a more or less fast component, which could be detrimental or desired, depending on the objectives of experimental programmes.

Furthermore, the spatial distribution of neutrons is not uniform and decreases from the centre to the core perimeter, with localised disturbances due to things such as the movement of control absorbers and the presence of experimental devices. This causes variable distribution of the residual heat over time and space and therefore the presence of "hot spots" that need to be well-anticipated and managed from a thermal hydraulic standpoint in order to prevent fuel from overheating beyond set limits and being damaged. This safety concern will be covered in section 10.1.1, with the discovery in 2004 of several melted fuel rods in the CABRI reactor driver core.

\subsubsection{Usage rates}

Another feature of research reactors is the specific ways they are used. Irradiation reactors or "neutron beams outside" reactors operate in cycles. During a cycle, they are generally in steady-state operation 24 hours a day. At the end of a cycle, they are shut down for refuelling. In this way, such reactors can provide a stable supply of neutrons (beams for experiments) and over a significant period of time (irradiation). 
The operating programmes for critical assemblies vary significantly and are closely linked to the test programmes performed, which may last from a few months to several years. Such test programmes start with construction of the experimental core, which may take several months. The test phase proper then follows, when the reactor may operate for just a few hours a day, or throughout the day. However, it is usually shut down every night. This phase may also involve changes to the core configuration, in order to meet testing needs.

For reactors used for specifically safety-related tests, preparation times for tests or series of tests may be fairly long. One example of this is the test loop on the CABRI reactor, which has required several years of work to change. The time between two tests may also be long, for example because special provisions are required to handle a degraded test fuel element. The actual test period can, however, be very short in comparison with the preparation periods and the times between tests.

\subsubsection{Organisational and human factors}

One aspect of research reactors, compared with other nuclear facilities such as nuclear power reactors, is the particular involvement of people in reactor operation and the use of reactors for research. People do perform a range of operations in most nuclear facilities, such as process management, refuelling, maintenance, monitoring, but with research reactors people may often have to handle fuel elements using handling poles or put together the fuel elements (this is the case, for example, for some critical assemblies).

In addition, the large amount of handling of experimental devices placed in or near the reactor core is to be noted.

Moreover, in many research reactors, there are two different groups of workers whose actions have an impact on safety: the reactor operating teams who are responsible for running the reactor within safe limits, and the scientists that use the experimental devices in order to generate research outputs. The latter group may not be so conscious of the safety limits and reasons for such rules. The authority of the facility manager over both groups of workers is therefore essential.

Furthermore, after a test campaign, many human operations may be necessary, such as disassembling or reassembling systems in preparation for the next experiments, or cleaning components. The potential safety and radiological protection consequences of such operations must be clearly understood.

Finally, research reactor activities very often are evolving and discontinuous over time. Activities can change, depending on the planned research programmes, and even the slightest consequences of such changes must be considered in terms of safety and radiological protection. Moreover, whenever major changes occur, involving longerterm stoppage of some activities in order to undertake equipment modifications, the effect of such stoppages on staff skills must be assessed. 
Risk assessments relating to human activities in research reactors can draw on a specific approach ${ }^{188}$ which involves:

- determining which activities are "safety-sensitive", meaning activities which could have significant safety consequences if incorrectly performed;

- identifying what provisions are in place to ensure such activities can be performed reliably;

- assessing the effectiveness of those provisions.

The sensitivity of any given activity can be assessed on the basis of a range of factors: potential consequences of incorrect performance, complexity of the tasks, repetitive nature of the operation, number of workers involved, coordination requirements, etc.

To illustrate the point, two activities in French research reactors can be mentioned that are deemed to be particularly sensitive:

- for the MASURCA model, the fabrication of "à la carte" fuel elements from rodlets or platelets in the storage warehouse (criticality risk in the event of error);

- for the ISIS reactor used for successive training sessions, the setting of safety thresholds (risk of inadequate reactor protection in the event of an unexpected transient).

In general, the experiments may require reconfiguration of the protection system, and such adjustments must be made in a reliable and traceable way.

Although facility operators have identified the vast majority of activities which could have significant safety consequences in the event of error, other activities that may have less obvious safety effects or which are sensitive chiefly due to the complexity of the operations to be performed may require further analysis.

As mentioned above, any needs for coordination between different teams are usually included in the aspects considered when assessing whether a given activity is sensitive. This is the case, for instance, for experiments that require preparation and especially close coordination between the operating personnel and the scientific researchers. Thus, the tests undertaken under the Phebus FP programme (see focus at end of chapter 5) required in-depth preparation to mitigate any risks of conflict of interest: the instruments used included redundant and diversified measurement devices and the test procedures specified various predetermined shutdown thresholds. The goal was to avoid stopping the tests too early, given the test objectives, but still to ensure the reactor would be shut down and containment maintained if there was any risk of excessive damage to the "barriers" between the test fuel and the driver core. Test procedures were developed for the operators, to specify in particular whether or not tests should be continued, based on the instrumentation status (whether the temperature measurement devices were in service, failed or saturated,

188. "Contrôle" Journal no. 176 of July 2007: "Les facteurs organisationnels et humains et la sûreté des réacteurs d'expérimentation", F. Jeffroy and M.-L. Delaporte-Normier, IRSN, P 47. 
etc.) and on predetermined limits. These provisions were submitted to the French Nuclear Safety Authority (ASN).

\subsection{Features of research reactors by main safety function}

This section presents the main technical features of research reactor that are important for safety.

\subsubsection{Controlling core reactivity}

Core reactivity (annotated $\rho$ and expressed in pcm - per cent mille) is a parameter used to represent the neutron population (number of neutrons) in a core and its variation over time. When the population is stable, the reactor is said to be "just critical" and reactivity is zero $(\rho=0)$. This population results from the neutrons generated by fission reactions, neutrons emitted later by some fission products (so-called "delayed neutrons") and neutrons that leak out or are captured (e.g. in absorbent materials). Operators control the reactivity in a reactor core by using neutron-absorbing materials (also known as "neutron poisons") such as boron, cadmium and hafnium. These materials are used in control absorbers (or safety absorbers in research reactors). These are mobile components inserted into the reactor core to enable its reactivity to be adjusted and controlled. Vertical absorber movements are controlled by mechanisms that are usually found above the core. However, in some cases, to facilitate access to experimental or irradiation devices, absorber motion may be controlled by mechanisms in the bottom of the reactor block. This is true of the OSIRIS and Jules Horowitz reactors, which have a room under the reactor pool that houses these mechanisms. This means that the potential risks of water leakage - possibly involving contaminated water in the event of a reactor accident - into reactor basements need to be managed by installing waterproof coatings in the control mechanism rooms.

Some absorbers are used for reactor control (control absorbers) and others are used for reactor scram (safety absorbers). To shut the reactor down, all absorbers are fully inserted into the reactor, thus bringing it to sub-criticality $(\rho<0)$, with an adequate deficit reactivity margin (or shutdown margin). Once the reactor has been shut down, safety reasons may require some safety absorbers (one or two) to be withdrawn from the core zone, in order to maintain an appropriate negative reactivity level in case of handling errors, for instance during core operations such as refuelling. When the reactor starts up, operators first withdraw the safety absorbers from the core, maintaining it in a sub-critical state ${ }^{189}$, and then the control absorber(s) is (or are) gradually withdrawn from the core until it reaches criticality $(\rho=0)$. This absorber (or these absorbers) are then used to increase or decrease reactor power and to compensate for fuel burn-up when the reactor is in operation. The safety absorbers are generally held axially outside

189. This is a design requirement for the core and absorbers. 
the zone of the core ${ }^{190}$ (usually by means of electromagnets). In incident or accident conditions, the electromagnets are disabled, and the absorbers drop or are rapidly inserted (with a pressurized gas device) into the core or core zone to cause automatic reactor shutdown (see figure 7.3).

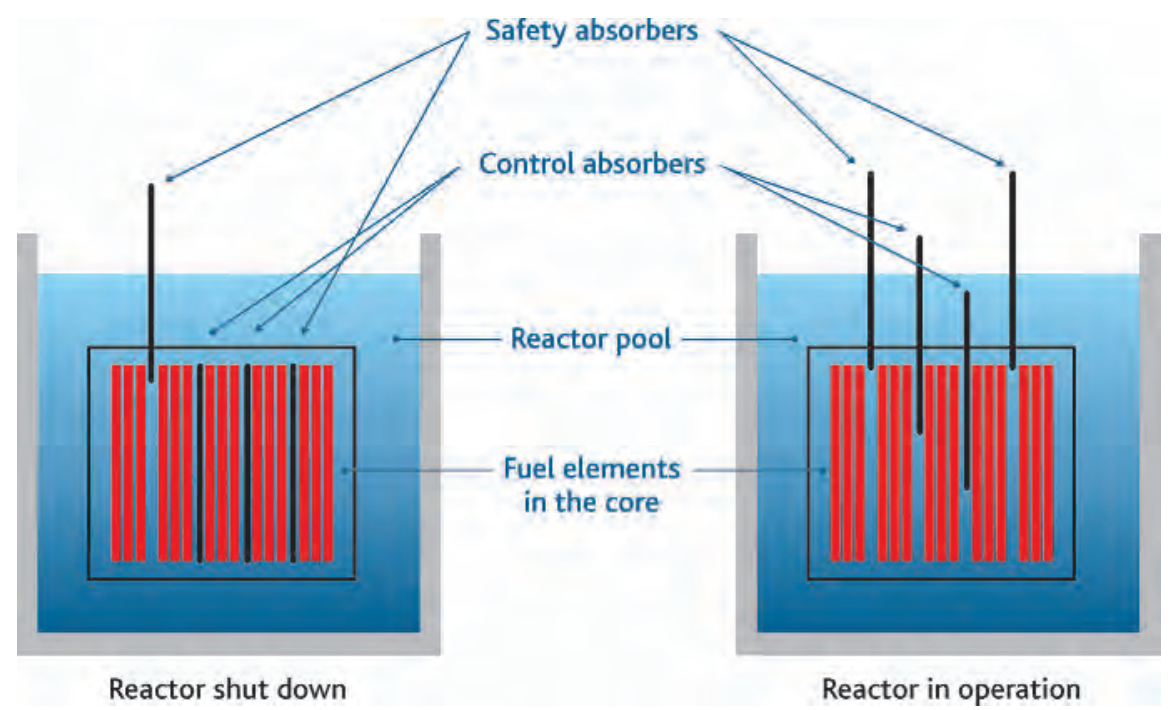

Figure 7.3. Position of the safety absorbers and control absorbers in a pool-type reactor in shutdown conditions (left) and in operation (right). (c Georges Goué/IRSN.

Each reactor has a protection system connected to various redundant sensors (temperature, pressure, neutron flux, etc.) and actuators. The signals emitted by the sensors are processed using an appropriate and safe "voting" logic. The monitored parameters and the threshold values that trigger safety actions (chiefly a safety absorber drop) are specific to each reactor. The threshold values are determined by "operating conditions ${ }^{191 " ~ s t u d i e s . ~ A ~ s a f e t y ~ a b s o r b e r ~ d r o p ~ m a y ~ a l s o ~ b e ~ t r i g g e r e d ~ b y ~ s i g n a l s ~ f r o m ~ o u t s i d e ~}$ the reactor (e.g. earthquake, impact on the reactor building, loss of required negative pressure in a room) or by signals from sensors that monitor certain operating parameters relating to the experimental devices, when this is deemed necessary for reactor safety.

The protection system is a key element in research reactor safety. Various options are used in design, in order to ensure a high level of protection system reliability, including redundancy, technological diversification and the physical separation of measurement pathways. A single failure criterion is used to check that no single failure can

190. The safety absorbers may indeed be outside, but close to the core, as is the case with the RHF, for example.

191. Conservative margins are added to the operating conditions in order to take into account uncertainties, for example with the measured reactor values or the time required to activate protective systems. 
prevent a system from performing its allocated safety function. This can be achieved by redundancy, which means that system elements are duplicated (or more) and distributed across different "channels" or "trains" to ensure that each path can perform the system function. In addition to redundancy, the "trains" can be separated from one another geographically, to ensure that no hazard, such as a fire, can affect all trains at the same time (referred to as a common mode failure). Diversification means using, as far as necessary, different designs or technologies for the components on the redundant trains of a given system, to ensure that the system is sufficiently reliable. Furthermore, design of important "active" components should be "fail safe", meaning that any component failure should switch it to a state that is favourable for safety. For instance, a "safe" position for the absorbers would be full insertion into the reactor core. The absorbers control system is designed with electromagnets that drop them into the core (for mechanisms located above the fuel zone) if electrical power is lost.

Core loading is an important operation, involving loading the fuel elements into the core, and is performed under procedures that require many checks and controls. Hardware design provisions can be used to physically prevent positioning errors that could jeopardize reactor safety.

During periodical safety reviews, in addition to the protection system described above, some research reactors have had a back-up system added to stop the chain reaction in some accident conditions under which core deformation could prevent or dangerously delay absorber insertion (e.g. in the event of a major earthquake). This may be as simple as a system to inject a neutron absorber in aqueous solution into the reactor coolant. This type of system has for instance been implemented on the CABRI reactor (borated water injection) and has been adopted as a core melt accident management provision on the Jules Horowitz reactor.

As well as the conventional reactivity control strategies described above, it is also important to prevent failures that could lead to reactivity insertions in a core.

From research reactor design phase, study is therefore required into any absorber mechanism malfunction that could lead to absorber withdrawal or ejection from the core zone (generating a reactivity insertion) instead of insertion into the core or core zone to control reactivity. Design provisions can be implemented to restrict the amplitude or rate of absorber withdrawal, as has been the case for the Jules Horowitz reactor.

Likewise, specific leakage scenarios or reactor block structure failures (reactor vessel, thimbles of neutron beams, etc.) that could lead to reactivity insertion into a core (e.g. for the RHF, ingress of light water into the heavy water flowing in the core) require analysis and appropriate in-service monitoring of the relevant structures in order to ensure their occurrence is sufficiently unlikely.

\subsubsection{Cooling the reactor}

This safety function is not particularly problematic for very low power reactors, up to approximately $100 \mathrm{~kW}$, in which the heat naturally dissipates through reactor structures. For higher power reactors, it is obviously essential to have enough coolant, and the core can be cooled either by the natural upward flow of this coolant in the 
reactor core (natural convection), or by a stronger flow of coolant which requires forced convection. In the latter case, the reactor core is cooled via a reactor coolant system, which uses circulator pumps to generate the coolant flow. This reactor coolant system is itself cooled by a secondary cooling system, in order to prevent radioactive releases, since the reactor coolant can potentially be contaminated.

The reactor coolant system may be an entirely closed circuit, or may be partially open to the reactor pool. Coolant system failures (loss of flow, pressure loss, loss of coolant) are detected by the protection system, which can trigger alarms or even shut down the reactor automatically. Residual heat still needs to be removed, and the level of this will depend on previous reactor operating regimes, in particular its operating power. For reactors that operate at a power of a few megawatts, natural convection may provide sufficient flow to cool the fuel in the reactor after shutdown. However, in order to start this flow, water from the pool in which the core is submerged must be able to get into the fuel elements. Valves in the core coolant pipes, at the entrance to the core, ensure that this connection can be made between the reactor coolant system and water from the pool. When the reactor is operating at power, these valves are kept closed by the pressure differential between the water in the pool and the reactor coolant system. They open naturally when the pressure differential reduces (e.g. loss of reactor coolant flow). These valves are generally duplicated to prevent any loss of this connection between the pool and the reactor coolant system in the event of a valve failure. (This is an application of the single failure criterion). Depending on the residual power released by the reactor core, it may also be necessary, in the first few minutes after reactor shutdown to maintain a higher coolant flow rate than the natural convection rate. The reactor coolant pumps therefore have flywheels, which slow them down gradually, to maintain sufficient reactor coolant flow in the reactor core for some time after shutdown. The valves and flywheels mentioned above are components that need no external supply of electricity, compressed air or other utilities to operate.

In some research reactors, natural water convection in the core can even remove heat from low operating power, and this possibility is provided for in the general operating rules for these reactors. This enables valve operation and natural water convection in the core to be checked in normal reactor operating conditions. In reactors whose core is cooled in normal operating conditions with a downward water flow (high-flux reactor in Grenoble, ORPHEE), natural convection does not start immediately upon shutdown, because it requires the flow direction in the core to be reversed. For such reactors, this switch of direction obviously needs to be checked in commissioning tests and in operation.

For high-power research reactors such as the $100 \mathrm{MW}$ Jules Horowitz Reactor which is currently under construction at the Cadarache site, the level of residual heat released means that forced core cooling flow must be provided for several hours after reactor shutdown. Residual heat removal requires the use of "active" systems, both normal systems and safeguard systems for accident conditions. These safeguard systems include pumps and heat exchangers that exchange heat with one or more cooling systems. Given the safety-importance of such systems, the design, manufacturing and operating requirements are high and include specifications concerning in-service monitoring and maintenance. These systems are provided as redundant, with each system geographically separated and individually capable of removing all residual heat. They are 
provided with back-up electrical power via batteries and generators, and the pipe lengths and number of flanges and unions are kept low in order to reduce risks of leakage or pipe break.

For research reactors whose core sits in a pool, the water inventory in the pool needs to be maintained in all possible situations. Maintaining this water inventory is one of the ways cooling function is managed, and is also a protection against ionising radiation. A drop in water level in the pool may be due to a leak in it or a leak or break in a circuit connected to it. To prevent a water level drop, one design provision is to ensure that all pipes penetrating the structure of the pool open out above the level of the reactor core. This applies in particular to the auxiliary systems, such as the "hot layer" system referred to below in section 7.3.3, which remove surface impurities from the water in the pool, or the make-up water system that makes up for water that evaporates from the pool.

In neutron beam reactors, the neutron channels (see figure 7.4) that penetrate the pool walls cannot comply with this provision because, by definition, they are located on the same level as the reactor core. A neutron beam channel is therefore fitted with:

- a "window" (in most cases ${ }^{192}$ ), which is a membrane made of a sufficiently neutron-transparent material (usually aluminium or an aluminium alloy), which separates the in-reactor part of the channel from the outside air in the areas used by scientists; this window is designed to withstand accidental loading (such as ingress of water into the channel in the event of a thimble failure, or a possible BORAX-type accident in the core);

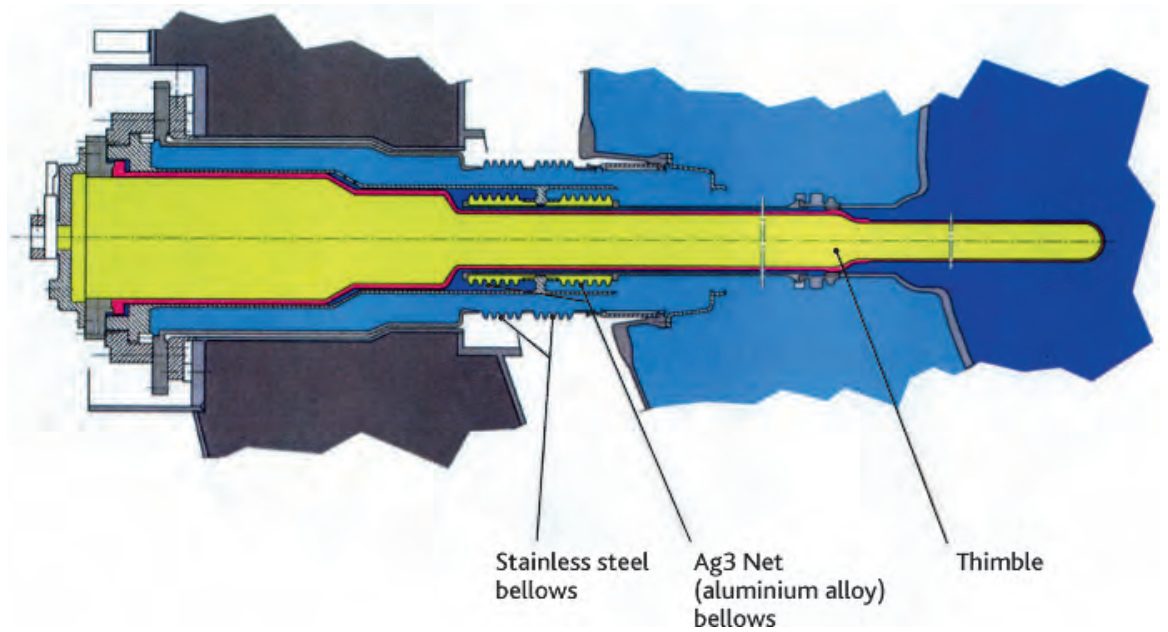

Figure 7.4. Section through a thimble from the high-flux reactor in Grenoble. (c) ILL.

192. In the the RHF, for example, thimbles $\mathrm{H6}$ and $\mathrm{H9}$, which are used for inserting samples onto a trolley where they will receive the highest neutron flux close to the core, do not have "windows". In this case, the redundant seal is provided by other valves downstream of the safety valve. 
- a shut-off valve at the pool wall, or "safety valve" that is permanently open when the reactor is in operation, to provide a double leaktight. If water enters the thimble, a time switch can trigger valve closure.

Furthermore, the channels have neutron beam shutters, which are separate components, in addition to the "windows" and safety valves described above.

Given the water flow velocity in the reactor coolant system, any leak in a portion of the system outside the pool could drain the system through a siphon effect. To avoid this, the reactor coolant pipes have vacuum relief valves (see figure 7.5 ), whose role is
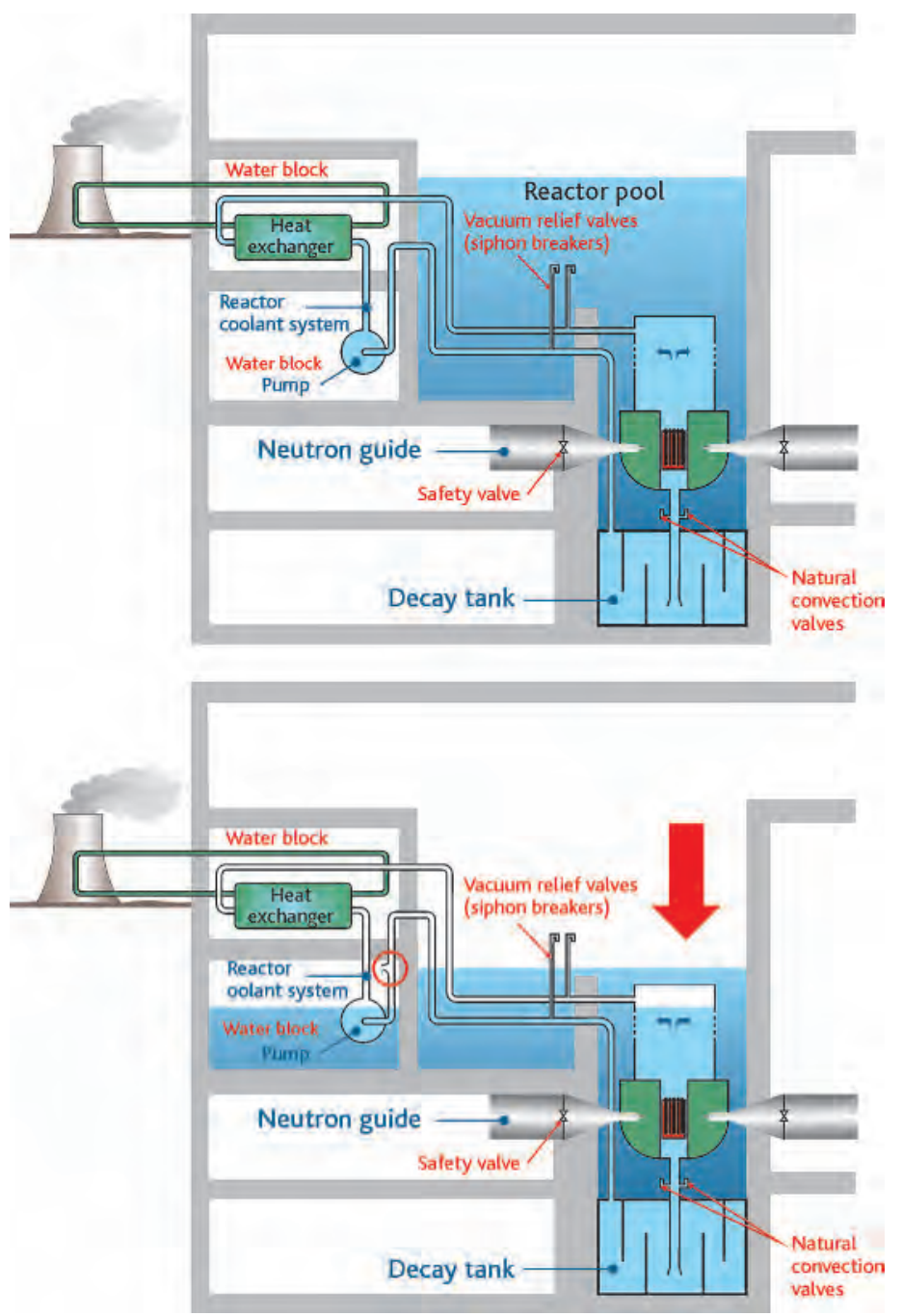

Figure 7.5. Schematic diagram showing "passive" siphon breaker systems on a cooling system. (c) Georges Goué/IRSN. 
to break the siphon effect, by letting air into the leaking system (either passive or active air injection using a valve or similar device).

In some French research reactors, including pool-type reactors such as OSIRIS, ORPHEE and JHR, a concept referred to as a "water block" is used to mitigate against the risk of reactor core uncover following a break on the reactor coolant system (see figure 7.6). This concept ensures that all rooms containing portions of a system in which a break or leak could drain the pool are sufficiently leaktight and of an appropriate volume. If there is a break of the system, water flows out into a leaktight room until it is completely filled. The quantity of water lost to the leak is limited by the volume of the room, which stops the pool from draining while it is still at a high enough level to prevent uncover of the fuel elements as a result of the reactor coolant pipe break. This however requires either strict operating procedures (doors kept closed), or design
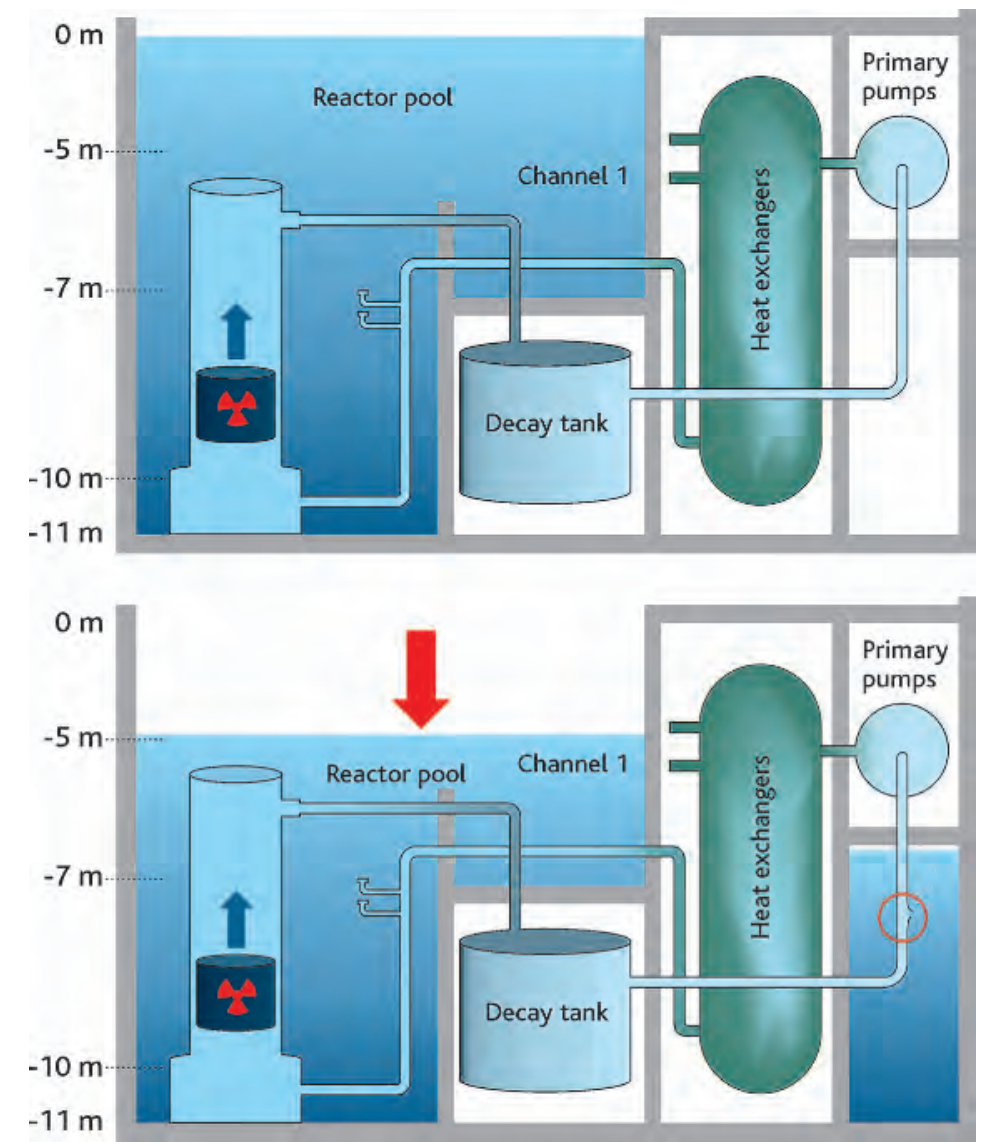

Figure 7.6. "Water block" concept: limiting water level drop in the reactor pool in the event of a coolant system break. (C) Georges Goué/IRSN. 
provisions (door position reported in the control room), to ensure that the relevant rooms remain tightly sealed.

Finally, the reactors pools of French research reactors that use a uranium-aluminium alloy-based fuel are designed to withstand the steam explosion from a BORAX-type accident.

\subsubsection{Confinement of radioactive substances}

The key principle for confining radioactive substances, both for research reactors and for all other basic nuclear installations in France, is to place several "barriers" between the substances and the environment. For the nuclear fuel, these "barriers" are as follows:

- the first confinement barrier is the metal cladding around the fuel elements;

- the second confinement barrier is generally the coolant circuit boundary; however, as previously mentioned, in some research reactors, this system is connected with the reactor pool and therefore does not form a proper confinement barrier;

- beyond this, the final confinement barrier comprises the building housing the reactor core (the lowest part being the basemat, the reactor pool floor or some rooms, depending on facility configuration).

It is important to highlight here that this final confinement barrier generally includes the building itself, providing "passive" confinement, and a ventilation and filter system, providing "dynamic" confinement.

Moreover, in neutron beam reactors, the heavy water systems contain tritiated water formed by neutron activation of deuterium atoms in heavy water. This requires these systems to be appropriately sealed, given the radiological risks associated with tritium.

The reactor building must be designed to restrict leakage into the environment. There must therefore be as few as possible piping or cable penetrations, and these must be sealed with appropriate materials. Since a building is never perfectly airtight, its passive confinement is generally supplemented by a dynamic confinement system, maintaining a slight negative pressure in the building compared with the outside pressure (the RHF is a special case, discussed later). With this pressure differential, air will preferentially leak from the outside in to the building. Such "active" confinement systems require equipment such as extractor and blower fans, along with filtration systems (high-efficiency particulate [HEPA] filters and iodine filters) that trap dangerous substances before they can be released into the environment in the air.

In the event of an incident or accident involving the dispersal of radioactive substances inside the reactor building, the ventilation systems are usually turned off automatically with reactor shutdown, in order to initially provide static confinement of the radioactive substances. This reduces the associated risks because the short-lived fission products begin to undergo radioactive decay. Ventilation systems 
can be turned back on later, in order to filter air releases. However, during the static confinement phase, pressure increases inside the building because the air is heated by the suspended fission products, and some of the building's atmosphere may escape into the environment without being filtered, through "natural" leakage. Some research reactors, such as ORPHEE and JHR, therefore have a "leakages grouping area", which is a room adjacent to the reactor building that contains a ventilation system with filters. All piping and cable penetrations from the building enter this room (see figure 7.7), enabling it to collect the majority of leaks from the building before they are released into the environment.

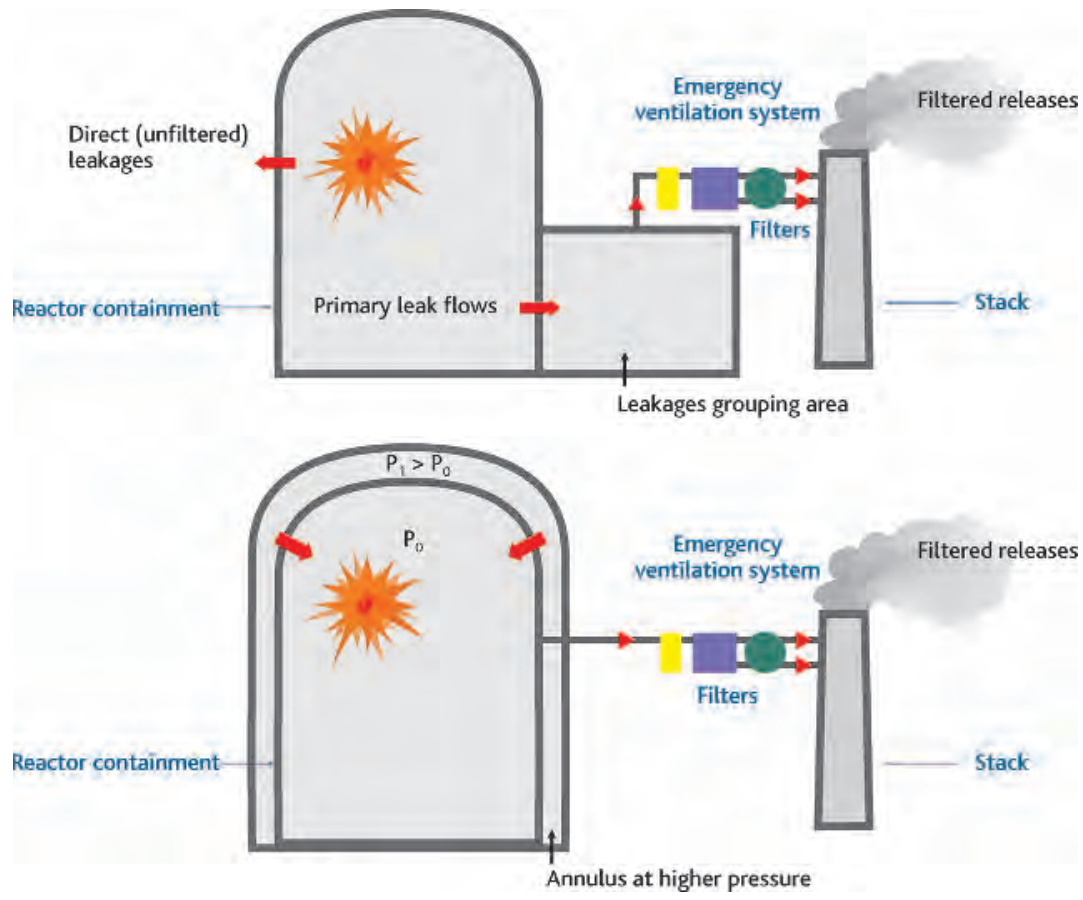

Figure 7.7. Schematic diagram of provisions implemented to prevent direct leakage from a reactor building atmosphere into the environment. @ Georges Goué/IRSN.

Another provision is to create an annulus around the reactor building, in which the air pressure is always higher than inside the building. This approach was adopted for the RHF.

The choice of strategy for this ultimate confinement (third barrier and associated systems) depends on the composition and quantities of radioactive substances that could be released in accident conditions, and on the kinetics of such releases. Other considerations such as the proximity of local communities may also feed into the choice. This is a key decision for reactor new-build projects, and the choice must feature in the Safety Options Report which is filed with the Safety Authority for examination. 
It should also be noted that most research reactors have an emergency ventilation system to remove air at a lower flow rate and maintain a slight negative pressure in the reactor building after the normal ventilation system shuts down. This emergency ventilation system, fitted with HEPA filters and iodine filters, filters any radioactive releases, spreads them out over time and measures the level of radioactivity released. There is an automatic switchover from normal to emergency ventilation if a predetermined level of radioactivity is exceeded in the reactor building.

Two further features of some research reactors are also worth a mention:

- as mentioned above, the reactor coolant system of some research reactors is connected to the reactor pool. In order to protect operators or scientists working on the edge of the pool, these reactors have a "hot layer" system, which sends hot water $\left(40^{\circ} \mathrm{C}\right)$ to the top of the pool and removes it again from the top layer by suction on the other side. This "hot layer" has a depth of between $2 \mathrm{~m}$ and $4 \mathrm{~m}$, and the water recovered is treated continuously using ion exchange resins. The temperature differential created by this "hot layer" keeps radioactive substances down in the colder water lower in the pool;

- in some cases, such as the CABRI reactor (see figure 5.11), the reactor coolant circuit may run partly outside the reactor building; in this case, both the reactor coolant tanks outside the reactor building have a double lining and a retention $\operatorname{tank}^{193}$.

\subsubsection{Criticality risks}

A criticality accident can expose people close to the affected area to severe levels of radiation, and can even cause death. Measures are therefore taken to maintain subcritical conditions whenever criticality is not required, whether in the reactor core when it is shut down or in any other part of the facility using plutonium, uranium that is more than $1 \%$ enriched in uranium-235 or certain minor actinides such as curium or americium.

A sufficient quantity of fissile nuclei are required to trigger a chain reaction in any given medium. This means that in any medium there is a mass below which a self-sustaining fission reaction is not physically possibly. One way of preventing a chain reaction is therefore to restrict the mass of fissile materials ${ }^{194}$. The limitations imposed by this control strategy, when used in isolation, are usually fairly stringent, and it is thus applicable to a container, glovebox or laboratory that uses small quantities of fissile materials, but not, on its own, to rooms containing larger quantities of fissile materials, such as critical assembly fuel element storage areas.

In such cases, two simple principles are used to guarantee subcriticality:

- reducing neutron generation as much as possible by reducing the likelihood of fission reactions;

193. Tanks with very low water pressure.

194. An isotope is referred to as "fissile" if its nucleus can split (undergo fission) under bombardment from fast or slow neutrons. The only naturally-occurring fissile isotope is uranium-235. 
- encouraging as far as possible neutron leakage out of the medium in question, or neutron absorption by non-fission capture ${ }^{195}$.

\#FOCUS

\section{Slowing down the neutrons - key to maintaining \\ a chain reaction}

When they are generated in a fission reaction, neutrons have high kinetic energy (around $2 \mathrm{MeV}$ ), and the probability of causing a further fission is fairly low. However, as they move through material, the neutrons collide with nuclei in the medium and gradually lose some of their energy. This increases the probability of their capture and of further fission. The lighter the nuclei that the neutrons encounter, the more they are slowed down (the slowing-down process is often called "moderation"). Hydrogen is thus a very good moderator.

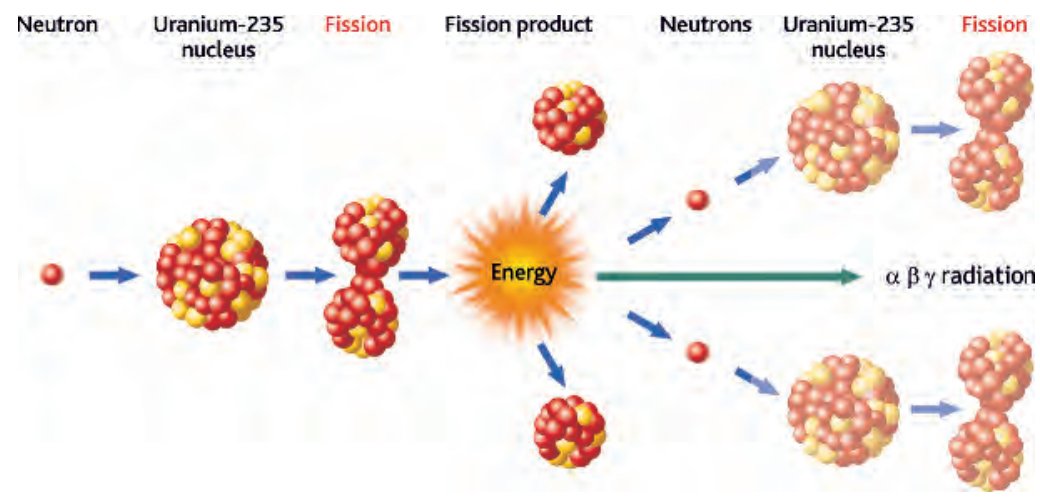

Figure 7.8. Uranium-235 fission reaction. (C) Georges Goué/IRSN.

Water and hydrogenated materials are "moderators" (see focus), increasing the likelihood of uranium-235 fission, and therefore raising the criticality risks. Water may therefore be prohibited in some rooms, even as a fire-fighting substance, with a specific low-hydrogen extinguishing powder used instead. This is a criticality control method that involves limiting moderation.

195. Neutrons can be captured by nuclei of the structural metals, the moderator, the fuel cladding, absorber rods or even by fissile nuclei without triggering fission. These neutrons are hence lost for the chain reaction. The affected materials are activated by these captures (meaning they have become radioactive). 
The potential presence of hydrogenated materials in waste or around fuel must be taken into consideration in criticality studies.

The geometric characteristics of the equipment in which the fissile materials are contained have a significant influence on neutron leakage. The geometric "criticality control method" has the advantage of low sensitivity to human operating errors. However, it must be adopted from equipment design phase wherever possible, taking into account any hazards and conditions that could change the "geometry" of fissile materials, such as corrosion and accidental deformation through temperature increases, earthquakes, etc. If such equipment is changed or modified, measures must be taken to ensure that appropriate geometric characteristics are retained.

When neutrons exit a fissile material, they continue moving and may end up returning to their original fissile medium because of collisions with the nuclei of these materials (neutron reflection). Some of the neutrons leaving a fissile medium may also enter a nearby piece of equipment that also contains fissile materials, and cause fission reactions there (neutron interaction). Both these phenomena must be taken into account in studies on criticality risks.

Finally, criticality risks can also be managed using "neutron poisons" such as boron, cadmium or hafnium, which are very good for absorbing neutrons.

Decisions as to the criticality control method(s) to be used for a facility (e.g. fuel element storage pool, fuel rodlets or platelets storage area for the MASURCA assembly) may lead to strict restrictions on specific parameters, taking account not only of normal conditions but also potential abnormal conditions (such as earthquakes) that may affect the fissile materials. Materials that may be present in the vicinity of the nuclear materials being studied obviously have to be taken into account in criticality studies, because of the potential neutron interactions that may increase criticality risks.

Fuel elements are often handled by operators in a research reactor, and in some handling phases, criticality risk prevention is largely based on organisational and human measures to ensure compliance with the restrictions defined in the criticality studies. Such measures may include hold points in handling operations or, for instance in the case of MASURCA, the use of sizing moulds that do not allow more than a permitted number of fuel strips. These provisions were adopted following a 2005-2006 safety review that analysed criticality risks at the facility in the light of organisational and human factors.

\subsection{Hazards}

As with other basic nuclear installations, there are two types of hazards to consider:

- internal hazards, originating inside the facility,

- external hazards, originating outside the facility.

\subsubsection{Internal hazards}

The main internal hazards that can affect research reactor safety are flooding (following a pipe or tank leak or failure), fire and explosions and load drops. Since 
research reactors do not usually use high-pressure coolants, the risks of pipe "whip"196 are lower than for pressurised water reactors, for instance. These issues may however need to be considered for test loops. The reactor safety consequences of each type of hazard have to be assessed and appropriate prevention and mitigation measures taken.

Electrical components are deemed to be sensitive to internal flooding, since any contact with water can lead to short circuits and outbreaks of fire.

Any rooms that contain, or could potentially contain, fissile materials are also sensitive to flooding, because of the criticality risk.

Provisions such as low walls at the entrance to rooms and placing fissile materials storage cabinets at a certain height may be adopted. It is also important to avoid routing water pipes through sensitive rooms or rooms containing flood-sensitive equipment, as far possible.

A waterproof coating may be fitted in some areas of a facility, as appropriate, to prevent internal flooding from water that could come in from outside the building as external flooding at ground level or through a rise in the groundwater level.

Alongside flood risks, the large range of electrical equipment used for experiments may make it harder to manage fire risks in a research reactor. Fire risk management is necessary throughout the duration of facility operation. A fire took place in August 1979 in the room housing the electronic equipment cabinets for the hodoscope ${ }^{197}$ at the CABRI reactor. The fire was found to have been caused by a transformer in the bottom of one cabinet overheating. Because all sides of the cabinet were closed, the fire had already developed significantly when the detector sounded the alarm. With dark, corrosive smoke filling several rooms quickly, the investigations and firefighting efforts were significantly hindered, since the most active area of fire was hidden by the electronic cabinet, and the rooms had no smoke extraction system. This resulted in confusion for quite a long period of time as to which room the incident started in. The fire was eventually fought with water spray systems and fully extinguished only after two hours. All the hodoscope electronic cabinets ${ }^{198}$ were destroyed and the hodoscope could not be used for eight months.

A Basic Safety Rule was established in 1991, specifically for fire risk management in research reactors (see section 6.2). More recently in 2014, an ASN decision ${ }^{199}$ established rules for fire risk management in all basic nuclear installations in general. Four levels of application of the defence in depth principle are outlined:

196. Complete pipe rupture can lead to movements known as "whip" in the pipe branches on either side of the break. The violence of the whipping depends on the fluid pressure inside the pipe system.

197. This device is used to observe the behaviour of fuel elements (specifically movements of the fissile material) placed in the CABRI reactor test section in experiments that simulate accident conditions leading to fuel melt and liquidation.

198. Some documents also report damage to the reactor protection system relay due to the propagation of smoke.

199. ASN Decision 2014-DC-0417 dated 28 January 2014. 
- "preventing outbreaks of fire;

- detecting and quickly extinguishing outbreaks, firstly to prevent them leading to a full fire and secondly, to return to normal operating conditions or, failing that, achieve and maintain a safe state ${ }^{200}$ in the facility;

- limiting the hazard and spread of any fire that cannot be controlled, in order to minimise the impact on nuclear safety, and to enable a safe state to be achieved and maintained in the facility;

- managing accident conditions resulting from any fire that cannot be controlled such as to limit consequences for people and the environment."

The first three levels of these rules are about avoiding jeopardising fundamental safety functions. Any equipment performing such functions must obviously be protected from the consequences of a fire.

As for other basic nuclear installations, prevention of the outbreak of fire in research reactors involves using low-flammable materials as much as possible, and limiting combustible materials to the quantities strictly necessary in those rooms or areas designated for their storage such as pools or warehouses, etc.

Facilities are also equipped with fire detection systems that notify operators of any outbreaks of fire and automatic actions may be triggered, such as stopping air supply from the ventilation system and closing fire dampers to limit the spread of the fire.

Finally, research reactors have firefighting systems that are appropriate to the types of fire that may occur and the equipment to protect. There are however various specific features that are worth highlighting. For example, in core fuel element handling and storage areas at the MASURCA facility (for fuel rodlets or platelets, solid sodium etc.), firefighting systems using graphite-based powders are installed for fires that could involve solid sodium elements, given the energy-releasing nature of the sodium-water reaction (sodium fire, emission of oxide and peroxide sodium aerosols). Moreover, as has already been stated in section 7.3.4, water may be prohibited in some rooms with criticality risks because water is a neutron moderator. This applies to the fissile element storage and handling areas in the MASURCA storage and handling building.

Facilities are organised into fire compartments to prevent the spread of any fire that is not quickly extinguished. A fire compartment is a clearly contained volume, closed off with walls such that a fire inside a compartment cannot spread to the outside (or vice versa) during a certain period of time, allowing firefighting systems to be used. By using fire compartments, common mode loss of a safety function can be avoided, as long as the function is provided by two redundant systems located in two different fire compartments. This is usually the case for a nuclear reactor protection system (that triggers reactor scram) and for electrical power supply systems, etc.

200. ASN Guide No. 22 on the design of pressurised water reactors, released in 2017, defines a safe state as follows: "stabilised condition of a facility in which subcriticality, residual heat removal and the containment of radioactive substances can be maintained in the long term." 
In some older research reactors however, fire compartmentation was not planned in design phase. Special attention is therefore paid to this issue, especially in safety reviews, when the possibility of improvements and upgrades in this area can be specifically examined.

Some fire compartmentation non-conformities have been discovered in basic nuclear installations in general, by the facility operators themselves or during inspections by the French Nuclear Safety Authority (ASN). Further study is ongoing into reducing firerelated risks, focusing on the possibilities of unburned gases and soot spreading outside of the compartment in which the fire started, such as to jeopardise the redundant trains of safety-classified systems in other fire compartments. IRSN is continuing to perform research and development work on this topic ${ }^{201}$.

For research reactors, the prevention of explosion-related risks is generally based on reducing the possible sources and distancing them from any safety-important equipment. Explosion risks associated with the experimental devices placed inside research reactors (including the "long-term" associated equipment such as "hot sources" and "cold sources") are discussed later.

Load drops are events that can occur during the handling of relatively heavy items (fuel elements or assemblies, experimental devices, transport packaging, etc.). Prevention of such events involves adopting robust design provisions and ensuring in-service monitoring of lifting equipment. However, it is not really feasible to rule out any possibility of load drops. For this reason, metal plates on shock absorbers (sometimes referred to as "resilient bearing pads") have been fitted to some reactor pools in order to protect their bottom or parts of their bottom from load drops. Likewise, some research reactors have "lifting accompaniment devices", which slow the fall of any load being handled if the lifting equipment fails.

\subsubsection{External hazards}

External hazards may have human ${ }^{202}$ or natural causes. Manmade hazards are related to the presence of industries and transport routes in the vicinity of the facility. Natural hazards will depend on the site at which the research reactor is built, and may include earthquakes, flooding, fire, lightning, violent winds and tornados and extreme temperatures.

When a new research reactor project is considered, the prevention of external hazards is firstly based on the choice of site, avoiding choosing a site that will engender insurmountable difficulties for facility protection and design. It is important to determine the external events that could constitute hazards for the facility; the determination method will vary depending on the hazard type considered.

It should be noted that some research reactors have been close to or on the site of universities or other academic centres (e.g. the Strasbourg university reactor, which has now been shut down).

201. See publication "Current state of research on pressurized water reactor safety", Science and Technology Series, IRSN/EDP Sciences, 2017.

202. Malicious acts are not covered in this document. 
For hazards caused by the industrial environment (e.g. chemical plants) or human activities (all forms of transport, including civil and military aviation), the hazard-causing events are usually identified on the basis of a probabilistic-type analysis. If the likelihood of occurrence is very low (of the order of $10^{-7}$ per year), current practice under the fundamental safety rules (see chapter 6) is to consider the hazard improbable enough to disregard in terms of facility protection or design verification.

The main risks associated with land-based transport routes and the industrial environment around a research reactor are a gas cloud explosion (explosion of a truck carrying hazardous materials or a warehouse storing hazardous materials) or a toxic gas cloud drifting to the facility. These risks were closely studied for the RHF at Grenoble, which is located close to an industrial area, a motorway and a railyard. In addition to the design provisions, supplementary considerations are taken into account as necessary during safety reviews, including an analysis of preparedness for potential emergency situations (crisis management).

The natural hazards considered are determined on the basis of available historical data, which is then extrapolated to define hazards in pessimistic terms, which may be associated with a given recurrence period.

ASN Guide No. 13, which was released in 2013, discusses how to determine trigger events relating to the various possible causes of external flooding and how to define the appropriate protection provisions ${ }^{203}$. For every research reactor site, all possible causes of flood risks need to be explored, including heavy rainfall, rain-induced river level rises, flash flooding from dam failure and rises in the groundwater level, etc. French research reactors are not built on the coastline, which rules out risks from high tides and tsunamis, etc.

With regard to the risks of heavy rainfall, rainwater drainage systems are designed to ensure that no water enters the facility and, if necessary, sills may be installed at certain doors.

The safety of the RHF at Grenoble in the event of dam failure, given its location at the confluence of the Rivers Drac and Isère, both of which have a number of dams, is an issue that has been analysed repeatedly in periodic reviews as well as in the complementary safety assessments (stress tests) carried out in France in the wake of the Fukushima Daiichi nuclear powerplant accident. This issue of safety reviews is addressed in section 9.2 .

The following paragraphs describe in greater detail the way in which seismic risks are managed. Given their locations, the risk that an earthquake of significant intensity may occur can be relatively high for some research reactors. This type of hazard, it should be noted, affects the whole of a facility simultaneously and can therefore lead to common mode failures.

203. On this subject, see the 2013 IRSN Report "L'aléa inondation - État de l'art préalable à l'élaboration du guide inondation pour les installations nucléaires". 
With regard to seismic risks, until the 1970s, research reactors built in France were built under the then-applicable earthquake protection rules ${ }^{204}$, which were not specific to any particular type of building, such as a basic nuclear installation. In 1974, when nuclear power reactors were being developed in France, the CEA Nuclear Safety Department ${ }^{205}$ drafted report DSN50 (on behalf of the standing group of experts for nuclear reactors) entitled "Protecting powerplants from earthquakes". The report surveyed relevant French and international practice and made a number of proposals, especially about how to determine which ground response spectra ${ }^{206}$ to use (with a dynamic analytical method) to assess the "response" of the structures to an earthquake. These proposals formed a basis for facility operators to work with, and prefigured fundamental safety rule RFS I.2.c, which was released in 1981 by the Nuclear Facility Safety Central Service for pressurised water reactors, proposing a deterministic method that would be acceptable for determining which seismic motions should be taken into account in earthquake design for such reactors. In 1992, fundamental safety rule RFS I.1.c extended this method to be applied to all basic nuclear installations, including research reactors. This method starts with surveying the strongest known earthquakes in the area around the facility site, based on available geological and seismological data, in order to determine the intensity of a "maximum historically probable earthquake". The intensity is increased, to give what is known as a "safe shudown earthquake", which is used as a reference for facility safety. In 2001, a new fundamental safety rule (RFS No. 2001-01), drawn up with the help of IPSN experts, was released by the Nuclear Safety Authority after several years of discussion between relevant parties. This new Rule maintained a deterministic approach, but also introduced some further developments about how paleoearthquakes and site effects should be taken into account. Moreover, for sites with very low seismic risks, a minimum spectrum is defined, for which peak ground acceleration (PGA: acceleration corresponding to infinite frequency) is set at 0.1 times gravitational acceleration $(\mathrm{g})^{207}$.

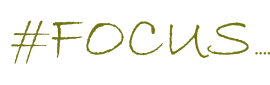

\section{Paleoearthquakes \& Site effects}

Paleoearthquakes are strong earthquakes that occurred in ancient times. They can be identified through the traces they have left in geological deposits in the Quaternary. The purpose of studying them is to understand and characterise the occurrence of such earthquakes and to supplement knowledge about seismicity

204. Recommendation AS 55 (1955), drafted following the Orléansville earthquake in Algeria in 1954, earthquake protection rules PS62, 64, 67, 69, etc.

205. The IPSN was only established as part of CEA in 1976.

206. Response (in terms of accelerations) of resonators at various natural frequencies, under the effects of the earthquake in question.

207. For zones of moderate seismicity, accelerations can be up to $0.3 \mathrm{~g}$ approximately. For highseismicity zones such as Japan or Turkey, accelerations can be up to a range between 0.4 and $0.6 \mathrm{~g}$. 
around a site, beyond the period for which instrumental data (over the last century) or historical records (over roughly the last millennium in France) are available.

Site effects that require study are potential amplifications of seismic motions due to the presence of a layer of low mechanical strength soil close to the surface (up to 30 metres below ground level).

In addition, in some specific cases, complex geometry or thick sedimentary layers (e.g. a sedimentary basin) may cause amplification or temporal prolongation of the seismic motion. These are referred to as site-specific effects, and are not caused only by soil properties in the first 30 metres below the surface.

Site effects have to be especially taken into account at a research reactor such as the RHF at Grenoble, because of the presence of an alluvial basin (figure 7.9,
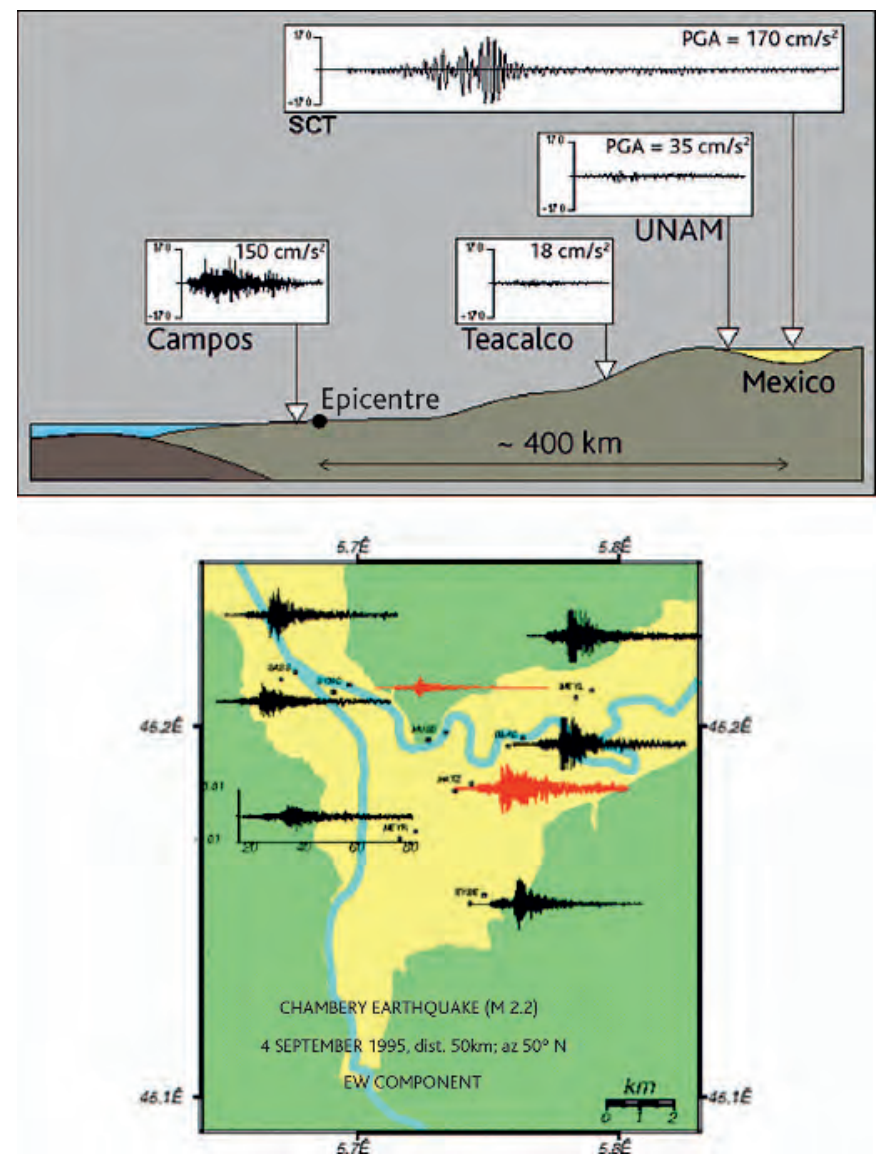

Figure 7.9. (Top) example of site effects in a coastal area of Mexico (C) J.F. Semblat, A. Pecker (IUSS Press, 2009); (bottom) example of site effects in the Grenoble basin during the 1996 Chambery earthquake. (C) All rights reserved. 
bottom side). The Saclay facilities are built on alluvial-type soil (but in a low-seismicity zone) and the Cadarache facilities are on a mixed rock/sediment soil.

Since all facility components are simultaneously affected by the seismic motions, facility safety relies on robust design ${ }^{208}$ of a set of key equipment that provides the main safety functions and if necessary, for a nuclear reactor, ensures it is placed in a safe state 209 . Alternatively, under an "event-level earthquake" approach (see section 7.1.2), design must ensure that components cannot themselves jeopardize safety-important equipment (e.g. by falling).

Calculations can be used to verify equipment behaviour under seismic loads (this method is used for concrete and metal structures). Full-scale testing on shaking tables can also be used for components such as natural convection valves or electrical cabinets or even safety absorbers (to check their ability to be inserted into the core zone in earthquake conditions, even if the core has been deformed by the earthquake).

Of the various equipment items that present potential hazards to safety-important equipment ${ }^{210}$, special attention is paid to handling cranes - particularly for research reactors whose core is directly accessible via the reactor pool (reactor coolant system connected to the pool). If a handling crane or its trolley were to drop, significant damage could be caused to the top part of a core, the instruments, absorber mechanisms, a pressurised circuit, reactor coolant pipe, natural convection valves, fuel elements or other components, and this could lead to a criticality accident or reactivity insertion accident, a sudden steam release or could prevent the safety absorbers from inserting properly into the core or the core from cooling properly. Some French research reactors have a system that detects seismic loads over a specific level and triggers a reactor scram, which reduces the consequences of an earthquake-driven crane or trolley drop. This system can ensure that subcriticality is maintained, but cannot necessarily guarantee that the fuel elements will be properly cooled, since these elements may have suffered deformation. It therefore seems essential to prevent any cranes or trolleys from falling, regardless of the cause. Design and manufacture must comply with tried-and-tested best practices, in-service inspections must be performed (including the statutory checks applicable to lifting plant and accessories), and operating rules must be complied with, to reduce any crane motions above at-risk zones to the strict minimum.

208. ASN Guide 2/01 dated 26 May 2006 addresses the way seismic risks should be taken into account in the earthquake-resistant design of basic nuclear installation civil works (with the exception of long-term radioactive waste disposal facilities.

209. See note footnote 191.

210. Some cranes may themselves be treated as safety-important equipment, requiring the general provisions adopted for such equipment, for example in-service inspections, maintenance, traceability of modifications, etc. 


\section{\#FOCUS \\ Improving knowledge on the behaviour of structures under seismic loading: handling cranes}

It is not easy to predict the behaviour of a crane and its trolley under seismic loads, with the potential to slip, slide and bump against its end buffers. There have been some difficulties in this regard during safety reviews, particularly when seismic motions were reassessed, leading to a significant increase in the loads to be taken into consideration. In the 2000s, IRSN and the CEA initiated studies on this issue, including tests on the AZALÉE shaking table at the CEA Saclay research centre (see figure 7.10). The focus of this work was to provide better understanding of the "response" of such complex structures to seismic motions, and to assess the robustness of the simplified methods used by facility operators to design structures.

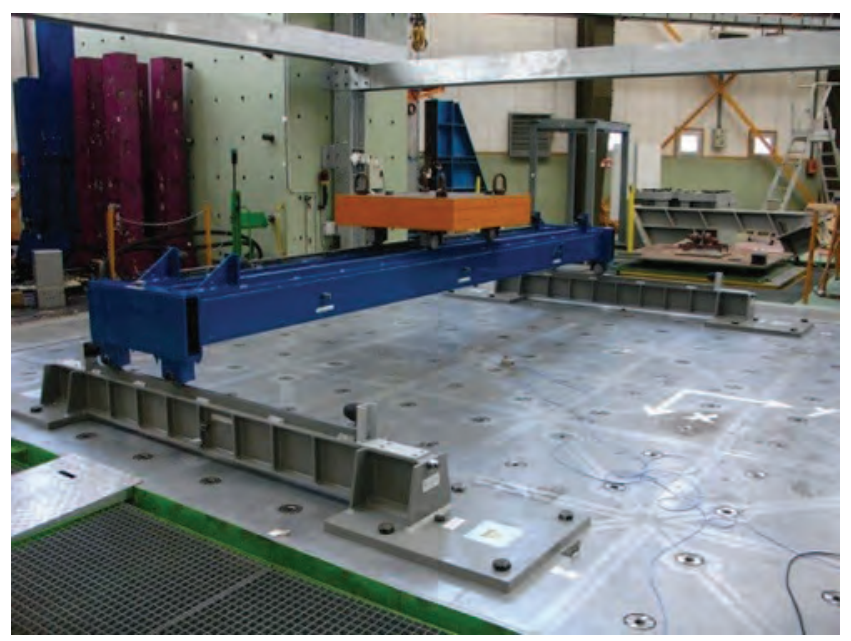

Figure 7.10. Handling crane undergoing testing on the AZALÉE shaking table at the CEA Saclay research centre. (C) CEA.

It should also be noted that there are systems that can be used to limit the motions that will affect a building and its equipment in the event of an earthquake. For instance, the reactor building basemat at the Jules Horowitz Reactor (JHR) on the Cadarache site, in a region with a history of strong earthquakes, such as the Lambesc quake in 1909, was laid on reinforced concrete bearing pads that were fitted with layers of elastomer and steel (see figure 7.11). This system (referred to as "seismic base isolation") reduces 


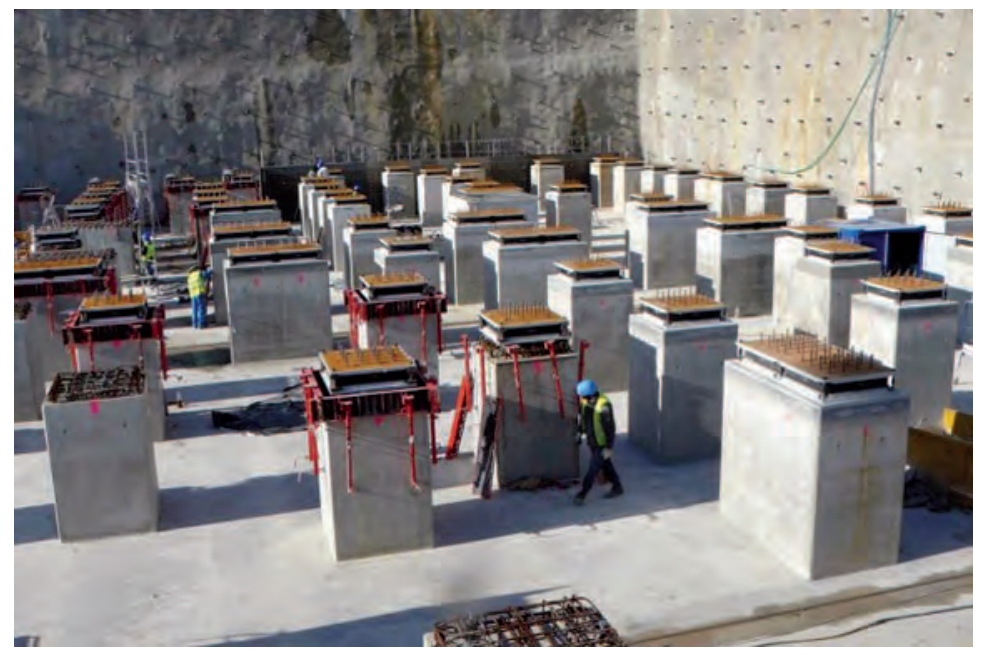

Figure 7.11. View of aseismic bearing pads during construction of the Jules Horowitz reactor (2009), from "Le Blog des Énergies". (C) DR.

high-frequency horizontal seismic loading ${ }^{211}$ for items such as floor-mounted equipment and handling cranes in the building. There is an obvious issue in keeping the bearing pads and elastomer layers in working condition throughout the duration of reactor operation, given their potential for ageing. It is therefore necessary to ensure that the bearing pads and elastomer layers can be replaced if any anomalies are detected during planned inspections.

JHR also includes a design provision that reduces impact risks from differential motions between the reactor building and auxiliary building. These two buildings, which make up the "nuclear unit" are built on the same basemat.

As stated previously, several French research reactors, such as MASURCA, RHF and $J H R$, feature accelerometers that send a signal to the reactor protection system. If a specific level of seismic loading is detected, the protection system triggers a reactor scram early enough to ensure that the safety absorbers are inserted far enough into the core zone when the bigger shocks come.

Research reactors are generally facilities with low sensitivity to weather-related hazards such as extreme heat or cold. For many research reactors, residual heat removal does not require any external heat sink other than the air, and their electrical power

211. The adoption of this base isolation system increases the amplitude of accelerations at the system's natural frequency (approx. $0.5 \mathrm{~Hz}$ ). France has experience in this area, since the four units at the Cruas-Meysse plant were installed on this type of base isolation system in 1977, because the ground response spectrum at the site was above $2 \mathrm{~Hz}$, the design spectrum EDF adopted for its nuclear powerplants. AFCEN has published a document on such seismic base isolation systems: "French Experience and Practice of Seismically Isolated Nuclear Facilities", PTAN RCC-CW 2015. 
requirements can, if necessary, be reduced to mere monitoring of the main safety-important parameters.

Research reactor buildings are fitted with lightning conductors, and lightning arresters are fitted to the electrical installations.

\subsection{Experimental devices and research reactor-specific equipment}

One feature of research reactors is that they include experimental devices or equipment, some of which is placed right in the reactor core, or in nearby peripheral areas. These devices and equipment items may include simple irradiation devices, more complex experimental circuits, neutron channels, "hot sources" and "cold sources". As stated in section 7.1.2, any interactions between these devices and components and the reactor core have to be analysed from a safety perspective, both in normal reactor operating conditions and in incident or accident conditions that could affect the reactor and the experimental devices.

Analysis of any experimental device or component requires the various potential "danger sources" to be identified, which could, in degraded conditions up to and including the complete rupture of the device or component, or its "removal" from the core zone, have a negative impact on reactor safety or radiological protection. These danger sources include fissile materials, absorbent materials, radioactive or toxic products, products that may be explosive in air, products that may be violently reactive in water, pressurised liquids or gases and high-temperature materials that may enter into thermodynamic interaction with water in the reactor core.

Depending on the properties of their materials, experimental devices or equipment may, in particular, modify core reactivity, since their materials may have neutron absorption (poison), reflection or moderation properties. The reactor protection system must therefore be capable of controlling any reactivity insertion in the core that could be caused by an inadvertent movement, such as an uncontrolled withdrawal from the core. For simple irradiation devices, this can be achieved through a design limit on the reactivity contribution of the relevant device or component; in such cases, the limit is also included in the technical operating specifications. For larger devices whose reactivity contribution cannot be sufficiently limited, design provisions are required to prevent or limit uncontrolled withdrawal (latching or hold-down devices).

For experimental loops, other risks may need to be considered, for example because of the use of pressurised fluids (e.g. to represent the conditions of pressurised water reactors - 155 bar [figure 7.12]) or reactive elements such as sodium which has a violent reaction with water. These loops may also contain molten materials, when the study of meltdown conditions is one of the objectives in an experiment on a fuel element.

Demonstration tests on mock-up assemblies may be necessary in order to assess the effects of explosion of an experimental loop on the nearby fuel elements in the reactor core. It is worth mentioning the OTHELLO loop for the OSIRIS reactor, which was designed for studies on high-temperature reactors (HTR): in the mock-up assembly, the loop had notches cut into it so that it would rupture at a given pressure. 


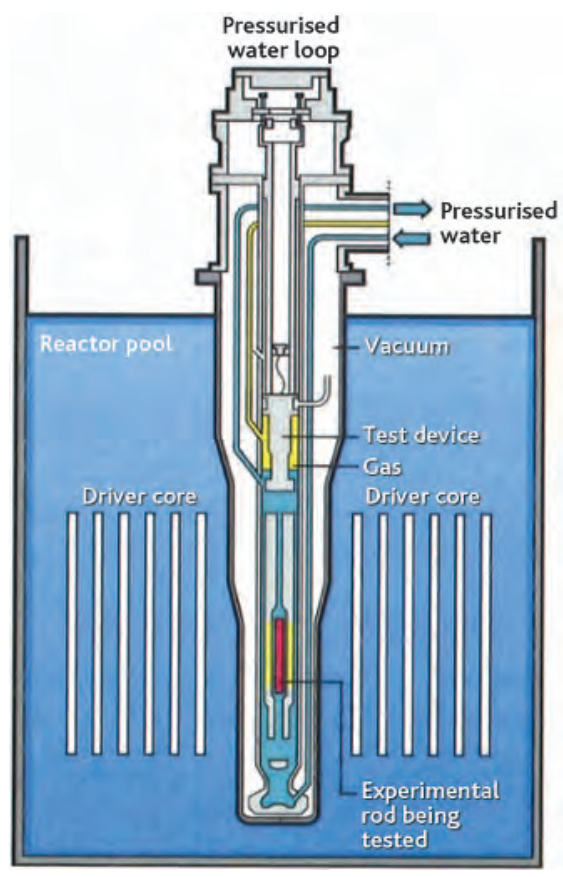

Figure 7.12. Schematic diagram of the pressurised water circuit in the CABRI reactor core. @ Stéphane Jungers/IRSN.

The "hot sources" and "cold sources" used in "neutron beam ouside" reactors generally contain liquid hydrogen $\left(H_{2}\right)$ or deuterium $\left(D_{2}\right)$ in the first case and graphite at more than $1,000^{\circ} \mathrm{C}$ in the second. Any failure of the casing(s) of such equipment would bring their contents into contact with water in the reactor core, causing a hydrogen, deuterium or steam explosion risk ${ }^{212}$ which could affect the core or the reactor confinement barriers. To prevent this risk, the main strategies are firstly to ensure there are "barriers" or casings of appropriate number and strength between the danger source and the reactor core, and secondly to manage the specific parameters of these devices (e.g. deuterium pressure, temperature).

One final key point in the design of experimental devices or equipment is material ageing. The materials will be subjected to neutron flux, which will gradually modify their mechanical properties. This applies especially, in "neutron beam outside" reactors, to the end parts of neutron channels (thimbles and their tips), which are constantly close to the reactor core. Neutron channels are generally made of aluminium or an aluminium alloy, or a zirconium compound such as Zircaloy. These materials are used for their neutron "transparency", but are weakened by exposure to neutron radiation. For this reason, such equipment (thimbles or core boxes, for example) must be replaced as appropriate during the service life of a research reactor. The effects of ageing can be

212. Steam explosion risk from thermodynamic interaction between graphite at $1,000{ }^{\circ} \mathrm{C}$ and water. 
anticipated by monitoring samples or specimens of the relevant materials that are irradiated in areas closer to the core than the experimental equipment itself (or actually in the core). This can help define the required frequency of equipment replacement.

\subsection{Radiological protection and waste substances}

\subsubsection{Radiological protection}

The French system of radiological protection is based on three major principles, which are part of the Public Health Code:

- justification of any activities that have a risk of exposure to ionising radiation;

- optimisation of radiation exposure to the lowest level reasonably possible, taking account of economic and social factors;

- limitation of individual radiation exposure doses.

French regulations establish annual individual dose limits for members of the public and workers (table 7.4).

Table 7.4. Exposure limits for members of the public and workers as a result of nuclear activities, as stated in the French Public Health Code (Article R. 1333-8) and Labour Code (Article R. 4451-13).

\begin{tabular}{|l|c|c|}
\hline \multicolumn{1}{|c|}{ Type of dose } & $\begin{array}{c}\text { Members of the } \\
\text { public } \\
\text { per year }\end{array}$ & $\begin{array}{c}\text { Exposed workers } \\
\text { (adults) } \\
\text { any twelve consecutive } \\
\text { months }\end{array}$ \\
\hline Annual effective dose & $1 \mathrm{mSv}$ & $20 \mathrm{mSv}$ \\
\hline $\begin{array}{l}\text { Equivalent dose to the skin, forearm, } \\
\text { feet and ankles (average dose per } 1 \mathrm{~cm}^{2} \text { area) }\end{array}$ & $50 \mathrm{mSv}$ & $500 \mathrm{mSv}$ \\
\hline Equivalent dose to the lens of the eye & $15 \mathrm{mSv}$ & $150 \mathrm{mSv}^{213}$ \\
\hline
\end{tabular}

In addition, the Labour Code requires facility operators to determine regulated monitoring zones around any sources of ionising radiation. These zones are defined in the "Zoning" Order of 15 May 2006 (table 7.5).

There are a wide variety of sources of ionising radiation in a research reactor and its related facilities, including fuel elements, neutron beams, start-up neutron sources, calibration sources and sources used for X-ray inspections. Likewise, a variety of operating activities can cause exposure to radiation:

213. The values given here are from ICRP Publication No. 60 from 1991. ICPR Publication No. 103 from late 2007 gives recommended values of $15 \mathrm{mSv}$ for members of the public and $20 \mathrm{mSv}$ for workers. French regulations were reviewed in 2018 (Health Code, Environment Code, Labour Code). 
Table 7.5. Limits for monitored and regulated zones defined in the "Zoning" Order (excluding natural irradiation).

\begin{tabular}{|l|c|c|}
\hline Type of zone & Colour & Effective dose \\
\hline Free access zone & & $<0.080 \mathrm{mSv} / \mathrm{mth}$ \\
\hline Monitored zone & & $<0.0075 \mathrm{mSv} / \mathrm{h}$ \\
\hline Controlled zone & & $<0.025 \mathrm{mSv} / \mathrm{h}$ \\
\hline Specially regulated controlled zone & & $<2 \mathrm{mSv} / \mathrm{h}$ \\
\cline { 2 - 3 } & & $<100 \mathrm{mSv} / \mathrm{h}$ \\
\hline Prohibited controlled zone & & $\geq 100 \mathrm{mSv} / \mathrm{h}$ \\
\hline
\end{tabular}

- reactor core loading or unloading,

- loading, unloading or modifying experimental irradiation devices or circuits,

- preparing fuel elements or assemblies, or irradiation or activation experiments,

- performing measurements on irradiated materials or fuels,

- in-service inspections, etc.

The facility operator uses analysis of the activities and of the characteristics of the ionising radiation sources to categorise rooms in the facility into "free access", "regulated", "specially regulated" or "prohibited" zones, in which the above limits must be complied with, through the implementation of technical and organisational measures. Figure 7.13 shows some examples of physical protection that might be used. Concrete blocks or lead walls are often used for this purpose (e.g. around the neutron guides in areas used by the physicists conducting experiments). For operations involving small irradiated objects, concrete or lead bricks will be placed around objects to which access is required, while still providing protection from ionising radiation. In some cases, operators may wear lead aprons.

In order to check compliance with the applicable dose limits, workers wear a measurement device appropriate to the nature of the ionising radiation at all times, providing ongoing exposure monitoring. Operational dosimetry ${ }^{214}$ is also used to warn them if

214. Operational dosimetry, also known as active dosimetry, involves real-time measurement of external exposure using a personal operational dosimeter. This device is provided and monitored by the Radiological Protection Officer under the responsibility of the Facility Manager. The electronic system in an operational dosimeter means that the dose received by the worker can immediately be read off. Measurements can be taken during a specific task or over a given duration (entry into a controlled zone). The devices have audio or visual alarm systems that are triggered if predefined doses are exceeded. This provides wearers with permanent information about the radioactive risk to which they are exposed. Wearers or the department responsible (using remote monitoring) can track and optimise exposure levels during the period of exposure itself. 


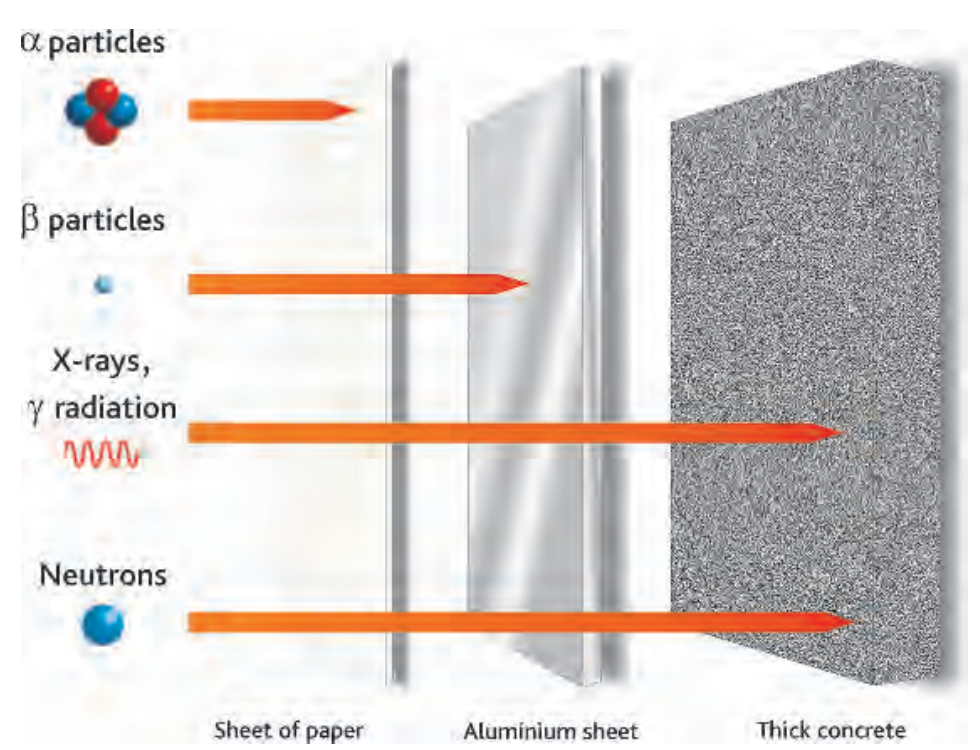

Figure 7.13. Effectiveness of various protections against different types of ionising radiation. (c) Georges Goué/IRSN.

a predetermined dose rate is exceeded, or a predetermined dose is exceeded over a certain duration.

If any work has to be performed on the facility, a safety analysis is performed, which includes a focus on radiological protection. A radiological protection optimisation study is conducted, which aims to ensure that personal doses, the number of people exposed and the likelihood of unplanned exposure during the work is kept as low as reasonably possible, taking into account economic and social factors. The main stages of the study are as follows:

- assess exposure conditions, including potential exposure occurrences if the operation does not take place as planned;

- select an appropriate upper limit for the dose restrictions;

- identify the possible protection options;

- select the best option in the applicable circumstances;

- implement the chosen option.

Operating experience is taken into account. The results are assessed, particularly in the perspective of future operations of the same type.

Optimising radiological protection does not necessarily mean minimising doses. Optimised protection comes as the result of an assessment and discussion, whereby the risks of the anticipated exposure are compared with the resources available for personal protection. The best option does not necessarily mean the one with the lowest 
doses. Moreover, radiological protection is not just about individual exposure levels; the number of people exposed must also be taken into account. The collective effective dose is a key parameter in optimising worker protection. When protection options are compared to achieve optimisation, careful consideration should be given to the distribution of individual exposure levels within the population of exposed people.

The experimental equipment or devices themselves may also be sources of ionising radiation. This is the case for example with experimental loops in which fuels are subjected to transients that could lead to cladding failure or fuel melt, contaminating the test circuits themselves. The components in these loops are fitted with biological shielding and specific handling equipment such as transfer casks are used to limit ionising radiation within the facility.

\subsubsection{Waste liquids and gases}

The management of waste liquids and gases from research reactor operation is generally similar to their management in any basic nuclear installation. However, two specific types of waste deserve a mention in this context:

- tritiated water produced from neutron capture by the deuterium in the heavy water used in "neutron beam outside" reactors (RHF and ORPHÉE);

- waste generated in experimental loops in which experimental fuel meltdown may occur or even be targeted.

Specific arrangements are put in place to manage these specific waste products (at ORPHEE, for example, there is a detritiation installation, and at the high-flux reactor in Grenoble there is a heavy water drum unloading installation, with the heavy water treated in a different facility).

The releases of waste liquids and gases from French research reactors are given in table 7.6, along with the annual limits established by official orders or decisions.

\subsection{Emergency preparedness and management (crisis management)}

Any significant release of radioactive substances that would require protection measures to be taken for local populations (e.g. evacuation, confinement to closed homes, distribution of stable iodine tablets, food restrictions) would mean that four initial levels of defence in depth had failed or proved ineffective. Specific measures are defined within the nationwide crisis management plans, which apply to all basic nuclear installations, including research reactors. These plans are not described in detail here $^{215}$, other than to mention the aspects that are specifically relevant to research reactors.

215. See for example: "La gestion d'une crise nucléaire : des responsabilités partagées" on the ASN website or "Face à un accident nucléaire", IRSN, Livrets des professionnels Collection - December 2008. 
Table 7.6. Releases from two research reactors (RHF, OSIRIS-ISIS) and annual limits.

\begin{tabular}{|c|c|c|}
\hline \multicolumn{3}{|c|}{ RHF } \\
\hline Type of releases & $\begin{array}{c}\text { Maximum annual value } \\
\text { over 2010-2015 period } \\
\text { Gaseous waste }(\mathrm{GBq}) \\
\text { Liquid waste }(\mathrm{GBq})\end{array}$ & $\begin{array}{c}\text { Annual limits } \\
\text { (Order dated 03/08/2007) }\end{array}$ \\
\hline Noble gases & 1,200 & 10,000 \\
\hline Tritium & 12,000 & 75,000 \\
& 370 & 1,000 \\
\hline Carbon 14 & 460 & 2,000 \\
& 0.3 & 1.5 \\
\hline lodides & $3.4 \times 10^{-3}$ & 0.1 \\
\hline Other $\beta \gamma$ emitters, aerosols & $1.3 \times 10^{-3}$ & 0.1 \\
& $3.1 \times 10^{-4}$ & 1 \\
\hline
\end{tabular}

OSIRIS-ISIS reactors (INB No. 40)

\begin{tabular}{|c|c|c|}
\hline Type of releases & $\begin{array}{c}\text { Maximum annual value } \\
\text { over 2010-2015 period } \\
\text { Gaseous waste }(\mathrm{GBq}) \\
\text { Liquid waste }(\mathrm{GBq})\left(^{*}\right)\end{array}$ & $\begin{array}{c}\text { Annual limits } \\
\text { (ASN Decision No. 2009-DC- } \\
\text { 0156 dated 15/09/2009) }\end{array}$ \\
\hline Noble gases & 7,356 & 10,000 \\
- & 297 & 2,000 \\
\hline Tritium & $3.4 \times 10^{-3}$ & 0.5 \\
\hline Carbon 14 & 1.14 & 20 \\
\hline lodides & $7.6 \times 10^{-4}$ & $10^{-2}$ \\
\hline Other $\beta \gamma$-emitters & $4.5 \times 10^{-4}$ & 0.5 \\
\hline$\alpha$-emitters & $6.3 \times 10^{-4}$ & 0.01 \\
& $2.3 \times 10^{-3}$ & $2 \times 10^{-2}$ \\
\hline & $1.7 \times 10^{-4}$ & $5 \times 10^{-3}$ \\
\hline
\end{tabular}

${ }^{(*)}$ Liquid waste released into the chemical waste system. Active liquid waste is also sent to the Saclay and Marcoule treatment plants.

Crisis management measures include "on-site emergency plans", which the facility operators are responsible for activating, and "off-site emergency plans" which are the responsibility of the public authorities. These emergency plans were generally initiated in the early 1980s, following lessons learned from the 1979 Three Mile Island nuclear powerplant accident in the USA ${ }^{216}$. In the case of research reactors operated by CEA, the relevant Director of the centre or his/her representative (or the On-Call Centre Manager outside working hours) is responsible for activating the "on-site emergency plan". In the case of the RHF, this responsibility falls to the Head of Reactor 
Division at Institut Laue-Langevin or his/her deputy (or the On-Call Duty Engineer). Whatever the circumstances, the authorities must be alerted within two hours at the latest.

The on-site emergency plan - some aspects of which are based on a "design study" included in the safety report (see below) - defines organisational measures, intervention methods and the necessary means to be implemented by the facility operator in emergency situations, in order to protect staff, the public and the environment from ionising radiation and to maintain or restore facility safety. It may also specify procedures for implementing measures that are the facility operator's responsibility under the off-site emergency plans (alerting and sheltering in "reflex mode").

If a facility operator implements its on-site emergency plan, it must regularly provide updates on its accident-stricken facility and issue a prognosis anticipating potential developments of the situation. This information is shared and discussed with the French Nuclear Safety Authority and IRSN. One of the "crisis management tools" is the so-called 3D-3P diagnosis and prognosis approach ${ }^{217}$ developed in the 1990s by IPSN and EDF for French nuclear powerplants. In principle, it is applicable to French research reactors. However, it needs to be adapted in a few ways in order to take into account their specific features, including their layout and the number of confinement barriers.

There are other "crisis management tools" (in addition to simplified simulation software - see chapter 11), including summary documents on "standard accidents".

Based on facility characteristics and the associated risks, facility operators responsible for research reactors consider one or more representative accidents (or "standard accidents") and plan crisis management measures to manage such situations. These "standard accidents" are selected from the accidents studied in the safety demonstration and presented in a chapter of the Safety Report ${ }^{218}$ entitled "On-site Emergency Plan Design Study". These "standard accidents" represent the various potential dangers for the facility and are not only radiological dangers (accidents entailing chemical-related consequences may for instance be included). BORAX-type accidents are included in these "standard accidents" for many French research reactors, because they lead to core melt and overpressure in the reactor building, which could cause releases into the environment. Less severe accidents may also be included as "standard accidents" in the on-site emergency plan ${ }^{219}$, including:

- cladding failure on a fuel plate under water, in the reactor core;

- a fuel plate melting under water, in the reactor core;

- a fuel element melting in air in the reactor building during reactor core unloading;

217. The number " 3 " refers to the three confinement barriers in pressurised water reactors.

218. As required by Decree No. 2007-1557 dated 2 November 2007, known as the "procedures" decree.

219. With reference to INSAG-10, a facility operator (in France) may make the decision to activate the on-site emergency plan for accidents that come under defence in depth level 3. (BORAXtype accidents come under level 4). 
- drop of a transport package containing multiple fuel elements, etc.

Some "standard accidents" may assume multiple internal failures or the occurrence of a natural hazard more intense than that considered in facility design.

In the event of an accident involving significant fuel damage, operating staff and researchers in the reactor building and adjacent rooms, such as the control room, may have to be evacuated, due to the dose rates generated. Direct radiation exposure outside the reactor building may also be significant in the event of a core melt incident in air (e.g. core uncovery) or if a fuel element melts during handling in the reactor building. For this reason, French research reactors all have emergency control rooms located at a safe distance from the reactor, given the dose rates that could be generated by the accident-stricken facility. This emergency control room includes information required for accident management (neutron and thermohydraulic parameters in the reactor core, water levels, dose rates, real-time measurement of activity released through the stack, etc.). Some facility systems can also be controlled from this location, such as the emergency ventilation system, which can be used to "manage" atmospheric releases in accident conditions.

Summary documents are produced and updated for different "standard accidents" (by IRSN in particular). These documents specify the potential consequences of the accident, with different variants depending on the weather conditions, time between reactor shutdown and the accident ${ }^{220}$, ventilation systems configuration and possible aggravating factors under the "prognosis" part of the 3D-3P method (e.g. iodine filters in operation or out of service).

Summary sheets describing the research reactors are also available to the crisis management teams, specifying the radiological inventories in the cores and spent fuel storage pools, and the characteristics of confinement barriers and ventilation and filtering systems, etc. These sheets are vital for research reactors, since a relatively small number of people have genuinely in-depth knowledge of these reactors.

The public authorities will analyse the conditions for evacuating or confining local people to their homes, under the "off-site emergency plans". Alongside these plans, short-, medium- or long-term measures to control the consumption or sale of potentially-contaminated foodstuffs are also prepared. The local Prefect is responsible for deciding on the implementations of such measures.

\subsection{Safety aspects for decommissioning research reactors}

Under the applicable regulations, the facility operator responsible for a research reactor now has to present the general principles and provisions for future facility decommissioning in a "decommissioning plan", at the time of the construction licence application. The information in the plan must, where relevant, be updated at the time of the facility commissioning application and at the time of safety reviews. Finally, as for

220. This time period will determine the residual power to be considered, which generally reduces exponentially over time. 
any basic nuclear installation, any facility operator that plans dismantling of a research reactor must file a specific application at the appropriate time.

In France, several research reactors have already been dismantled, including the Strasbourg University Reactor (RUS) and HARMONIE; the SILOE reactor at Grenoble has now been fully dismantled and the ULYSSE reactor in Saclay is at an advanced stage of dismantling. Some other reactors are currently being dismantled. The strategy is to aim for "immediate" dismantling ${ }^{221}$ after final reactor shutdown, in order to draw as much as possible on the skills and knowledge of operators who are still present. The dismantling of the PHENIX reactor has therefore been ordered, following on from the decision by the CEA to shut it down.

Current regulations emphasize the need to take decommissioning into account as early as possible in the life of a facility - from design phase - in order to facilitate dismantling operations and minimise the related risks. With this in mind, it can be noted that the complete removal of the reactor vessel was planned as part of the design of "neutron beam reactors" such as ORPHEE and the RHF.

221. ASN Guide No. 6 (revised version dated 30 August 2016) on INB final shutdown and decommissioining quotes the French Environmental Code, which requires the licensee responsible for operating a basic nuclear installation to "start decommissioning work as quickly as possible, in economically acceptable conditions and in compliance with the principles set forth in Article L. 1333-1 of the Public Health Code and in Article L. 110-1, paragraph II hereof". 


\section{Chapter 8 \\ The reference accidents selected for French research reactors}

\subsection{Definition and examples}

The reference accidents ${ }^{222}$ considered for French research reactors are accidents of internal origin (e.g. equipment failure, errors) that are considered likely to have the most severe consequences on the integrity of the fuel elements or the entire reactor core. They are very improbable in nature as they assume the occurrence of multiple failures. For some of them, reactor scram (insertion of absorber elements into the core) failure is assumed $^{223}$, or is considered ineffective given the rapidity of the accident.

The reference accidents adopted for French research reactors are primarily reactivity insertion accidents ${ }^{224}$ in the core. Others may be loss of coolant or fuel element uncovery.

222. The meaning of the expression "reference" for these accidents in (French) research reactors is different from that of the reference transients, incidents and accidents defined in the "technical guidelines for the design and construction of the next generation of nuclear power plants with pressurized water reactors" established by the GPR and German experts, and used for the EPR. These "reference" transients, incidents and accidents are broken down into four categories, depending on the estimated frequencies of the groups of events they represent; they correspond to the "operating conditions" of categories 1 to 4.

223. Transients with reactor scram failure are also known as ATWS (Anticipated Transients Without Scram) according to English terminology used for power reactors. They were studied following the Three Mile Island accident in 1979.

224. Readers are reminded that the expressions "insertion", "injection", "introduction" or "input" are used synonymously. The expression "power excursion" refers to the power transient caused by the insertion of reactivity. 
Reference accidents contribute to the very design of reactor containment, or at least verification of the design choices adopted for containment. Other external loads are taken into account for containment design or verification, including earthquakes, plane crashes, external explosions, etc. The term containment covers the third confinement barrier, consisting of the reactor building superstructures above and, depending on the configuration, below, the floor of the reactor pool or pools and underground rooms, the basemat, and the systems and equipment involved with dynamic confinement, such as ventilation systems, discharge filtration systems, etc. Other system penetrations (e.g. Systems contributing to reactor cooling) should also be taken into account. At the design phase, studies precisely define the functional requirements and technical characteristics of equipment contributing to reactor containment: thickness of concrete walls, rebar ratio, cable prestressing values, thickness of metal coatings for reactor pools, materials used, types of welds selected, ventilation rates, efficiency of filtration systems before discharge into the environment, etc.

For pool-type reactors using fuel composed of uranium and aluminium ${ }^{225}$ (OSIRIS, ORPHEE, high-flux reactor in Grenoble, JHR), a BORAX-type accident - whose main aspects will be outlined in the following sub-chapter - constitutes a reference accident. However, other reference accidents may also be studied for these reactors: clogging of water channels located between the fuel plates, a fuel element melting in air (during handling or core uncovery); these are then not reactivity accidents, but cooling accidents, resulting in fuel melt more or less quickly. Fuel melt in air accidents generally have the greatest radiological consequences (external radiation through the containment building, transfer of radionuclides into the environment); these accidents draw more on the containment capacity of the reactor building with regard to its superstructures, whereas BORAX-type accidents generally ${ }^{226}$ put more stress on the walls of the reactor pool.

For a reactor like the RHF located in the immediate vicinity of the city of Grenoble, the results of studies of reference accidents (meltdown of fuel underwater, meltdown of fuel in the air) are especially important for assessing the acceptability of the installation's design, particularly the containment building and associated systems.

The reference accidents currently ${ }^{227}$ selected for French research reactors, other than pool-type reactors, are listed briefly below.

\section{EOLE and MINERVE reactors}

For the EOLE reactor, the reference accident selected is the inadvertent lifting of a control absorber while the reactor is in operation, with supposed reactor scram failure (absorber not inserted into the core). The resulting reactivity insertion does not lead to fuel meltdown $\left(\mathrm{UO}_{2}\right)$.

225. Section 2.1 showed that all $\cup \mathrm{Al}_{x}, \mathrm{U}_{3} \mathrm{Si}_{2}$ and $\mathrm{UMo}_{\mathrm{x}}$ formula fuels also contain aluminium, added at the end of the grinding operation with the fuel powder.

226. Except for a BORAX-type accident, in the event of the possibility of a spray of water or water hammer under the reactor building dome.

227. They have changed in line with safety reviews. 
For the MINERVE reactor, the reference accident selected is reactor criticality (startup) with an abnormally constituted assembly (too powerful), loaded erroneously into the reactor core, with reactor scram failure. This leads to the insertion of $1,000 \mathrm{pcm}$ in approximately 1 second, without leading to fuel meltdown.

\section{MASURCA reactor}

For the MASURCA reactor, the reference accident selected is reactor criticality with an abnormally constituted assembly (too powerful), loaded erroneously in the largest considered core for the reactor ${ }^{228}$, with reactor scram failure. Reactivity insertion is $4.9 \$^{229}$ in 10 seconds. The facility operator had initially considered that this scenario could be excluded given the successive failures it assumes, but IRSN maintained that this was difficult to justify, given that its prevention is primarily based on provisions of an organisational nature. This type of accident does not lead to fuel meltdown, but, given the temperatures reached, the solid sodium of rodlets or platelets melts ${ }^{230}$. Given the large number of these rodlets or platelets in the reactor core, IRSN considered that it is not possible to exclude the presence of latent defects in some of their cladding. The ejection of liquid sodium from these strips would then lead to a sodium fire in contact with the core cooling air. Ultimately, the radiological (and chemical) consequences of the accident were assessed on the assumption of a fire involving $1 \%$ of the sodium present in the reactor core. The cladding of the fuel rodlets or platelets located close to the sodium strips on fire is assumed to be defective, leading to a release of radioactivity (representing approximately $4 \mathrm{TBq}$ ) into the reactor building (including fission products). Assessment of the radiological consequences of this type of accident in the environment led the French Nuclear Safety Authority (ASN) to ask the facility operator to study various provisions intended to reduce them (management of the containment building ventilation, back-up ventilation, leakages grouping, etc.) and assess the toxic risks due to sodium aerosols, particularly for operators required to perform rounds in the installation before launch of the sodium fire extinction system using argon.

\section{CABRI reactor}

The reference accident selected for the CABRI reactor is an overpower accident during operation, resulting from the simultaneous failure of four helium 3 rod pressure-relief valves (two "quick" opening valves and two "slow" opening valves - see section 5.2), with reactor scram failure, leading to an insertion of reactivity of 2,100 pcm in $20 \mathrm{~ms}$. The reactor power increases to a peak of around $25 \mathrm{GW}$, after which neutron feedback results in a rapid decline in power. Study of the scenario by the operator shows that the

228. It is possible to load different-sized cores into MASURCA.

229. For fast neutron reactors or the MASURCA mockup, which use plutonium, reference is often made to the "dollar" (\$), which corresponds to the proportion of delayed neutrons (see section 7.1 which gives some values for different types of reactors and fuels). For reactivity insertion, this is the reactivity threshold beyond which a chain reaction reaches criticality by prompt neutrons alone.

230. Sodium melts at a temperature of approximately $98^{\circ} \mathrm{C}$. 
temperature of the fuel rods increases but does not reach $\mathrm{UO}_{2}$ meltdown temperature $^{231}$ and that the mechanical criteria selected for the risk of cladding failure are not reached during the transient.

\subsection{BORAX-type accident - main aspects}

The BORAX-type accident has been selected in France as the reference accident for pool-type research reactors using uranium- and aluminium-based metal fuel in the form of plates (cores), contained between two thin aluminium sheets, which serve as cladding. For this type of fuel, meltdown begins with aluminium at $660{ }^{\circ} \mathrm{C}$.

The 1961 accident in American reactor SL-1 (Stationary Low Power Reactor Number One) and experiments conducted in the USA in the 1950s and 1960s demonstrated that in the event of a sudden and significant input of reactivity, these types of reactors may be subject to explosive phenomena resulting from the degradation or fast meltdown of part of the reactor core. Since then, this type of accident has been called a BORAX-type accident, named after the (five) reactors of the same name at the ANL (Argonne National Laboratory) in the state of Idaho (National Reactor Testing Station), which were used to conduct experiments into this type of accident.

The circumstances surrounding the accident on Reactor SL-1 are summarised briefly below, with the lessons learned. The phenomena involved in this type of accident and the way in which they are taken into account for the design of pool-type research reactors ${ }^{232}$ will then be explained.

\subsubsection{Accident at the SL-1 reactor}

The SL-1 reactor was a US Army experimental reactor built at the the Idaho National Laboratory (INL) site, approximately $65 \mathrm{~km}$ west of Idaho Falls, as part of a programme seeking to develop power reactors to supply electricity to remote sites, such as surveillance radar stations. It was commissioned on 11 August 1958. The reactor's maximum thermal power was $3 \mathrm{MW}$ and it was capable of electricity output of $200 \mathrm{~kW}$. The reactor core consisted of approximately one hundred uranium- and aluminiumbased plates, with aluminium cladding, and grouped into fuel assemblies; the fuel was manufactured at the Argonne National Laboratory. The uranium was enriched to $93 \%$ in isotope 235 . The reactor had nine cadmium-based absorber rods. The water in the (closed) reactor vessel served both as coolant and moderator.

In late December 1960, the decision was taken to perform maintenance on the absorber rods following various jamming incidents affecting these rods. The reactor was shut down to carry out this maintenance; the rods were placed in the low position and disconnected from their control mechanisms.

231. It will be seen in section 10.1.1 that slow ramps were in fact more damageable for the fuel that pulses, that was not identified, but there will be no more slow ramps in CABRI.

232. For more detail, please consult the following document drawn up by IRSN in 2011: Consideration of BORAX-type reactivity accidents applied to research reactors, Reference documents series, IRSN 2010/128, available at https://www.irsn.fr/EN/Pages/home.aspx. 
On the afternoon of 3 January 1961, after maintenance operations had been completed, a team reconnected the mechanisms to their respective rods in order to restart the reactor.

At $9 \mathrm{pm}$, alarm signals from the reactor building sounded at three fire stations. These alarms did not make it clear whether the problem was a fire or an abnormal radiation level. Upon their arrival on site, the emergency response teams could not detect any visible signs of damage or fire. However, very high dose rates were detected at the entrance to the reactor building, with values of around 1,000 rad/hour (10 Gy/h) in the reactor hall. Two people were found motionless near the reactor, while the third had been projected and pinned to the ceiling of the building by one of the absorber rods. Two of the three men were killed instantaneously, while the third died two hours after the accident, while being transferred to hospital.

The inspections performed with the support of a robot concluded that only the central absorber rod had been ejected. The other absorber rods had remained inside the core, which had suffered major radial deformation. A radiation shielding plug had been ejected onto the ceiling of the building. The state of the core can be seen in figure 8.1. The vessel and the reactor building both withstood the accident.

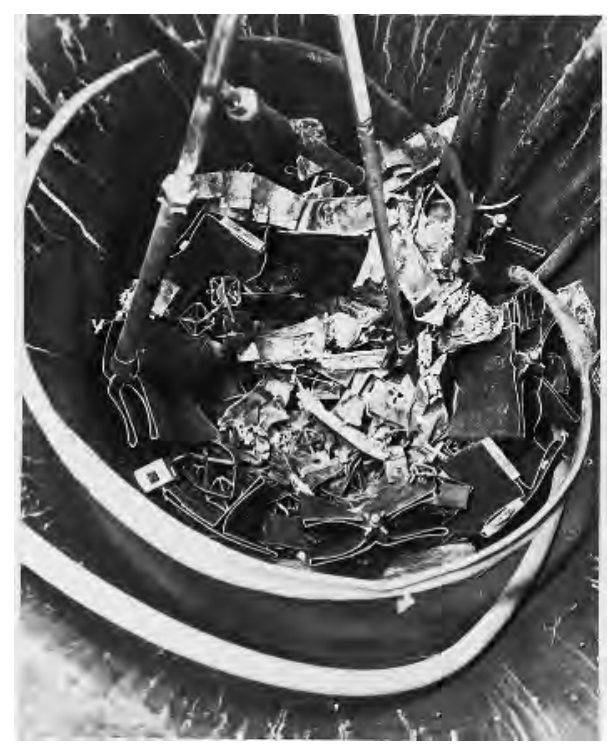

Figure 8.1. View of the SL-1 reactor core after the reactivity accident in 1961, three of the rod mechanisms are visible. @ INL.

The most widely-accepted theory to explain the accident is that an absorber rod got stuck and one of the operators decided to free it manually, but withdrew it too far. The rod was raised too high, exceeding the limit above which chain reaction runaway becomes uncontrollable, thus leading to the reactor explosion. Mainly due to the presence of a short-lived yttrium isotope found on the dead operators' clothing, it has been estimated 
that the reactor power may have surged to around 20,000 MW during the accident ${ }^{233}$. Given the damage observed, it was estimated that the vessel pressure exceeded 30 bars.

It took over a year to decontaminate the SL-1 reactor building. All debris from the reactor was fully removed and the building was demolished in 1962.

The most exposed members of the rescue crew received an estimated dose of 30 rad (0.3 Gy). There were no significant radiological consequences outside the building, which contained almost all (99.99\%) of the radioactivity (figure 8.2). Downwind of the SL-1 reactor, the radiological impact on plants remained low and no groundwater contamination was detected.

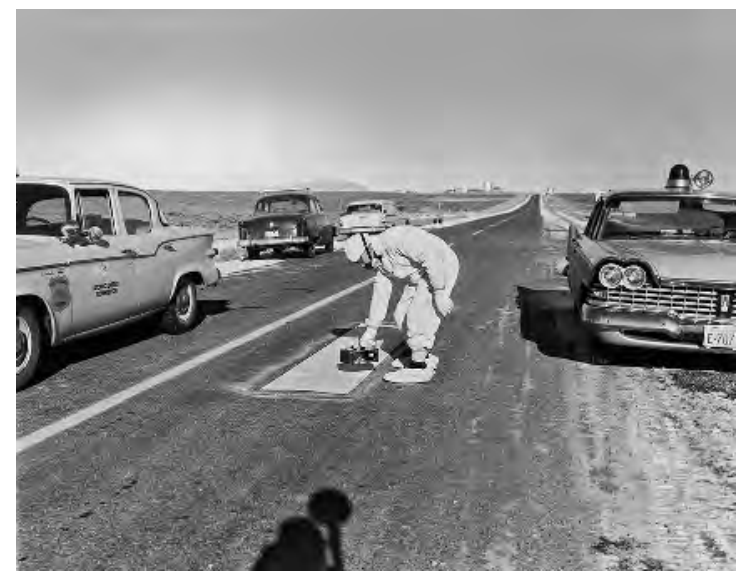

Figure 8.2. Measurement of ground contamination near Reactor SL-1. @ INL.

The data available regarding this accident shows that, in addition to ensuring radiological protection of crews, one of the main concerns of the people in charge of organising the emergency response was to avoid any risk of a second nuclear accident, by ensuring that there were enough absorber rods in the reactor core and that there was no danger of the ejected plug falling back down on top of the reactor.

\subsubsection{Key lessons learned from the SL-1 reactor accident}

The accident that occurred in the SL-1 reactor, together with tests carried out in the USA in 1954 in the BORAX-1 reactor and then in 1962 in the SPERT-1 reactor (see table 8.1 at the end of this chapter) showed that in the event of a sudden and significant input of reactivity, water-cooled research reactors that use uranium- and aluminiumbased fuel may be subject to the following two explosive mechanisms resulting from

233. With a total of $1.5 \times 10^{18}$ fission reactions. 
the degradation or fast meltdown of part of the reactor core (the two mechanisms could potentially co-exist):

- sudden water vaporisation (steam explosion),

- sudden aluminium vaporisation.

These phenomena can result in the creation of shock waves and the expansion of bubbles in the reactor coolant, and for pool-type reactors, in the pool. These bubbles may contain non-condensable gases (e.g. hydrogen resulting from the oxidation of aluminium or experimental devices), which could amplify the mechanical effects of the expansion of steam bubbles - leading to a mechanical "impulse ${ }^{234 "}$ on structures.

This type of accident may lead to:

- significant damage to the reactor block, reactor coolant system and reactor pool walls;

- damage to the lower part of the containment (bottom of the reactor pool), due to the thermal effects of the molten materials accumulating there;

- water transfer into the reactor building due to a steam explosion, which may impact the reactor building ceiling ("water hammer" effect) before falling back into the reactor pool. Part of this water transferred into the reactor building may be projected in the form of a water spray;

- an increase in atmospheric pressure and temperature in the reactor building, particularly due to thermal exchanges with the water spray, volatile fission products and noble gases released into the building, and potentially any fuel fragments or particles released;

- very high dose rates inside the reactor building and potentially outside;

- radioactive discharge into the environment.

\subsubsection{Consideration of the BORAX-type accident in France}

\subsubsection{General considerations}

In France, the possibility of a BORAX-type accident has systematically been taken into account in containment design for water-cooled research reactors operated using uranium- and aluminium-based fuel.

Consideration of this type of accident includes:

- definition of the provisions intended to make it highly improbable, considering all possible initiating events of an insertion of reactivity into the reactor core;

- determination of an envelope accident to define the potential consequences within the installation itself;

234. Characterised by a pressure time profile, with the peak value and duration. 

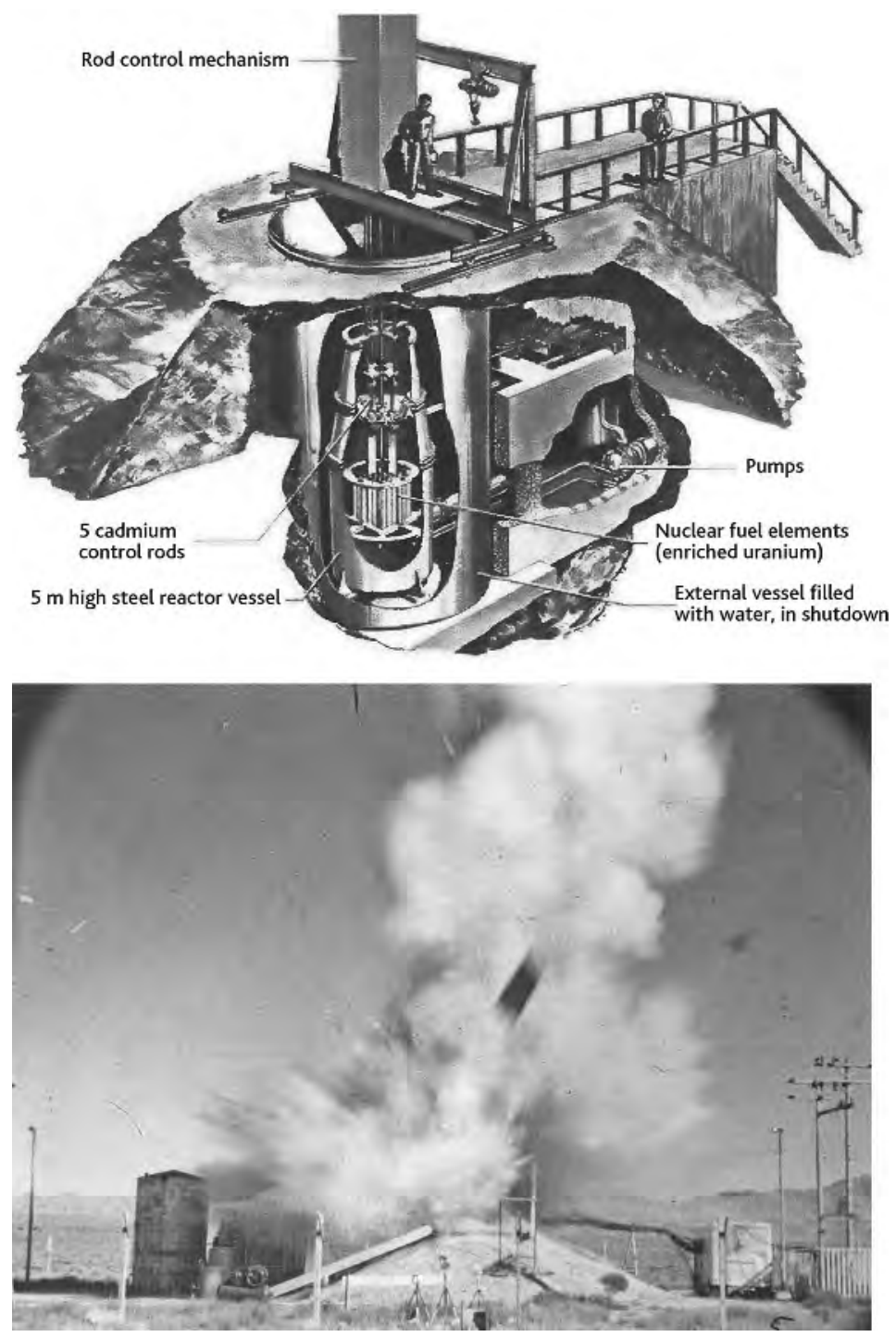

Figure 8.3. Top, diagram of the BORAX-1 reactor. ( $)$ All rights reserved. Bottom, photograph taken during the final destructive testing of the BORAX-1 reactor. () Argonne National Laboratory (creative commons).

- assessment of these consequences in order to check compliance with the necessary functional requirements in such a situation for the different equipment items that contribute to maintaining the core underwater (after the initial phase during which a spray of water may be produced) and containment (reactor building, liners and pools, ventilation and filtration systems, and post-accident cooling systems, etc.). 
In order to ensure robust reactor containment in the event of a BORAX-type accident, the characteristics selected for this accident must be sufficiently conservative or fall under an envelope approach.

Examples of the initiating events considered are the ejection of one or more absorbers elements and reactivity insertion associated with the inadvertent removal of an experimental absorbing device.

Consideration of a BORAX-type accident in the design of pool-type research reactors operated using uranium- and aluminium-based fuel remains necessary when a reactivity accident is possible. In this respect, it should be noted that:

- the reactors in question are installations whose purposes require them to offer a variety of uses so that they can be used to carry out experimental programmes, produce radioisotopes, etc., often at the same time. Many operations can be performed in the reactor core or nearby;

- these reactors can undergo changes in their purposes or equipment over time. The chosen experiments may require the installation of dedicated support systems, which may create risks that were not explicitly considered during initial reactor design (e.g. use of pressurised gas). Consideration of a BORAX-type envelope accident at the initial design stage makes it easier to implement such changes at a later date;

- these reactors may use specific equipment for which there is no reliable data or very little operating feedback;

- for some of these reactors, organisational and human factors can have particular importance for the prevention of incidents and accidents. Although lessons were learned from the Reactor SL-1 accident and major accidents affecting power reactors (particularly Three Mile Island and Chernobyl), the possibility of human error remains and the chances of recovering from such errors are difficult to assess. More generally, it is difficult to determine the robustness of organisational lines of defence. Finally, as stated in section 7.2.3, the co-existence of two types of personnel in the installation (facility operators and scientists), each with their own objectives, creates a complex situation, particularly during experimental phases where both types of personnel are in constant interaction.

\subsubsection{Key aspects and parameters}

A certain number of aspects and parameters associated with a BORAX-type accident are of prime importance in the design of a pool-type reactor operated using uraniumand aluminium-based fuel:

- determination of the thermal energy "deposited" in the reactor core, which is intended to form an envelope for potential reactivity accidents in this reactor;

- conditions for triggering a steam explosion by heat transfer between the molten fuel and water;

- assessment of the potential resulting pressure; 
- assessment of thermomechanical loads (shock waves, water thrust associated with the expansion of bubbles, etc.) on structures contributing to containment (including the pool), and any potential resulting damage;

- post-accident cooling of molten materials that may flow to the bottom of the pool or into the lower parts of the reactor building through singularities (absorber mechanism penetrations, etc.);

- the risks of a second reactivity accident ("recriticality" or "return to criticality"), particularly by (molten or solid) fuel shuffling;

- the corresponding radiological consequences following the transfer of radionuclides from the core into the building housing it, and then from said building into the environment.

As for core meltdown accidents in pressurised water reactors, it is complex to characterise and quantify the various consequences of a BORAX-type accident due to the large number of simultaneous equipment geometry phenomena (reactor core tank or vessel, reactor coolant system, reflector, experimental systems, pool liner, pool concrete walls, etc.). Therefore, in order to determine the validity of the fundamental assumptions adopted for the design of elements that contribute to the confinement of radioactive substances, during the design phase of a new reactor, one approach is to use specific assessment tools - using sufficiently conservative assumptions - for each of the effects of the accident, each considered separately (shock waves and expansion of bubbles on the side walls of the pool, "water hammer" and water spray on the top part, radiological consequences in the environment, etc.), in order to estimate these effects with sufficient margins.

Some effects may not be taken into account, for example a spray of water or "water hammer" under the ceiling of the reactor building, if based on representative experiments.

For this publication, only two important aspects of a BORAX-type accident will be developed: the "deposition" of thermal energy in the reactor core and the steam explosion, by stating the main points of concern for each aspect.

\section{The notion of energy deposition in the reactor core}

The power transient resulting from the insertion of reactivity in a reactor core can be characterised by various parameters: maximum power reached, transient duration until return to initial conditions, or the total power integrated for this duration, which corresponds to what is generally referred to as the (thermal) energy deposited in the reactor core. This final parameter is especially important in design studies for a research reactor where the possibility of a BORAX-type accident is considered, as it largely determines the scale of the potential resulting steam explosion, and therefore the consequences for the reactor and especially the elements contributing to its containment.

It should be noted that for the last research reactors built in France in the $20^{\text {th }}$ century, i.e. the RHF at Grenoble and then the ORPHEE reactor at Saclay, an "inclusive" approach was adopted: an energy deposition of $135 \mathrm{MJ}$ was selected, which corresponds 
to meltdown of the entire reactor core, which is assumed to reach a temperature of around $800{ }^{\circ} \mathrm{C}$ during the reactivity transient. At the time of the design of these reactors, these values were considered to offer reasonable envelope values, on the basis of lessons learned from the SL-1 reactor accident and tests carried out on the BORAX-1 and SPERT-1 reactors.

The thermal energy must be calculated on the basis of the reactor specifics, in particular the quantity of fuel in its core, especially considering that experimental data for a BORAX-type accident, which is mainly taken from feedback from the Reactor SL-1 accident and tests conducted in the BORAX-1 and SPERT-1 reactors, does not demonstrate any phenomena that should limit energy deposition in the reactor core during the accident at a generic value, independent of the reactor characteristics. Energy deposition is heavily dependent on the reactivity inserted, the kinetics by which it is inserted, neutron feedback and the quantity of fuel in the reactor core. The energy value adopted in the end must be an envelope value that offers sufficient margins to ensure the robustness of reactor containment under the various potential reactivity insertion scenarios, which of course must take in to account the provisions adopted for reactivity control (substantiated by tests where necessary).

It should also be noted that the oxidation of aluminium in the reactor core during the accident may lead to a very high increase in thermal energy in the pool water, which could modify the scale of the steam explosion. This is also true for the potential exothermic destruction of "heat sinks" and "heat sources".

\section{Steam explosions}

A steam explosion is assumed in reports on the destructive tests carried out in the BORAX-1 and SPERT- 1 reactors and the Reactor SL-1 accident.

A steam explosion can occur through contact between two liquids, between the molten fuel, which is extremely hot, and the coolant, which is cold and volatile. This is an interaction of a thermodynamic nature, with complex trigger conditions. It leads to the fragmentation and solidification of the molten materials and the vaporisation of the cold liquid.

The scale of a steam explosion depends on multiple parameters, in particular:

- the total quantity of energy potentially mobilized: the thermal energy deposited, as mentioned above (fraction of molten core and its temperature), in addition to the energy contributed by the oxidation of aluminium and any energy released through the destruction of experimental systems, in particular "hot sources" and "cold sources";

- the duration of thermal exchanges between the molten materials and water.

Although the experimental observations demonstrate that an explosive thermodynamic interaction between molten fuel and the coolant does not occur systematically, it remains necessary to consider the possibility of such an interaction when molten materials come into contact with coolant in liquid state. 
The steam explosion may lead to the propagation of shock waves and the movement of masses of water by the surge of the steam bubble expanding. These phenomena may lead to:

- deformation or failure of structures and equipment: metal casing surrounding the reactor core, the upper core plate and reactor coolant piping, experimental systems located around the core, equipment in the pool, the reactor pool liner, sluice gate (cofferdam) between the pool and a transfer channel, etc.;

- the ejection of a mass of water in the reactor building, potentially with a "water hammer" effect on the building dome.

Special attention must be paid to the potential mechanical effects of thermodynamic interactions between the molten materials and water for each reactor studied, depending on factors such as the hydrostatic pressure of the water in the reactor core pool (water level above the core), the volumes and inertia of masses of water liable to be moved, the stiffness and inertia of internal metal structures and the pool liner, etc. In this respect, the stiffness of the "environment" around the interaction zone may differ depending on the direction. For example, water movement in an upwards direction would be preferential.

The shock waves produced by the steam explosion cause pressure spikes on the pool walls, which can reach extremely high levels of several dozen bars, but for very short durations (around $10 \mathrm{~ms}$ ). The expansion of the steam bubble generates a longer-lasting pulse. These two types of mechanical loads need to be studied on a case-bycase basis, without excluding either of them, depending on the characteristics (inertia, stiffness, etc.) of the elements comprising the pool of the reactor being considered (very thick concrete walls, thin metal liner, whether or not it is attached to the concrete walls, etc.).

Protection of the pool walls and bottom may be strengthened:

- by leaving an empty space between the liner or reactor vessel and the pool walls axially to the core. This provision enables mechanical energy to be absorbed by deformation of the liner or vessel, which reduces stresses on the pool structure (provision adopted for the SILOE, ORPHEE and JHR reactors);

- by installing deformation-based energy absorption mechanisms, e.g. metal plates on "resilient bearing pads" at the bottom of the pool (as adopted for the SILOE reactor). For the Jules Horowitz reactor, a metal plate is placed on the ceiling of the absorber mechanisms vault; measures ("provisions") have also been taken to install shock absorbers (honeycomb structure type) in the reactor pool to protect its side walls.

\subsection{Demonstrative testing conducted in France}

The quest for a robust research reactor design with regard to reference accidents may lead to the use of various types of testing in addition to assessments carried out using numerical simulations. This is especially true where inherent limitations in 
the simulation and tools used appear, for example, when it is impossible to correctly model structure singularities. But this generally raises delicate questions regarding the similitude 235 sought and the representativity of testing.

These kinds of tests were carried out for French research reactors, for various aspects related to reference accidents (see table 8.2 at the end of this chapter), focusing on:

- for the high-flux reactor in Grenoble, specifying the variation kinetics in the core reactivity in the event of switching from light water to heavy water in the core: tests were carried out on the reactor itself using heavy water mixed with light water at various concentrations;

- for the Jules Horowitz reactor, determining, with a mockup, the speed at which an absorber is raised in the event of accidental ejection due to failure of the control mechanism;

- for the ORPHEE reactor, ensuring, with the use of in-basin testing ${ }^{236}$, proper pool resistance at the horizontal neutron channel penetrations (pool liner by the channel penetrations, safety "windows" and valves on the thimbles - see section 7.3.2) in order to ensure that the core would not be uncovered due to loss of neutron channel watertightness in the event of a BORAX-type accident. The tests involved subjecting the abovementioned equipment (on models at a scale of $1 / 10$ for liner resistance tests and 1/2 for channel watertightness mechanisms) to a water pressure wave (from an "air canon" or rapid expansion of a volume of compressed air), representative of a BORAX accident - expansion of a steam bubble initially at 40 bars with a volume of $4 \mathrm{~m}^{3}$;

- checking the overall behaviour of structures in the event of a BORAX-type accident. For example, a test was conducted using an explosive (TNT) on a $1 / 3$ scale model of the OSIRIS reactor (table 8.2 ).

235. Various similitudes are possible: structure deformation, structure displacement, etc.

236. Carried out by SODERA (Société pour le développement de la recherche appliquée) in its laboratories. 
Table 8.1. Some characteristics and observations concerning the SL-1 reactor accident and power excursion tests conducted in the SPERT and BORAX reactors.

\begin{tabular}{|c|c|c|c|c|c|c|c|c|c|}
\hline Reactor & Description & $\begin{array}{c}\text { Total } \\
\text { mass of } \\
\mathrm{Al} / \mathrm{U}(\mathrm{kg})\end{array}$ & $\begin{array}{c}\text { Reactivity } \\
\text { inserted } \\
(\$)^{3}\end{array}$ & $\begin{array}{c}\text { Power } \\
\text { spike (MW) }\end{array}$ & $\begin{array}{l}\text { Thermal } \\
\text { energy } \\
\text { deposited } \\
\text { (MJ) }\end{array}$ & $\begin{array}{c}\text { Chemical } \\
\text { energy released } \\
\text { (MJ) }\end{array}$ & $\begin{array}{c}\text { Max. fuel } \\
\text { temperature } \\
\left({ }^{\circ} \mathrm{C}\right)\end{array}$ & $\begin{array}{l}\text { Pressure } \\
\text { spike (bar) }\end{array}$ & $\begin{array}{l}\text { Damage } \\
\text { observed to } \\
\text { reactor core }\end{array}$ \\
\hline BORAX-I & $\begin{array}{l}\text { Destructive } \\
\text { test }\end{array}$ & $100 / 4.2$ & 3.1 & $<19,000$ & 135 & Undetermined & $<1,800$ & $400-700$ & $\begin{array}{l}\text { Extensive core } \\
\text { meltdown }\end{array}$ \\
\hline $\mathrm{SL}-1$ & Accident & 189/14 & 3.0 & $\sim 19,000$ & $133 \pm 10$ & $24 \pm 10$ & $>2,075$ & 700 & $\begin{array}{c}\sim 20 \% \text { of core } \\
\text { melted } \\
\sim 2 \% \text { of core } \\
\text { vaporised }\end{array}$ \\
\hline \multirow[t]{2}{*}{ SPERT-I } & $\begin{array}{c}2 \text { final non- } \\
\text { destructive tests }\end{array}$ & $51 / 3.8$ & $\begin{array}{l}2.6 \\
2.7\end{array}$ & $\begin{array}{l}1,130 \\
1,270\end{array}$ & $\begin{array}{l}11 \\
19\end{array}$ & - & $\begin{array}{l}585 \\
680\end{array}$ & $\begin{array}{l}0.5 \\
0.5\end{array}$ & $\begin{array}{c}\sim 0,5 \% \\
\text { of core melted } \\
\sim 2 \% \text { of core } \\
\text { melted }\end{array}$ \\
\hline & $\begin{array}{l}\text { Destructive } \\
\text { test }\end{array}$ & & 3.55 & 2,250 & 31 & 3.5 & 1,360 & $<300$ & $\begin{array}{c}-35 \% \text { of core } \\
\text { melted }\end{array}$ \\
\hline
\end{tabular}


Table 8.2. Simulation testing on models of a BORAX-type accident for French research reactors.

\begin{tabular}{|c|c|c|c|c|c|}
\hline \multirow[t]{2}{*}{ Reactor } & \multirow[t]{2}{*}{$\begin{array}{c}\text { Operating } \\
\text { power }\end{array}$} & \multicolumn{2}{|c|}{$\begin{array}{c}\text { Structure } \\
\text { characteristics }\end{array}$} & \multirow[t]{2}{*}{$\begin{array}{l}\text { Model } \\
\text { scale }\end{array}$} & \multirow[t]{2}{*}{$\begin{array}{l}\text { Structures } \\
\text { studied }\end{array}$} \\
\hline & & Pool & Reactor building & & \\
\hline TRITON & $6 \mathrm{MW}$ & $\begin{array}{l}\text { Prestressed } \\
\text { concrete }\end{array}$ & $\begin{array}{l}\text { Concrete building } \\
\text { with glass windows }\end{array}$ & $1 / 5$ & $\begin{array}{l}\text { Pool and effect of } \\
\text { the spray of water } \\
\text { on the building }\end{array}$ \\
\hline MELUSINE & $8 \mathrm{MW}$ & $\begin{array}{c}\text { Prestressed } \\
\text { concrete, with } \\
\text { steel } \\
\text { liner in the } \\
\text { compartment } \\
\text { containing the } \\
\text { core }\end{array}$ & $\begin{array}{c}\text { Concrete building } \\
\text { with observation ports }\end{array}$ & $1 / 3$ & $\begin{array}{l}\text { Pool and neutron } \\
\text { channels }\end{array}$ \\
\hline SILOETTE & $100 \mathrm{~kW}$ & $\begin{array}{l}\text { Steel vessel } \\
\text { contained in } \\
\text { ordinary solid } \\
\text { concrete }\end{array}$ & $\begin{array}{c}\text { Metal } \\
\text { containment }\end{array}$ & $1 / 3$ & $\begin{array}{l}\text { Pool and neutron } \\
\text { channels }\end{array}$ \\
\hline OSIRIS & $50 \mathrm{MW}$ & $\begin{array}{l}\text { Reinforced } \\
\text { concrete with } \\
\text { steel liner }\end{array}$ & $\begin{array}{c}\text { Concrete building } \\
\text { with observation ports }\end{array}$ & $1 / 3$ & $\begin{array}{c}\text { Pool, core support } \\
\text { structure and effect } \\
\text { of the spray of water on } \\
\text { the building }\end{array}$ \\
\hline
\end{tabular}





\section{Chapter 9 Maintaining compliance with the applicable requirements - Safety Reviews}

\subsection{Maintaining compliance with the applicable requirements, managing obsolescence and ageing}

Nuclear facility compliance with applicable requirements must be maintained over time. A specific chapter of the General Operating Rules (GOR) is dedicated to periodic inspection and testing which helps verify compliance. This periodic inspection and testing (defined for safety-important elements ${ }^{237}$ ) is supplemented in preventive maintenance programmes, which help avoid the preventive replacement of certain equipment.

Periodic inspection and testing targets two specific types of potential difficulty for research reactors, due to their service life, which can be very long, to their conditions for operation, which can be discontinuous, and to the high neutron fluxes in some structures. These difficulties are:

237. Hereinafter EIP: as per French Order of 7 February 2012, as amended, setting the general rules relative to basic nuclear installations, an EIP is an Element Important for Protection of the interests mentioned in Article L. 593-1 of the French Environment Code. This element contributes to the prevention of risks and drawbacks associated with public security, health and safety or the protection of nature and the environment. 
- equipment obsolescence: on this topic, research reactor instrumentation and control systems dating from the 1970s - 1980s were fully renovated in the late 1990s, including the implementation of programmed software systems ("SIREX racks");

- the ageing of structures and other equipment (cables, polymer materials, etc.); for example, for "neutron beam outside" reactors, the heavy water vessel and neutron or irradiation channels are systematically inspected, given the level of neutron fluxes they are subject to.

Inspections at all stages in an installation's life are the primary responsibility of the facility operators. Nevertheless, it is worth noting that other stakeholders may occasionally intervene to ensure correct implementation (on-site or factories inspections carried out by the French Nuclear Safety Authority (ASN), or by the Nuclear Pressure Equipment Department (DEP) ${ }^{238}$, etc.) - for building structures, IRSN can propose the scheduling milestones and objectives of these inspections to the French Nuclear Safety Authority, as was the case for the Jules Horowitz reactor.

Non-compliance identified by the facility operator during periodic inspection and testing is subject to the same declaration and processing methods as for nuclear power reactors.

However, safety reviews are the opportunity to conduct a detailed review into compliance every ten years, and particularly on how efficiently the facility operator has processed non-compliance identified over the previous ten years. More detailed investigations can be conducted during these reviews.

\subsection{Safety reviews}

\subsubsection{History and approach}

By nature, full safety of a basic nuclear installation can never be definitively achieved. Improvement must be sought, particularly by drawing on feedback and new knowledge.

Since 1978, "safety reviews" have been performed on French power reactors (GCR system reactors, Chooz A pressurised water reactor). This practice was then extended to different series of pressurised water reactors (900 MWe, 1,300 MWe, 1,450 MWe), with an approach that was gradually structured into (ten-year) safety reviews, as specified below. Research reactors operated in France were also subject to safety reviews in the early 1980s, which initially targeted specific subjects. However, from the late 1990s, the principle of systematic ten-year reviews was adopted, following the same approach used for pressurised water reactors in nuclear power plants.

238. For pressure vessels, only equipment that is nuclear class 1 (N1) as per the "ESPN" Order is inspected by ASN (DEP). Equipment that is nuclear class 2 or 3 is inspected by approved bodies. Part of the reactor coolant system for the Jules Horowitz reactor is nuclear class 1 (N1). 


\section{Regulations and approach}

The obligation for basic nuclear installation operators to periodically review (in practice, every ten years) the safety of a basic nuclear installation dates back to the TSN Act in 2006. The safety review process includes several steps with the following two components:

- a facility "compliance assessment" component,

- a facility safety "reassessment" component.

The compliance assessment consists of comparing the real state of the facility with applicable requirements as per the various texts and documents in force: regulations, safety report, general operating rules, etc.

The purpose of the safety reassessment is to assess the safety of the facility with regard to the most recent French and international safety practices and targets, developments in knowledge and operating feedback from the facility or other nuclear installations in France or overseas.

For French research reactors, a safety review currently includes three steps:

- three years before the safety review is due, the operator draws up and sends ASN a "safety review preparation file", specifying the scope and scale of the planned compliance assessment and safety reassessment, which may only focus on some topics, providing appropriate justifications are supplied. In return, after assessment by IRSN, ASN sends a letter to the facility operator with comments on the review preparation;

- the facility operator then conducts a compliancy assessment, including, in particular, inspections of structures, systems and components, and studies for the safety reassessment of its installation;

- after these inspections and studies, the operator sends ASN a review report, specifying the conclusions of its review and the safety improvements it has planned to implement, with the corresponding schedule. After IRSN assessment of this file, and potentially consultation with the standing groups of experts (primarily the standing group of experts for nuclear reactors [GPR], ASN issues an opinion $^{239}$ on the conditions for continued facility operation, and can set additional requirements, particularly concerning works that need to be carried out within specified deadlines.

For a research reactor, works resulting from a safety review may take two or three years to carry out, or more if large amounts of work are deemed necessary. Safety reviews are major steps in the life of a research reactor and can therefore lead to significant work (earthquake reinforcement for concrete structures, improved fire risk protection [compartmentation], etc.) to continue its operation or integrate new technologies.

The following major topics are usually assessed during safety reviews for French research reactors:

239. ASN also sends its opinion to the French minister responsible for Nuclear Safety. There is no "approved" decision. 
- obsolescence and ageing management,

- suitability of containment (structures, ventilation and filtration systems) in the event of a severe accident affecting the reactor or in the event of an external hazard (explosion, plane crash, etc.),

- earthquake resistance, to take into account the most recent seismotectonic data,

- control of fire risks.

In particular, compliance assessments are the opportunity to use in-depth inspections (potentially drilling into concrete structures, etc.) to check that the reactor pool liner and concrete have maintained sufficient characteristics - for reactors designed to resist a potential BORAX-type accident, these characteristics are an essential source of data to ensure conservation of a sufficient water inventory in the pool in such an event.

Similarly, platforms hanging over the reactor pool may need detailed checks on their stability in the event of an earthquake in order to prevent them from falling onto the reactor; the seismic motions considered are generally part of the safety reassessment, in line with new knowledge in this field.

\subsubsection{Examples of significant safety reviews}

As stated above, safety reviews ${ }^{240}$ have regularly been conducted on research reactors since the 1990s. These safety reviews have often focused on a specific safety issue (taking into account operating feedback, significant change to the characteristics or use of the installation, earthquake behaviour reassessment, etc.) and have been an opportunity for in-depth examination of research reactor safety. They have led to the implementation of technical or organisational provisions to improve safety.

This was true for the PHEBUS reactor after the decision was made in the 1980s to conduct experiments which could lead to test fuel meltdown under the Phébus-PF programme. This required continuous operation of the reactor over several weeks (whereas the duration of reactor operation in previous tests had never exceeded a few days per test). These new operating conditions required significant earthquake reinforcement works to ensure that the reactor building could resist a safe shutdown earthquake (it had been designed to resist the maximum historically probable earthquake): building belting, processing of non-compliance discovered during evacuations with regard to the embedding into the rock ( $-5 \mathrm{~m}$ depth) of pillars from auxiliary buildings adjacent to the reactor building.

A leak was detected from the SILOE reactor pool and the decision was made in 1986 to make significant changes (installation of a liner - see section 10.1.2 on this subject) as part of a safety review for this installation.

In the early 1980s, a first review was carried out for the RHF at Grenoble, targeting renovation works on the reactor block and the lifetime of safety-important reactor

240. For the sake of simplicity, the expression "review" will be used in this section, although in some cases, it only corresponds to some of the two-component review content, as defined in the early 1990s and specified above. 
components. Furthermore, following the discovery in 1983 of cracks in the top part of the (internal) concrete containment, at the level of the handling crane bracket, the containment received local external belting in 1989. This operation was especially complicated given the limited space between this containment and the metal containment surrounding it $(80 \mathrm{~cm})$. The prestressing cables had to be inserted through a manhole in the dome of the metal containment.

In the early 1990s, an unusual mark was discovered during a visual examination on an internal RHF structure, the "anti-turbulence grid" ${ }^{241 "}$ located under the core. A second safety review was then conducted for this reactor, with a greater focus on the state of internal reactor structures. In-depth controls showed that there were cracks in one part of this aluminium grid (in AG3NET), which had been directly subject to significant irradiation from the core that had weakened it - this damage had probably been increased by a vibration phenomenon. Given the estimated two-year period required to remove all internal reactor structures and repair or replace the grid, the Laue-Langevin Institute decided after one year to replace the entire reactor block, including the piping sections located in the pool. The facility operator adopted a new design for the "anti-turbulence grid", known as the turned down grid (figure 9.1) that could be replaced more easily. This new grid was qualified by tests conducted in water. These significant works were completed in 1994. The new turned down grid has since only been replaced once.

In 2002, a second safety review of the RHF was conducted, mainly focusing on:

- updating facility safety documents (safety report, general operating rules and on-site emergency plan),

- taking into account lessons learned from facility operation since the previous safety review,

- earthquake behaviour of the facility.

With regard to this last point, the RHF had initially been designed by applying PS 67 earthquake protection rules, considering an earthquake at level 8 on the Mercalli intensity scale ${ }^{242}$, with maximum horizontal ground acceleration of $0.3 \mathrm{~g}$ at basemat le$\mathrm{vel}^{243}$. This seismic reassessment led to significant reinforcements and merits further development.

241. This grid was composed of two layered grids and served to restrict flows entering the core, with water arriving at a (high) speed of $17 \mathrm{~m} / \mathrm{s}$. The fluence (integrated neutron flow over time) to which it had been subject since the start of reactor operation in 1971 was estimated at $3 \times 10^{23}$ neutrons $/ \mathrm{cm}^{2}$.

242. Representing between level VIII and IX on the international macroseismic intensity scale MSK. These are qualitative scales. According to the MSK scale, which became more widely used, level VIII corresponds to "partial collapse of buildings" (conventional) and Level IX to "substantial damage to buildings". The maximum level XII has been defined by "landscape generally changed".

243. Data from Report DSN 50 in 1974. As stated in footnote 198, an acceleration of $0.3 \mathrm{~g}$ corresponds to an area with average earthquake activity. In very active areas (Japan, Turkey, etc.), accelerations can reach 0.4 to $0.6 \mathrm{~g}$. 

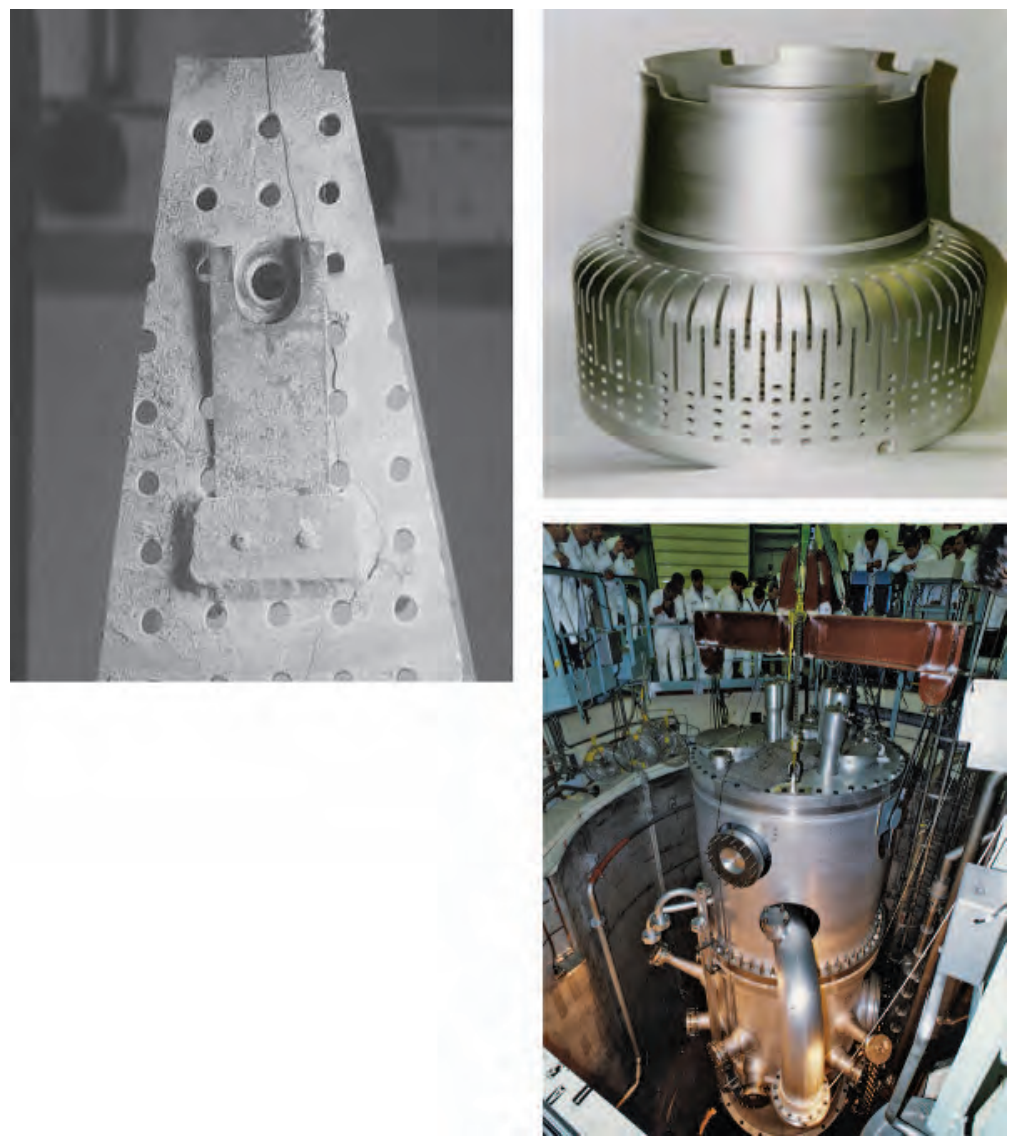

Figure 9.1. Left, the cracked part of the initial "anti-turbulence grid" in the RHF, top-right, the new turned down grid, bottom-right, lowering of the new reactor block into the pool. ( $)$ ILL.

This reassessment was conducted by applying fundamental safety rule (RFS)I.1.c, established in 1992, then, for reinforcement work not yet begun in 2004, the very latest fundamental safety rule 2001-01, with initial assessment ${ }^{244}$ of the site effects (see the focus in section 7.4.2). For the safe shutdown earthquake, application of RFS 2001-01 led to an increase (up to $20 \%$ ) in accelerations for frequencies below $4.5 \mathrm{~Hz}$ - which is particularly important for concrete structures - and a significant decrease in accelerations for the $[4.5 \mathrm{~Hz}-30 \mathrm{~Hz}]$ range. Maximum ground acceleration (or peak ground acceleration - PGA) remained close to $0.3 \mathrm{~g}$.

The operator carried out simulation calculations for the linear behaviour of all structures on the RHF (the calculation mesh is shown in figure 9.2) in order to quantify the resistance deficits of these structures for the new earthquake spectra. The following deficits were identified:

244. The Laue-Langevin Institute partnered with the CASHIMA project, led by the CEA for the part relating to site effects. 

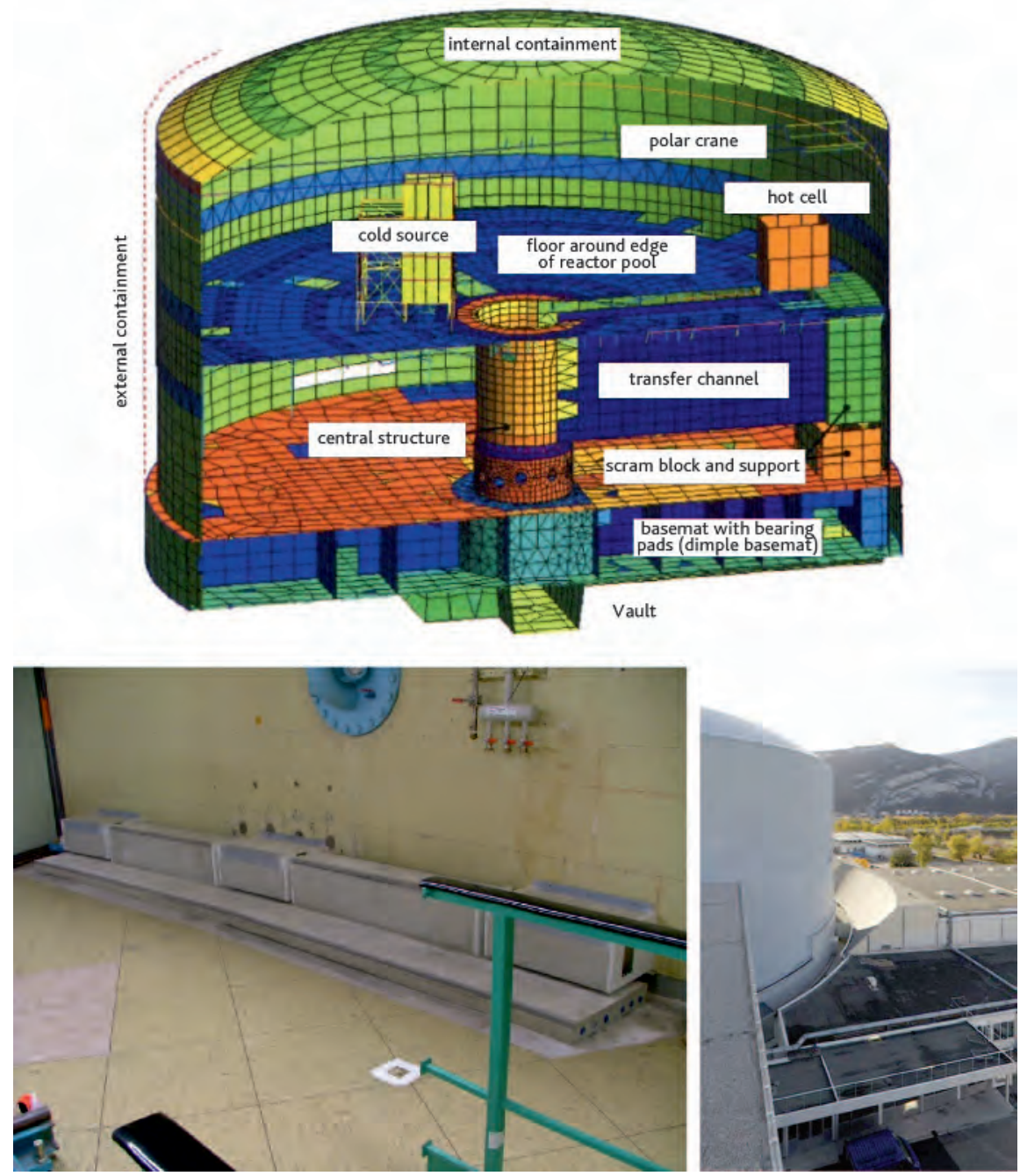

Figure 9.2. Top, reactor concrete structure grid used for earthquake reassessment of the high-flux reactor in Grenoble in the 2000s; bottom-right, view of the part removed from one of the neutron guide halls; bottom-left, partial view of the "teeth" located between the Level D slab and concrete containment. () ILL.

- $15 \%-40 \%$ for the pool's concrete walls,

- $60 \%$ for the extremity of the transfer channel ${ }^{245}$.

These observations led the facility operator to conduct various works to reinforce the reactor:

245. Channel composed of three compartments: Channel 1, Channel 2 and Channel 3, which can be separated using sluice gates (cofferdams). 
- deconstruction of peripheral buildings located on the floor around the edge of the reactor pool (one of which represented a load of 1,500 tonnes);

- creation of a vertical support wall for the transfer channel;

- creation of 70 "teeth" (tangential stops or "comb" system) between the floor around the edge of the reactor pool and the concrete containment wall, with a $1 \mathrm{~mm}$ gap between the teeth (figure 9.2);

- reinforcement of Building ILL4 adjacent to the reactor (building housing the reactor control room) and removal of part of the extremity of this building located closest to the reactor's metal containment in order to create a $20 \mathrm{~cm}$ space between Building ILL4 and the metal containment to prevent impacts between these structures in the event of an earthquake;

- cutting away at $45^{\circ}$ the extremities of the neutron guide halls closest to the metal containment (figure 9.2).

Furthermore, this seismic reassessment of the RHF led to the installation of an emergency core cooling system (CRU) for managing potential leaks from the reactor pool in the event of an earthquake.

The MASURCA reactor was subject to a first safety review in 1988, during which the lessons learned from the first years of reactor operation were analysed. Similarly, the ORPHEE and OSIRIS reactors were subject to safety reviews in 1997 and 1999 respectively. For the ORPHEE reactor, the review mainly focused on provisions for managing accident situations or fire risks. For the OSIRIS reactor, the review conducted in 1999 mainly focused on the lessons learned from operation, fire risk protection and behaviour of the containment in the event of a BORAX-type accident.

The CABRI reactor was also subject to a seismic reassessment as part of an overall safety review integrating plans to install a pressurised water loop. This reassessment led to reinforcements, which were carried out from 2003, mainly consisting of the reinforcement of the walls, columns and beams of the reactor building and auxiliary buildings, and the belting of the reactor building superstructures using reinforced concrete tie beams. 


\section{Chapter 10 Operating experience feedback from French research reactors}

Operating experience feedback is vital for maintaining and improving the safety of all nuclear facilities. In the case of research reactors, this operating experience feedback is based on:

- the lessons learned from events ${ }^{246}$ that have occurred at nuclear facilities internationally, whether research reactors, nuclear power reactors or other types of facility;

- the detailed analysis (up to identification of the root cause) of events that have occurred at French research reactors, with the definition and implementation of measures to prevent them occurring again;

- information shared between the operators of research reactors and, more broadly, with other stakeholders, including on an international scale (notably under the aegis of the IAEA).

Regarding the lessons learned from events that have occurred at nuclear facilities internationally, three elements may be highlighted:

246. The expression used now in France is "event", as the expression "incident" refers instead to the operating conditions of the second category of the deterministic safety analysis. An ASN guide published on October 21, 2005, draws a distinction between "interesting events" and "significant events". "Interesting events" (i.e. those affecting safety, radiological protection or the environment) are events whose "immediate importance does not justify an individual analysis but whose repetitive character may be indicative of a problem calling for a detailed analysis". 
- firstly, the need to take into account reactivity accidents - including the BORAXtype accident - in the design of French research reactors, given the past accidents of this type that have occurred internationally (see chapters 4 and 8 of this document);

- the investigations following the Chernobyl accident, which occurred in 1986, into the correct management of protection inhibitions and temporary connections ("shunts"). These investigations, prompted by IPSN, notably resulted in the removal of the possibility of disabling some safety actions and the introduction of measures to better protect access to mechanisms allowing the adjustment of research reactor safety thresholds;

- the investigations following the 2011 accident at the Fukushima Daiichi nuclear power plant, which led to the "stress tests" (ECS) covered in section 10.2.

In the case of events linked to anomalies or deviations detected during the operation of French research reactors, experience is shared among operators and their facility managers via ad hoc bodies, in addition to the event being identified, reported to ASN if it is categorized as significant ${ }^{247}$ and managed according to the standard INB process. For its part, IRSN performs, in addition to analyzing each event and the measures proposed by the operator concerned to prevent its recurrence, a "second-level" analysis, which is broader and covers the various types of INB (research reactors, power reactors and fuel cycle facilities).

Unlike in the case of power reactors, it is harder to immediately apply the lessons learned from an event affecting one research reactor to other research reactors, given their diversity in terms of design and technology. However, the analysis of certain events, concerning lifting equipment, measurement systems, I\&C racks, iodine filters or even organizational systems, for example, may provide useful lessons for several facilities. In this way, the discovery in 2012 of an incorrectly positioned air sampling tube $^{248}$ in the ORPHÉE reactor stack led ASN to alert all INB operators regarding the matter. Several other concerns common to research reactors are covered by specific basic safety rules (including purification equipment on ventilation systems and protective measures against fire risks - see section 6.2).

Operating experience feedback from research reactors can also be used to assess the changes in the dose received by workers at the facilities over several years and draw up, where necessary, actions to reduce the dose received by personnel, notably by applying radiological protection principles.

At this point, it should be recalled (see section 4.1 of this document) that, alongside the operators of French research reactors, IRSN, in its role as coordinator for France, sends the IAEA annual reports on notable events that have occurred in these reactors in cases where the lessons learned are worth sharing at an international level. These reports are added to the IRSRR system database, used by the IAEA, which contains all

247. The criteria for reporting significant events are specified in an ASN guide dated October 21, 2005.

248. Sampling for measuring tritium. 
the reports sent by the various countries. The IRSRR database is an information and knowledge resource available to operators ${ }^{249}$, who can take it into account, notably during facility safety reviews.

Lastly, it should also be recalled, as indicated in section 6.1, that operators inform the public of any significant events that occur at their facilities, providing the analysis that they have completed and the measures taken to avoid repeat events, in accordance with the provisions of the TSN Act.

\subsection{Trends, some notable events and their management}

\subsubsection{Trends}

At end of June 2018, the event database maintained by IRSN since June 1972 contained 1,515 events that had affected French research reactors, together with their classification on the INES scale. This corresponds to three events per reactor per year on average $^{250}$. The events are listed in the ASN's annual (public) reports.

Several major families of events and trends may be identified:

- events that are not specific to research reactors:

- the discovery of foreign bodies in fuel elements,

- the faulty operation of or damage to components (fuel elements, internal structures, reactor coolant systems, absorbers mechanisms, safety valves, diesel generators, lifting equipment, etc.), up to fuel melt (SILOE, 1967),

- leaks from pools or tanks (notably in the case of the SILOE reactor between 1965 and 1986), water infiltration into fissile material storage rooms,

- electrical insulation faults, loss of off-site electrical power,

- malfunctions in the ventilation systems and pressure loss in rooms, poor efficiency of iodine filters,

- incorrect safety threshold settings, non-compliance with operating rules or operating procedures (for example regarding the limits set to prevent criticality risks, access conditions for controlled areas or the frequency of in-service inspections);

249. In all cases, it is the national coordinators who are responsible for sending incident reports from the IRSRR, IRS, etc. databases to the operators in their country.

250. The average for pressurized water reactors in the nuclear power fleet, which are much more complex facilities than research reactors, is around 13 (significant) events per reactor per year (events affecting safety and radiological protection). It may be useful here to highlight that the number of events that occur at a nuclear facility does not, in itself, constitute an indicator of the level of safety of the facility. However, the in-depth analysis of each event is a vital learning resource. 
- events related to the specific design features of research reactors: objects falling into pools, heavy water system leaks, tritium releases (via the stacks or into the ground) from detritiation facilities, anomalies regarding natural convection valves, etc.;

- events linked to specific equipment, such as anomalies regarding the neutron channel thimbles (ORPHÉE, RHF) or cold sources (ORPHÉE, HFR). One example occurred at RHF, which experienced corrosion due to irradiation, detected from 1972, on the inside of the aluminum alloy thimbles (in AG3NET), more specifically on the "collimator plugs". These plugs seized due to corrosion caused by the formation of nitric acid, in turn resulting from radiolysis of the air ${ }^{251}$ subjected to neutron flux (which led to the air in the thimbles being replaced with helium, and, as the thimbles were gradually replaced, new Zircaloy thimbles being installed). Another example occurred in August 1988, when an error caused the rupture disks protecting RHF's vertical cold source against overpressure to crack and release, at the facility stack ( $45 \mathrm{~m}$ high), approximately $9 \mathrm{~m}^{3}$ of deuterium containing several tens of $\mathrm{TBq}$ of tritium;

- events linked to experimental devices and their use: the triggering of safety systems specific to these devices, chemical reactions with sodium or sodiumpotassium alloys, device explosions, etc.;

- operator exposure or the contamination of pools, buildings, rooms or people. Here it is relevant to mention the spillage of antimony 124 from a startup neutron source into the RHF pool in 1974. In the end, after numerous events ${ }^{252}$, this resulted in a combined release into the Isère River of $20 \mathrm{TBq}$ of this radioactive element (over 1974 and 1975);

- the discovery of undocumented radioactive sources or objects;

- outbreaks of fire, notably a fire in the electronics room of an experiment measurement facility (CABRI, 1979) and a deflagration in an electrical cabinet (RHF, 2000).

There have been several events linked to handling operations and lifting equipment:

- a traveling motor-reducer unit falling from a crane (OSIRIS, 1975),

- the rupture of a winch drive band (ULYSSE, 1975),

- a transportation container falling due to the overhead crane hook becoming detached from the block and tackle (ISIS, 1976),

- assembly (MASURCA, 1977) and rodlets (same reactor, 1989) falling,

- elements of an experimental loop falling into the pool (SILOE, 2004),

- the rupture of a hoist cable and a hook falling onto the "edge platform" (RHF, 2012),

- the rupture of a sling (RHF, 2013).

251. More specifically, radiolysis of traces of water in the air.

252. As reported in the press (for example Sciences \& Avenir $n^{\circ} 360$, February 1977). 
The risks associated with handling operations therefore require special attention ${ }^{253}$. An in-depth analysis should be performed on the various safety elements of these handling operations: the reliability of lifting equipment, handling sequences ${ }^{254}$, human and organizational factors, measures to limit the consequences of an item falling, etc.

In addition, between 1991 and 2007, the ventilation systems at the MASURCA facility malfunctioned repeatedly, with the loss of negative pressure in various rooms. This was due to fan failure or loss of electric power, which could be attributed to aged components. These elements were taken into account when these reactors were renovated.

Although the frequency of "human error" or "handling error" events tends to drop from the 2000s onward, cases of failure to comply with regulatory requirements or operating rules have emerged, associated with the gradual strengthening of safety documentation at research reactors (notably for their operation). The frequency of events concerning experiments and associated devices has fallen over the decades, indicating improved control.

It is interesting to note the appearance, from the 2000s, of events corresponding to the identification of gaps or imperfections in the safety demonstration (study anomalies, errors in the operational application of requirements, etc.), such as:

- "an error in the criticality safety evaluation, in the safety report, of a box containing surplus nuclear materials" (MASURCA, 2003);

- "the use of the equipment access hatch to the ring gallery in a way that is not covered by the safety documentation" (OSIRIS, 2005);

- "the incorrect formulation of the mass limit [in a] "hot laboratory" during the revision of the safety report in 2004" (MASURCA, 2012).

In the next section, some of the most notable safety events that have affected French research reactors are covered in more detail, together with the corrective measures taken as a consequence. A certain number of these events have been analyzed as part of safety reviews. These events, which generally occurred some years ago, have been selected for their educational interest, and more specifically due to the way in which they unfolded, the physical phenomena involved, the safety issues raised and the measures introduced as a response.

\subsubsection{Some notable events and their management}

\section{Recurring leaks in the SILOE reactor pool (1965-1986) $)^{255}$}

The design of the SILOE reactor pool was called into question by water leakage from this pool into the groundwater, which occurred between 1965 and 1972, then again in 1986.

253. This observation is also valid for nuclear power reactors.

254. The handling sequence refers to the sequence of movements in terms of horizontal and vertical movements, movement speed, the area or objects passed over, etc.

255. Le Matin and Le Monde newspapers, dated April 16, 1987, and October 23, 1987, respectively, reported on these events. 
The civil engineering structure of the SILOE reactor had two compartments:

- a compartment known as the "main pool", measuring $213 \mathrm{~m}^{3}$, which contained the reactor core - this was the pool that leaked;

- a compartment known as the "work pool", measuring $322 \mathrm{~m}^{3}$, arranged in a horseshoe layout around the main pool and generally used for storing and performing operations on experimental devices.

The first water leak from the main pool was detected in 1965 from the records of the makeup water added to compensate for the evaporation of water from the pool. The leak stopped in 1968 and reappeared in 1969. In 1970, a stream of bubbles was observed in the pool water, which made it possible to detect a crack between the ceramic tiles at the bottom of this pool (separated by araldite seals), near the foot of the "stool" supporting the reactor core. Leaktightness was restored by installing a stainless steel plate on the tiled floor, with a synthetic foam seal. However, the leak reappeared in 1971 due to the degradation of the seal caused by radiation. The leak was only sealed durably in 1972, with the installation of a flat, natural rubber seal held against the bottom of the pool with lead.

The total volume of contaminated water that entered the groundwater between 1965 and 1972 was estimated to be around 1,500 $\mathrm{m}^{3}$. The total activity released in this way, principally due to tritium, was estimated to be in the order of $2.7 .10^{11} \mathrm{~Bq}$. During work to replace the "stool ${ }^{256 "}$ of the reactor core grid in 1977, the pool was resealed by installing a layer of epoxy resin and glass wool fabric $4 \mathrm{~mm}$ thick on the tiled floor and up to a height of $75 \mathrm{~cm}$ on the vertical walls.

The ongoing leak in the pool notably led the nuclear safety department ${ }^{257}$ of the CEA to evaluate the potential radioactive releases into the groundwater in the hypothetical case of a BORAX-type accident, taking into account the contamination of the pool water (due to the accident) and the transfer of radionuclides through the groundwater to the Isère River (calculated to take 55 days). In this way, it was demonstrated that, even without purifying the contaminated water from the reactor pool, the added activity ${ }^{258}$ concentration in the Isère River would be low (in the order of $140 \mathrm{~Bq} / \mathrm{L}$ ). The study did, however, lead to the examination of measures to limit the consequences of such an accident with a leaky pool: purifying the pool water (starting the "hot layer" [see section 7.3.3] and "pool floor" systems would reduce the added activity concentration in the Isère River to $0.7 \mathrm{~Bq} / \mathrm{L}$ ), transferring the pool water to a tank at the SILOETTE facility, pumping water under the foundation raft, into pits, etc.

However, in November 1986, an increase of approximately $1 \mathrm{~m}^{3}$ in the makeup water added to the pool to compensate for evaporation was observed once again. After checking the leaktightness of various reactor systems, the reactor was shut down at the start of December 1986 for a detailed inspection of the main pool, suspected to be the source of the water leak. This inspection required the fuel elements to be unloaded,

256. This was replaced by a grid-stool-box assembly.

257. The forerunner of IPSN, which was created in 1976.

258. Due to all the fission products liberated by the core melt. 
the pool to be drained, the various reactor core structures to be dismantled and the tiling to be removed. The water was transferred from the pool to a tank designated for this purpose at a deliberately slow rate, in order to take advantage of the gradual drop in level to decontaminate the pool walls and thereby prevent the resuspension of radioactive particles in the air. Injecting inert gas ${ }^{259}$ under the foundation raft then made it possible to locate a hole approximately $5 \mathrm{~mm}$ in diameter in a corner at the bottom of the pool, as well as two small cracks. This event resulted in a release of approximately $30 \mathrm{~m}^{3}$ of water chiefly contaminated with tritium into the groundwater; the total activity was estimated at $2 \cdot 3 \cdot 10^{10} \mathrm{~Bq}$.

This event threatened the future of $\operatorname{SILOE}^{260}$, given the high cost of the work needed to return the reactor to good condition. However, the CEA decided to undertake this work so it could continue operating and performing experiments at this reactor, and scheduled the permanent shutdown of the MELUSINE reactor, which had been commissioned in 1958 and whose experiments could be transferred to the SILOE facility. The corresponding modifications, authorized by the SCSIN in summer 1987, were considerable. A stainless steel liner was installed in the main pool, welded to backing strips also made from stainless steel and fastened to the pool walls. A gap was left around the edge of the pool, equipped with a system to detect leaks and recover any leaks from the liner. Regarding the capacity of the pool to withstand a BORAX-type accident, while the leaktightness of the neutron channel penetrations seemed assured, the technical inspection highlighted the weakness of one of the pool walls. This led the operator to install a tank - known as a BORAX tank - able to deform and thereby absorb some of the energy that would be released in the event of such an accident ${ }^{261}$, in order to protect the liner and pool walls. With the same aim in mind, a stainless steel plate $20 \mathrm{~mm}$ thick, positioned on shock absorbers known as "resilient pads", was installed on the basemat, under the BORAX tank, in order to guarantee the mechanical resistance of the pool basemat to the pressure that would result from a BORAX-type accident. Liners were also installed in the decay tanks, with leak detection and water recovery systems. These various liners and tanks are shown in figure 10.1.

In addition, two more piezometers were installed in 1988 to improve groundwater monitoring.

Later on, the leaks in the SILOE reactor pool had consequences for the dismantling of this reactor, which are only mentioned briefly below.

The permanent shutdown and dismantling operations at the SILOE reactor were subject to a public inquiry and the associated operating license was awarded in January 2005. The final state, as envisaged by the CEA, was full cleanup of the walls of the reactor rooms. In this respect, the CEA set the following quantitative $\operatorname{targets}^{262}$ in 2008 :

259. The gas used was sulfur hexafluoride, SF6, which is non-toxic, non-flammable and practically insoluble in water, and has high chemical and thermal stability.

260. See footnote 245 .

261. The other part of this energy is dissipated by being expelled towards the top of the water.

262. In the information package related to the cleanup of structures (DIRAS), with a view to decommissioning. 


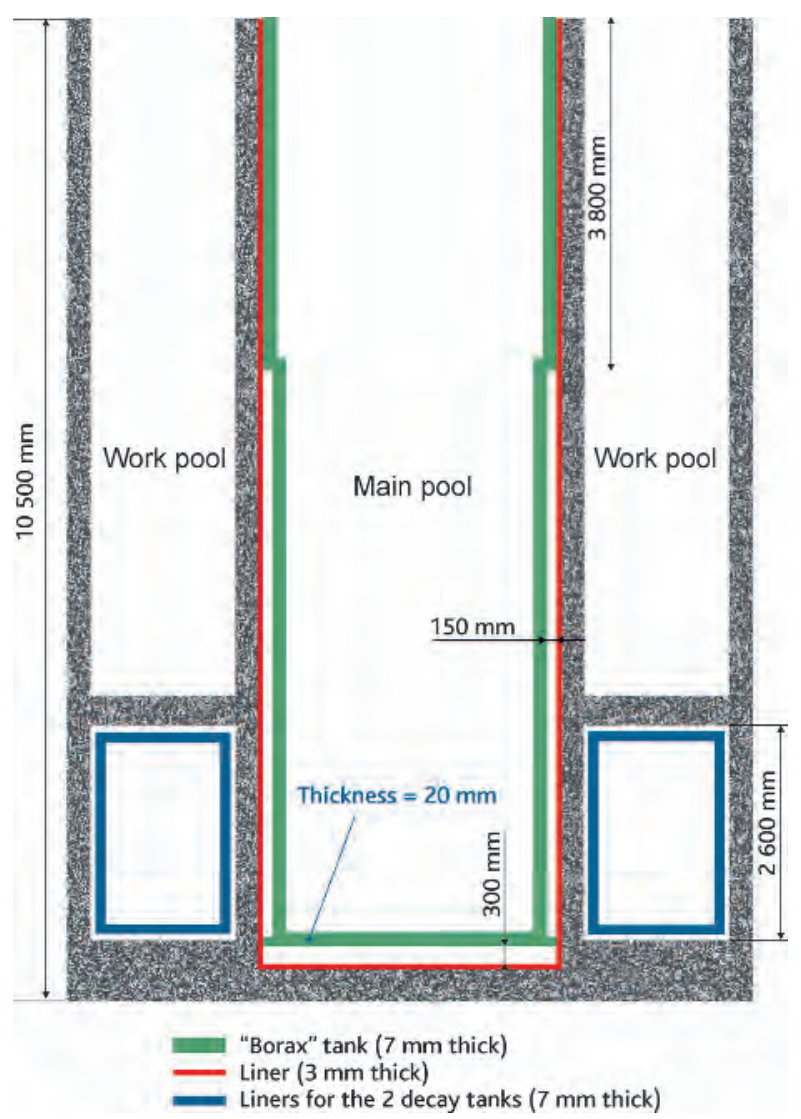

Figure 10.1. Pools and decay tanks at the SILOE reactor: tanks and liners installed in 1987-1988. (c) Georges Goué/IRSN.

- a theoretical "acceptable modeled value for residual activity" (VARMA), below which structures can be considered conventional, of $1 \mathrm{~Bq} / \mathrm{g}$ of concrete for $\beta \gamma$ emitters, excluding tritium, and of $100 \mathrm{~Bq} / \mathrm{g}$ for tritium;

- for $\beta \gamma$ emitters excluding tritium, a end of cleanup decision criterion, on the basis of the measurements performed for some radionuclides, of $0.4 \mathrm{~Bq} / \mathrm{g}$, lower than the previous value and incorporating an additional margin to take into account measurement uncertainties in particular.

At that point, the cleanup strategy for the reactor pool basemat and underlying ground had not been determined, as the pool needed to be removed before the level of contamination of these elements could be measured.

In 2010, the CEA suggested removing part of the foundation raft through its whole thickness, and across a surface area covering the whole of the main pool. In addition, given the uncertainties regarding the leak pathways through the thickness of the 
basemat, it suggested examining the vertical walls, stripped at the point where they met the thickness of the foundation raft, with a view to checking that there was no contamination at the various possible leak pathways in the concrete, along the length of the rebars and the prestressing cable ducts, and in the bitumen felt elements ensuring leaktightness.

In 2011, the CEA informed ASN of the presence of contamination in the thickness of the basemat around the prestressing cables and in part of the ground located under the basemat (locally, the specific activity reached $25 \mathrm{~Bq} / \mathrm{g}$ ). This meant that the cleanup of the SILOE foundation raft had not, at this stage, achieved the cleanliness targets initially set. For its part, ASN did not favor managing this situation through the implementation of a "public service easement ${ }^{263 "}$. Furthermore, full cleanup required in-depth treatment that could affect the mechanical strength of the reactor building. This is why the CEA ultimately decided to fully demolish the dome and cylindrical walls of the reactor building, as well as the auxiliary buildings, before completely removing the basemat and the contaminated soil. The corresponding work is illustrated in figure 10.2.
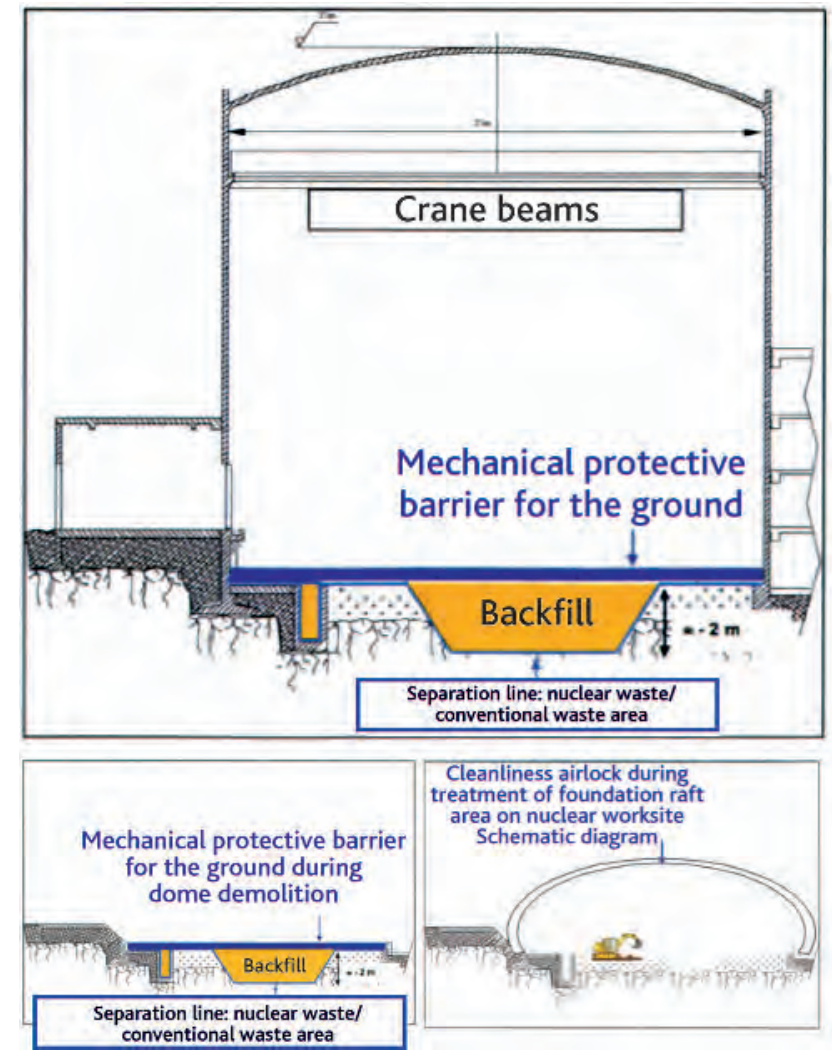

Figure 10.2. Some of the dismantling stages of the SILOE reactor (2010s). ( ) All rights reserved.

263. A public service easement is an administrative easement appended to the land use plan in accordance with article L. 126-1 of the French planning code. An impact study is also produced. 
The soil below the SILOE reactor basemat had to be excavated to a depth of $1.8 \mathrm{~m}$.

The license governing the permanent shutdown and dismantling of the SILOE reactor was modified ${ }^{264}$ to take into account new cleanup work that would extend the duration of operations. The SILOE reactor was decommissioned ${ }^{265}$ by an ASN resolution dated January 8,2015 , ratified by an order of the minister in charge of nuclear safety dated February $12,2015^{266}$.

\section{- Melting of fuel plates in the SILOE reactor $(1967)^{267}$}

On November 7, 1967, six fuel plates in a control element ${ }^{268}$ partially melted in the SILOE reactor during a power increase to $42.3 \mathrm{MW}$ performed as part of preparatory tests for taking nominal reactor operation up to $30 \mathrm{MW}^{269}$. These tests, authorized by the $\mathrm{CSIA}^{270}$, notably aimed to determine the power margins available in relation to the "flow redistribution" phenomenon in fuel elements (described in detail below). At 42.3 MW, a sudden drop in power was observed of approximately $7 \mathrm{MW}$ in one second, followed by a slower drop until it stabilized, 20 seconds later, at $20 \mathrm{MW}$. The reactor was shut down manually 26 seconds later by dropping two safety absorbers. A rapid increase in $\gamma$ radiation dose rates was then observed (in an immersed measurement chamber, up to $1,000 \mathrm{rad} / \mathrm{h}$, and in another measurement chamber, located above the pool water, up to a value of $220 \mathrm{rad} / \mathrm{h}$ ), which led to the evacuation of the reactor building and auxiliary buildings, as well as the use of the iodine filters on the emergency ventilation system.

This event caused $187 \mathrm{~g}$ of uranium and aluminum alloy (enriched to $93 \%$ uranium-235) to melt, corresponding to a mass of $36.8 \mathrm{~g}$ of uranium-235, $18 \mathrm{~g}$ of which was released into the reactor coolant system. The remainder was found in the form of magma at the bottom of the control element (figure 10.3).

Approximately $74 \mathrm{TBq}$, chiefly noble gases, were released via the reactor stack in the two days following the event. Contamination of both the reactor building and the site was negligible, due to the low burnup (4\%) of the element concerned. The fuel dispersed in the reactor coolant system was recovered in the decay tanks on the occasion of tank inspections performed in 1970 and 1971.

The cause of melting was not clearly established. In this respect, the results of the investigations carried out by the operator following this event, which notably involved measuring the temperature of the same type of control element cladding positioned in the location where the melted fuel plates were found, at powers of between 0 and

264. Decree 2013-677 of July 24, 2013.

265. Removed from the list of INBs.

266. Official Journal of the French Republic of February 20, 2015.

267. Contrôle review 128, April 1997, ASN.

268. Fuel element containing an absorber for power control.

269. Since commissioning in 1963, the reactor had operated at a nominal power of $15 \mathrm{MW}$.

270. "Commission de sûreté des installations atomiques" (nuclear facility safety commission), France. 

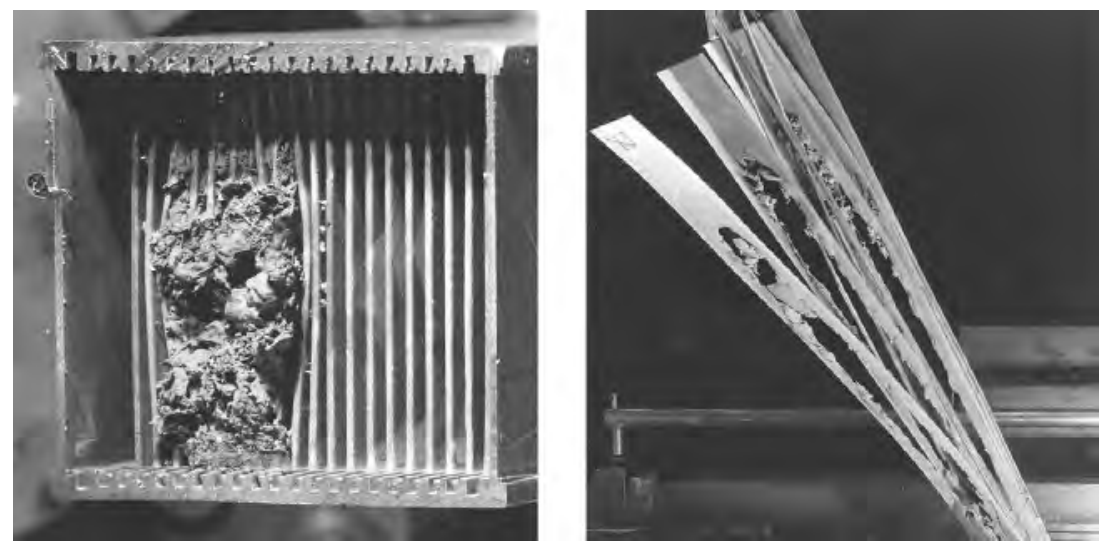

Figure 10.3. Two views of the melted plates in the control element at the SILOE reactor. (C) ILL.

$39 \mathrm{MW}$, seem to rule out the flow redistribution hypothesis ${ }^{271}$; indeed, the extrapolation of these measurements to $42.3 \mathrm{MW}$ gave, for the melted plates, a temperature at the hot point of the cladding below that corresponding to local boiling $\left(116^{\circ} \mathrm{C}\right.$ as opposed to $128^{\circ} \mathrm{C}$ ). In addition, the hottest plate of the control element did not melt.

As flakes of dry paint, from the structures located over the pool, were discovered several times on the core elements, the operator finally attributed the melting of the plates to the partial blockage of several cooling channels on the control element concerned.

The following improvements were made after this event:

- the painted sheet metal structures overhanging the core, used for routing the cables and hoses of experimental devices, were replaced with stainless steel structures;

- a second emergency exhaust system was installed at the facility to improve the reliability of this safety-related system;

- systems were installed to allow the air above the pool and the water from the pool to be sampled from outside the reactor building;

- controls for the pool water purification system were installed in the control room.

Decontamination was not required following this event. Authorization to restart the reactor was granted a few days later.

271. Phenomenon that can result in local overheating and boiling, resulting in a change in water flow between the plates. Various tests performed in the CABRI reactor had already shown that, in general, flow redistribution is accompanied by power oscillations due to local boiling and the corresponding vacuum effect; such oscillations were not observed during the event reported here. 


\section{Explosion of the AQUILON experimental irradiation device in SILOE} (1979)

The explosion of the AQUILON experimental irradiation device occurred at the SILOE reactor on April 10, 1979. This device - similar to the "boilers"272 used for tests on light water reactor fuel - was positioned at the edge of the core and contained an irradiated uranium oxide fuel rod $\left(\mathrm{UO}_{2}\right.$; uranium enriched to $4.7 \%$ isotope 235$)$. The explosion of the device caused uranium oxide and fission products to be released into the reactor pool, and noble gases and iodine to be released into the reactor building and environment.

In the device (figure 10.4), the water was practically static ${ }^{273}$; its pressure was adjusted depending on the heat released by the fuel rod in such a way as to achieve

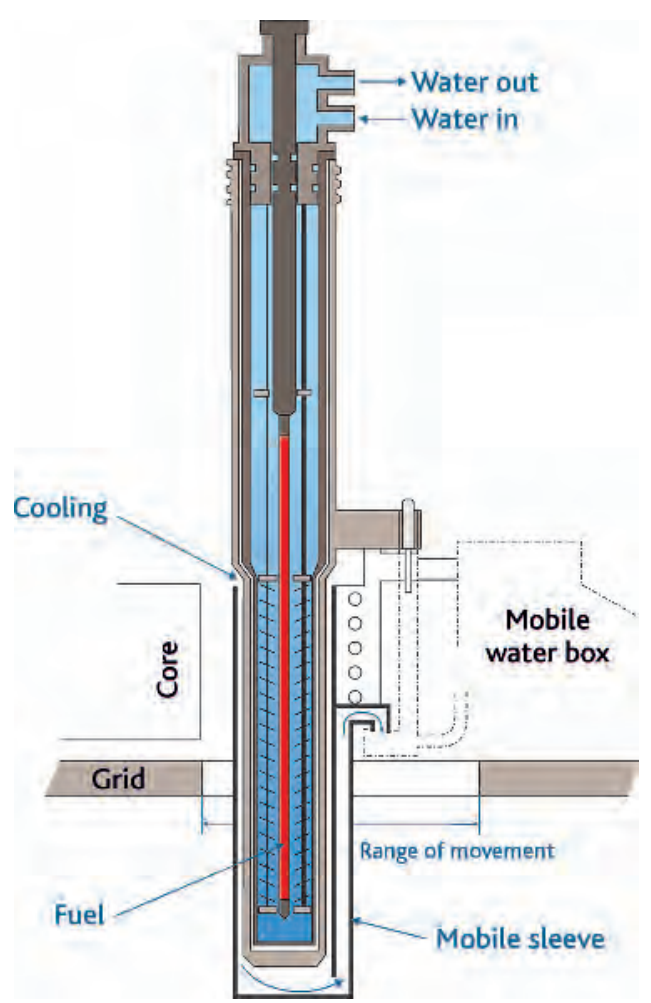

Figure 10.4. Section view of AQUILON device (c) Georges Goué/IRSN.

272. The pressure inside the AQUILON device had reached 130 bars, as opposed to 78 bars in the "boiler devices".

273. The device was not equipped with a water circulation pump, meaning that only natural convection was possible. 
nucleate boiling. The superheated steam produced was directed by the rod guide rings to the cold wall of the device, where it condensed. The external wall of the device was cooled by circulating water from the pool. For this purpose, a cooling channel $(2 \mathrm{~mm}$ "thick") was created by positioning a cylindrical sleeve around the lower part of the device in line with the SILOE reactor core. This was connected to the reactor coolant system via a mobile "water box" (allowing the device to be moved closer to or further away from the core). The sleeve, weighing approximately $10 \mathrm{~kg}$, rested on the "water box", but was not mechanically fastened to it.

Reactor shutdown could be triggered automatically by security devices linked to the loop (in the event of the tube breaking under high pressure, or in the event of low water level in the pressurizer, or even high temperature in the lower part of the device).

On April 10, 1979, at 9:17 am, the device had been positioned away from the core for around 17 hours (the security devices were disabled via "shunts") and the reactor was in operation. Three handling operators were removing the device using an overhead crane.

At 9:20 am, the order to evacuate the reactor hall was given from the control room, as the second dose rate threshold (set to $0.25 \mathrm{mGy} / \mathrm{h}$ ) had been exceeded at a $\gamma$ radiation measurement chamber located over the pool. Five minutes later, an explosion was perceived in the control room and the two safety absorbers dropped. Almost simultaneously, the alarm and safety thresholds of numerous radiation measurement channels were exceeded. Orders were given to evacuate the building (with the dose rate reaching $0.4 \mathrm{mGy} / \mathrm{h}$ in the control room) and these were followed once the operators had ordered the three control absorbers to be dropped, the reactor coolant pumps to be stopped and the emergency air exhaust system to be started (for reactor hall ventilation with iodine filters).

The following observations were made during the subsequent investigations:

- the device sleeve showed signs of heating and had two holes;

- the test fuel rod was partially melted;

- the upper part of the external plate of a fuel element located near the device "water box" was deformed, without cladding failure.

Approximately $190 \mathrm{~g}$ of $\mathrm{UO}_{2}$ (7.5 g of uranium-235) was expelled from the device into the pool.

The explosion of the device notably led to $18.5 \mathrm{TBq}$ of fission products being released into the pool. The environmental releases were estimated at $2.6 \mathrm{TBq}$ of noble gases and approximately $7.10^{8} \mathrm{~Bq}$ of iodine, $10^{8} \mathrm{~Bq}$ of which was iodine 131 . Due to the rapid evacuation of the reactor hall by the three handling operators before the explosion, the dose received by the most exposed worker was limited to $1.8 \mathrm{mGy}$. The maximum activity concentration of gaseous releases via the reactor stack was 1.48.10 $\mathrm{Bq} / \mathrm{L}$ (xenon). The measurements taken in the environment, downwind, did not indicate any activity due to aerosols or iodine above the natural background noise.

The cause of the event was determined: the sleeve had shifted when the AQUILON device was being removed, which had: 
- interrupted device cooling (uncoupling of the connection between the sleeve and "water box");

- stopped the cooling water guide function usually performed by the sleeve, until the lower part of the device was completely outside the reactor core.

Moreover, it was not possible to confirm whether the pressurizer valve on the device had worked correctly.

All the fuel elements in the SILOE reactor core were checked using a mobile cladding failure detection device. The six elements closest to the AQUILON device were replaced. Authorization to restart the reactor was granted by the SCSIN after a shutdown lasting ten days, largely spent purifying the pool water. However, the use of "boiler"-type devices was suspended, notably to assess the status of these devices in relation to pressure equipment regulations.

The general measures taken by the CEA after the event - following the meeting of the reactor safety commission on July 11, 1979 - notably included:

- banning the use of "shunts" on safety systems associated with experimental devices during their removal from or insertion into a core;

- requiring sleeves to be fastened to "water chambers";

- ensuring that procedures for inserting or removing various devices into or from a core, with the reactor in operation or shut down, were made more comprehensive and detailed.

\section{Underestimation of the operating power of RHF (1971-1990)}

An ongoing anomaly in which the real operating power of RHF (Grenoble) was underestimated by around 10\% was discovered in January 1990 after some reactor operating parameters were checked. Following this observation, the operator reduced this operating power in order to comply with the maximum value of $58.3 \mathrm{MW}$ th set out in the operating rules.

This anomaly was declared to the SCSIN on January 23,1990 . It arose due to an error in the calculation of the heavy water flow rate in the main reactor system. The formula used, established on the basis of measurements performed using light water, had not been corrected to take into account the difference in density between light water and heavy water. In fact, the real flow rate was $10 \%$ higher than the flow rate calculated. This error had also been made when the reactor protection system thresholds were determined, meaning that there was no automatic reactor alarm or reactor scram.

On January 24, 1990, the SCSIN ordered the operator to keep the reactor shut down ${ }^{274}$, with restarting subject to SCSIN authorization.

274. The operator, which had initially lowered the reactor power, ultimately decided to shut down the reactor. 
It became clear that observations made previously by the operator could be explained by this underestimation of the operating power. Indeed, the operator had observed that fuel was consumed more rapidly than expected, resulting in shorter operating cycles (the control rods reached their post-irradiation position after 42 days, instead of 46 days as expected).

This anomaly led the operator to fully review the studies on the core physics of RHF (neutronics and thermohydraulics).

\section{Melting of fuel in driver core rods in the CABRI reactor (2004) 275276}

As part of the safety review associated with the project to modify the CABRI facility to allow tests in a pressurized water loop, examinations were performed on the hottest fuel rods in the reactor core. During the first non-destructive examinations performed on three of these rods, folds were observed on their cladding. The amplitude of these folds measured several tens of micrometers and the pitches (the distance between folds) were close to $10 \mathrm{~mm}$ - approximately corresponding to the height of a fuel pellet - on the lower part of the three rods. For two of the rods, a significant area of deformation of a few per cent was observed above the fold area.

After these observations were made, a radial cross-section was taken across the area of maximum deformation of one of these rods. A macrograph of this cross-section showed the presence of local melting at the center of the fuel and signs of pelletcladding interaction. These observations constituted deviations from the technical requirements for the CABRI reactor and were reported to the French Directorate for Nuclear Safety (DSIN) on January 12, 2004.

As indicated in chapter 5 , the CABRI reactor was designed for power excursions ("pulses" - see figure 10.5) from maximum steady-state operating conditions of $25 \mathrm{MW}$. With a view to preventing the fuel melting, and ensuring the leaktightness of the cladding of rods in the driver core, the technical requirements for the facility stated that, during these power excursions, the maximum fuel temperature should not exceed $2,400^{\circ} \mathrm{C}^{277}$, all uncertainties combined, and the surfacic thermal power of the core rods ${ }^{278}$ should remain below $750 \mathrm{~W} / \mathrm{cm}^{2}$ (criteria to be respected in estimates via calculation, prior to experiments). In addition, these technical requirements authorized reactor operation above $25 \mathrm{MW}$ up to $42.5 \mathrm{MW}$ for a maximum cumulative duration of 23 minutes in order to perform slow power ramps; in these conditions, the maximum temperature of the fuel should not exceed $2,768^{\circ} \mathrm{C}$, all uncertainties combined (requirements indicated in the safety report, justified by calculations).

Since the CABRI reactor went critical in 1977, around 500 rapid power transients ("pulses") and 16 slow power ramps above $25 \mathrm{MW}$ had been performed with the driver

\footnotetext{
275. ASN website, incident reports.

276. Summary of the IRSN report on restarting the CABRI reactor, dated January 22,2009 , available to the public.

277. The melting point of $\mathrm{UO}_{2}$ is around $2,840^{\circ} \mathrm{C}$.

278. Value from tests (CAPRI) performed in a loop at the CEA in Grenoble.
} 


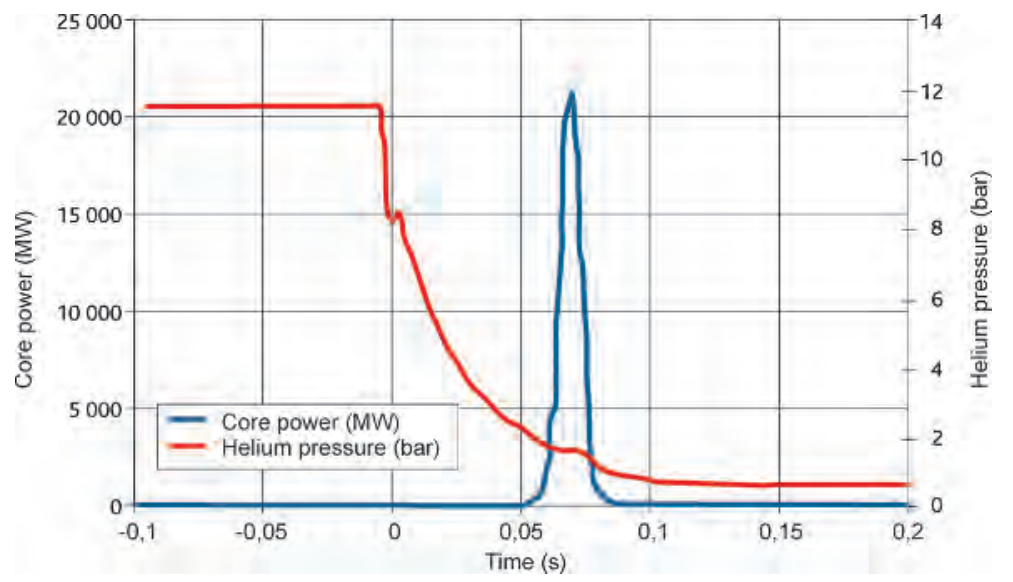

Figure 10.5. Example of a power-time profile for a "pulse" of power in the CABRI reactor. $\odot$ Georges Goué/IRSN.

core for a cumulative duration of 19.8 minutes. The average burnup of the reactor core was $88 \mathrm{MWd} / \mathrm{tU}$ (approximately 2.3 equivalent full power days [EFPD]).

The fuel in the reactor core is made up of $\mathrm{UO}_{2}$ at a low level of uranium-235 enrichment, in the form of pellets stacked in stainless steel cladding (grade $304 \mathrm{~L}$ as per the American AISI standard).

The following provisions were selected at design to limit the risk of fuel rod dryout during rapid power transients:

- the adoption of a high initial radial clearance between the fuel and the cladding to limit pellet-cladding interaction;

- the adoption of a cold internal helium pressure sufficient to prevent cladding creep at high temperature under the effect of external pressure;

- the selection of a special type of pellet ${ }^{279}$ unlikely to fracture under the effects of a radial thermal gradient (conservation of initial pellet geometry);

- the choice of steel cladding with a high expansion coefficient, which contributes to limiting the closure of the pellet-cladding clearance during power transients.

The good condition of the fuel had been checked previously by examining some of the hottest rods in the reactor core, firstly in 1988 after around 200 rapid transients had been performed, then in 1991 after nearly 10 minutes of cumulative operation above $25 \mathrm{MW}$ in slow ramps (out of the 23 minutes authorized).

After investigation, the cladding deformation and core fuel melt were attributed to slow ramp transients, which cause fuel pellets to deform into a diabolo shape; this

279. Using a sintering process that differs from that used for fuel pellets destined for reactor rods to be used in nuclear power reactors. 
means that in the event of pellet-cladding interaction during such transients, folds may appear in the cladding (rapid power transients cause the pellets to deform into a barrel shape). In addition, only slow ramps heat the fuel to a temperature close to its melting point, leading to the conclusion that the deformations observed had probably appeared after the tenth minute of operation above $25 \mathrm{MW}$.

The observations made raised a number of questions regarding safety, ultimately concerning in fine the capacity of the CABRI reactor driver core to undergo the tests planned for the future (10 rapid transients as part of the CIP program ${ }^{280}$ ):

- What was the overall state of the reactor core?

- What measures were needed to return the core to compliance?

- What additional measures were needed for the in-service monitoring of the core fuel rods?

- Was the distribution of power released in the reactor core well known?

- Did the simulation tools used to check, before each new test, that the fuel and cladding criteria would be observed give reliable results?

- Should there be restrictions on using the reactor in future programs?

Given the involvement of IRSN in the research performed using the CABRI reactor, the files drawn up by the operator, the CEA, had been examined, at the request of IRSN, by the Belgian nuclear safety body, AVN (Association Vinçotte-Nucléaire).

In the light of the observations on the three rods mentioned above, an "extended inspection" approach ${ }^{281}$ was taken. Non-destructive examinations were therefore also performed on six additional rods taken from among the 1,488 rods in the CABRI reactor core; only minor deformations in their cladding were observed.

The reactor was returned to compliance by replacing four rods (the one subjected to destructive expert assessment, and the other three rods producing power similar to that produced by the assessed rod) with new rods. It was estimated that there was no risk of damage to the other reactor core rods, as they were not producing sufficient power.

In addition, a detailed analysis of the transients experienced by the reactor core made it possible to attribute the fuel melt and associated deformations to a slow ramp transient performed in 1995. The CEA then took the decision to perform no more slow ramp-type tests in the CABRI reactor.

The analyses performed showed that important parameters had been poorly estimated by the various software tools used to simulate fuel rod behavior as part of the safety analyses performed prior to the scheduled transients. This explains why the fuel melt had not been anticipated. A new simulation tool was then developed by the CEA (covered in more detail in chapter 11). In addition, based on the fact that

280. Cabri International Program. See "Current state of research on pressurized water reactor safety", Sciences and Technology Series, IRSN/EDP Sciences, 2017.

281. Standard approach not specific to research reactors. 
the number of transients experienced by the reactor core had subjected the fuel rods to greater loads than would be possible in the future, without any detection of cladding failure, the CEA suggested that, in the future, the demonstration of the absence of cladding failure during a transient could be based on ensuring compliance with two criteria associated with circumferential deformation and cladding temperature. This was accepted, notably given the good ductility of the austenitic steel used for the cladding of fuel rods for the CABRI reactor, only slightly irradiated, as well as the low quantity of fission products accumulated in this fuel. In this respect, IRSN performed a study, during the expert assessment of CEA files, to compare the energy that a reactor core rod should produce during a rapid transient to achieve the new criteria at the energy level representative of a cladding failure limit determined on the basis of tests performed in the USA and Japan ${ }^{282}$; this study showed that these criteria were consistent for the transients expected in the CABRI reactor (CIP program).

Lastly, the results of the calculations performed using the new simulation tool made it possible to demonstrate that the cladding deformations and cladding and fuel temperatures should not result in cladding failure during CIP program tests.

In terms of in-service monitoring, the program selected by the CEA for the rods in the CABRI reactor core includes:

- establishing a "point zero" reference. This first step has been performed and involved performing a reference profilometry ${ }^{283}$ on the four rods substituted for those that experienced local melting (located in two control and safety rod [BCS] assemblies $^{284}$ );

- performing a profilometry at the end of the CIP program. This second step will involve unloading one of the two BCS assemblies containing the hot rods and removing one of them for profilometry. If there is a significant change (fold height greater than $60 \mu \mathrm{m}$ ), the inspection will be extended to two other hot rods in the BCS assembly. However, a slight change in the folding is to be expected, as the substitute rods (already irradiated) were not, by definition, in the hot spot position. The bounding "pulse" for future tests should therefore generate folding in the cladding of the new hot rods of around 60 to $100 \mu \mathrm{m}$ according to the predictive thermomechanical calculations.

\section{Exposure of workers to radiation}

Between 1973 and 2014, there were 18 events in which workers were exposed to radiation $^{285}$ at French research reactors (less than one event of this type per reactor

282. SPERT-CDC tests in the USA and NSRR tests in Japan, performed in 1969 and the 1970s with different cladding materials, including stainless steel as used for the driver core rods in the CABRI reactor. These tests led to the selection of a limit value, for rapid transients, of $240 \mathrm{cal} / \mathrm{g}$ for pressurized water reactor fuel rods.

283. Diameter measurements performed for two azimuths $90^{\circ}$ apart, based on a close axial pitch.

284. The driver core of the CABRI reactor has six assemblies, known as BCS assemblies or simply BCS, each with 21 fuel rods and 25 tubes containing control rods.

285. Including some (rare) contamination events. 
per decade). These occurred at six reactors, chiefly the SILOE, ISIS and OSIRIS reactors, as well as RHF. The change in the number of events over time is shown in figure 10.6 below.

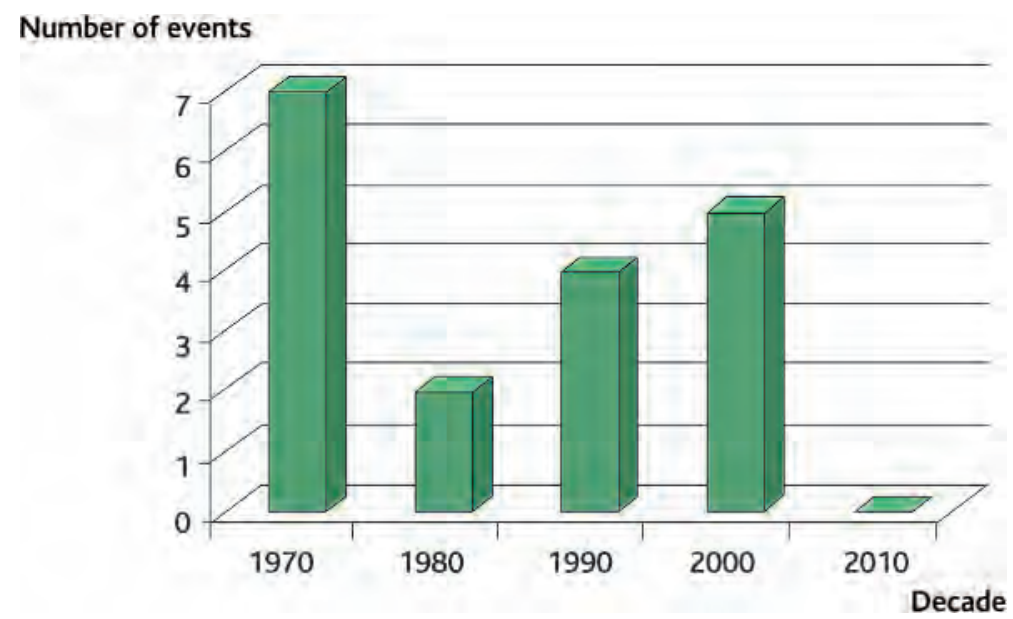

Figure 10.6. Change in the number of worker exposure events over the 1970s, 1980s, 1990s, 2000s and 2010s (2010-2014) in French research reactors. @ Georges Goué/IRSN.

Over a period of 41 years (1973-2014), around 30 people were exposed to radiation, with maximum doses in the order of $40 \mathrm{mSv}$, with the exception of the event that occurred at the SILOE reactor on November 15, 1979: when a photographic film was being placed on an activated dysprosium plate previously irradiated in the axis of a beam, an operator received a dose estimated at $140 \mathrm{mSv}$ (X-ray, $\beta$ and $\gamma$ radiation). Since 1990, there have been no cases in which workers have received significant doses of radiation (figure 10.7).

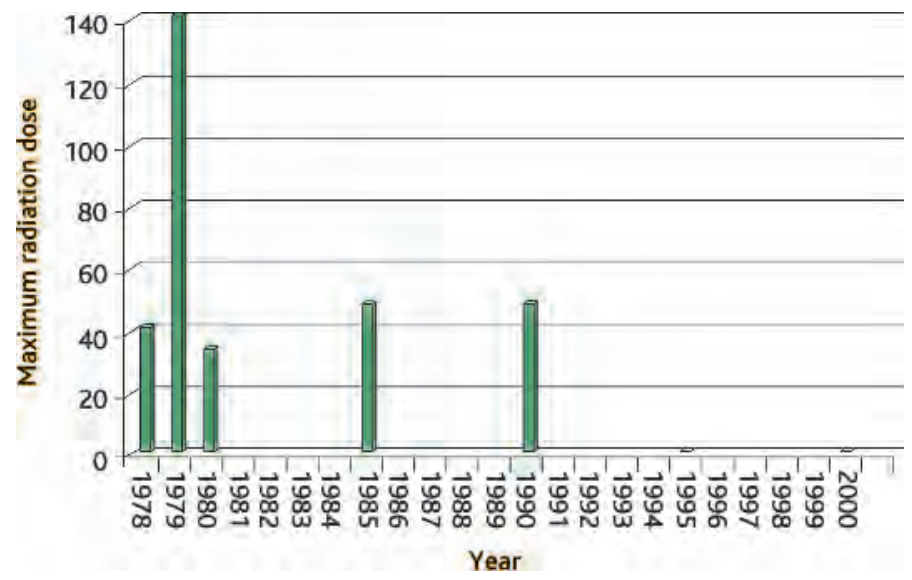

Figure 10.7. Change in the maximum radiation dose received by operators at French research reactors, in mSv $(1978,1979,1980,1985,1990)$. @ Georges Goué/IRSN. 
It is worth including here a description of one event that occurred at the SILOE reactor in October 1985, as it provides a general illustration of the risks that can arise when multiple activities are being performed simultaneously at one facility. The development of the film badge belonging to an external operator, who was working to restore the leaktightness of the reactor containment (metal structure), indicated that a dose of $47 \mathrm{mSv}$ had been received. The investigations carried out showed that this operator had been working on the reactor dome (metal containment), in line with a "hot cell" located in the reactor hall. At the same time, a cobalt 60 source of almost 100,000 Curies (for medical use) was being maneuvered in this cell using lifting equipment located on the roof of the cell, with the cable from this equipment passing through the thickness of the concrete via a narrow hole. During the operation, a very thin beam of ionizing radiation was directed towards the dome, affecting a small surface area of around $1 \mathrm{~m}^{2}$. The investigations also showed that this dose of $47 \mathrm{mSv}$ could be attributed solely to the period (20 minutes) when the source was being removed from the cell. After this event, the procedure for removing a source from the "hot cell" was updated to include a requirement to check that no work was being undertaken on the SILOE reactor dome at the same time.

There have been several events associated with the use of neutron channels at the ORPHÉE and RHF reactors. These have occurred more frequently at RHF due to the higher number of physics experiments performed simultaneously at that reactor ( 40 at RHF compared to 25 at ORPHÉE) and due to their duration, which is shorter on average at RHF.

Two events of this type, one in June 1989 at the ORPHÉE reactor - which could have led to the accidental exposure of personnel - and the other in August 1990 at RHF which led to the (low-level) exposure of two physicists and two operators (maximum dose in the order of $20 \mathrm{mSv}$ ) - are worth describing here as they illustrate the difficulties, mentioned in section 7.2.3, that arise when different populations are working at research reactors, namely operating personnel, on the one hand, and researchers, on the other. These two events led the relevant operators and IPSN to carry out an indepth analysis into:

- the technical measures for blocking the "neutron beams",

- human and organizational factors.

The technical measures for blocking the beams notably rely on the presence of physical shutters (a "head" shutter, positioned upstream of the neutron beam, and a secondary shutter ${ }^{286}$; these may use different technologies ${ }^{287}$ ), which make it possible to interrupt the neutron beam and re-establish continuous biological shielding for the reactor. These shutters, which are safety-related elements, are checked regularly. The two events in 1989 and 1990 highlighted shutter design anomalies (shutter off balance $^{288}$ due to a minor compressed air leak in the case of the ORPHÉE reactor, resulting

286. The neutron beam may, after a head shutter, be directed to several channels, each of them equipped with its own secondary shutter.

287. Flap, barrel, liquid plug, etc.

288. These were dual-action shutters in which the membrane was held in the closed position by pressurized air on each side. They have been replaced by spring and compressed-air shutters so that, if the air pressure drops on one side of the membrane, it is held in the closed position by the spring acting from the other side. 
in the untimely opening of the beam; shutter cut off [for operational reasons] from its compressed air supply at RHF, making it impossible to interrupt the beam). Various improvements have been made, notably to the compressed air systems controlling the shutters.

Regarding human and organizational factors, the event that occurred at the RHF reactor led IPSN, with the operator's agreement, to perform its own analysis. This gave rise to the following observations:

- the research physicists at the Institut Laue-Langevin had been put in a difficult position, as they received numerous requests to perform applied research experiments;

- three people in succession had persisted with an incorrect understanding of how the shutters worked and the role of a key used for the secondary shutter control rack, despite the visual and audio alarms, until a fourth person, the operator responsible for "managing" the shutters, had made them aware of the hazardous situation in which they were working. It therefore appeared that operator training regarding the shutter systems, their operating conditions and the associated monitors and alarms (visual and audio) was insufficient;

- the role of the internal security committee (CIS) in relation to experimental devices and experiments was limited at that time.

In the case of the ORPHÉE reactor, the coordination between the reactor operator and the Laboratoire Léon Brillouin ( LLB $^{289}$ ), where the researchers were based, had room for improvement; the facility manager was unable to properly exercise their safety responsibilities in relation to the experimental devices.

As a result of these two events, the responsibilities of the two relevant facility managers for the safety of people and property were extended to cover experimental devices within their basic nuclear installation, and the training of operators in charge of experimental devices was improved.

For the ORPHÉE reactor, an agreement was signed in September 1989 by the facility manager and the LLB, specifying the interfaces between the reactor facilities and the experimental devices, and making provision for the designation of a facility manager and safety engineer for experimental activities. This agreement also set out the respective responsibilities of this facility manager and safety engineer, and their relationship to the ORPHÉE facility manager. The experimental activities facility manager was given responsibility for the safety of people and property in the context of the general operating rules of the reactor, and charged with:

- training the operators involved in experimental activities,

- establishing the corresponding instructions and ensuring they are correctly applied,

- examining all significant modifications to existing experimental equipment and the implementation of new equipment, 
with the use of experimental devices (or the implementation of significant modifications to previously authorized devices) dependent on, as for RHF, an examination by the internal security committee (CIS).

\subsection{Measures to improve the safety of French research reactors following the Fukushima Daiichi accident}

The accident that occurred at the Fukushima Daiichi nuclear power plant on March 11, 2011, led the French Prime Minister to ask the Chairman of ASN, on March 23, 2011, to perform a study on the safety of nuclear facilities, prioritizing nuclear power reactors, in the light of this incident. The study had to cover five points: the risk of flooding, earthquake, loss of electrical power supply and loss of cooling, as well as the operational management of accident situations. The Prime Minister wanted this study to consider, facility by facility, whether safety improvements were required, in a way that was consistent with the work carried out in a European context by ENSREG and WENRA. He asked for the initial conclusions to be presented by the end of 2011.

At the same time, the European Council asked all the countries in the European Union, at its meeting of March 24 and 25, 2011, to perform "stress tests" on their nuclear power reactors, with regard to potential natural hazards (chiefly earthquakes and flooding) on a scale exceeding the characteristics considered in the design of the facilities (so-called "extreme" hazards).

In response to the Prime Minister's request, ASN ordered nuclear facility operators EDF, the CEA, AREVA and the Institut Laue-Langevin, through 12 resolutions taken on May 5, 2011, to present:

- "Provisions taken in the design basis of the facility and facility compliance to its design requirements ${ }^{290}$;

- the robustness of the facility beyond its design basis, by identifying, on the one hand, a step change in the event sequence (cliff edge effect) and, on the other, measures for its avoidance;

- proposals for modifications likely to improve safety of the facility and organization in the event of an emergency."

The studies performed in France by the operators constituted the "complementary safety assessments" (CSA).

As explained in section 7.3.2, the design of French research reactors allows them, as a general rule ${ }^{291}$, to reach, soon after shutdown, a state that requires no forced water flow and limited electrical power supplies (for facility monitoring, any releases, etc.).

290. This involved a full assessment of these areas, incorporating the elements and justifications in the safety reports (latest versions in force), any deviations or anomalies detected over time and their resolution, and past safety reviews.

291. Except in the case of the Jules Horowitz reactor. 
Furthermore, their radiological inventories are clearly significantly lower than those for power reactors. On the other hand, it is important to take into account their specific risks (construction in notable seismic areas or downstream of dams, near urban areas, etc.).

This is why CSA have been performed for research reactors, according to the specifications drawn up by ASN, based on those proposed by WENRA for the European power reactor stress tests, with an additional section on contractors providing services to operators. Priorities were, however, identified according to the risks associated with these reactors (taking a "proportionate" approach).

Regarding subcontractors, the Fukushima Daiichi accident showed that the capacity of an operator and, where relevant, its subcontractors to organize work in severe accident conditions is a key element of controlling such situations. This organizational capacity is also a key element of preventing such accidents, maintaining facilities and ensuring the quality of operations. As a result, the conditions of recourse to subcontractors are of special importance, and must allow the operator to retain full control over and full responsibility for the safety of its facility. It became clear that this aspect also needed to be covered in the CSA (the subjects to be covered by French operators are described in the focus section at the end of this chapter).

The complementary safety assessments involved assessing the behavior of research reactors in response to extreme hazards, chiefly earthquakes and flooding, as well as in the event of the loss of off-site electrical power or the off-site heat sink ${ }^{292}$, and in the management of severe accidents, in a context in which all or part of the facilities at a site may be affected over the long term.

It should be noted that all the CSA performed in France, whether at power reactors or research reactors (or other types of INBs), should be situated in the general context of work to improve their safety, which is based on:

- the integration of operating experience feedback,

- the ten-yearly safety reviews, which include the reassessment of safety rules and requirements based particularly on advances in knowledge.

In general, although they concluded that their facilities were well enough designed to withstand plausible natural hazards, the operators of research reactors proposed introducing a series of additional provisions, chiefly to increase the autonomy of the measures planned at the corresponding sites to deal with ongoing situations that could affect the long-term cooling of the reactor ${ }^{293}$ - which could arise from a loss of electrical power - or to strengthen the provisions for managing a large-scale emergency.

More specifically, the operators of French research reactors assessed the margins available, beyond the reference seismic loads ${ }^{294}$, for essential safety-related equipment items (sometimes referred to as "key SSCs"), such as reactor buildings and pools, natural convection valves, safety valves for neutron channels, etc. The behavior of equipment

292. Water from outside the facility that can be used to remove the heat released by the reactor.

293. For example, without special cooling measures, the gradual evaporation of water from a reactor pool would make it necessary to provide makeup water to avoid core uncovery.

294. Loads identified during the most recent seismic reviews. 
likely to jeopardize, in case of failure, these "key SSCs" has also been examined (overhead cranes in particular).

The expert assessment of the CSA sent to ASN by the operators of French research reactors was performed by IRSN; ASN also sought the opinion of the standing group of experts for nuclear reactors (GPR).

The margins estimated by the research reactor operators led ASN to rule that the facilities could continue operating, but that improvements should be made to obtain a "hardened safety core" (see the focus section below) of particularly robust equipment items, in order to withstand extreme hazards, such as an earthquake (hardened safety core design-basis earthquake [SND]) and its effects. The operators of research reactors were formally ordered to implement these "hardened safety cores" in 2013 through ASN resolutions. These "hardened safety cores" must aim to:

- "prevent a severe accident or limit its spread,

- mitigate large-scale releases,

- enable the licensee to fulfill its emergency management duties,"

through appropriate measures to strengthen defense in depth.

Regarding the last point above, it became clear in particular that there was a general need to strengthen post-accident monitoring provisions at research reactors in terms of analyzing the state of these reactors in extreme situations, for instance in order to obtain information regarding the position of the natural convection valves or safety rods.

In its 2013 resolutions, the ASN issued requirements regarding the situations to be taken into account when designing "hardened safety cores", specifically the "hardened safety core design-basis earthquake":

- The situations (known as "hardened safety core situations") to be taken into account are:

- the loss of electrical power supplies that do not form part of the "hardened safety core",

- the loss of the heat sink (reactor cooling) that does not form part of the "hardened safety core",

- the external hazards identified for the "hardened safety core",

- situations arising from the state of the facility, the site and its environment after one or more external hazards identified for the "hardened safety core".

- The hardened safety core design-basis earthquake must:

- encompass the seismic margin earthquake (SMS) for the site, augmented by $50 \%$,

- encompass the spectra established using a probabilistic approach for a 20,000 year return period,

- take into account special site effects, notably soil type. 


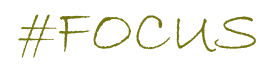

\section{The "hardened safety core" concept}

Safety improvements to facilities such as nuclear reactors, in the light of lessons learned from the accident that occurred at the Fukushima Daiichi nuclear power plant in March 2011, aim to limit, as far as possible, short-, medium- and long-term radioactive releases in the event of an extreme external hazard with the long-term loss of electrical power and the heat sink at a site. Indeed, in such situations it is desirable that a nuclear facility avoid adding to the difficulties already facing the emergency teams responsible for assisting the population. In the event of a natural catastrophe of the kind that occurred in Japan in March 2011, the environment of the affected site would be severely damaged, making it difficult to take action to protect the site's neighboring populations and, in the long term, manage the contaminated area.

The post-Fukushima "hardened safety core" therefore contains provisions to guarantee all the fundamental safety functions in the situations mentioned above ("hardened safety core situations").

In addition, it has become clear that the "hardened safety core" should be defined by considering the loss of all the provisions already implemented as part of in depth defense, whose robustness to natural hazards significantly more extreme than those identified during facility design cannot generally be established with great certainty.

This means that the "hardened safety core" includes provisions sufficiently robust to prevent, as far as possible, the fuel melting (in the core or storage pool) ${ }^{295}$ in the situations mentioned previously; this involves stopping the nuclear chain reaction and maintaining fuel cooling, and implementing measures to limit releases in such a way that reduces the radiological consequences in the event of the fuel melting, in terms of scale and duration. It must also be possible to guarantee that the operator can perform the duties required of it in emergency situations. To do this, the "hardened safety core" provisions must ensure that emergency teams can access the information needed to assess the state of the facilities and prepare for on-site operations. In the event of radioactive releases into the environment, the operator must also be able to assess the consequences of these releases using not only the data available from the facilities, but also measurements performed in the environment (meteorological, dose rate and radiological activity measurements). This information must allow the operator and public authorities to make the decisions for which they are respectively responsible in order to protect the personnel present at the site and the general public. In this respect, it is therefore vital for the site to have operational external communications systems in the situations under consideration.

$295 . \quad$ Principle applied in the various ASN resolutions issued to operators in 2013. 
In the definition of the "hardened safety core", attention must also be paid to the "support systems", which enable the operation of systems that directly perform safety functions. These notably include electrical power generation and distribution systems (generators or batteries, electrical switchboards), instrumentation and control systems, and ventilation systems (which perform the thermal conditioning functions for rooms). For these systems, the aim is to ensure independence and diversification in relation to existing systems.

For existing nuclear facilities, or facilities in an advanced state of design or construction (Flamanville 3 [EPR], the Jules Horowitz Reactor), it is not possible to ensure that the "hardened safety core" contains only new equipment. It will ultimately consist of existing structures, systems and components, strengthened if necessary to ensure that they remain operational in the event of an external hazard, and new structures, systems and components.

It is not easy to define the "levels" of extreme hazard to be considered when designing the "hardened safety core", especially in the case of seismic hazards. The traditional approaches used to assess seismic hazards have been supplemented with probabilistic methods, notably to target earthquakes associated with a 20,000year return period as requested by $\mathrm{ASN}$ in its requirements issued to operators.

The reports on the complementary safety assessments carried out by French operators, drawn up according to the plan described in the focus section below and incorporating the additional provisions proposed (relating to the "hardened safety core" in particular), have been made public ${ }^{296}$. It should be noted that, in some cases, these CSA brought to light instances of noncompliance (related to equipement items, studies, etc.) in relation to the "key SSCs", which therefore had to be resolved.

The RHF complementary safety assessment ${ }^{297}$ is covered in further detail below, given the specific features of this facility in terms of earthquake and flood risks, and its proximity to urban areas. For example, this CSA resulted in the facility introducing (in stages from 2012 to 2016) various systems designed and sized for the hardened safety core design-basis earthquake (see figures 10.8 and 10.9):

- a seismic reactor shutdown system (ARS);

- an emergency core flooding system (CRU) linking the reactor block, which has a limited volume $\left(15 \mathrm{~m}^{3}\right)$, to the large-volume reactor pool $\left(500 \mathrm{~m}^{3}\right)$;

- a groundwater supply system (CEN) to mitigate potential reactor core uncovery, with a flow rate of $250 \mathrm{~m}^{3} / \mathrm{h}$ (for each of the two channels), compared to just $60 \mathrm{~m}^{3} / \mathrm{h}$ for the emergency cooling system (CES) implemented in 2006;

- a new emergency ventilation system for the reactor building (seismic depressurization system [CDS]);

296. On the ASN website.

297. Rapport RHF $n^{\circ} 399$ on the ASN website. 


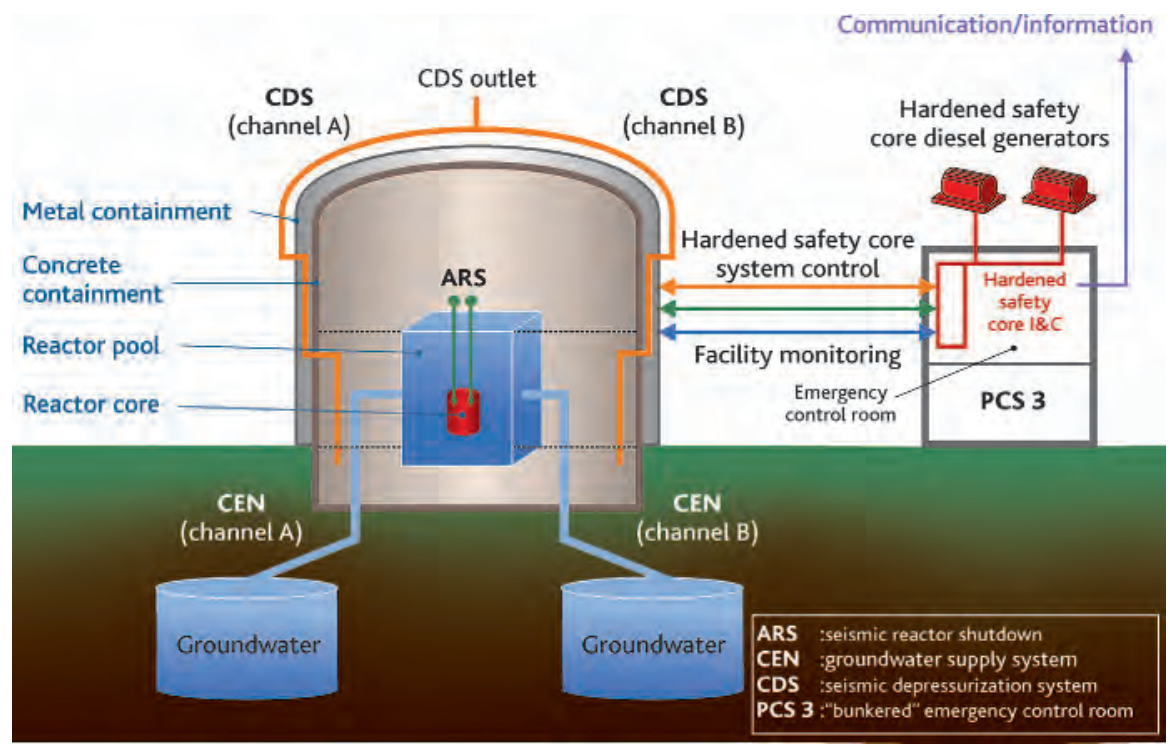

Figure 10.8. Schematic diagram of additional measures installed at RHF after the Fukushima Daiichi accident. () Georges Goué/IRSN.

- a new emergency control room (PCS ${ }^{298} 3$ building);

- specific equipment (in PCS 3) to monitor some key parameters of the state of the facility (the core neutron flux, with two new neutron detectors attached to the reactor block in the light water pool; the configuration of the natural convection valves; the water levels in the reactor block and pool; and the pressure in the reactor hall and in the annulus between the two containment walls), with the values also being automatically sent to $\operatorname{IRSN}^{299}$ in the event of an accident.

These systems, the majority of which are redundant ${ }^{300}$ and automatic, are electrically powered by emergency generator sets in the new PCS 3 building, which was designed to withstand not only the extreme hazards considered for the RHF site (hardened safety core design-basis earthquake, equivalent to twice the seismic margin earthquake at the relevant frequencies), but also the failure of the upstream dams (PCS 3 is positioned six meters higher than the HFR site platform). They have been fully operational since 2016.

Regarding the seismic reactor shutdown system, it is important to note that the instrumentation and control for the reactor protection system had already been adjusted to ensure that the safety rods ${ }^{301}$ drop automatically in the event of seismic

298. Poste de contrôle et secours [emergency control room].

299. To strengthen the analysis of the facility with the operator (in the context of implementing the 3D-3P approach mentioned in section 7.7).

300. There is only one PCS 3.

301. These are five control rods located in the reflector area, outside the fuel element that forms the reactor core in which the regulating rod slides. 

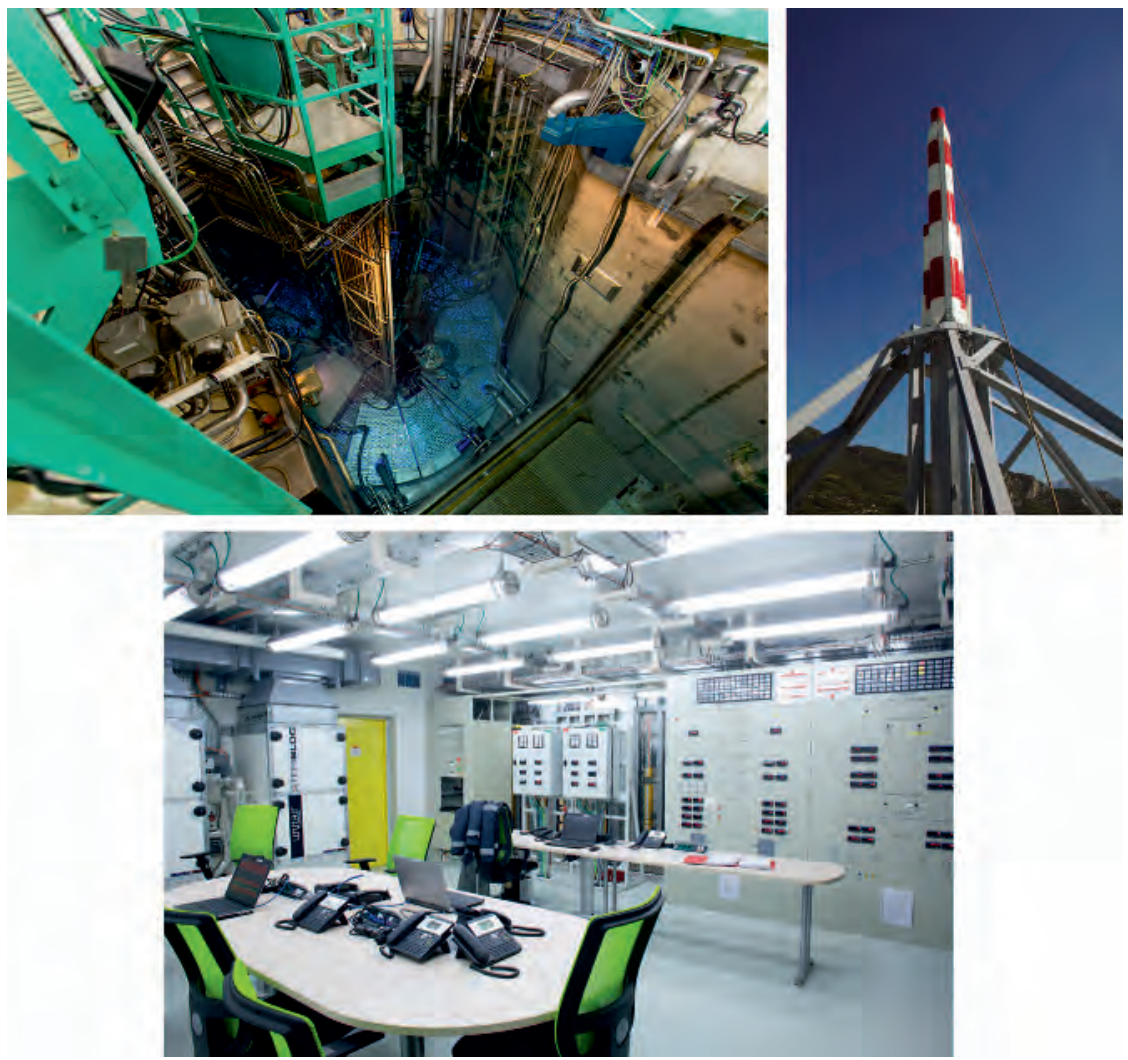

Figure 10.9. Three measures selected for the RHF at Grenoble after the Fukushima Daiichi accident, all designed and sized for extreme earthquakes and flooding: on the top left, the pool inlet elbow of the groundwater supply system. (C) IRSN; on the top right, the seismic depressurization system stack positioned on the dome of the metal containment. () ILL; at the bottom, the PCS 3 emergency control room. (c) Jean-Marie Huron/Signatures/IRSN.

loads, by setting the trigger threshold to $0.01 \mathrm{~g}^{302}$. It was then completely renovated to make it independent from the other reactor protection systems, and it was qualified for the "hardened safety core design-basis earthquake". This provision ensures that the safety rods drop - even in the event of an earthquake without a weak movement phase (compressional waves known as P-waves) before the strong movement phase (shear waves known as S-waves).

Still in the case of RHF, the operator studied two scenarios for failure of the dam(s) upstream on the Drac River, and their possible impact on the "key SSCs". They were:

302. The trigger threshold value for reactor scram is selected to be lower than the peak ground acceleration to allow sufficient time to implement this reactor scram. A value of $0.01 \mathrm{~g}$ is typically reached when the primary seismic waves ( $P$-waves) arrive; accelerations at the level of peak ground acceleration (several tens of $g$ ) are detected several seconds later, with the arrival of the S-waves, which cause the most damage to equipment. 
- failure of the Monteynard dam, which could lead to the failure of the NotreDame-de-Commiers dam downstream;

- failure of all the dams on the Drac River, which would result in the highest possible water level at Grenoble.

As a result of these studies, the operator considered a hypothetical water level of six meters at the RHF platform. This was taken into account in the design of the new emergency control room building (PCS 3). The large openings in the reactor building (truck entrances, etc.) were strengthened to ensure they could withstand a hardened safety core design-basis earthquake and a water level of six meters at the site, while maintaining sufficient leaktightness to prevent large quantities of water entering the building.

In the definition of a "hardened safety core design-basis earthquake", the issue of site effects is particularly relevant in the case of RHF, as the reactor is positioned in an alluvial valley (the alluvium is around $700 \mathrm{~m}$ above the bedrock, and partially composed of clay). This is why the operator has been involved in research into the site effects since the 2000 s (the CASHIMA project and, more recently, the SIGMA project ${ }^{303}$ ), and has had measurements (crosshole measurements ${ }^{304}$ ) and two-dimensional simulations performed with a view to better understanding these site effects. The multiplication factors applied to the spectra - which were previously established without taking the site effects into consideration - are between 1.3 (for frequencies above $3 \mathrm{~Hz}$ ) and 2 (for frequencies below $0.3 \mathrm{~Hz}$ ). The peak ground acceleration of the hardened safety core design-basis earthquake at infinite frequency is $0.6 \mathrm{~g}$, compared to the value close to $0.3 \mathrm{~g}$ identified during the seismic review in the early 2000s. Ultimately, at the relevant frequencies for structures, systems and components, the hardened safety core design-basis earthquake for RHF is twice as high as the seismic margin earthquake selected for the seismic reassessment in the early 2000 s.

The capacity of the "key SSCs" (overhead cranes, neutron channel safety valves, etc.) to withstand a hardened safety core design-basis earthquake was checked, including by vibrating table tests. This led the operator to strengthen:

- the overhead cranes for fuel casks,

- the large equipment near the edge of the pool (vertical "cold source", etc.),

- the cask maintenance station (potential hazard to the reactor containment),

- the large openings in the reactor building (truck entrances, etc.).

The operator of RHF decided to make some modifications to the "hardened safety core" as initially planned. In particular, these modifications involved rerouting the emergency ventilation system, rerouting cables to ensure they were not swept away in the event of extreme flooding (they are buried at a depth of 5 meters) and taking into account the chemical risks associated with the site environment. They also included designing the PCS 3 emergency control room to be habitable and operational in the

303. See "Current state of research on pressurized water reactor safety", Science and Technology Series, IRSN/EDP Sciences, 2017. Numerous European partners, both industrial operators and research organizations, including universities, are involved in these two projects.

304. Measurement of the velocity of the shear waves at a depth of $30 \mathrm{~m}$ - see the same publication. 
event of an accident involving phosgene release from the Pont de Chaix chemical platform (special ventilation/filtration system).

As mentioned previously, the "water block" principle was adopted for the design of the CEA reactors, such as OSIRIS, ORPHÉE and the Jules Horowitz reactor; this is a favorable design option for reactor cooling, as it guarantees that there is a sufficient volume of water in the reactor in the event of a leak in a section of core cooling system piping outside the reactor block. However, it is impossible to fully rule out the possibility, in extreme situations, of a loss of leaktightness in the rooms or bunkers in which these sections of piping are located, even though margins are built into the design of these rooms and bunkers ${ }^{305}$.

For reactors in operation (ORPHÉE, CABRI, etc.), various supplementary provisions have been proposed by the CEA: additional electric generator sets, makeup devices with a mobile water supply, additional measurement systems (water levels, etc.) and remote shutdown stations to monitor the facilities after an extreme hazard. In addition, strengthened provisions have been scheduled for 2015 to 2018 to allow effective emergency control even in extreme situations (setting up facility survey teams after an extreme hazard, strengthening or building rooms for equipment and systems that may be used in extreme situations).

For the Jules Horowitz reactor, the complementary safety assessments ${ }^{306}$ was performed by the CEA on the basis of the reactor design as of 2011. Various types of provision were selected for the continuation of the project, such as:

- the introduction of additional design margins for some items of equipment (new fuel storage rack anchors, rollers and tracks for the walkway over the reactor pool, etc.). In addition, measurement systems (natural convection valve position, water levels in pools and the reactor pool water temperature) were identified as "hardened safety core" equipment items;

- the decision to make available, in addition to emergency generator sets and the possibility of electrical power being supplied by a mobile set at the Cadarache center, a permanent ultimate diesel generator (GUS), qualified as "hardened safety core" (notably installed on a non-floodable platform);

- the creation of two connections on the emergency secondary cooling system to allow the supply of cold water from external sources (tankers equipped with an autonomous pump);

- the storage of a sufficient volume of water in the pool drain tanks for emergency water makeup to these pools, with this makeup system designed for the hardened safety core design-basis earthquake;

- the addition of a system for reactor scram in the event of an earthquake being detected.

305. Designed for the seismic margin earthquake.

306. File published on the ASN website: Réacteur Jules Horowitz - Évaluation complémentaire de la sûreté au regard de l'accident survenu à la centrale de Fukushima I [Jules Horowitz reactor Stress test following the Fukushima I accident] (CEA/DEN/CAD/DIR/CSN DO 575 13/09/11). 
\#FOCUS

\section{Subjects covered in the reports on the complementary safety assessments performed by operators after the Fukushima Daiichi nuclear power plant accident}

The complementary safety assessments reports were drafted based on the following standard format:

- site characteristics and current state,

- identification of cliff edge effect risks and essential structures and equipment:

The cliff edge effect is defined as a sudden change in the behavior of a facility caused by a slight change in the envisaged scenario for an accident, the consequences of which are then much more severe ${ }^{307}$.

- $\quad$ earthquakes: events considered (during design studies, then during safety reassessments), quantification of margins,

- external flooding: events considered (during design studies, then during safety reassessments), quantification of margins,

- other extreme natural phenomena,

- loss of electrical power and loss of cooling systems,

- severe accident management,

- conditions of recourse to subcontractors:

- the scope of the activities in question, with supporting arguments,

- the process by which subcontractors are chosen: requirements in terms of qualifications, training in nuclear safety and radiological protection, etc.),

- measures taken to allow for satisfactory working conditions for subcontractors, the organization implemented to provide radiological protection for workers,

- procedures for oversight of subcontracted activities, particularly the way in which the operator continues to assume responsibility with regard to nuclear safety and radiological protection.

- summary, including any proposals for supplementary measures.

307. Official Journal of the French Republic No. 0125 of May 31, 2012. 



\section{Chapter 11}

\section{Overview of simulation software used in design studies and safety analyses for French research reactors}

The design or modification of research reactors and their experimental devices (including the modification of cores), just like the associated safety demonstration - including during safety reviews - is based on studies, generally performed using simulation software ${ }^{308}$, in various areas: neutronics or criticality (for cores and areas dedicated to fuel storage), thermohydraulics (for cores and cooling systems), structural mechanics (for metal structures and civil engineering works), etc. It is chiefly the operators (CEA, Institut Laue-Langevin) that perform these studies, but IRSN may also perform them as part of its expert assessment of the files submitted by these operators to the ASN.

It is, of course, important to validate simulation software before it is used for studies. The ability of each simulation software tool to accurately or conservatively represent the physical phenomena in question must also be established as part of a safety demonstration, or the expert assessment of such a demonstration.

In this respect, section 8.3 on the so-called "BORAX" reference accident presents examples of general demonstration tests performed in reactors or on models to reinforce evaluations performed by calculation. Indeed, this type of verification can be desirable, or even necessary, in cases where the evaluations performed by calculation are subject to or result in too high a level of uncertainty (including due to simplification of the modeling) or when the software has only been validated separately to its various physical models. 
It is also important to recall here the special importance, in the case of a new reactor (or a reactor that has undergone substantial modification), of startup tests (or restart tests) performed by the operator on various items of equipment or systems to ensure, as far as possible ${ }^{309}$, that they are able to perform the functions for which they were designed, with the performance expected from the design studies largely based on the use of simulation software.

Some of the software used ${ }^{310}$, in gradually improved versions over time, and their key applications ${ }^{311}$ in French research reactors are described briefly below. This description is generally limited to the possibilities offered by these software tools, the context and aims of the studies for which they are used, as well as some elements concerning the modeling, and precautions to be taken to achieve a satisfactory level of confidence in the results obtained - adjustments based on operating experience or the comparison of different software.

A number of these software packages were initially developed for power reactors (for example FLICA, CATHARE and SIMMER). They have been adapted for use with research reactors (e.g. for reactors using uranium- and aluminum-based fuel in the form of plates, with heavy water as a coolant or moderator, etc.). In addition, neutronics and thermohydraulics software for cores and reactor systems can be combined ${ }^{312}$, for example CRONOS-FLICA, CRONOS-CATHARE or even CRONOS-FLICA-CATHARE - this last combination forms the HEMERA (Highly Evolutionary Methods for Extensive Reactor Analysis) software chain.

Lastly, attention may be drawn to the fact that the complexity of research reactor cores, which combine standard fuel elements, fuel elements that may partially contain neutron absorbers, control absorbers (rods or plates) in or close to the core and highly diverse experimental devices in various locations in or close to the core (for example, loops that may be cooled with coolants other than those used to cool the core in which they are installed, such as liquid sodium), naturally requires the use of relatively sophisticated simulation software, especially in relation to neutronics. The 2004 discovery of melted rods in the driver core of the CABRI reactor (section 10.1.2), which was caused by underestimating the temperatures reached in the rods in question, confirms this complexity.

\section{$\checkmark$ Neutronics}

- APOLLO: this software ${ }^{313}$ for two-dimensional (2D) simulation in the field of neutronics, based on neutron transport theory (the Boltzmann equation) in a

309. Indeed, it is not possible to envisage creating accident situations in order to check that the equipment designed to control these situations works correctly.

310. In particular, see "Neutronics", a monograph by the Nuclear Energy Division of the CEA, Le Moniteur, 2013.

311. The applications detailed in this chapter also form the subject of publications.

312. Although they were produced for pressurized water reactors, some of these coupled software packages have been, or can be, used for certain research reactors, while others need to be adapted.

313. In the field of neutronics, a distinction is drawn between the expressions "software" and "calculation scheme": "calculation scheme" refers to the sequence of physical models linked to a clearly defined "library" of cross sections. 
stable state (stationary), but able to simulate fuel burnup ${ }^{314}$ (so-called "evolution" code) and take into account a large number of neutron energy groups (300 for normal calculations), is principally used to determine the "libraries" of cross sections ${ }^{315}$ than can then be used with the CRONOS software presented below. These are multi-parameter "libraries" of cross sections (the parameters may be temperature, water density, etc.) "condensed" into several energy groups and homogenized in "cells" selected for the representation of the system being studied (an assembly, a rod or a plate, a pellet, etc.). In principle ${ }^{316}$, APOLLO (2) can also be used to determine the core neutron balance (production of neutrons via fission, absorption and leakage) with the relevant neutron parameters (neutron balances such as the effective neutron multiplication factor $k_{\text {eff; }}$ kinetic parameters such as neutron life or delayed neutron production; neutron feedback; the efficiency of absorbers, etc.).

- CRONOS: This software for the three-dimensional simulation of reactor core neutronics solves either the transport equation or the diffusion equation by using the finite element method for several neutron energy groups (two groups are sufficient for the current calculations). It can be used to determine the distribution, in three dimensions, of the core power as well as the change in this power over time during incident or accident transients, the efficiency of neutron absorbers, etc. CRONOS can also simulate fuel burnup (so-called "evolution" code). The cross sections needed for the code come from calculations performed using the APOLLO software and are entered as input data. CRONOS is a multi-reactor type code: there is nothing in its organization or structure that makes an assumption about the type of reactor for which the calculations are being performed. This means that calculation schemas using CRONOS (2) have been assembled (notably in terms of meshing) for a large number of reactors, including research reactors (figure 11.1).

- MCNP: This software for three-dimensional geometrical simulation, developed by the Los Alamos National Laboratory is historically the first simulation software based on the Monte Carlo method (Monte Carlo N-Particle transport code). MCNP can be used for a variety of particles (neutrons, electrons, photons, etc.). It is used in a range of fields, including, in addition to reactor physics, radiological protection, dosimetry, criticality and medical physics.

For a reactor core, the principle behind the software involves following the history of each neutron in the system being studied, from birth (external source, from fission, etc.) to death (capture by a nucleus or leakage outside the system). With the MCNP software, a continuous neutron energy spectrum is usually used, but a discretized spectrum may also be used. Although the MCNP software can simulate fuel burnup (so-called "evolution" code), it is not suitable (similarly to the other Monte Carlo software described below, at the current stage of its development) for simulating transients in a reactor, as the neutron feedback is not correlated to temperature.

314. Fuel consumption through irradiation.

315. Cross sections constitute indicators of the likelihood of interaction between neutrons and the material; this likelihood depends on the neutron energy.

316. Highly complex calculation with APOLLO version 2; it will be simpler with version 3 . 


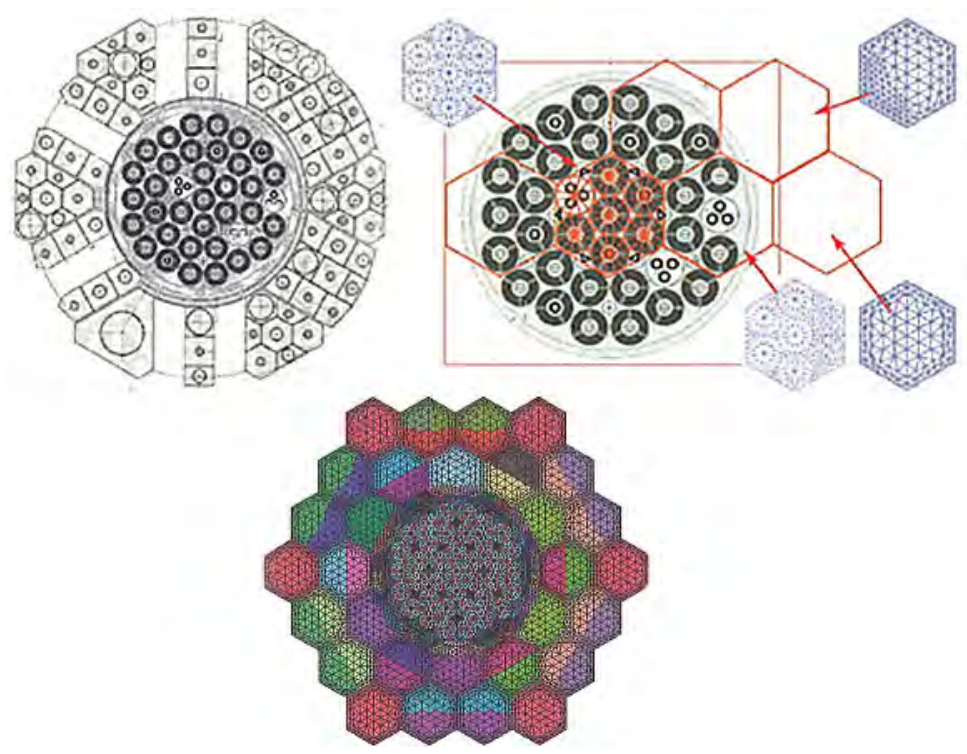

Figure 11.1. From the actual core geometry of the Jules Horowitz reactor (top left) to its subdivision into hexagonal macro-elements (top right) and meshing in finite isoparametric elements (bottom), performed by the CEA in order to calculate, using the CRONOS (2) software, the core power distribution (source: CEA monograph). @ DR.

The history of each neutron depends on its interactions with the material. The distance traveled by the neutron between two collisions, the nuclei involved and the interaction types are parameters that are randomly sampled by using experiment results grouped into "libraries" of nuclear data. In this way, by increasing the monitoring of many neutrons, it is possible to simulate the natural behavior of the system and calculate numerical values close to certain core neutron parameters (balances such as $k_{\text {eff }}$ and kinetics coefficients, but not temperature-dependent feedback). As this type of calculation is based on probabilities, it is necessary to perform extensive random sorting to reduce the statistical uncertainty ${ }^{317}$. Some calculations can last several months, hence the importance of using powerful computers. The geometric representation of the system studied is based on a precise, geometric description of the surface of objects, defined according to the problem to be solved and which may vary a great deal in size (from a core area to a fuel pellet, for example). This is known as "surface representation". The MCNP software package can therefore be used for precise neutronics calculations.

- TRIPOLI (TRIdimensionnel POLYcinétique): This three-dimensional simulation software tool, under development by the CEA since the 1960s, uses the Monte Carlo method to solve the transport equation for neutrons and photons, the latter

317. The statistical uncertainty regarding the result of a calculation is given by the central limit theorem: the standard deviation of the result is proportional to the inverse of the square root of the number of neutrons monitored. 
resulting from the nuclear reactions generated by the neutrons (fission or capture - the photons take the form of $\gamma$ radiation). Similarly to the MCNP software, a continuous neutron energy spectrum is usually used for TRIPOLI, but a discretized spectrum may also be used. The TRIPOLI software can simulate fuel burnup (socalled "evolution" code), but, for the same reason as in the case of the MCNP software, it cannot simulate transients in a reactor. With TRIPOLI, the system being studied can be processed by surface definition (as for MCNP) or using a combinatorial volume method (in which the user specifies the volume types and the link between the volumes). It is mainly used for reactor core physics, criticality and radiological protection. The TRIPOLI software is frequently used in France for precise neutron calculations (so-called "reference" calculations).

\section{Examples of use:}

The CEA uses the TRIPOLI software for neutronics studies at its research reactors (CABRI, the Jules Horowitz reactor, etc.). It also used TRIPOLI (4) in parallel with APOLLO (2) ${ }^{318}$ to examine the impact of UMo fuel on the cycle duration and performance of the Institut Laue-Langevin high flux reactor.

- MORET: This simulation software, under development by IRSN since the 1970s, calculates neutron transport using the Monte Carlo method. It is generally used with a discretized neutron energy spectrum. The geometric representation is less detailed than that possible using the meshing tools associated with MCNP and TRIPOLI. The MORET software makes it possible, for complex three-dimensional systems containing fissile materials, to determine the following main values (excluding feedback correlated to temperature): the effective neutron multiplication factor $\left(k_{\text {eff }}\right)$, the neutron flux, the reaction rates (fission, absorption and diffusion) in the different volumes, neutron leakage outside the system and the kinetic parameters of the system (proportion of delayed neutrons and their generation times, neutron life, etc.). The geometric model of the system being studied is processed using the combinatorial volume method. More specifically, the software is used to study the criticality risks in nuclear facilities (i.e. the appearance of an uncontrolled chain reaction outside the reactor cores in operation), in its "environment" known as CRISTAL ${ }^{319}$, which offers different datasets (and other software such as APOLLO (2) and TRIPOLI (4)).

\section{Examples of use:}

- The MORET software is principally used by IRSN for its expert assessments of the criticality risks in fuel cycle facilities. However, for the past ten years or so, IRSN has also been using it for reactors, as in the case for a study designed to learn lessons from a fuel loading error that occurred in reactor 4 of the Dampierre nuclear power plant (Loiret department) in 2001. At the start of the 2010s, IRSN also used MORET (5) to simulate tests

318. CEA publication cited in footnote 300 .

319. The CRISTAL formula is being developed and qualified as part of a collaboration between IRSN, the CEA, AREVA-NC (Orano) and AREVA-NP (Framatome). This ensemble includes "libraries" of nuclear data, calculation procedures, simulation software and interface tools. Its purpose is to evaluate the criticality conditions of nuclear facilities and fissile material transport packaging. 
performed in the American reactor SPERT in the 1960s, which aimed to study the response of a reactor core to stepwise reactivity insertions. This simulation was carried out as part of an exercise to benchmark simulation software packages organized by the IAEA (on innovative methods for research reactors ${ }^{320}$ ), which aimed to evaluate the ability of different simulation software tools (used in reactor design, safety demonstrations or the expert assessment for these demonstrations) to reproduce some measurements performed directly on various research reactor cores, in the fields of both neutronics and thermohydraulics. The MORET (5) simulation software notably made it possible ${ }^{321}$ to reproduce the radial distribution of power in SPERT-IV-D 12/25 core assemblies (see figure 11.2), which was then used for assembly heating calculations using the CESAR software from the ASTEC code (see below).

- In 2008, in the context of the review of the BORAX-type accident for the ORPHÉE reactor, the CEA decided that the envelope reactivity insertions considered likely for the reactor would not lead to an explosive interaction between melted fuel and water (steam explosion). In order to evaluate the basis for this conclusion, IRSN performed a study in 2010 using the MORET (5) software to independently determine the reactivity insertions for the scenarios identified by the CEA, including the simultaneous rupture of the two "cold sources", the "hot source" and the nine horizontal thimbles (figure 11.3). Physically, these items of equipment, most of which contain a gas, create leakage spaces for neutrons, which do not therefore participate in the chain reaction. If heavy water gets into these spaces, the effect of neutron reflection by the heavy water is heightened, which increases core reactivity. The reactor model used was refined in order to re-establish some neutron parameters based on the calculations performed when the reactor was designed (before 1980) - using the TRIPOLI and TRIDENT software - or measured, such as the multiplication factor $k_{\text {eff }}$, for various control absorber positions, critical absorber position, efficiency in terms of reactivity, etc. The IRSN study indicated a maximum reactivity insertion significantly higher than that derived from the CEA calculations, leading the CEA to update its own studies by using a more recent version of the TRIPOLI software, which confirmed IRSN's results. It was then important for IRSN to make sure that the simultaneous failure of all horizontal thimbles, in particular, could be ruled out, by ensuring that the thimble material (AG3NET alloy) was sufficiently ductile at the end of its service life. Due to having underestimated the fluence ${ }^{322}$ received by these thimbles, the operator reviewed its thimble replacement schedule. More specifically, the ASN ordered (on the advice of the GPR) the operator to check the schedule

320. IAEA Coordinated Research Project 1496 (2008-2013): Innovative Methods in Research Reactor Analysis.

321. See IRSN communication at the TOPSAFE 2012 conference: Interpretation of reactivity accident transient on research reactors on example of SPERT-IV-D 12/25 Benchmark, Ivanov E., Maas L., Écrabet F.

322. Value used to establish the maximum service life for thimbles (see footnote 231). 

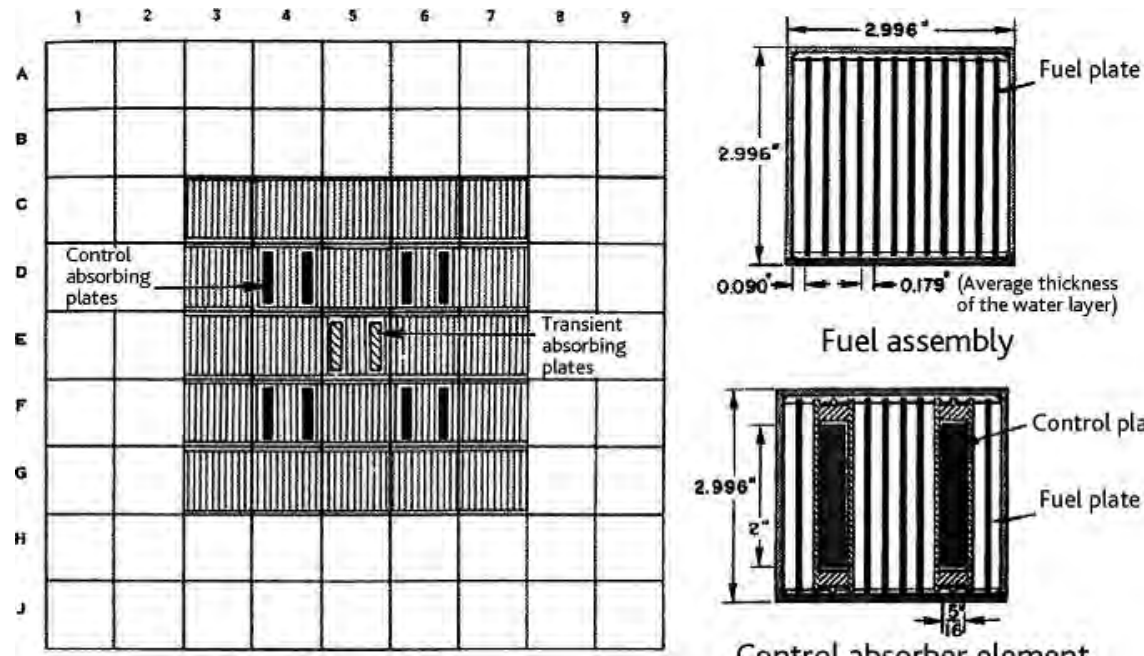

Fuel assembly

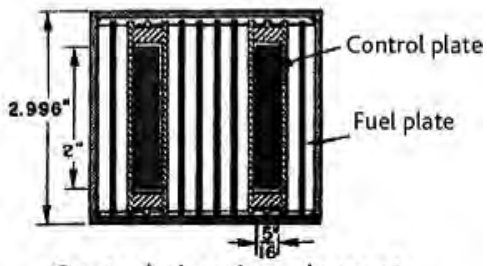

Control absorber element

Figure 11.2. On the left, general diagram of the SPERT-IV-D 12/25 core; on the right, a fuel element and control element containing control plates. () Phillips Petroleum Company-Atomic Energy Division.

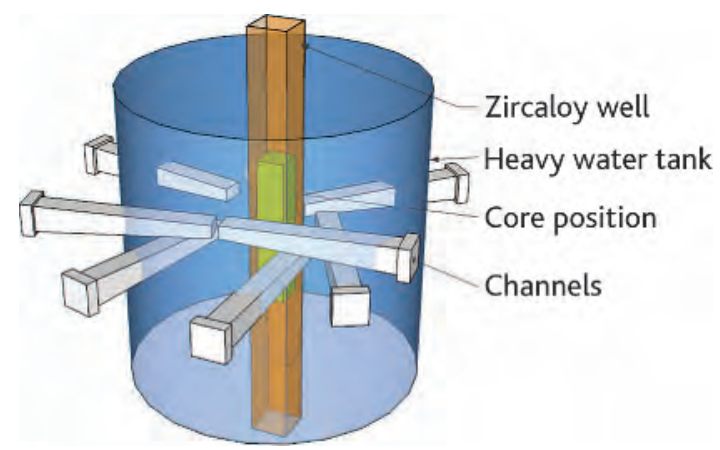

Figure 11.3. 3D model of the ORPHÉE reactor, notably showing the neutron channels, prior to use of MORET simulation software. () IRSN.

for replacing the horizontal thimbles and "cold source" thimbles to ensure that the reactivity "weight" of the devices with very low ductility was limited (with the operator giving a precise definition of the ductility and reactivity "weight" criteria used).

- In 2011, a similar study ${ }^{323}$ was performed by IRSN using MORET (5) software to evaluate the envelope nature of the reactivity insertion

323. For this study and the previous, see the IRSN publication presented at an IAEA conference in Rabat, Morocco, in 2011, entitled "Safety approach of BORAX type accidents in French research reactors", Chegrani Y., Gupta F., Tiberi V., Heulers L. 
identified by the CEA in its study on the BORAX-type accident for the Jules Horowitz reactor. The reactivity insertion corresponds to the ejection of a control rod containing hafnium, which is the material that absorbs neutrons. An envelope reactivity insertion value had been determined by the CEA on the basis of calculations performed using the APOLLO (2), CRONOS (2) and TRIPOLI (4) software. The aim of the IRSN study was to verify this envelope nature, notably by calculations to establish sensitivity to various parameters. The MORET (5) software can be used to determine the reactivity insertion by taking the difference in two effective multiplication factors $\left(k_{\text {eff }}\right)$ calculated for two core states: control rod inserted and control rod ejected (leaving a "water hole").

The modeling used with the MORET (5) software had already been verified ${ }^{324}$ for a core configuration by comparing certain parameters, such as $k_{\text {eff }}$, to those from the CEA calculations (APOLLO (2) and TRIPOLI (4)).

The parameters studied in the sensitivity calculations were core fuel burnup, the initial configuration of the control rods and the reactivity of experimental devices (figure 11.4).

The results obtained using the MORET (5) software confirmed the results of the CEA study into the reactivity insertion in the event of control rod ejection, notably: the higher reactivity "weight" of the control rods in the first core ring and the conservative nature of the new core in comparison to an irradiated core. They also demonstrated the weak influence of experimental device reactivity on the reactivity insertion in the event of an accident.

\section{Thermohydraulics}

- CATHARE (Code Avancé de THermohydraulique pour l'Etude des accidents de

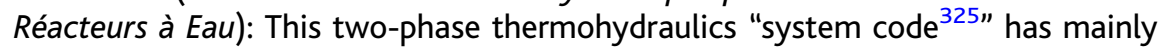
been developed and used for safety analyses on pressurized water reactors (a study on the thermohydraulic behavior of reactors during incident or accident transients, updates of the associated processes), and research and development work. It has also been incorporated into IRSN's SOFIA simulator ${ }^{326}$.

The CATHARE software has been under joint development by the CEA, EDF, AREVA-NP and the IRSN since 1979. The core and systems selected for a study

324. The match was found using the same library of cross sections as that used by the CEA.

325. A "system code" allows a system and its components (fuel, exchangers, pumps, structures, etc.) to be modeled in their entirety.

326. SOFIA (Simulateur d'Observation du Fonctionnement Incidentel et Accidentel - simulator for observing operation during incidents and accidents) is an information system used by IRSN for studies and training. It can calculate and monitor changes in the physical parameters of a pressurized water reactor in real time. It can also be used to simulate equipment failure and operator actions. The calculation can be stopped at a given moment to examine the state of the facility, and it is possible to go back to modify the scenario being studied. The reactors modeled in SOFIA are those in the French nuclear power fleet (900 MWe, 1,300 MWe, 1,450 MWe and EPR reactors). 


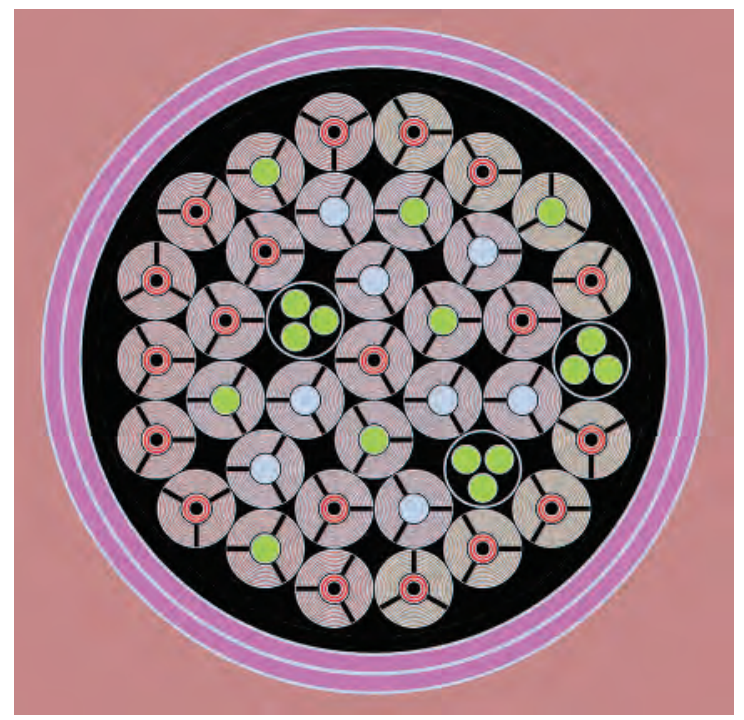

Figure 11.4. One of the core configurations of the Jules Horowitz reactor studied by IRSN using the MORET (5) software (with the inserted rods in red, the withdrawn rods in blue, and the experimental devices in green). ๑ IRSN.

can be modeled in one dimension (1D), with the core represented by a "standard" channel or assembly, but the CATHARE software also has a 3D module that can provide a three-dimensional representation of the vessel and core.

\section{Example of use:}

In the early 2010s, the CEA, in order to draw up the preliminary safety analysis for the Jules Horowitz reactor, and IRSN, to perform the expert assessment of this report, used the CATHARE (2) software to study the "guillotine break of a particular element" (RGEP) accident for this reactor (the single core water supply collector - see figure 5.11). The aim was to ensure that this type of break could not initiate core melt in the reactor. The criteria selected for this purpose were a zero void fraction in the core (no boiling) and a maximum fuel plate cladding temperature of $400^{\circ} \mathrm{C}$ (to avoid failure due to creep).

The two cases studied (figure 11.5) were a double-ended guillotine break in the pool and a guillotine break with limited displacement in a room (a bunker, where the piping in this bunker has an anti-whip restraint). Several conditions were selected for the initial state of the reactor just before the break, namely those that initially seemed the most conservative (maximum reactor power, minimum core cooling flow rate, minimum water pressure at the core outlet, minimum water temperature at the core inlet and minimum water level in the reactor pool). The simulations performed notably resulted in:

- the reactor scram being triggered almost immediately, due to the lowpressure threshold at the core outlet being exceeded; 
- gravitational flow in the emergency suction lines, from the pool, compensating for the outflow via the break and maintaining a satisfactory water inventory in the reactor coolant system (figure 11.5);

- in the case of the break in the bunker, the outflow through the break decreasing as the bunker filled with water and the broken section of piping was submerged.

The minimum margins in relation to the criteria selected were generally achieved shortly after the reactor scram.

The study performed by IRSN notably assessed the sensitivity of the results obtained by the CEA - indicating compliance with the criteria given above - to some scenarios, including, for example, the behavior of the reactor coolant pumps (risk of cavitation) just after a break has occurred, or the time it takes for a break to open. This study highlighted a risk of failing to comply with the criteria and, consequently, showed that the CEA needed to provide evidence to justify that there would be a sufficient water flow rate through the pumps to cool the core, even if the reactor coolant pumps were (temporarily) operating in degraded mode.

In addition, the CATHARE (2) software allowed the CEA to determine the forces experienced, notably by the anti-whip restraint in the case of a break in the bunker; these forces had to be calculated for the mechanical design of this device. The CEA calculation showed the full importance of this device, as a double-ended break in the bunker could lead to core melt.

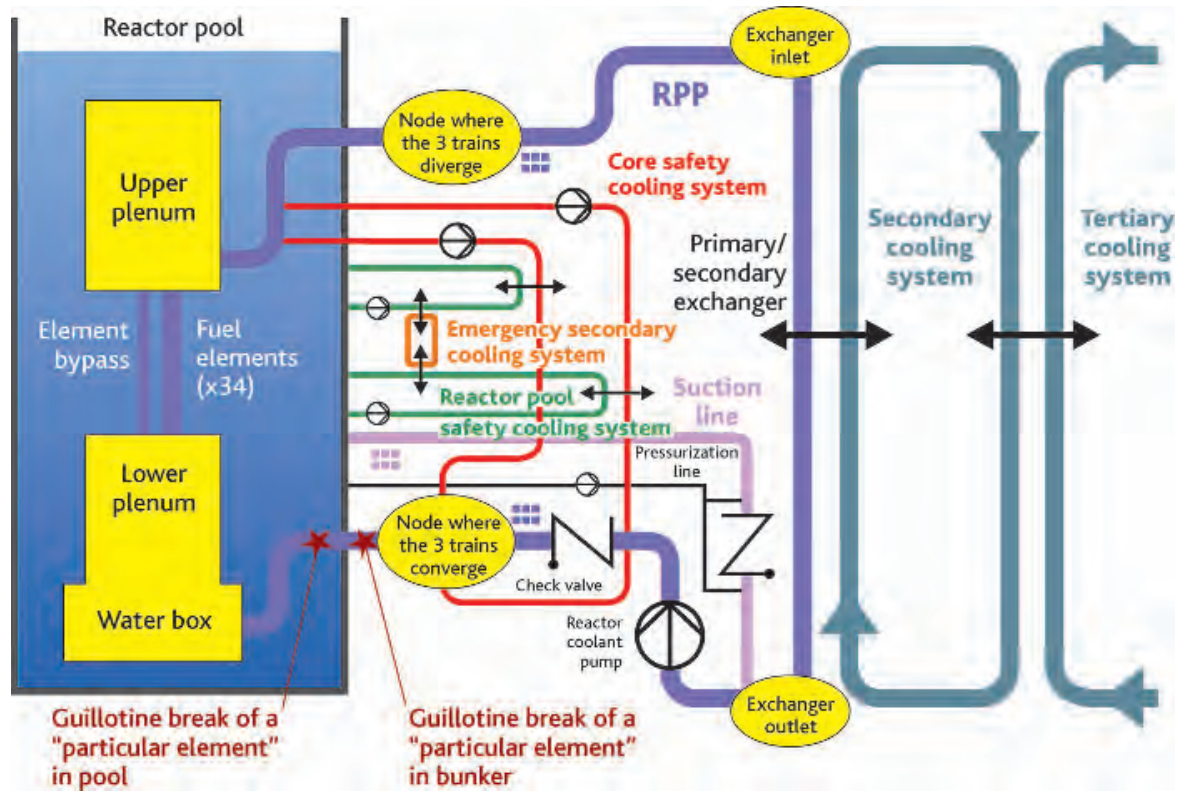

Figure 11.5. Diagram of Jules Horowitz reactor circuits and position of guillotine breaks (RGEP) studied. @ Georges Goué/IRSN. 
- FLICA, DULCINEE: These software tools are used to simulate the thermohydraulics in a reactor core and the thermal behavior of the fuel. They have been used at French research reactors for several decades. The DULCINEE software has a neutron model known as a "point kinetics" (or "OD") model, which can perform calculations combining simplified neutronics and thermohydraulics.

The FLICA (4) software can be used to create a three-dimensional representation of a reactor core and process the two phases of the cooling fluid (liquid and steam). For thermal transfers in the fuel, the modeling is one-dimensional (1D).

Together with the CRONOS software, the FLICA software can be used to obtain a more detailed representation (3D) of the core for transient studies performed using the CATHARE "system code". Figure 11.6 shows how they can be combined in the HEMERA software chain.

\section{Example of use:}

In order to determine the thermal energy deposited in the Jules Horowitz reactor fuel in the event of the accident reactivity insertion selected for the BORAX-type accident (control rod ejection) study, the CEA used ${ }^{327}$ the combined CRONOS (2) and FLICA (4) software (without modeling the expansion of the fuel plates, a phenomenon that reduces the thickness of the water channels between the plates, thereby generating negative reactivity). The "point kinetics" DULCINEE code was also used for sensitivity studies, as this software ("OD") is suitable for small cores such as that at the Jules Horowitz reactor.

- CFD (Computational Fluid Dynamics) codes: The use of this type of simulation software is becoming more common, including at research reactors, to determine fluid flow on a local scale by solving Navier-Stokes equations averaged over time and space, in a domain discretized using meshes ranging from a millimeter to a centimeter in size.

\section{Examples of use:}

- In 2010, the Institut Laue-Langevin performed, in collaboration with the Argonne National Laboratory (ANL, Illinois, USA), studies ${ }^{328}$ on the feasibility of "converting" RHF to UMo fuel with low uranium-235 enrichment. Two CFD-type software tools were used: the STAR-CD software (used by the ANL) and the CFX software developed by ANSYS ${ }^{329}$ (used by the ILL). The validity of the models was checked through comparison with in-reactor measurements and benchmarking against the results of various models. These studies showed that changing the fuel without modifying the fuel plates would result in a significant degradation

327. In particular, see the CEA presentation at the TOPSAFE 2008 conference: "The BORAX accident in the JHR", Maugard B., Elie J.-P., Trémodeux P., Iracane D., Lemoine P., Ratel G., Berthoud G. et al.

328. In particular, see the ANL-ILL-communication at the RERTR 2010 conference on reduced fuel enrichment for research and test reactors: "Thermal-hydraulic safety analyses for conversion of the Laue Langevin Institute (ILL) High Flux Reactor (RHF) from HEU to LEU fuel", Tentner A., Thomas F., Bergeron A., Stevens J. (https://www.rertr.anl.gov/RERTR32/pdf/S10-P4_Tentner.pdf).

329. ANSYS Inc. is an American company. 


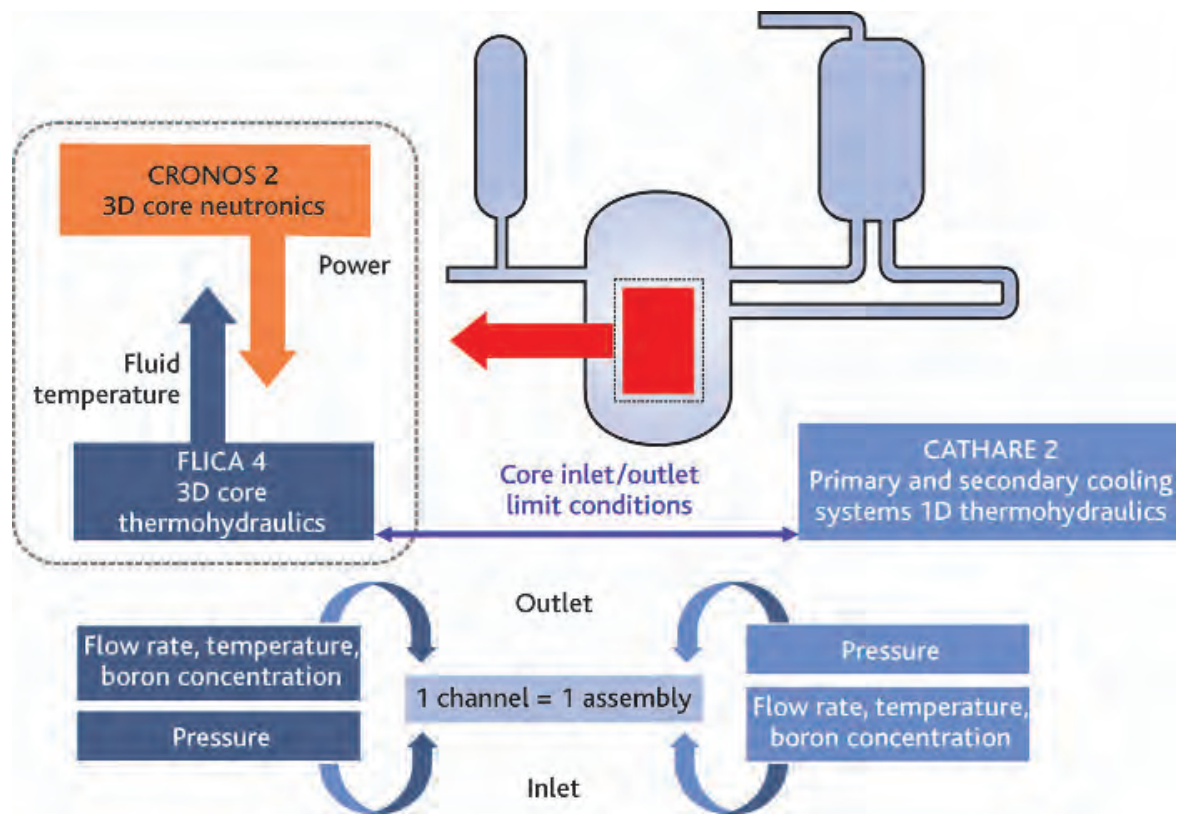

Figure 11.6. The combined CRONOS (2), FLICA (4) and CATHARE (2) software packages in the HEMERA chain: interface parameters between these three software packages. () IRSN.

in reactor performance, notably in terms of neutron flux. Other designs were then studied for the fuel element. One of these, which increased the quantity of fuel without changing the external dimensions of the plates, would maintain good reactor performance while securing safety margins in relation to the risk of boiling in the water channels between the plates. "Converting" the RHF core, however, is still dependent on developing and qualifying a new type of fuel with higher density than UAl.

- In 2010, the Institut Laue-Langevin also used a CFD code (CFX) to study the behavior of RHF thimbles, to demonstrate that the core fuel element would not melt in the event of a reactivity insertion resulting from the rupture of one or several thimbles.

\section{Thermomechanics}

- SCANAIR: This software, which has been under development by IRSN since 1990, can be used to simulate the thermomechanical behavior of fuel rods in pressurized water reactors during power transients, and evaluate the risks associated with a loss of leaktightness or cladding failure. It is notably used to define, prepare and interpret tests to assess the capacity of fuel rods to withstand such transients, such as those that have been, or will be, performed as part of the CIP program at the CABRI reactor. The SCANAIR software can simulate rapid reactivity insertions (Reactivity Injection Accidents [RIA]) or slow power ramps such as those that could 
result from the rupture of steam piping or even the uncontrolled withdrawal of a rod cluster control assembly in the core of a pressurized water reactor. In particular, the SCANAIR software models the thermomechanical interactions between the fuel pellets $\left(\mathrm{UO}_{2}, \mathrm{UPuO}_{2}\right)$ and rod cladding, the boiling of the coolant (water) and the various deformation mechanisms of the cladding material.

\section{Example of use:}

In its research to explain the melting of the fuel rods in the driver core of the CABRI reactor, discovered in 2004 (section 10.1.2), the CEA, the operator of this reactor, used several simulation software tools, including APOLLO (2), TRIPOLI (4), DULCINEE and SCANAIR. As indicated in section 10.1.2, the CEA concluded that the effects of the transients at CABRI on the rods of the driver core were insufficiently estimated in the safety analyses performed before these transients were carried out. The CEA then decided to develop a new calculation tool for the studies to be performed before future tests in the pressurized water loop as part of the CIP program. This tool links the SCANAIR ${ }^{330}$ software to appropriate datasets. As part of the expert assessment of the file sent by the CEA aiming to demonstrate that the driver core could undergo future tests as part of the CIP experimental program without any damage, IRSN, as the developer of the SCANAIR software, had the expert assessment of the new CEA tool completed by AVN (Belgium), which did not issue any contraindications regarding the use of this tool. In addition IRSN used the SCANAIR software for a study ${ }^{331}$ aiming to assess the validity of new strength criteria for the cladding of fuel rods in the CABRI core, which were proposed by the CEA. The aim of this IRSN study was to assess whether these new criteria were consistent with the results of tests performed in the SPERT and NSRR reactors in the USA and Japan respectively. These tests had made it possible to determine a failure threshold for stainless steel cladding expressed in terms of the energy deposited in the fuel (approximately $240 \mathrm{cal} / \mathrm{g}$ ). In order to perform this study, it was vital to strictly use the same version of the SCANAIR software and datasets as those developed by the CEA for its own calculations of the impact of the future CIP tests on the driver core. The CEA made these elements available to IRSN. The IRSN study showed that the new criteria, expressed ${ }^{332}$ in terms of maximum cladding temperature $\left(1,300^{\circ} \mathrm{C}\right)$ and maximum equivalent cladding deformation $(3.65 \%)$, were consistent with a failure threshold of $240 \mathrm{cal} / \mathrm{g}$.

\section{Core melt accidents}

- SIMMER: This software, which combines neutronics and fluid mechanics, can simulate a core melt accident in a fast neutron reactor. It was initially developed

330. The CEA had initially envisaged linking the CATHARE and SCANAIR simulation software, but in the end it decided to use just the SCANAIR software and undertake major work to calibrate and validate the thermohydraulic module to adapt it to the configuration of the CABRI driver core.

331. See the communication by IRSN at the IGORR 12 conference in 2009: "Analysis of CABRI driver core new safety demonstration for fuel rods integrity during fast power transients", Écrabet F., Pelissou C., Moal A.

332. Excluding the absence of fuel melt (the melting point of $\mathrm{UO}_{2}$ is around $2,840^{\circ} \mathrm{C}$ ). 
at Los Alamos, from 1974 onwards. PNC (Power reactor and Nuclear fuel development Corporation, Japan), FzK (Forschungszentrum Karlsruhe, Germany, later the Karlsruher Instituts für Technologie [KIT]) and the CEA have continued its development for studies on fourth-generation fast neutron reactors. In France, it was used in the 1980s and 1990s to study theoretical core melt accidents in fast reactors (chiefly SUPERPHENIX).

\section{Example of use:}

In the 2000s, IRSN, together with FzK, adapted the SIMMER III software for the Jules Horowitz reactor, for exploratory studies into a BORAX-type accident. Numerous adaptations were necessary, notably to be able to correctly simulate the neutronic behavior of the core and the fuel used in this type of reactor, in the form of curved plates ${ }^{333}$. These studies have notably shown that the energy deposited in a core like that of the Jules Horowitz reactor could potentially exceed the inclusive value of $135 \mathrm{MJ}$ and that the sequences involved (the simultaneous ejection of several control rods, for example) should be highly unlikely (through robust design, manufacture and in-service monitoring measures).

- MC3D: MC3D is a multi-phase thermohydraulics software developed by the CEA then IRSN. It can be used to simulate the steam explosion that would result from a thermodynamic interaction between the fuel (notably when it is in a liquid state) and the coolant in a reactor; such a phenomenon could occur during a reactor core melt accident. In particular, this software can be used to determine the dynamic pressures on structures (such as the walls of the reactor pool, for example). To begin with, it simulates the first phase of the thermodynamic interaction, called premixing, which is the rough mixing of the two fluids accompanied by varying degrees of vaporization. In some conditions, premixing can be destabilized, which may lead to a violent explosion similar to a detonation (second phase).

\section{Example of use:}

The CEA used the MC3D software to study the interactions between melted fuel and water during a BORAX-type accident for the Jules Horowitz reactor ${ }^{334}$, notably to determine the loads that could be experienced by, firstly, the reactor block vessel and piping connections and, secondly, the reactor pool walls and floor; these loads would be created by the shock waves and their multiple reflections, as well as the expansion of the steam bubble.

333. IRSN communications: International Conference on the Physics of Reactors, PHYSOR 2008: Upgrading of the coupled neutronics-fluid dynamics code SIMMER to simulate the research reactors core disruptive RIA, Biaut G. et al.; TOPSAFE 2008 conference, "Reevaluation of BDBA consequences of research reactors", Biaut G. et al. See also the joint IRSN-CEA communication at the $18^{\text {th }}$ International conference on Nuclear Engineering [ICONE]) in 2010: "Validation of SIMMER III neutronics module for the simulation of reactivity injection accident in material testing reactors", Chegrani Y., Ivanov E., Di Salvo J., d'Aletto C.

334. CEA communication quoted in footnote 317. 
- ASTEC: The ASTEC (Accident Source Term Evaluation Code) simulation software system aims to simulate all the phenomena that would occur during a core melt accident in a water reactor, from the initiating event to any releases of radioactive products outside the reactor containment, with the exception of the steam explosion, which can be processed using the MC3D software, and the loads on structures, which can be processed using a software package like Cast3M (see below). The ASTEC software system (see figure 11.7) was developed jointly over a number of years by IPSN then IRSN, together with its German equivalent GRS; since then it has been developed further by IRSN alone. The applications of the ASTEC system chiefly concern the safety analysis of pressurized water reactors, with the evaluation of the radioactive releases that could result from core melt in such a reactor, and the examination of the procedures to implement in the event of such an accident. The ASTEC software system is also used by IRSN in its level-2 probabilistic safety analyses for nuclear power reactors. Lastly, it has also been used in the preparation and interpretation of experimental programs, in particular the Phebus FP global test program and in the tests carried out as part of the ISTP (International Source Term Program).

\section{Examples of use:}

- The CEA used the IODE software from the ASTEC system to study iodine transfer in the reactor building of the Jules Horowitz reactor during a BORAX-type accident - it used the CERES and GAZAXI software to evaluate the contribution made by the principal radionuclides to the (effective) doses during their migration into the environment ${ }^{335}$.

- As part of the previously mentioned exercise to benchmark simulation software organized by the IAEA (the coordinated research project on "Innovative Methods in Research Reactor Analysis" - 2008-2013), IRSN performed calculations using the CESAR thermohydraulics software in the ASTEC system to interpret the reactivity insertion tests performed in the SPERT reactor. The CESAR software had to be adapted for fuel in the form of plates. This software made it possible to find the same plate cladding temperatures as those measured in the SPERT-IV-D 12/25 core assemblies (see above for the neutronics simulation using the MORET (5) software).

- IRSN also used the CPA software from the ASTEC system, which is dedicated to reactor containment thermohydraulics, to assess the effectiveness of a new confinement management system (dynamic rather than static) proposed by the operator of the RHF for accident situations ${ }^{336}$. The objective was to evaluate the conclusions drawn from the operator calculations that aimed to demonstrate the possibility of maintaining the reactor building at negative pressure (in relation to the annulus between the two containment walls) in such situations, taking into account the

335. CEA communication quoted in footnote 317.

336. See the communication by IRSN at the RRFM 2010 conference: "Development of a numerical tool for safety assessment and emergency management of experimental reactors", Maas L., Beuter A., Seropian C. 


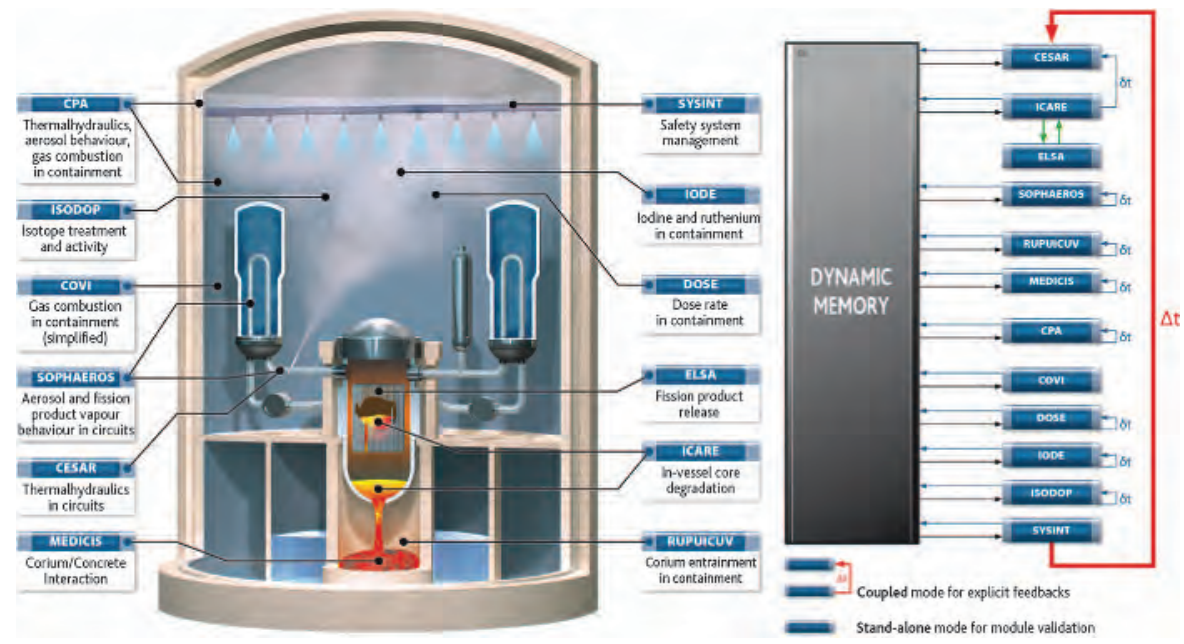

Figure 11.7. The various phenomena involved in a core melt accident (pressurized water reactor) and the modules that simulate them in the ASTEC software system. $\odot$ IRSN.

increase in air temperature (due to the fission products released in the reactor building and the heating of the pool water in the event of core melt), the possibility of direct air leaks into the environment and the "swelling" operation of the annulus between the two containments (the internal concrete containment and the external metal containment). Three accident scenarios were studied: a BORAX-type accident, the fuel melting under water and the fuel melting in air.

\section{Mechanics}

- Cast3M, ASTER, ANSYS software: Cast3M is a finite element simulation software developed by the CEA for structural and fluid mechanics. ASTER (Analyses des Structures et Thermomécanique pour des Etudes et des Recherches [simulation code for thermomechanical and structural analysis for research]) is a similar software developed by EDF. ANSYS Inc. is an American company that creates and distributes various structural mechanics software packages (including for loads leading to major deformation).

\section{Examples of use:}

- Cast3M is generally used by the designers and operators of French nuclear facilities for applications relating to metal structures or civil engineering works (reactor pools and buildings, etc.), notably at research reactors. It is widely used by IRSN, which also occasionally collaborates with the CEA for special development work. For example, in the field of civil engineering, developments $s^{337}$ include improving the laws simulating the delayed or

337. These developments are produced as part of theses, linking IRSN and other partners, including the CEA. 
dynamic behavior of concrete works in the event of loading during an accident (such as an earthquake, for example). These developments are then integrated into Cast3M, thereby being made available to all Cast3M users.

- The Institut Laue-Langevin used the ASTER software for the design studies for the PCS 3 building at RHF (which forms part of the post-Fukushima "hardened safety core").

- EUROPLEXUS, LS-DYNA, RADIOSS: EUROPLEXUS is a finite element simulation software for fast dynamics phenomena taking into account structures and fluids, originally developed by the CEA (PLEXUS code) and the Joint Research Centre (CCR) in Ispra in Italy (PLEXUS-3C), then reworked by a user group including EDF and ONERA. LS-DYNA is a computer code of the same type, developed in the USA by the Livermore Software Technology Corporation (LSTC), as is RADIOSS, developed by Altair Engineering. These software can be used to study the behavior of structures subjected to shocks, for example.

\section{Example of use:}

For the Jules Horowitz reactor, the CEA used ${ }^{338}$ the EUROPLEXUS and RADIOSS software to study the behavior of the reactor pool structures in the event of a BORAX-type accident. It did this by modeling a steam bubble with characteristics such that it leads to the cases of overpressure determined previously using the MC3D software.

\section{- Evaluations in emergency situations}

During emergency situations ${ }^{339}$ or emergency exercises, the operators of French research reactors and IRSN would base, or do base, their assessments on evaluations performed using simulation software simplified to a greater or lesser degree. More specifically, IRSN has a simulation software used for facilities other than pressurized water reactors in the nuclear power fleet, which can be used to determine the transfer of radioactive products within a facility and the releases into the environment (quantity and kinetics of releases for each radionuclide). This software models, in a simplified way, radionuclide leakage between rooms, transfers via ventilation systems and releases outside the facility. The deposition rate (for aerosols) and the efficiency of filtration devices are entered in the software as data. The software is used to produce and update "standard accidents" sheets (see section 7.7). In addition, it is used by IRSN experts to define the scenarios used in emergency exercises, and may also be used in the expert assessments performed by IRSN. This type of simplified software lends itself well to pre-calibration with the relevant data for the various research reactors, which makes it possible to create models available for rapid use in emergency situations or during exercises.

338. CEA communication cited in footnote 317.

339. In practice, as soon as an on-site emergency plan is triggered. 


\section{Elements of nuclear safety Research reactors}

\section{Jean Couturier, Hassan Abou Yéhia et Emmanuel Grolleau}

This publication gives a global overview of the diversity and complementarity of research reactors, some of which have been or are still being used to conduct experiments that are essential for the development and operation of nuclear power reactors, including in relation to safety issues. This work highlights the many uses of these reactors, which have very different designs, use highly varied quantities of radioactive substances with varying levels of risk for safety and radiation protection, and which — in many cases because they are old or have been shut down — require appropriate measures to control the ageing or obsolescence of some of their equipment, as well as, on an organisational and human level, to ensure that they continue to be operated safely. For some research reactors, safety and radiation protection aspects must be considered, taking into account that two types of operators are present at the same time within these reactors: reactor operating personnel and operators in charge of experimental devices using neutrons from the reactor for fundamental or applied research purposes. There are two specific chapters on the safety standards established under the aegis of the IAEA for research reactors and on serious accidents, notably those involving criticality and reactivity, in research reactors. The second part of the work focuses on French research reactors, including the regulations and official documents applicable to these reactors, on lessons learned in France from significant events and accidents - as well as abroad, such as the Fukushima Daiichi nuclear power plant accident in 2011 - on the consideration of reactivity accidents in the design of French research reactors, and on the ten-yearly safety reviews carried out in France.

The Institute for Radiological Protection and Nuclear Safety (IRSN) is a public body undertaking research and consultancy activities in the field of nuclear safety and radiation protection. It provides public authorities with technical support. It also carries out various public service missions entrusted to it under national regulations. In particular, these include radiological monitoring of the environment and workers in France, managing emergency situations, and keeping the public informed. IRSN makes its expertise available to partners and customers both in France and worldwide.

Head office

31, avenue de la Division Leclerc 92260 Fontenay-aux-Roses RCS Nanterre B 440546018 Telephone +33 (0)1583588 88 Postal Address

B.P. 17 - 92262 Fontenay-aux-Roses Cedex France

Website www.irsn.fr
ISBN : 978-2-7598-2356-7

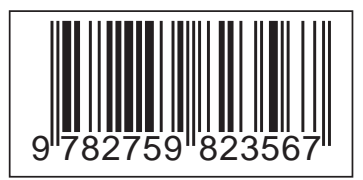

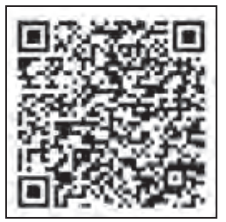

